\title{
La Arquitectura de la Hochschule für Gestaltung Ulm, de la Objetividad a la Revolución
}

tesis doctoral carlos asensio-wandosell garcía. arquitecto

director jose manuel lópez-peláez

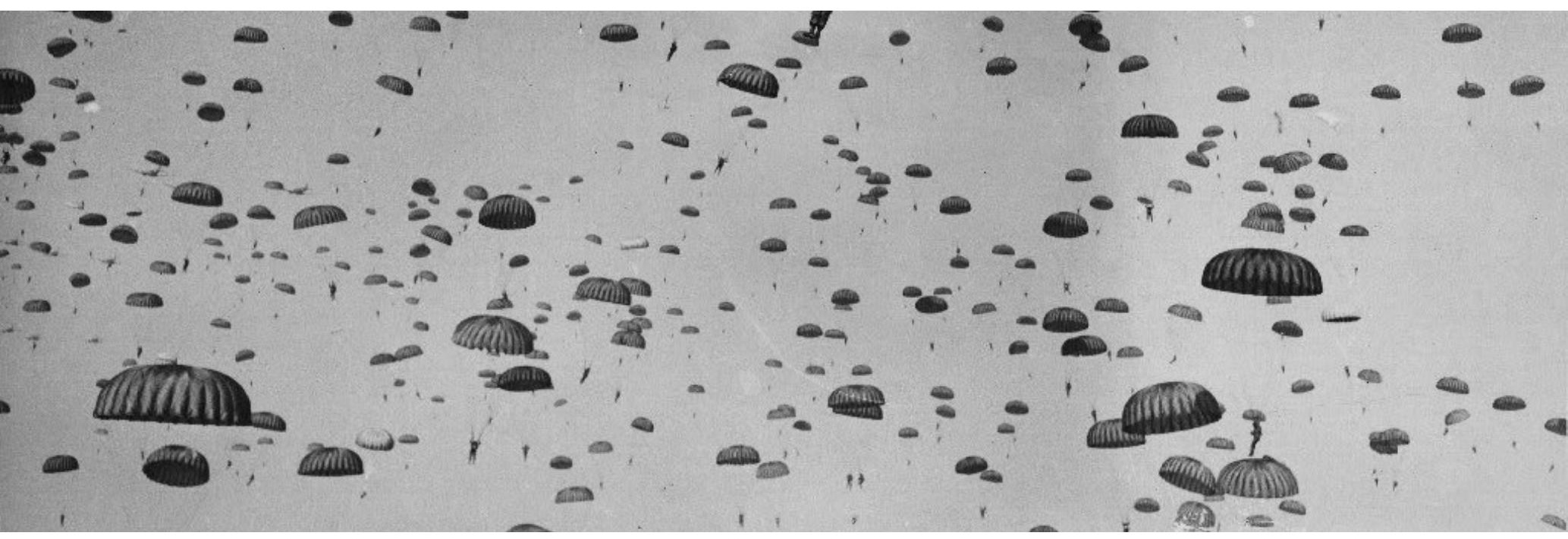

universidad politécnica de madrid escuela técnica superior de arquitectura departamento de proyectos arquitectónicos 

Tribunal formado por el Magnífico y Excelentísimo Sr. Rector de la Universidad Politécnica de Madrid, el día de de

Presidente D.

Vocal D.

Vocal D.

Vocal D.

Secretario D.

Realizado el acto de defensa y lectura de la tesis

el día de de

en

Calificación:

EL PRESIDENTE LOS VOCALES

EL SECRETARIO 

índice

resumen/abstract

introducción y objetivos

1> construcción horizontal (infinity

1.1 fondo

1.1.1_ el origen de la escuela

1.1.2_ el entorno social e intelectual

1.1.3_darmstadt 1951: "mensch und raum

1.2 figura

1.2.1_la elección de Bill

1.2.2_ las influencias de Bill 1. Europa en Europa

1.2.3_ las influencias de Bill 2, Europa en América

2> construcción vertical (finite

2.1 fondo

2.1.1_la generación de un programa

2.1.2_ die vorprojekte

2.2 figura

2.2.1_ desarrollo final Zürich

2.2.2_ la construcción del edificio

2.2.3_ las otras arquitecturas

3) construcción emotiva (infinity -finite

3.1 fondo (el espacio como anhelo

3.1.1_la nueva relación hombre espacio

3.1.2_ el espacio unitario como aspiración

\section{2 figura (el espacio en la HfG}

3.2.1_leyes de articulación y ritmo

3.2.2_ las funciones espaciales aplicadas a su psicodinámica

3.2.3_ topología geométrica en la HfG

\section{conclusiones}

C.1 la resolución de la hipótesis

C.2 la concepción espacial de la HfG en la arquitectura de hoy

\section{bibliografía}

bibliografía comentada

bibliografía específica $\mathrm{HfG}$

bibliografía específica Max Bill

bibliografía general

anexo

planos originales HfG

traducciones inéditas de textos

planos redibujados $\mathrm{HfG}$ 

resumen/abstract

introducción y objetivos

\section{1> construcción horizontal (infinity}

\section{1 fondo}

1.1.1_ el origen de la escuela

die weisse Rose y los hermanos scholl

- la fundación Geschwister Scholl

. las volkhochschule alemanas

la importancia de la ciudad de UIm

1.1.2_ el entorno social e intelectual

- la Alemania de entreguerras

- la guerra y la posguerra

- la sociedad después de la guerra

1.1.3_ darmstadt 1951: "mensch und raum

las once obras maestras (arquitectura alemana)

. Heidegger y Ortega

\section{2 figura}

1.2.1_la elección de Bill

. die gute form y la Werkbund suiza

. la elección de Bill

1.2.2_ las influencias de Bill 1. Europa en Europa

la bauhaus

Roth: the new Architecture + the new School

Roth, Ruf, Scharoun, Meyer

1.2.3_ las influencias de Bill 2, Europa en América

- américa américa. Frank Lloyd Wright y Taliesin West

. Illinois Institute of Technology y the new bauhaus

gropius, neutra, breuer 
2> construcción vertical (finite

2.1 fondo

2.1.1_ la generación de un programa

. verano 1950-agosto 1952, un recorrido epistolar Sholl-Bill

- las propuestas de aicher

2.1.2_ die vorprojekte

. vorprojekte 1, 22_06_1950

. vorprojekte 2, 23_06-10_07_1950

. vorprojekte 3, 11_07_1950

. vorprojekte 4, 18_08_1950

. vorprojekte 5, 18_08_1952

2.2 figura

2.2.1_ desarrollo final Zürich

. los siete meses de Zurich. Bill, Voltz, Haubensak y Walder

inicio 1a fase de construcción_ agosto 1953

acto de cubrir aguas_julio 1954

funcionamiento primeros talleres_agosto 1954

traslado administración_diciembre 1954

primeras clases_enero 1955

acto de inauguración_1-2 octubre 1955

2.2.2_ la construcción del edificio

. posiciónamiento en el lugar, cimentación y vegetación

. la estructura espacial

cubiertas y fachadas

- acabados interiores, instalaciones

- amueblamiento y uso

2.2.3_ las otras arquitecturas

viviendas de profesores

. los objetos del UIm

\section{3) construcción emotiva (infinity -finite}

\section{1 fondo (el espacio como anhelo}

3.1.1_la nueva relación hombre espacio

. el hombre como dimensión variable (factor dinámico

. superposición del espacio real (espacio cambiante por el movimiento

del hombre) y el espacio psíquico (estado en el que el hombre se encuentra)

. las imágenes de la memoria y su interacción con el espacio real

3.1.2_ el espacio unitario como aspiración

. el nuevo efecto espacial resultado del intersecado del espacio interior con el exterior

. la combinación del espacio interior y exterior para dar lugar a un tercera totalidad

. la descomposición del volumen de Ibram Lassaw

. la transparencia y la limitación en Vantogerloo

. los hermanos Pevsner

. ensayos de compenetración espacial. Theo Van Doesburg y Frederick Kiesler 


\section{2 figura (el espacio en la HfG}

3.2.1_ leyes de articulación y ritmo

. proporcionalidad constante, irregularidad aparente

- la estructura espacial, horizontalidad sobre la pendiente.

. principio generador: la belleza nace de la función y existe como función.

3.2.2_ las funciones espaciales aplicadas a su psicodinámica

. sistematización para conseguir la multiplicidad espacial

- recorridos topológicos, el intento de conseguir una superficie única, de borde único (fachada), no orientable. La representación mediante Graphos

3.2.3_ topología geométrica en la HfG

. concepto de proximidad, número de agujeros, consistencia

. atributos de los espacios: conectividad, compacidad, metricidad, metrizabilidad

\section{conclusiones}

C.1 la resolución de la hipótesis

C.2 la concepción espacial de la HfG en la arquitectura de hoy

\section{bibliografía}

bibliografía comentada

bibliografía específica HfG

bibliografía específica Max Bill

bibliografía general

\section{anexo}

planos originales HfG

traducciones inéditas de textos

planos redibujados $\mathrm{HFG}$ 

resumen/abstract 


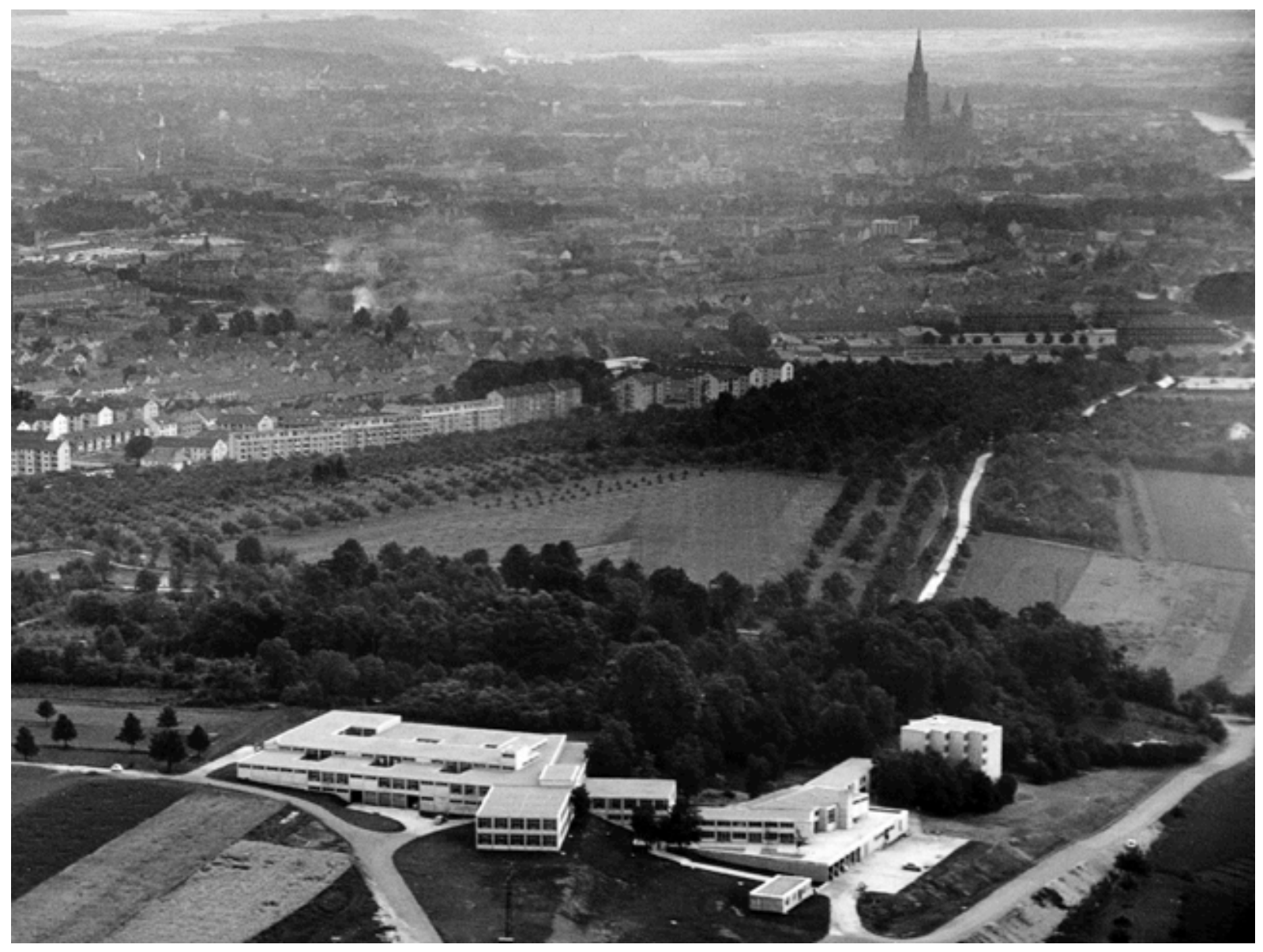


resumen

Esta tesis tiene como objeto demostrar (hipótesis) que el edificio de la Hochschule für Gestaltung de Ulm no es del arquitecto y artista suizo Max Bill, a pesar de serlo.

Esta paradoja constituye una figura de pensamiento en la que hay una incompatibilidad aparente, que se resolverá en el desarrollo de la tesis con un análisis más profundo del que la enuncia.

Max Bill no es el autor del edificio de la Hochschule für Gestaltung (HfG). El enunciado más preciso sería que Bill absorbe o deja pasar a través de sí el lenguaje de la Arquitectura, lenguaje que todavía no le pertenece y que aplica en UIm en unas condiciones muy concretas.

¿Por qué "a pesar de serlo" porque a pesar de no ser arquitecto -o serlo como fueron los primeros Mies o Corbus-, introduce una concepción espacial que, como artista, ya le pertenecía. Max Bill va a pensar el espacio de la HfG como un espacio topológico, entendido como una estructura matemática que le permite la definición formal de conceptos como convergencia, conectividad, continuidad, vecindad.

¿por qué el edificio de Bill ha despertado y despierta interés en el mundo de la arquitectura? ¿Por qué se ha mitificado? En realidad lo que hace Max Bill es poner sobre la mesa temas revolucionarios como lo infinito finito (infinity finite) referido a un espacio no euclidiano sino topológico.

El año 1949 publica Bill un texto con el título: "die mathematische denkweise in der kunst unserer zeit" dejando muy clara su posición intelectual. Para él los artistas llegaban al constructivismo, en un camino reduccionista necesario para relacionar el arte con la sociedad. Sin embargo, las matemáticas, en su avance, llegaban a un punto en que perdían claridad: los límites se hacían borrosos. La concepción matemática del arte de los cincuenta no es la matemática en un sentido estricto. Difícilmente servía ya lo que se entendía por matemática exacta. En la opinión de Bill, la geometría euclidiana conservaba solo una vigencia limitada para los hombres de ciencia del siglo XX, y por tanto, su importancia debía ser relativa para el arte. El principio de infinitud finita, se convertía en un recurso indispensable y vital para el pensamiento matemático y físico.

Este es el pensamiento en el que estaba Bill cuando regresa en otoño del año 52 a su estudio en Zurich. Allí trabajará durante 7 meses, sin apenas contacto con el círculo de Ulm, con el que había desarrollado, en colaboración directa, todos los anteproyectos. El 5 de Mayo de 1953, después de más 

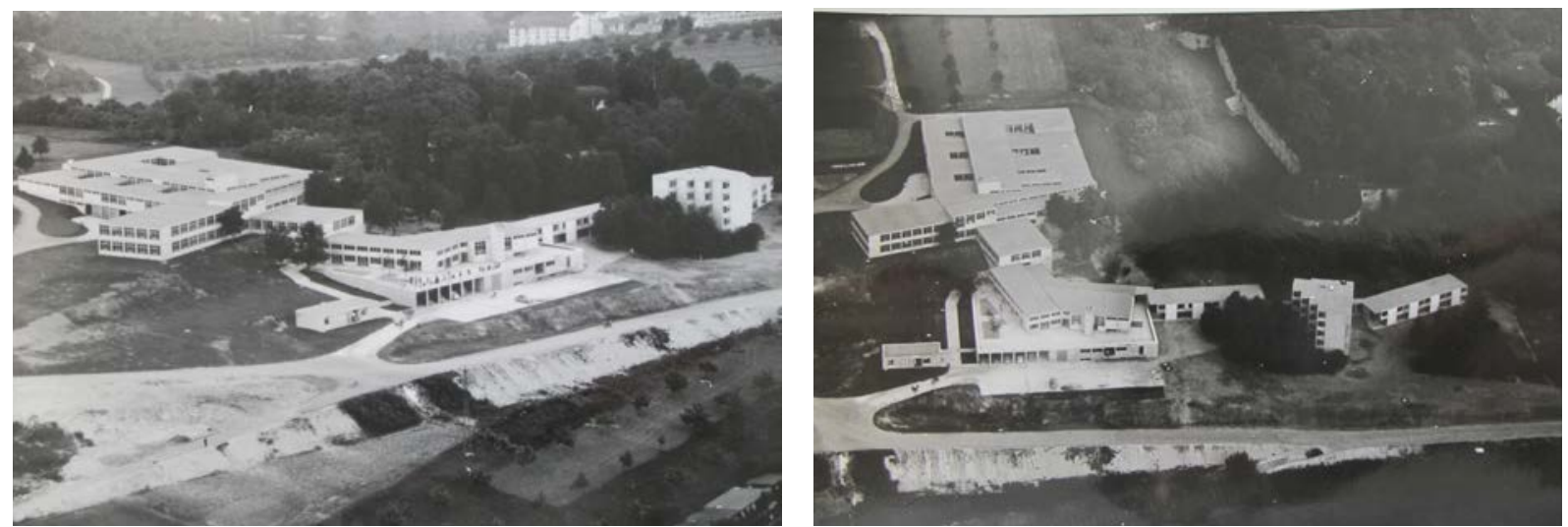

de medio año, se presentó la solicitud oficial para construir la escuela en Ulm. Esta contenía un plano de situación (1:500), así como diez planos del edificio (1:100).

Faltaría por resolver algunas preguntas fundamentales para que surja el acontecimiento ¿por qué en Ulm? ¿por qué Max Bill?

El origen de la escuela es el de una Alemania devastada física y moralmente tras finalizar la Segunda Guerra mundial. La elección de Ulm por los americanos y en particular por Shepard Stone, alto comisionado americano en la Alemania ocupada, se apoya en una estrategia ideológica y territorial: al sur, en Ulm, existía una fundación (Geschwister Sholl Stifftung) creada a partir del asesinato por los nazis de dos jóvenes pertenecientes a la resistencia interna al nacismo. Esta fundación y un grupo de intelectuales de Ulm (UImer Kreises) crearon una Volkhochschule o escuela para enseñar a gente mayor sin formación. Los americanos les proponen transformarla en una Hochschule (escuela universitaria), dentro de su política reeducativa antinazi.

Los americanos no querían un rector para esta nueva escuela que pudiera tener la mas mínima relación con el nacismo. Por una serie circunstancias que se detallan en la tesis aparece Max Bill en la escena. Suizo y artista con reconocimiento internacional.

El edificio de Max Bill se proyecta y se construye en medio de todo esto, convirtiéndose poco a poco en el elemento cristalizador de una revolución hacia una sociedad más justa, igualitaria y en paz.

Ni arte calculado ni arte geométrico la tesis intenta transformar una objetividad en un razonamiento que de luz sobre una forma de concebir el espacio arquitectónico absolutamente nueva, que hoy en día reconocemos en algunos de los edificios más paradigmáticos de la contemporaneidad. Mas que la obra de un creador, es la representación de un pensamiento colectivo, en el que el arquitecto actúa casi como médium de una colectividad. 


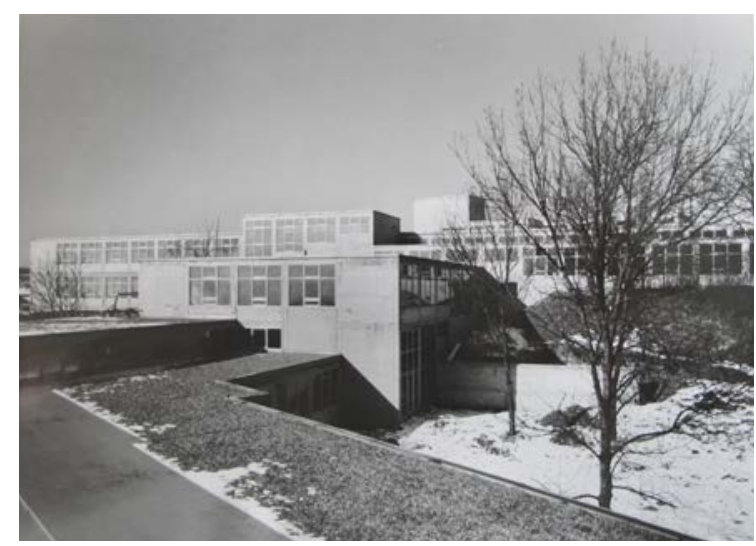

\section{Abstract}

This thesis aims to demonstrate (hypothesis) that the building of the Hochschule für Gestaltung in Ulm is of the swiss architect and artist Max Bill, despite so.

This paradox is a figure of thought in which there is an apparent incompatibility, which will be resolved in the development of the thesis with a deeper analysis of the states.

Max Bill is not the author of the building of the Hochschule für Gestaltung ( $\mathrm{HfG})$. The most accurate statement would be that Bill absorbed or allowed to pass through himself the language of architecture, language that does not belong to him and that applies in UIm in very specific conditions.

Why "in spite of being" because despite not being -or to be architect like the first Mies or Corbu were - introduces a spatial conception, as an artist, already he belonged. Max Bill will think the HfG space as a topological space, understood it as a mathematical structure that allows the formal definition of concepts such as convergence, connectivity, sustainability, neighbourhood.

Why has the Max Bill building attracted and arouse interest in the world of architecture? Why has it been mythologized? Actually what Max Bill makes is put on the table revolutionary themes like the infinite-finite referred to a non-Euclidean but topological space.

In 1949 Bill published a text entitled: "Die Kunst der mathematische Denkweise in unserer Zeit" leaving very clear his intellectual position. For him the artists came to constructivism, in a needed reducionist way in order to link art with society. However, mathematics, in their advance got to a point where they lost clearly, the boundaries became blurred.

The mathematical conception of art of the fifties is not in a strict mathematical sense. Hardly it served what was meant by exact mathematics. In the opinion of Bill, the Euclidean geometry retained only a limited effect for the scientists of the twentieth century, and therefore, its importance should be relative to the art. The principle of finite infinity, became an indispensable and vital resource for mathematical and physical thinking. 


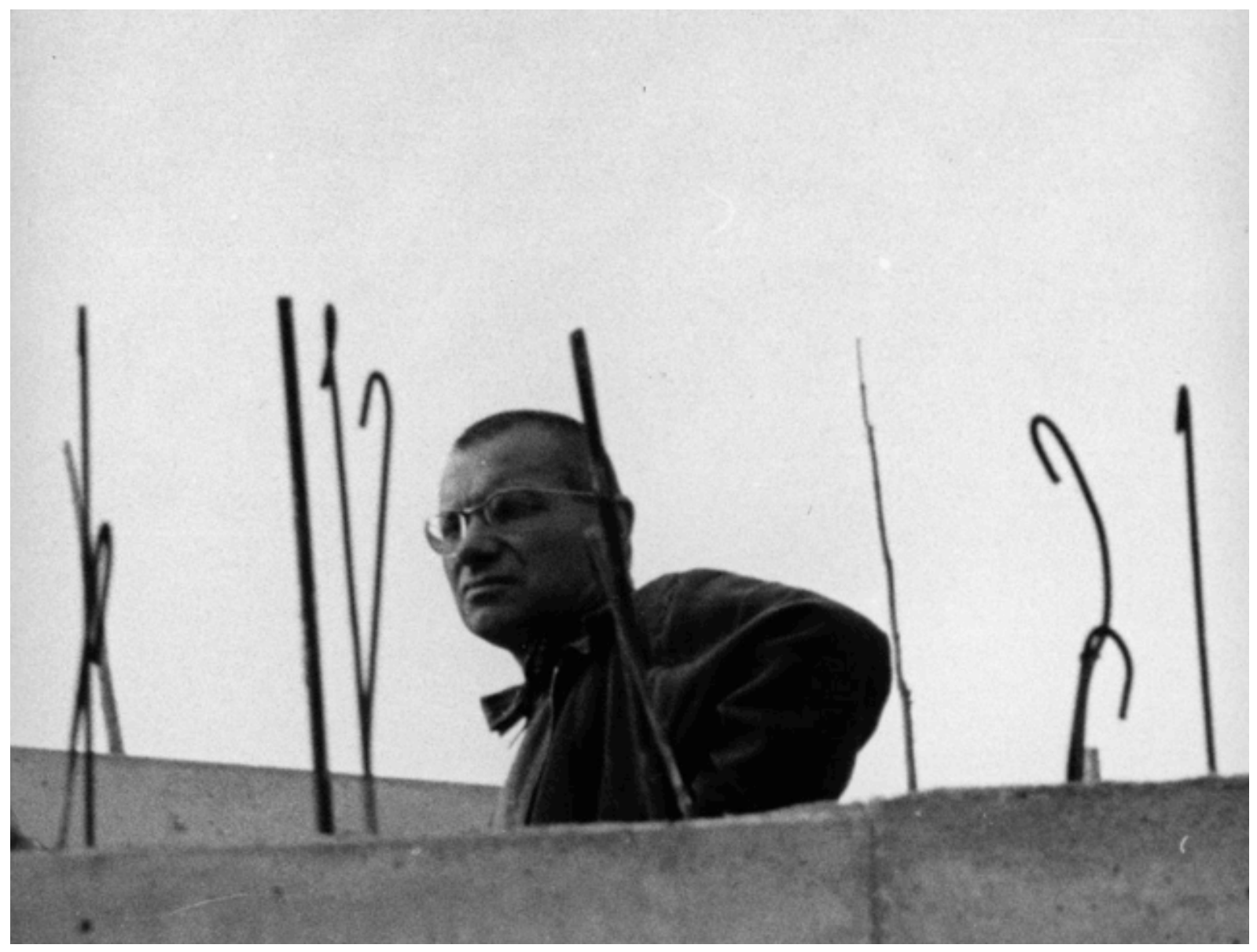


This is the thought site in where Bill was when he returns in the fall of 1952 to his study in Zurich. There he worked for seven months, with little contact with the circle of UIm, with whom he had developed, in close collaboration, all drafts. On May 5, 1953, after more than half a year, the official request was made to build the school in Ulm. This contained a location map (1: 500), as well as ten building plans (1: 100).

It would fail to solve some fundamental questions in order to rise the event up, why in Ulm? Why Max Bill?

The origin of the school is from a physically and morally devastated Germany after the end of World War II. The choice of Ulm by the Americans and in particular by Shepard Stone, American high commissioner in occupied Germany, is based on an ideological and territorial strategy: to the south, in Ulm, there was a foundation (Geschwister-Sholl-Stifftung) created from the murders of two young people, who belonged to the internal resistance to Nazism, by the Nazis. This foundation and a group of intellectuals from UIm (UImer Kreis) created a Volkshochschule or a school to teach elderly people without training. The Americans propose them to transform it into a Hochschule (College), within their anti-Nazi re-educational politic.

The Americans did not want a dean for this new school that could have the minimal connection with Nazism. Due to variety circumstances detailed in the thesis Max Bill appeared on the scene. He was Swiss and an internationally recognized artist.

Max Bill designed and built the new building in the middle of this circunstances, turning it slowly in the crystallizer element of a revolution towards a more just, equitable and peaceful society.

Neither calculated art nor geometric art the thesis attempts to transform an objectivity in a reasoning that lights on a way of conceiving the absolutely new architectural space, that today we recognize in some of the most paradigmatic of contemporary buildings. More than the work of a creator, is the representation of a collective thought, where the architect acts almost as a medium of a community. 

introducción

introducción

hipótesis y objetivos

estado de la cuestión

metodología de la investigación

estructura de la tesis 


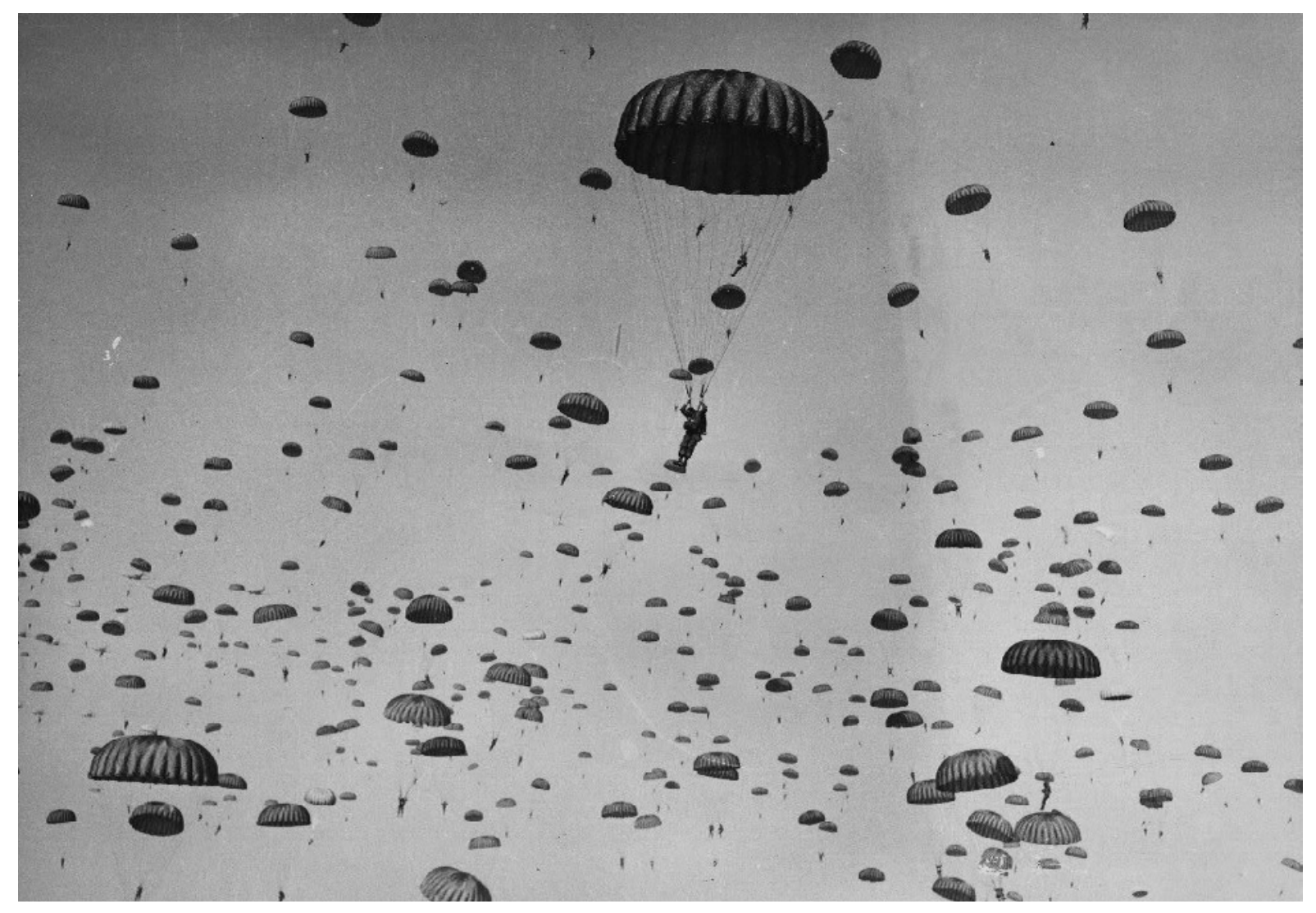




\section{introducción}

Esta tesis tiene como objeto demostrar (hipótesis) que el edificio de la Hochschule für Gestaltung de Ulm no es del arquitecto y artista suizo Max Bill, a pesar de serlo.

Esta paradoja constituye una figura de pensamiento en la que hay una incompatibilidad aparente, que se resolverá en el desarrollo de la tesis con un análisis más profundo del que la enuncia.

Max Bill no es el autor del edificio de la Hochschule für Gestaltung (HfG). El enunciado más preciso sería que Bill absorbe o deja pasar a través de sí el lenguaje de la Arquitectura, lenguaje que todavía no le pertenece y que aplica en UIm en unas condiciones muy concretas.

¿Por qué "a pesar de serlo" porque a pesar de no ser arquitecto -o serlo como fueron los primeros Mies o Corbus-, introduce una concepción espacial que, como artista, ya le pertenecía. Max Bill va a pensar el espacio de la HfG como un espacio topológico, entendido como una estructura matemática que le permite la definición formal de conceptos como convergencia, conectividad, continuidad, vecindad.

Según Stanislaos von Moos "la obra pictórica de bill presenta una grandeza órfica, su escultura de una monumentalidad faraónica, y su arquitectura de una áspera funcionalidad. Dentro de cada grupo existen diferencias, que emanan de los medios necesarios para la creación de un objeto y del uso a que sirve". Este comentario encaja, de alguna manera, con la opinión de Reyner Banham que, en ese sentido, tiene razón al incluir a Max Bill -aferrado a algo cuya actualidad se encontraba ya entonces en decadencia- entre los laudatores temporis acti (portavoces de un tiempo pasado). Y ahora, en el siglo XXI, cuando el movimiento moderno despierta aún menos interés entre nuestros contemporáneos, ¿existe alguna razón histórica que justifique el interés por Max Bill? Marcel Breuer y Konrad Wachsmann, estrechamente relacionados con Walter

Gropius, veían en la escuela una solución de urgencia más que un problema de escasez de medios materiales. Pero sobre todo, para ellos, tenía una gran carencia de arquitectura. La hfg suponía un terrible retroceso con respecto a la bauhaus, vinculado al método, poco convencional, que desarrolló Bill en su formación como arquitecto. 

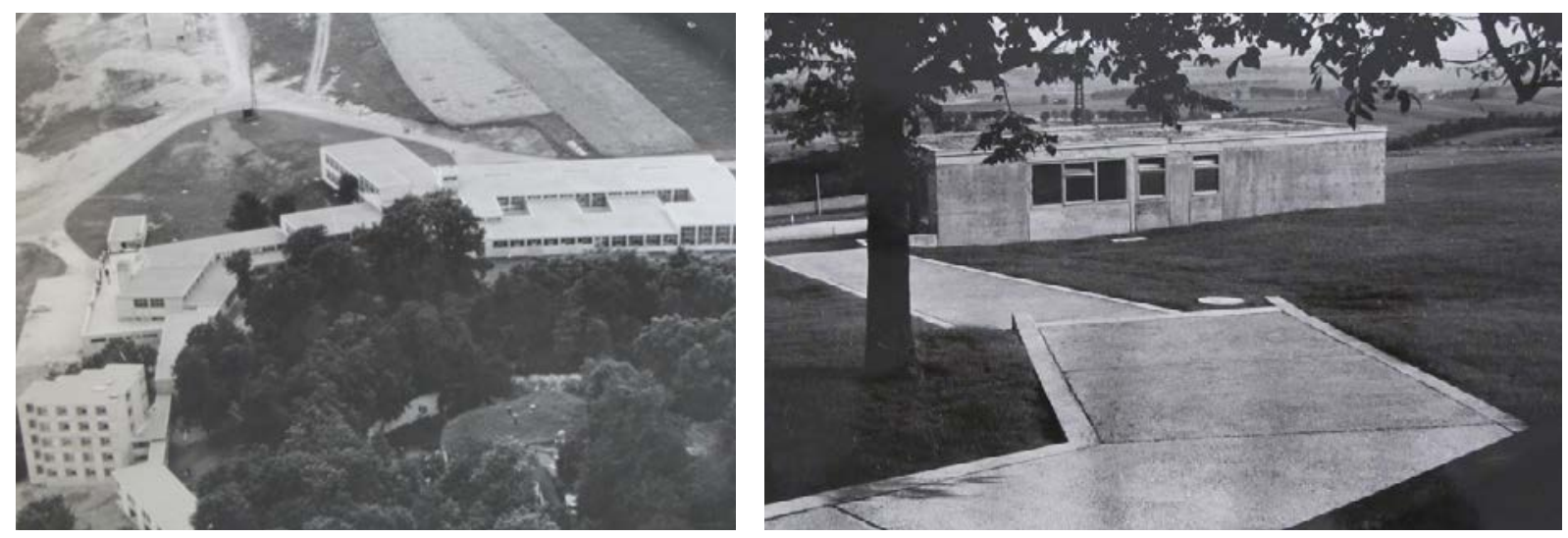

Ante estas abrumadoras opiniones, la pregunta es inmediata ¿por qué el edificio de Bill ha despertado y despierta interés en el mundo de la arquitectura? ¿Por qué se ha mitificado? En unas conversaciones mantenidas durante un seminario en la Arizona State University, (otoño 2011) en el que se debatía sobre la obra y los escritos de Alison y Peter Smithson, el propio Peter Smithson, en respuesta a una pregunta sobre la cultura del consumo, afirmó "la arquitectura no participa de ese juego. Pero es un tanto puritana. Me viene a la mente la Hochschule für Gestaltung de Max Bill en Ulm (aquí introduce la siguiente nota: "Max Bill (1908-1994) pertenece a la segunda generación del movimiento moderno. La Hochschule für Gestaltung de Ulm, Alemania, es uno de los pocos edificios con capacidad generativa del siglo XX) edifico que considero como el mejor de todo el s.XX en Alemania. Sin retórica alguna crea algo muy importante sobre una ladera. La gente se posiciona acerca de este edificio y eso me parece algo maravilloso. Personalmente, no creo que sea obra de Max Bill: él no proyectaba así. A mi parecer, seguramente algún ayudante desarrolló el edificio. La aportación de los Eames en la arquitectura es la aceptación de la colaboración de otros, lo que significa que alguien podía hacer una parte del proyecto y eso podría cambiar totalmente la dirección del mismo. Me pregunto si había alguien en el despacho de Bill con una sensibilidad sobre la arquitectura diferente a él. Me estoy refiriendo al tipo de espacios que incorporan el vacío como parte de ellos." En este comentario Peter Smithson no puede comprender que, mientras Alison y él proyectaban y construían el edifico de la Hunstanton secondary modern school (1949-54), edificio homenaje a los del IIT de Mies en Chicago, con una simetría incomprensible y un leguaje importado, al mismo tiempo Max Bill pusiera sobre la mesa temas revolucionarios como lo infinito finito (infinity finite) referido a un espacio no euclidiano sino topológico.

El año 1949 publica Bill un texto en la revista Werk (no. 3, 1949, Winterthur) con el título: "die mathematische denkweise in der kunst unserer zeit" (la concepción matemática en el arte visual de nuestro tiempo) en el que deja muy clara su posición intelectual. Para él los artistas llegaban al constructivismo, en un camino reduccionista necesario para relacionar el arte con la sociedad. Sin embargo, las matemáticas, en su avance, llegaban a un punto en que perdían claridad: los límites se hacían borrosos. La concepción matemática del arte de los cincuenta no es la matemática en un sentido estricto. Difícilmente servía ya lo que se entendía por matemática exacta. En la opinión de Bill, la geometría euclidiana conservaba solo una vigencia limitada para los hombres de ciencia del siglo XX, y por tanto, su importancia debía ser relativa para el arte. El principio de infinitud finita, se convertía en un recurso indispensable y vital para el pensamiento matemático y físico. También para la 


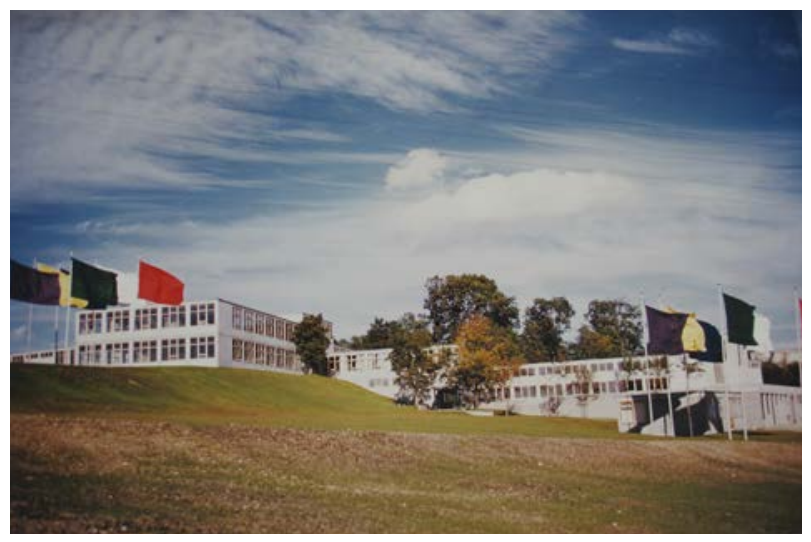

creación artística. Es evidente que con este texto Max Bill abre una puerta a la nueva complejidad en el entendimiento del espacio. Su trabajo como escultor ya bebía de estas fuentes desde principios de los 40 con su obra "konstruktion aus einem kreisring" (construcción de un anillo circular) en el que la importancia de la forma desaparece por la disposición del anillo partido por la mitad y recompuesto al revés.

En el año 1947 construye su primera continuidad, o superficie no orientable. En topología está permitido doblar los objetos, estirarlos, encogerlos, retorcerlos... Siempre que se haga sin romper -ni separar lo que estaba unido, ni pegar lo que estaba separado-. Es lo misterioso de la problemática matemática respecto del espacio inefable: la lejanía y/o proximidad de la infinitud. La sorpresa de un espacio que empieza y acaba desde distintos lados que son el mismo, la limitación sin límites exactos, la multiplicidad que es una unidad, la uniformidad alterada por la aparición de un acento, el campo de fuerzas compuesto por variables, las paralelas que se cortan y la infinitud que vuelve a sí misma como presencia, además el cuadrado con toda su solidez y la recta no turbada por ninguna relatividad. Cuanto más se estructure la ilación del pensamiento, cuanto más homogénea la idea fundamental, tanto más armonía con el pensar matemático.

Este es el pensamiento en el que estaba Bill cuando regresa en otoño del año 52 a su estudio en Zurich. Allí trabajará durante 7 meses, sin apenas contacto con el círculo de Ulm, con el que había desarrollado, en colaboración directa, todos los anteproyectos. C. W. Voltz, que había llegado a dibujar uno de los anteproyectos, trasladó su trabajo de Ulm a Zurich, donde con René Haubensak y Edwin Walder se ocuparía de seguir dibujando. El 5 de Mayo de 1953, después de más de medio año, se presentó la solicitud oficial para construir la escuela en Ulm. Esta contenía un plano de situación (1:500), así como diez planos del edificio (1:100).

La tesis indaga en lo ocurrido en el estudio de Bill. En cómo desarrolla su pensamiento sobre el espacio topológico del proyecto, y cuál es el tipo de colaboración que establece con otros arquitectos, sobre todo con Gugelot, quien trabajó allí desde el 48 al 50, después únicamente mantuvo el contacto como freelance. Finalmente, se fue a Ulm como profesor el año 54, invitado por Bill. Llama la atención el que coincida el desarrollo del proyecto de la HfG con su sistema de construcción de mobiliario modular para oficina M-125.

Falta por resolver algunas preguntas fundamentales para que surja el acontecimiento ¿por qué en Ulm? ¿por qué Max Bill? 
El edificio, que de alguna manera representa y contiene la forma paradigmática de la modernidad clásica del s.XX (de los años 50s a final de los 60), se comprende, desde el punto de vista actual, como una forma nueva de concepción espacial donde, desde la continuidad, se resuelven los específicos problemas planteados por una colectividad que propuso una nueva objetividad desde la revolución. El edificio surge como una declaración de intenciones sobre el futuro del mundo (desde el punto de vista social) y una revolución en la docencia de las artes aplicadas. También fundamentaba su estructura en un rechazo al romanticismo posmoderno de la Bauhaus de Gropius. De alguna manera el propio Gropius advirtió de la pertinencia de introducir un sistema docente que de manera directa enlazara el desarrollo del objeto con lo sociopolítico.

El origen de la escuela es el de una Alemania devastada física y moralmente tras finalizar la Segunda Guerra mundial. En un ambiente donde, entre otros elementos significativos, los americanos hablan de reeducación política. Es una sociedad dirigida por estructuras militares. El congreso de Darmstadt del año 1951, al que asisten varias generaciones de arquitectos, discute sobre el futuro del país. En él se cuestiona cómo desarrollar la reconstrucción, y como plantear la nueva educación.

La elección de Ulm por los americanos y en particular por Shepard Stone, alto comisionado americano en la Alemania ocupada, se apoya en una estrategia ideológica y territorial: los americanos financiaron la Freie Universität en Berlín, con una finalidad claramente reeducativa y antinazi, al sur, en Ulm, por la existencia de una fundación (Geschwister Sholl Stifftung) creada a partir del asesinato por los nazis de dos jóvenes pertenecientes a la resistencia interna al nacismo. Esta fundación y un grupo de intelectuales de Ulm (Ulmer Kreises) crearon una Volkhochschule o escuela para enseñar a gente mayor sin formación. Los americanos les proponen transformarla en una Hochschule (escuela universitaria), dentro de su política reeducativa antinazi.

Los americanos no querían un rector para esta nueva escuela que pudiera tener la mas mínima relación con el nacismo. Por una serie circunstancias que se detallan en la tesis aparece Max Bill en la escena. Suizo y artista con reconocimiento internacional. Su procedencia neutral en la guerra deja bastante tranquilo a Shepard Stone, que además tiene un telegrama de Gropius, donde apoya claramente a Bill. Este además tiene como lengua materna el alemán, e ideas sobre el futuro de la docencia en las artes visuales, además de conferenciante atrevido e interesante. En el año 1950 Inge 

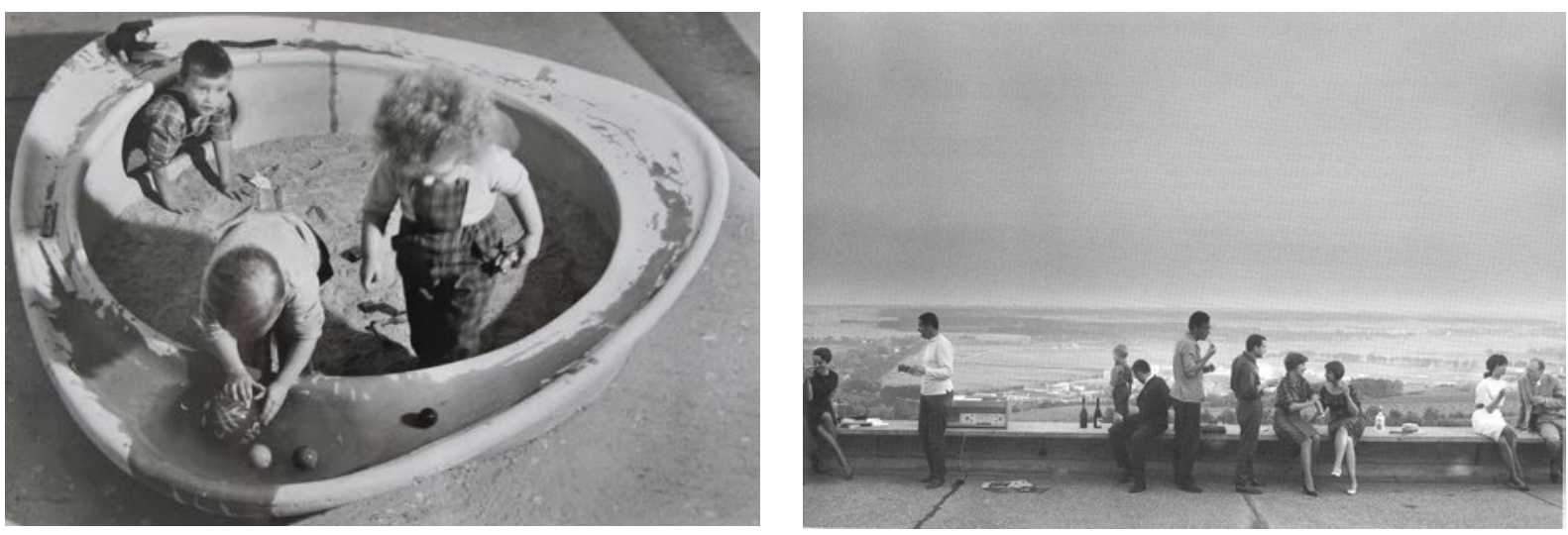

Scholl por carta comunica a Bill que quieren que se encargue de elaborar el currículo de la nueva Hochschule además de diseñar el nuevo edificio.

El edificio de Max Bill se proyecta y se construye en medio de todo esto, convirtiéndose poco a poco en el elemento cristalizador de una revolución hacia una sociedad más justa, igualitaria y en paz. La obra de la HfG es fruto del trabajo de Bill bajo la influencia de varias situaciones. La primera es el desarrollo de un programa docente absolutamente nuevo que produce más que diseño diseñadores. Donde la conciencia social, la política y la técnica estuvieran al mismo nivel. La segunda y más importante es el momento de Bill como artista total. Su intención de convertirse en arquitecto, le lleva a aprovechar esta oportunidad y al modo de Le Corbusier y Mies, hacerse arquitecto en el desarrollo del proyecto y su posterior construcción. Max Bill como tantos otros tienen ese momento de cordura intelectual que les hace dar un salto radical y definitivo en su carrera. Y tercero, es la relación de los elementos de la arquitectura con el paisaje, con el entorno socio-político-económico y con las condiciones propias del encargo - en el que el limitadísimo presupuesto se convierte, por ejemplo, en material fundamental de proyecto-. Como los grandes creadores Bill sabe hacer del defecto virtud.

$\mathrm{Ni}$ arte calculado ni arte geométrico la tesis intenta transformar una objetividad en un razonamiento que de luz sobre una forma de concebir el espacio arquitectónico absolutamente nueva, que hoy en día reconocemos en algunos de los edificios más paradigmáticos de la contemporaneidad. Mas que la obra de un creador, es la representación de un pensamiento colectivo, en el que el arquitecto actúa casi como médium de una colectividad.

\section{hipótesis y objetivos}

La hipótesis, claramente enunciada en el tema, plantea como objeto demostrar que el edifico de la Hochschule für Gestaltung de Ulm no es de Max Bill a pesar de serlo. Planteamiento paradógico que invoca a una forma de pensamiento en que hay una incompatibilidad aparente y de partida, que se resolverá en el desarrollo de la investigación. Este objetivo abre un campo de conocimiento para entender este edificio desde un punto de vista nuevo.

La complejidad del programa, no sólo en el hecho en sí, también en su indeterminación. La ambición intelectual de todas las personas que participaron en la gestación del proyecto y el momento 

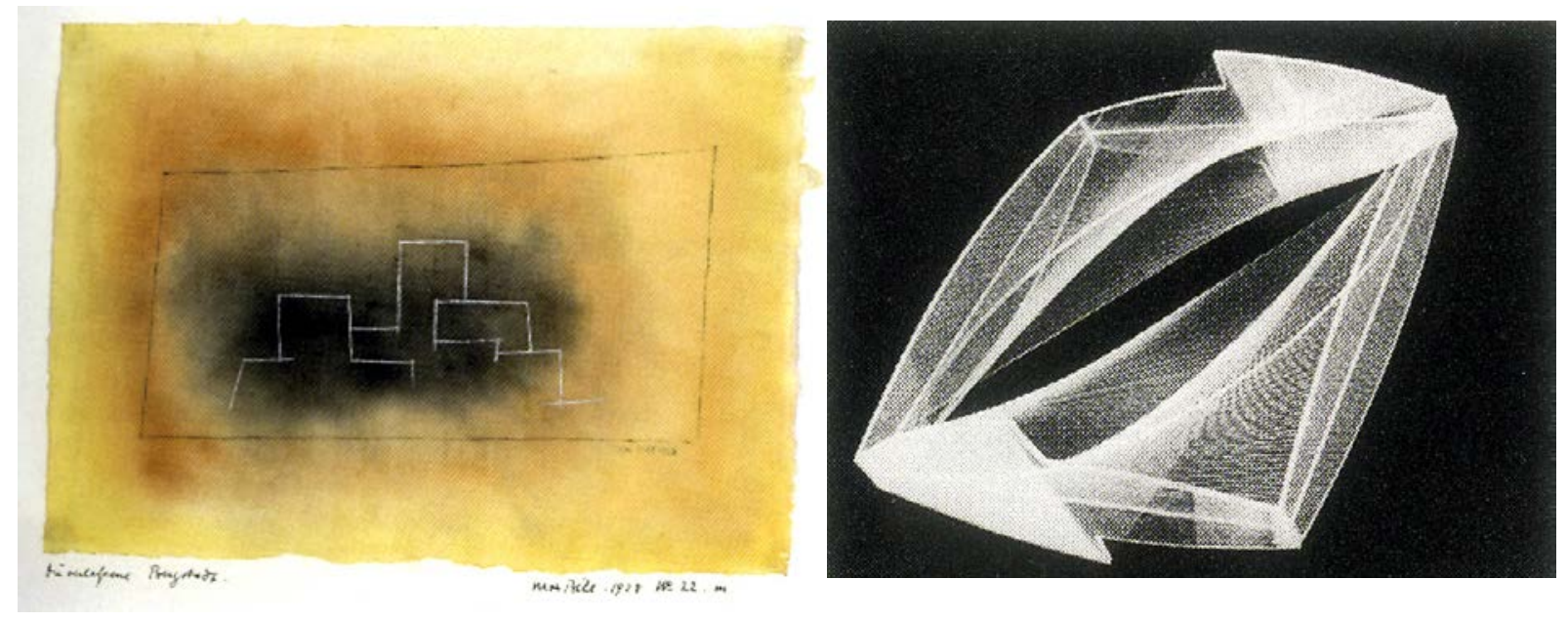

intelectual de Bill, provocaron una situación de extrema clarividencia en el autor, que todavía hoy no se comprende bien.

Lo esencial de la HfG no es su lenguaje arquitectónico, claramente importado, ni la compacidad de su materialidad, ni la forma de posarse en el lugar y de relacionarse con él. Tampoco en la forma de solucionar los problemas funcionales. El edificio de la HfG tiene interés en el desarrollo de un tipo de lógica de la forma. Es el mismo Bill el que dice que hay dos razones por las que se mantuvo interesado y atraído por este tema particular:

_la idea de infinito espacio que, sin embargo, era finito, por tanto la idea de un infinito finito.

_la posibilidad de desarrollar espacios que, como consecuencia de sus leyes intrínsecas e implícitas, produjeran formas en una nueva realidad estética.

Si las estructuras topológicas no orientadas podían existir solo en virtud de su realidad estética, a pesar de su exactitud, él no podía estar satisfecho con ellas. Estaba convencido que la base de su eficacia está, en parte, en su valor simbólico. Son modelos para contemplación y reflexión.

La tesis en su intento de entender la objetividad de un edificio conocido y reconocido, no plantea especulaciones ni de carácter histórico ni arqueológico. Es un desarrollo razonado que indaga sobre una forma de concebir el espacio arquitectónico absolutamente diferente, en el que la geometría euclidiana se usa aplicada directamente a la lingüística del edificio, y aparece en las modulaciones de estructura, de fachada, pero que nunca explicó la verdadera esencia espacial de este edificio. En la espacialidad compleja de los sótanos de la Opera de Sídney de Utzon, en la conexión con lo explícitamente urbano del edificio 6 este de la Universidad de Bath de A\&P Smithson y también en la amalgama barroca de la embajada de Holanda en Berlín de Koolhaas reconocemos variedades topológicas de dimensión finita que ya existen en los planteamientos de Bill para la HfG. Y es ahí donde verdaderamente el edificio de la Hochschule für Gestaltung es de Max Bill. 


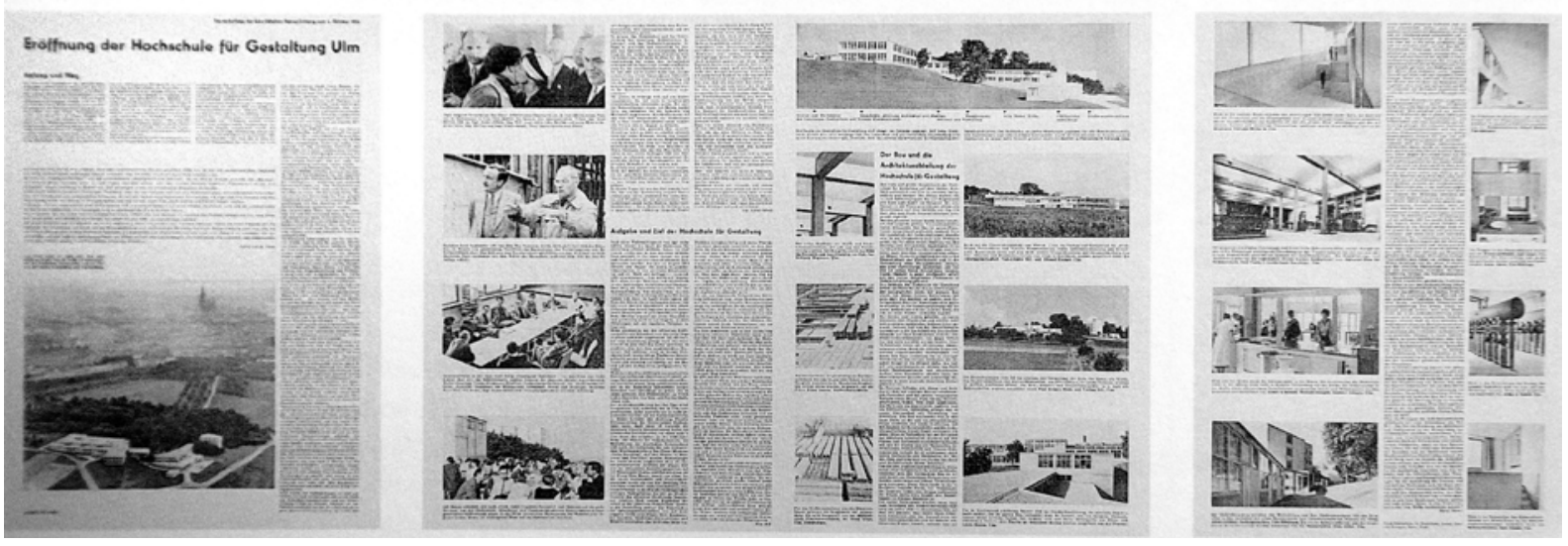

estado de la cuestión

Cualquier aproximación al pensamiento producido sobre el edificio de la HfG anterior a esta tesis pone de manifiesto la condición periférica de esta obra en el contexto de su autor y en el marco del fin para la que fue creada.

Max Bill ha trascendido fundamentalmente como artista, su formidable aportación al arte concreto ha superado y eclipsado su labor como arquitecto para la mayoría de estudios y publicaciones. Por otro lado, la HfG ha trascendido por su legado ético y material. Las publicaciones y estudios en torno a la escuela de Ulm se ha centrado fundamentalmente en su producción y aportación al mundo del diseño y de la docencia. El edificio de la HfG pues, ha quedado en cierta manera diluido como un acontecimiento tangencial, un personaje secundario en la historia de dos grandes protagonistas. El edificio de la HfG aparece descrito y analizado como un elemento más, bien de la escuela o bien de la obra de Bill en numerosas tesis, libros y artículos de la amplia bibliografía sobre la escuela de UIm, de los que se mencionan los más relevantes.

Mientras que escuela estuvo en funcionamiento, la publicación periódica de la revista Ulm recogía la versión oficial del devenir de esta institución a lo largo de los 21 números que se sucedieron desde 1958 y 1968, año de cierre de la escuela. Junto a Output, revista publicada por los alumnos, es el compendio de referencia de todos los temas relativos a la existencia de la HfG en las que el edificio aparece como un escenario de la vida y producción de aquellos años.

Además de las notas en la prensa local que recogían sucintamente la construcción e inauguración del edificio, la primera mirada sobre la obra fue publicada en la revista das Werk en 1954. Eugene Gomringer, profesor de la $\mathrm{HfG}$, considerado el padre de la poesía concreta, publica las primeras imágenes del edificio y una breve descripción. Max Bill muestra por primera vez su edificio en el número monográfico 259 de la revista

Casabella, que está completamente dedicado a la escuela. Este artículo se estableció como una referencia de publicaciones posteriores.

También las revistas Archithese y Rassegna dedicaron dos de sus números monográficos a la escuela: "HfG Ulm, ein Rückblick. une retrospective" en: Archithese 15, 1975, con artículos de Claude Schnaidt, Otl Aicher, Herbert Ohl, y Kenneth Frampton; y el número "il contributo della scuola di Ulm. the legacy of the school of Ulm" en: Rassegna heft 19, 1984 con artículos de Tomás Maldonado y Martin Krampen entre otros. 


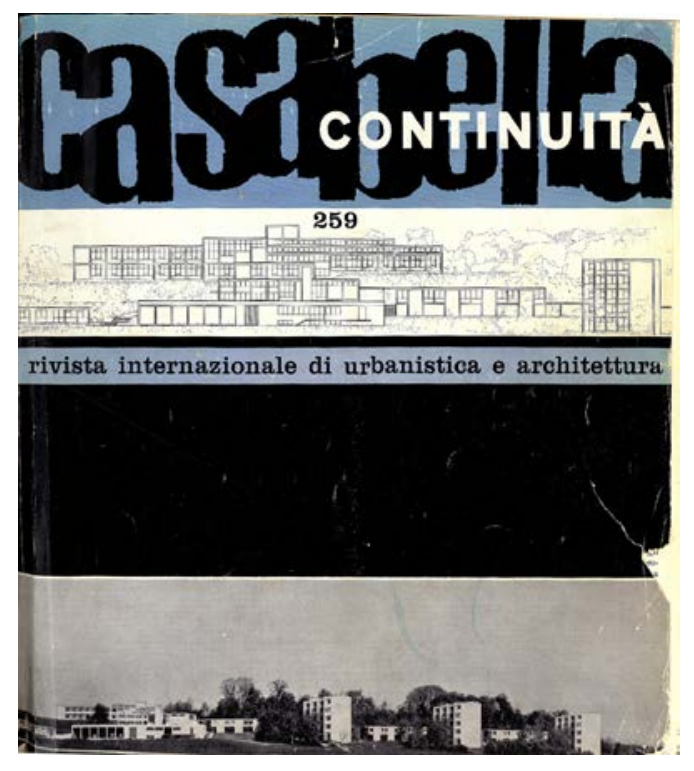

Tras el cierre convulso de la escuela en 1968 todo el material y documentos testimonio de su historia permanecieron en un encierro por más de diez años. El primer esfuerzo por poner en orden y organizar una recopilación cronológica de la escuela sucede en 1982, año en el que el antiguo alumno de la HfG Hans Nick Roericht junto a Petra Kellner, Marcela Quijano y Sibile Riemann ocupan con un equipo el antiguo comedor de la HfG y producen en tan solo 9 meses la que todavía hoy es una exposición y publicación de referencia sobre la escuela: el HfG synopse. La exposición se convierte en una crónica que recoge los aspectos políticos, docentes y la producción del instituto de diseño a lo largo de la vida de la escuela.

Las dos primeras tesis específicas sobre la HfG se remontan a 1985, obra del historiador Hartmut Seeling Geschichte der Hochschule für Gestaltung in UIm, 1953 - 1968 (Colonia) y del arquitecto Norbert Korrek die Hochschule für Gestaltung in Ulm (Weimar. La primera contiene un breve capítulo dedicado al edificio de la HfG. Norbert Korrek organiza una exposición sobre el edificio en la escuela de arquitectura de Weimar en 1983.

Las investigaciones de Seeling y Korrek no tienen difusión y habrá que referirse como trabajos con mayor impacto a la tesis de Eva von Seckendorff: die Hochschule für Gestaltung in Ulm. Gründung (1949 - 1953) und Ära Max Bill (1953 - 1957); defendida en Hamburgo y posteriormente publicada en 1989 y la tesis sobre la historia sociopolítica de la HfG de René Spitz "die Politische Geschichte der Hochschule für Gestaltung Ulm .

(1953-1968)"; defendida en colonia en 1997. Esta última, publicada en 2002 es la de mayor difusión hasta la fecha. El trabajo de von Seckendorff contiene un estudio comparativo del edificio de la HfG y sus referentes directos como la Bundesschule des ADGB de Hannes Meyer en 1930.

Por proximidad, es necesario mencionar la tesis del arquitecto Alberto Martínez Castillo: "Max Bill: variaciones sobre la belleza", de reciente defensa en la Etsam. Martínez Castillo dedica uno de sus quince capítulos -la belleza cruda- a la descripción de la génesis del edificio a través de los anteproyectos, basándose en publicaciones anteriores, y al análisis de su espacio acudiendo de nuevo a la comparación con las arquitecturas de referencia directa de la HfG. 

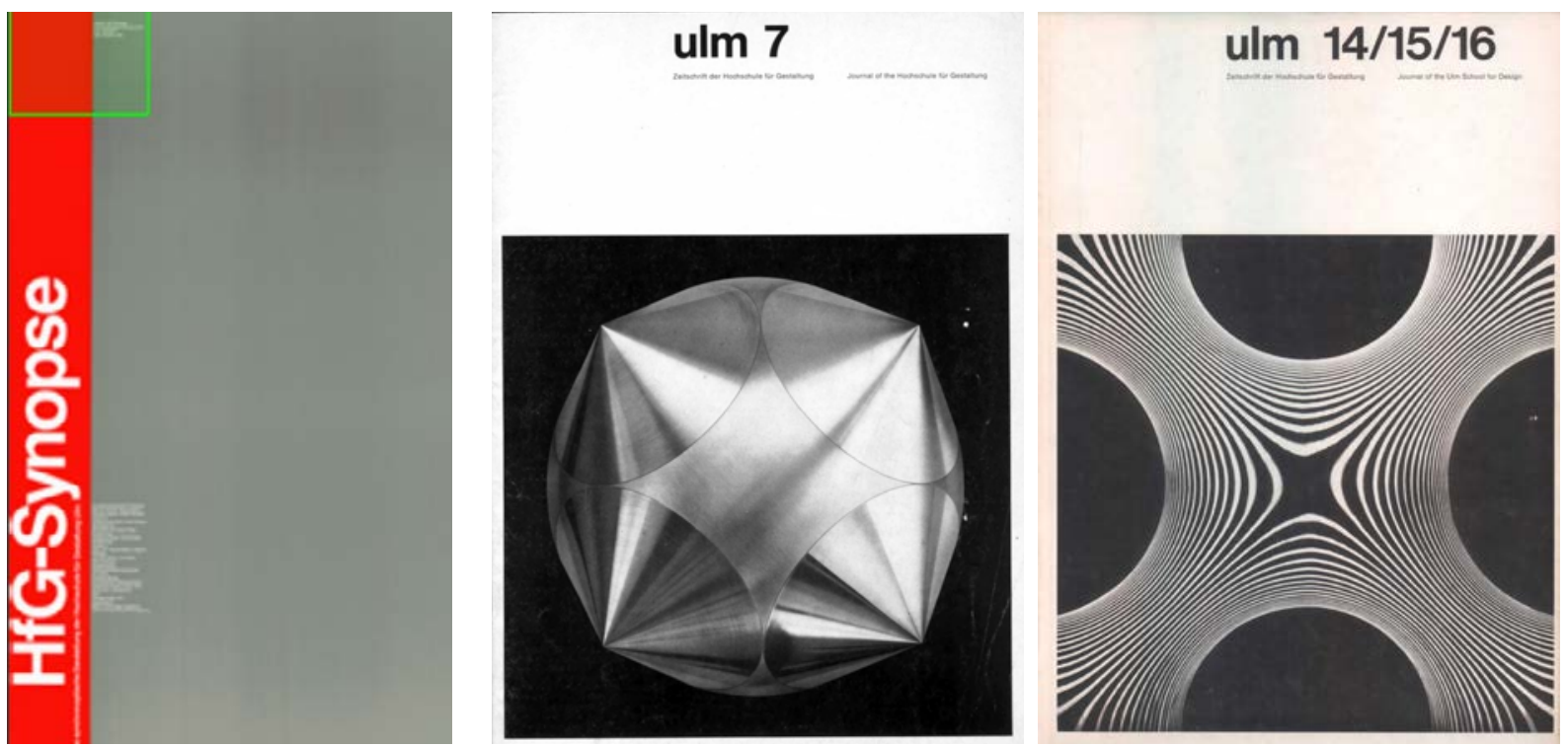

El primer libro que aborda la figura de Max Bill exclusivamente como arquitecto es el publicado por Hans Frei en 1991: konkrete Architektur? - über Max Bill als Architekt, Baden (Schweiz),1991. Este libro se convertirá en una referencia fundamental para artículos en revistas y libros sobre el edificio de la HfG.

Posteriormente, en 1998 Marcela Quijano publica el libro monográfico sobre el edificio: HfG Ulm: Programm wird Bau. die Gebäude der Hochschule für Gestaltung Ulm, Stuttgart: edition solitude. En él se exponen las circunstancias de la construcción publicando algunas fotografías hasta entonces inéditas de la obra y aporta una mirada sobre la adecuación del los espacios al programa didáctico.

El estudio más completo y todavía inédito es el realizado por el arquitecto de origen suizo Daniel Meister, antiguo alumno de la HfG. Meister ha realizado una labor de recopilación de todos los documentos, planos y fotografías que se encuentran repartidos entre el archivo de la HfG y el archivo Bill. La investigación, que todavía no ha concluido, fue presentada parcialmente al público en una conferencia celebrada en Ulm en noviembre del 2014. Daniel Meister realiza un estudio muy minucioso y exhaustivo del edificio con carácter notarial y persiguiendo el objetivo de preservar su memoria para que la obra original sobreviva a las modificaciones que ya ha sufrido.

Como se puede ver tras esta síntesis, la mayoría de publicaciones y estudios que se pueden mencionar se ocupan del edificio con escasa extensión y en el contexto más amplio bien de la escuela, bien de la obra arquitectónica de Bill.

La óptica histórica del edificio unida al programa de la escuela es la más habitual, y también la vertiente analítico-comparativa que sitúa a la obra en el repertorio de los modelos clásicos de los espacios para la enseñanza y toda la genealogía arquitectónica de la que procede. La investigación de Daniel Meister desde una mirada arqueológica sin duda establecerá una restauración de la memoria material del edificio. 

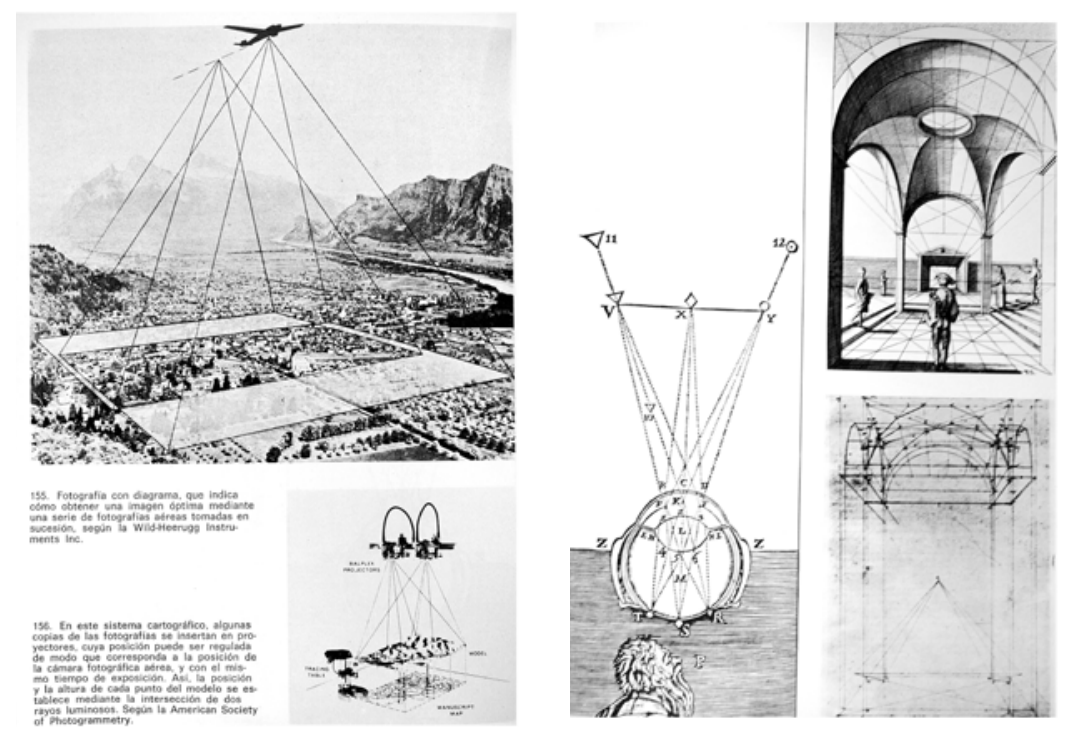

Estas miradas comparten un hecho: no buscan más allá de las evidencias que el edificio, sus antecesores y sus circunstancias ofrecen. Una mirada crítica, más compleja, que profundice en el pensamiento que ha generado esa arquitectura y no otra, que cuestione las decisiones del edificio hasta llegar a su autoría, es la contribución que esta tesis pretende aportar al campo de conocimiento ya existente.

\section{Metodología}

La Hochschule für Gestaltung de Ulm (1946-1968) es un paradigma de la sociedad europea tras la segunda guerra mundial, sin duda, por la complejidad del edificio, pero también por el sistema docente de la escuela y los resultados que produjo.

\section{Fase Documental}

La investigación, en su fase documental, ha intentado abarcar todo lo que fue la escuela, la evolución del entorno social, el paso de los diferentes profesores y el cambio de programa docente. En este transito dinámico de la docencia, lo que permaneció como un invariante que acogía con naturalidad todos lo eventos que allí ocurrían, fue el edificio.

Por tanto, en la fase de análisis de todo el material obtenido de las visitas al archivo de la HfG en Ulm, la visita al estudio de Max Bill en el barrio de Zumikon en Zurich, la entrevista de 6 horas con Tomás Maldonado en su casa estudio de la Via Manzoni de Milán, el estudio de libros y textos fue centrando la investigación en el edificio como un ente extraño, ahora ya no reconocido.

Fase de Análisis

La fase de Análisis ha centrado la investigación por un lado en el rastreo del trabajo de Bill como artista interesado en la matemática. Y por otro en cuáles pudieron ser las referencias arquitectónicas que adoptó de forma directa y por qué. 


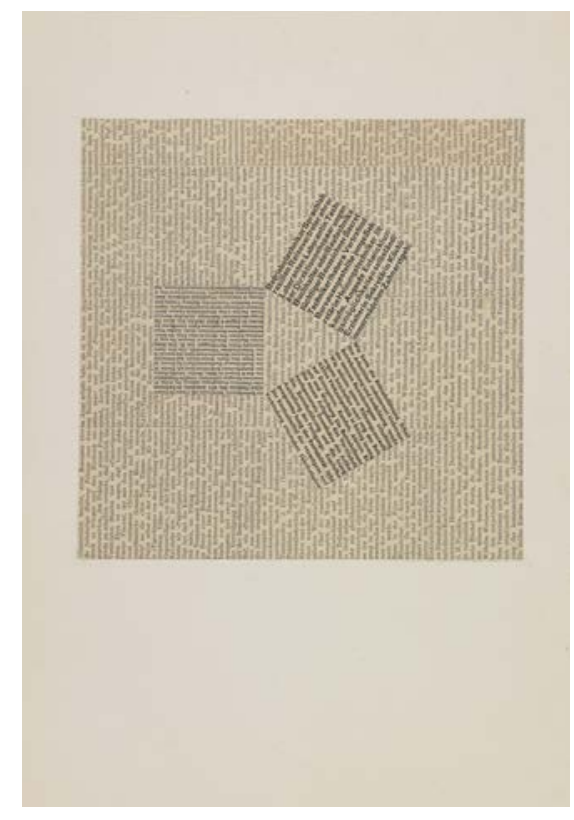

Estos caminos han abierto nuevas vías de investigación dirigidas únicamente al entendimiento de la gestación del edificio. La concreción del lenguaje utilizado en el edificio y su relación con otros analiza de forma exhaustiva las posibles referencias en las que se pudo apoyar Bill. El estudio analítico de la rama de las matemáticas conocida como Topología General ha hecho entender algunas referencias que el propio

Bill iba dejando de forma suelta en muchos de sus textos sobre la conocida como "conjetura de Poincaré".

En este momento el trabajo se centraba en el estudio de la documentación gráfica de la escuela atendiendo a diferentes conceptos relacionados con la geometría euclidiana en lo que tiene que ver con el lenguaje arquitectónico del edificio y con la topología en toda su configuración espacial.

La fase analítica se divide en dos partes que se trabajan de manera separada, la primera de ellas a su vez se divide en dos:

1 Análisis de la arquitectura en el espacio euclidiano:

Análisis de la arquitectura en lo que tiene de lenguaje y consideración referencial con la historia.

Análisis en la pertenencia al espacio euclidiano, donde las herramientas de trabajo son la modulación, la escala, la posición relativa, el uso de giros, cambio de ángulos y el juego de volúmenes bajo la luz.

2 Análisis de la concepción espacial del edificio desde la topología:

Conectividad

Compacidad

Metricidad

Metrizabilidad 
Fase de Síntesis

En esta fase se demuestra por un lado lo planteado en la hipótesis de partida, que es la afirmación de que el edificio, como leguaje arquitectónico, no pertenece a Max Bill. Lo que aporta el autor es una concepción geométrica clara referida al espacio euclidiano -con poca significación posterior por la falta de novedad-. Y una nueva concepción espacial, con gran significación actual, cuando el proceso de proyecto aborda un entendimiento topológico, en su concepción formal-espacial. Para esto el espacio interior del edificio se someterá a una descripción desde los siguientes puntos de vista:

Interior-exterior-frontera

Adherencia, acumulación y puntos aislados

Convergencia

Continuidad de aplicaciones

Conjuntos conexos

Compacidad

Metrización

Separación

Densidad.

\section{Estructura de la tesis}

El desarrollo lógico de la tesis se ha organizado en tres capítulos denominados construcción horizontal, construcción vertical, construcción emotiva.

Es Max Bill quien introduce estos términos en alguno de sus planteamientos.

construcción horizontal(infinity es la base de apoyo sobre la que se fundamentan todos los razonamientos posteriores. Soporta fuerzas externas que no le preconfiguran, simplemente se limita a un crecimiento hacia la infinitud.

construcción vertical(finite se apoya en la anterior y se configura por fuerzas externas como la gravedad. Tiene un límite finito. 
construcción emotiva(infinity finite Bill se refiere a la construcción horizontal-vertical de la obras de Mondrian como una configuración puramente emotiva, a pesar de todo el rigor de los medios de expresión empleados. En este caso la tesis finaliza en una construcción emotiva (en el sentido transformador de la objetividad) que se refiere con rigor a las construcciones horizontal-vertical de los capítulos anteriores. La idea de infinitud, finita presente en parte de la obra de Bill a partir del año 1942, define los límites de este apartado.

Dentro de cada capítulo existen dos apartados que tienen que ver con los fenómenos perceptivos y la teoría de la Gestalt. Un apartado dedicado a la parte de cada capítulo mas indiferenciada y periférica que captamos de modo difuso, denominada fondo. Y otra mas estructurada y bien delimitada, denominada figura. Fondo y figura presentan un contraste y se halla necesariamente presente en cualquier percepción.

Construcción horizontal(infinity es una gran base en donde se sitúa el origen de la Hochschule für Gestaltung.

Como fondo el entorno social e intelectual de la posguerra europea y en particular de la posguerra alemana. También uno de los hechos más sobresalientes de la década de los 50 en Europa que fueron los coloquios de Darmstadt de 1951. Heidegger pronunció allí la famosa conferencia "Mensch und Raum", en el entorno de unos encuentros entre arquitectos y teóricos sobre el tema "el ser humano y el espacio". Además se indaga en la decisión política, por parte de los americanos de elegir Ulm como lugar para fundar una Hochschule.

Como figura la de Bill. Por qué su elección, en qué momento se encuentra cuando recibe el encargo. Como arquitecto, cuáles eran sus influencias más directas, en Europa, en América.

Construcción vertical(finite trata de la generación de la escuela, los programas, los anteproyectos, el proyecto definitivo y la construcción.

El fondo de la cuestión está en las relaciones de Bill con el Ulmer Kreises en donde se establecieron el programa del edificio, la disposición y el currículo de la nueva escuela. Este apartado finaliza con el estudio de los cinco anteproyectos desarrollados por Bill. 
||||| |||||||||||| ||||| |||||| ||||| ||||| |||||

||||| |||||| |||||| |||||| |||||| ||||| |||||| |||||||||

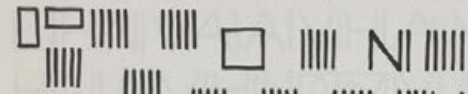

|||||| |||||| |||||| |||||| ||||| |||||| |

||||| $\square \mid$ ||||| $\square$ ||||| $\square$ |||||

|||||||||||||| $\square^{||||||}$

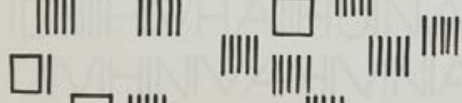

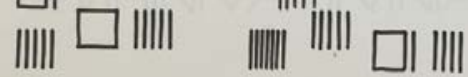

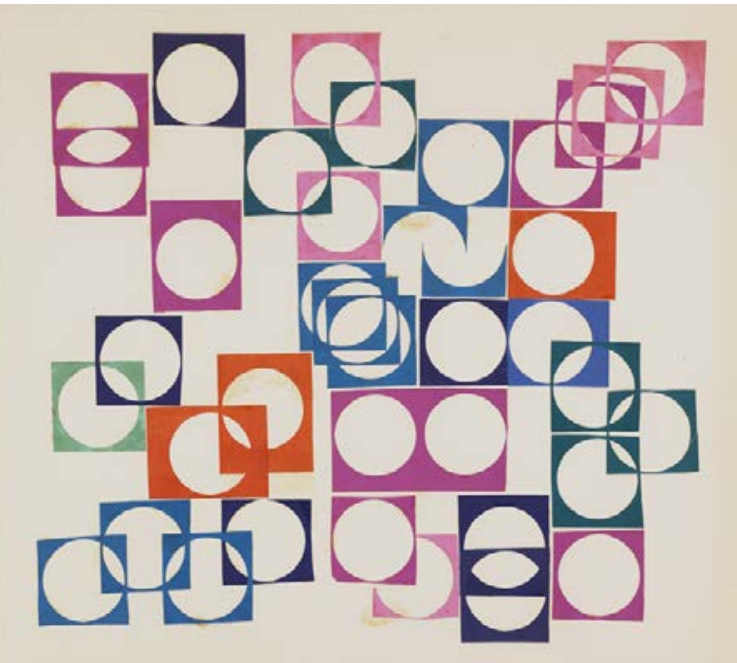


La figura en este caso es el edificio. El proyecto definitivo desarrollado en Zurich y la construcción final. La intervención de otros agentes como profesores y estudiantes también es analizada en este apartado.

Construcción emotiva(infinity finite es el capítulo conclusivo y en el que se resuelve la hipótesis y algunas temas importantes como es la repercusión de edificio de HfG en la actualidad.

En el fondo de este capítulo está toda la estructura matemática que Bill maneja en esos años. También su fuerte interés por convertirse en arquitecto. Hasta este momento quiso ser algo que no era.

En la figura se resuelve la paradoja de la hipótesis, analizando el edificio desde tres puntos de vista: la arquitectura, la geometría del espacio euclidiano y la geometría del espacio topológico. Finalmente se analizan las repercusiones de este edificio en la carrera de Bill y las repercusiones en la arquitectura actual. 

$>1$ construcción horizontal (infinity 


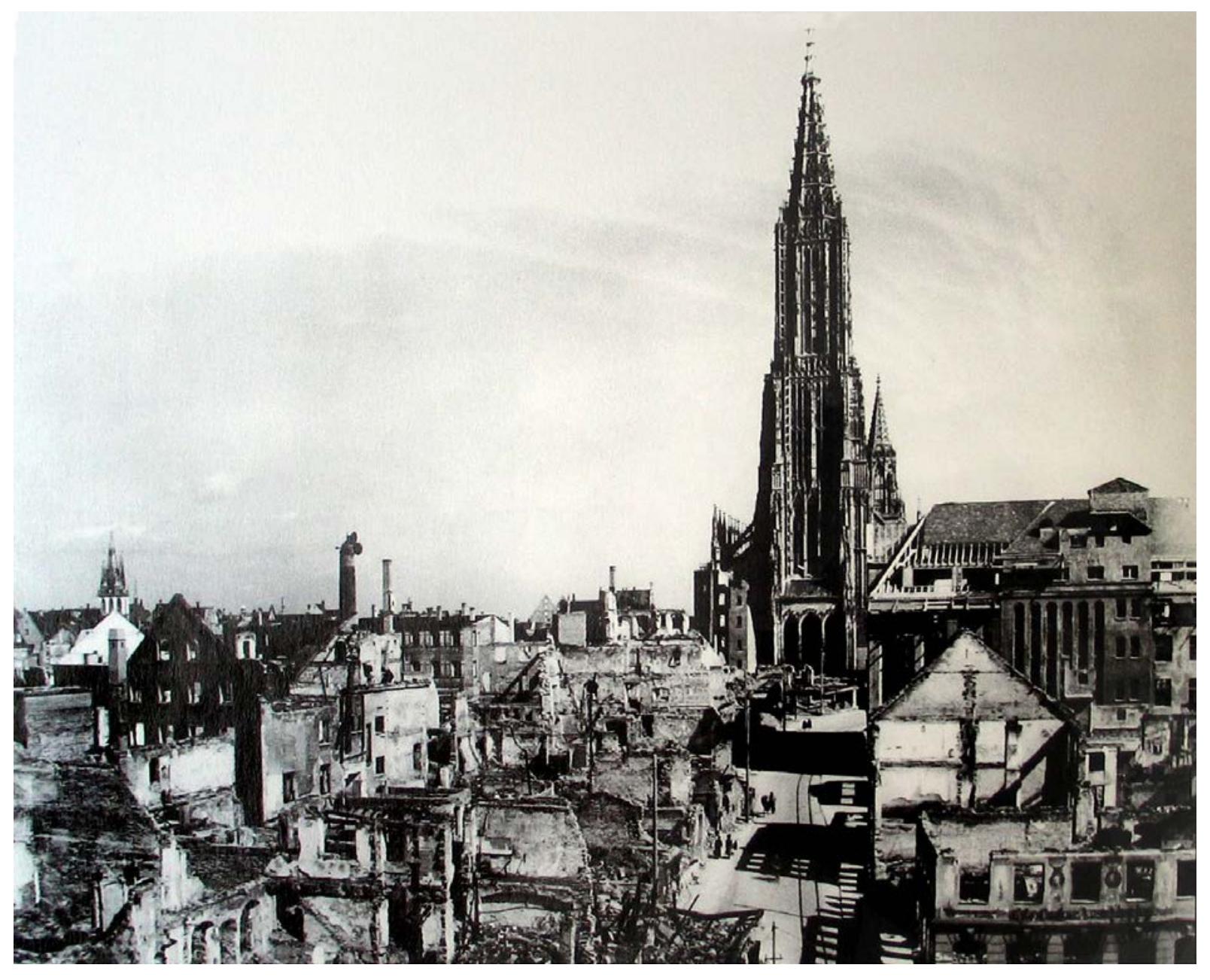




\section{1> construcción horizontal (infinity \\ 1.1 fondo}

\subsection{1 el origen de la escuela}

. die weisse Rose y los hermanos scholl

. la fundación Geschwister Scholl

Ante la pregunta por qué Hochschule für Gestaltung y no Bauhaus Ulm, Otl Aicher en un artículo titulado Bauhaus y UIm contestó: "cuando Walter Gropius nos hizo el ofrecimiento de llamar a la escuela Bauhaus UIm, nosotros lo rechazamos.

Estoy todavía hoy casi sorprendido por eso. En nuestra civilización contemporánea a menudo es más importante el envoltorio que su contenido, conexiones laterales, clasificaciones y relaciones llevan el gran peso. Pero alguien que acababa de volver de la guerra y estaba intentando levantar una nueva escuela se encontraba en un medio ambiente diferente.

Por supuesto que nosotros éramos conscientes en ese tiempo del aura política y cultural que una escuela ganaría siendo llamada Bauhaus Ulm. queríamos hacer lo que fuera correcto sin especular sobre los efectos y las consideraciones públicas."

En su respuesta Otl Aicher expresa con claridad la necesidad de separarse de la mítica escuela alemana, y de buscar otro camino para lo que estaban creando.

. las volkhochschule alemanas

La historia de la hochschule für gestaltung de ulm comienza el año 1942. A mitad de ese año los alemanes intentan conquistar los pozos de petróleo soviéticos y son cercados, con la llegada del invierno, a finales de ese año en Stalingrado, 250000 alemanes morirían en esa batalla. algunos de los heridos más graves fueron trasladados a Alemania. Entre ellos el novio de una chica de 21 años que vivía en Ulm. El nombre de ella es Sophi Scholl, la cuarta de 5 hermanos hijos de una familia de clase media alemana. El novio de Sophi es repatriado a Leipzig y desde allí puede enviar correspondencia a sus familiares y amigos, algo que era imposible desde el frente de guerra. En sus misivas contaba 


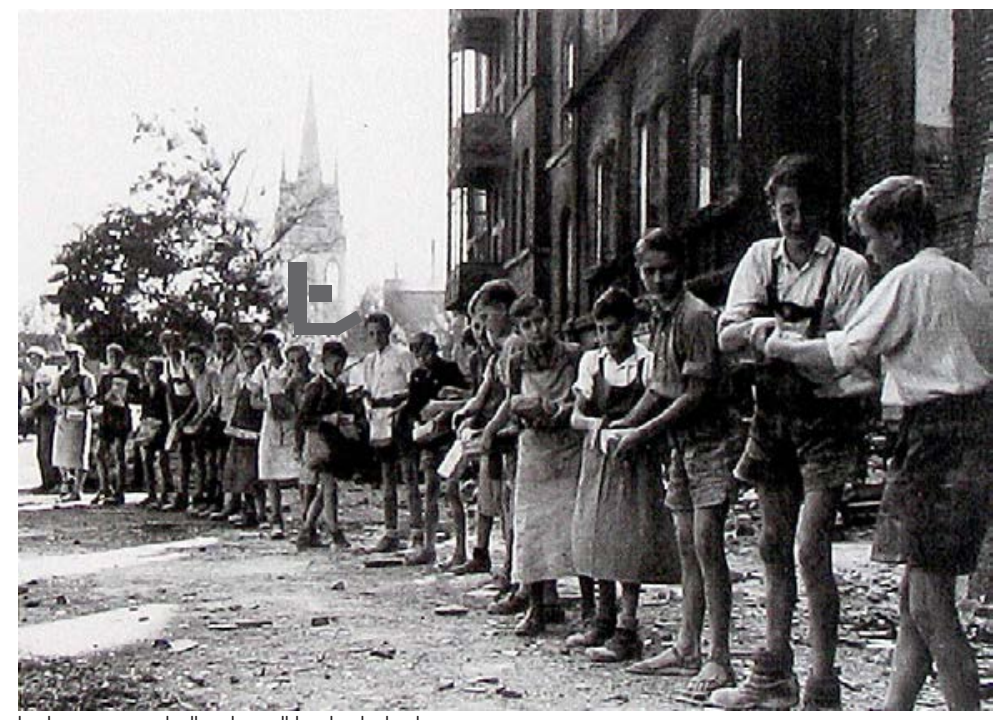

los hermanos scholl en las volkhochschule alemanas

que la batalla de Stalingrado estaba siendo terrible para los alemanes, una carnicería sin posibilidad de triunfo. Noticia que contrastaba con la propaganda nazi dentro de Alemania, que arengaba por la guerra total en el camino de conseguir la victoria. Sophi Scholl muy impresionada por lo que le contaba su novio decide difundirlo. Tanto ella como su hermano Hans estudiaban en la universidad de munich y fue allí donde se organizaron con otros estudiantes en un especie de asociación de ideología cristiana que se llama la "die Weisse Rose". A partir del momento en que descubren que Alemania está perdiendo la guerra se dedican a difundirlo, primero repartiendo pasquines de puerta en puerta, y luego por la calle. En febrero de 1943 son detenidos por la Gestapo, y en un juicio sumarísimo que dura tres días son condenados a muerte por guillotina y ajusticiados en Berlín. La noticia impacta duramente sobre la familia Scholl y los ciudadanos de la ciudad de Ulm, que era el lugar donde vivían.

. la importancia de la ciudad de UIm

La ciudad de Ulm es una ciudad especial por algunas razones: tiene en su haber tener la torre de catedral mas alta del mundo $(161,53 \mathrm{~m})$, pero esto no es lo importante, sino que la promoción y financiación de la catedral en su totalidad fue de parte de los ciudadanos. Además, y como curiosidad, a mitad del siglo XVI, y ya consagrada la catedral al catolicismo, los ciudadanos de UIm, en contra de la totalidad del entorno de la ciudad, deciden declararse seguidores de Lutero.

En la primavera de 1960 se disipa la nieve Descartes sigue en movimiento. pasa el verano en Ulm, donde se entrevista con un tal Johannes Faulhaber, matemático y astrólogo nacido en ulm el 5 de mayo de 1580. fue un reconocido tejedor que acabo como aparejador municipal de la ciudad de Ulm. colaboró con Kepler y Lodoph van Ceulen. su trabajo sobre fortificación de ciudades (Frankfurt y Basel), además construyó molinos de agua en ulm e instrumentos de precisión para los militares

La ciudad siente la necesidad de responder, mirando al futuro, a la muerte de esos inocentes. Inge y su marido Otl Aicher después de la guerra recogen el sentir de la ciudad y crean una Volkhochschule (escuela popular de formación) recuperando una tradición alemana interrumpida por los nazis. La leyes instauradas por los aliados, en este caso por los americanos, que son los que gobiernan la ciudad, implicaban la imposibilidad de reuniones de varias personas adultas. La creación de la escuela popular permitió la posibilidad de establecer un debate entre grupos de ciudadanos interesados en encontrar soluciones de futuro para una ciudad completamente destruida por los aviones de la Raf. 


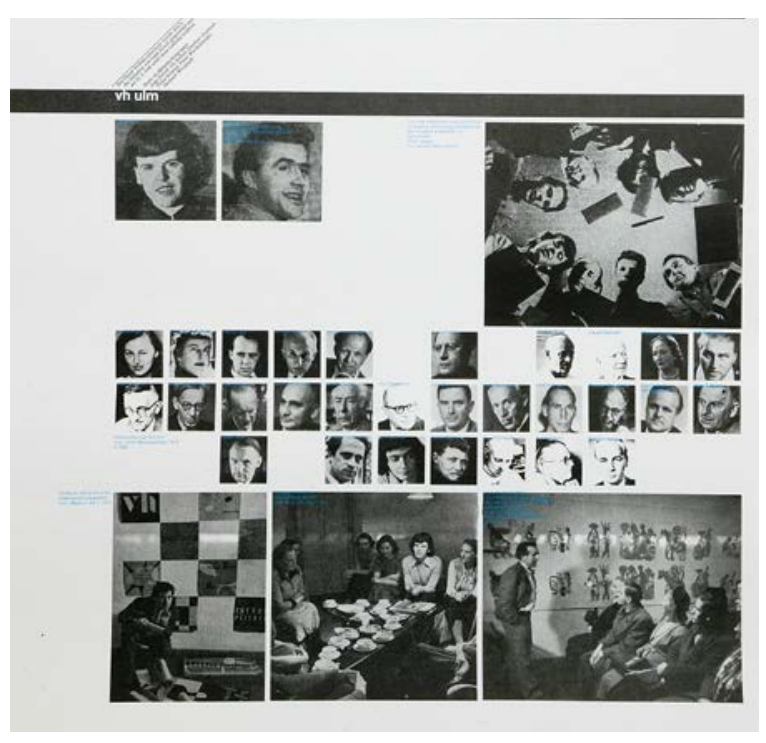

\subsection{2 el entorno social e intelectual}

. la Alemania de entreguerras

- la guerra y la posguerra

. la sociedad después de la guerra

En septiembre de 1944, la capital del Ducado de Hessen, Darmstadt, fue destruída sistemáticamente por los aliados. La capital quedaba totalmente arrasada, en ruinas. Por esta razón se decidió que la administración de la ocupación américana fuese trasladada a Wiesbaden. De esta forma, Darmstadt - ciudad cuya actividad central había sido la administración - quedaba despojada de su base de subsistencia y de desarrollo para el futuro. Considerando la antigua tradición cultural de la ciudad, los políticos dicidieron darle una perspectiva como centro urbano universitario - o de formación profesional-y cultural. En el año 1947 se planificó una exposición de homenaje para recordar el 50 Aniversario de la gran exposición "Un documento del Arte alemán" (Del Jugendstil) que había tenido lugar en 1901. La intención desde un principio no fue mostrar los documentos arquitectónicos y culturales de 1901 sino dedicarse a los problemas del presente, en especial, a lo referente a la construcción de vivienda.

\subsection{3 darmstadt 1951: "mensch und raum}

. las once obras maestras (arquitectura alemana)

La temática al encuentro de Darmstadt colocándole como tema central la construcción de edificios comunales y administrativos, los cuales debían ser realizados por arquitectos alemanes y extranjeros. Dichas construcciones pasaron a la historia con el nombre de "las once obras maestras", construcciones que consistieron en siete escuelas y un kindergarten, realizadas por Otto Ernst Schweizer, Rudolf Schwarz, Franz Schuster, Hans Scharoun, Hans Schwippert, Willem Marinus Dudok y Max Taut, así como un asilo de madres solteras de Ernst Neufert, una clínica para mujeres de Otto Bartning, una sala de concierto de Paul Bonatz y la casa de cultura de Peter Grund. A excepción del diseño clasicista de Bonatz, el resto de las construcciones fueron realizadas siguiendo el estilo funcionalista importado de américa de los años 50. Lo único realmente espectacular fue el diseño de Scharoun, con el concepto de 'ruptura de formas' y de 'escalonamiento'. 

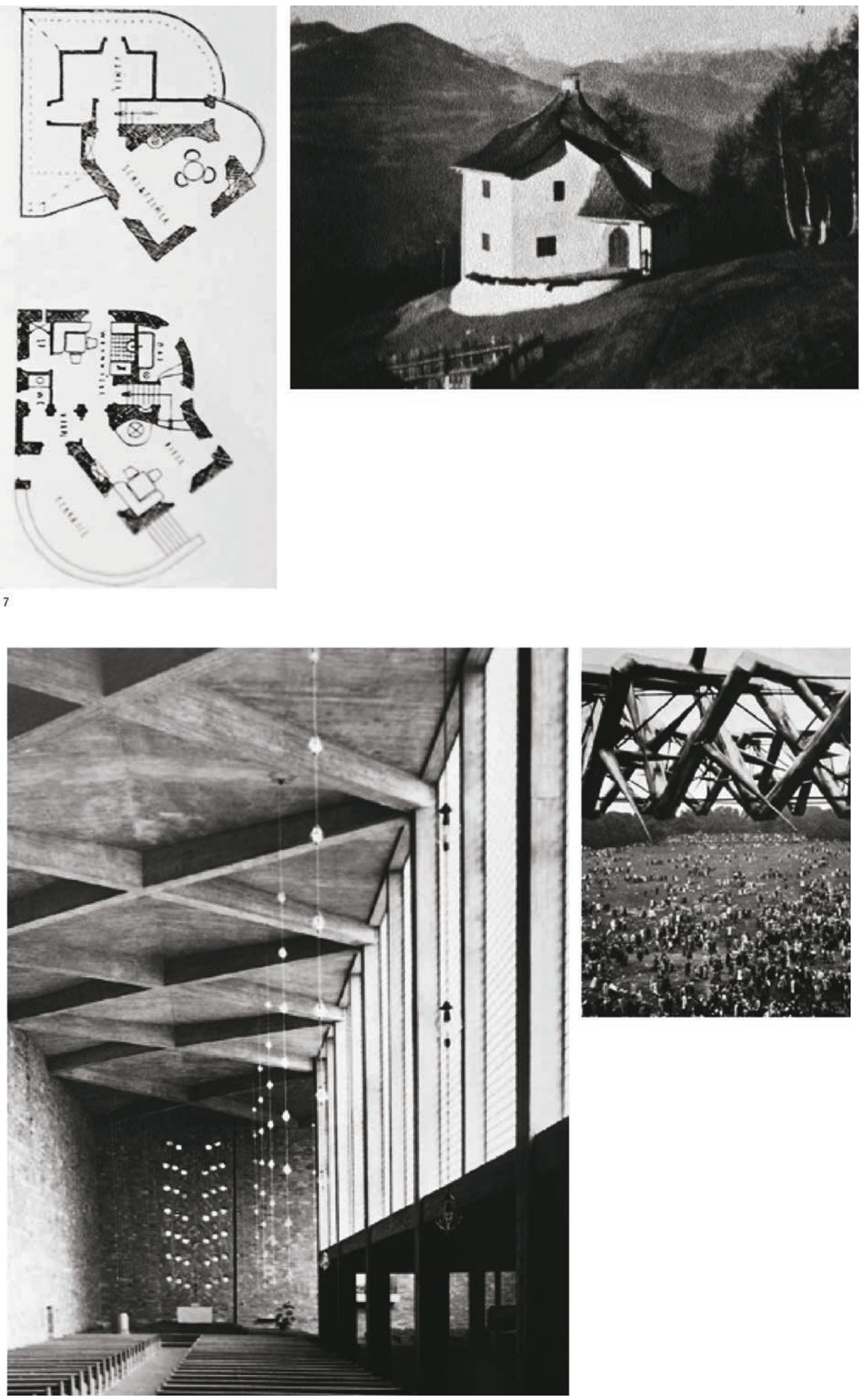

42 / la arquitectura de la hfg ulm. de la objetividad a la revolución 

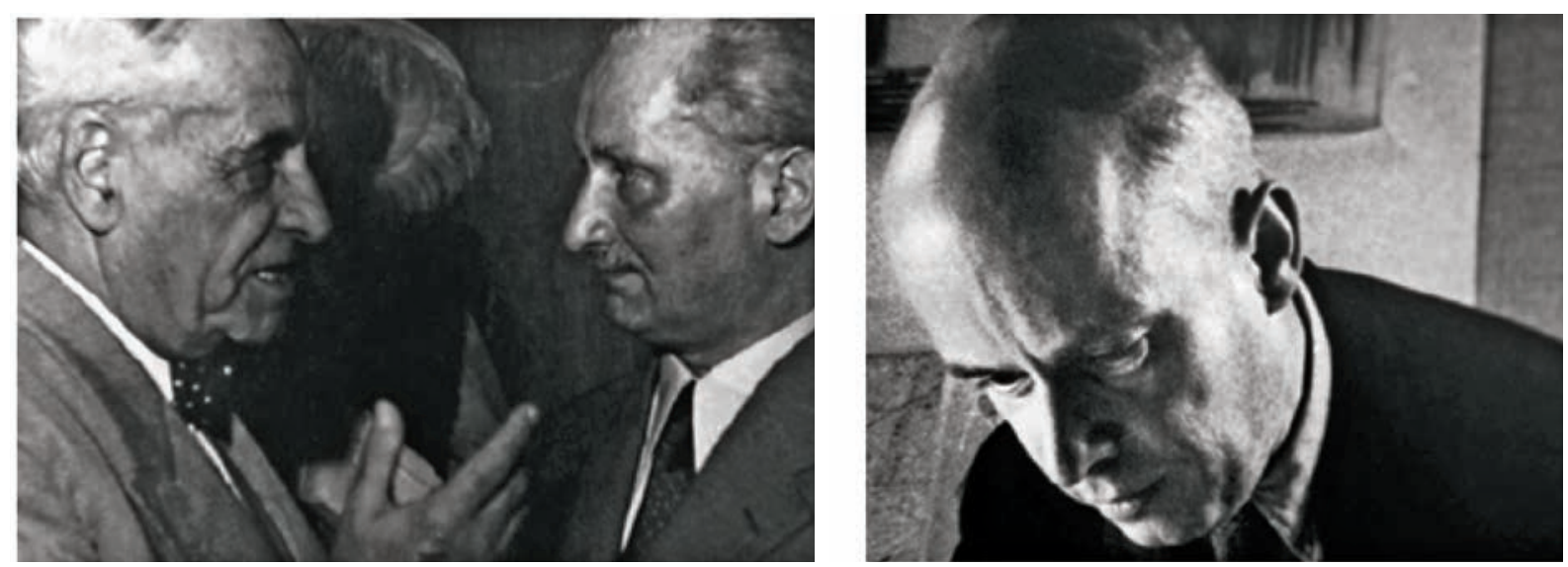

Al encuentro de Darmstadt del año 1951 sobre lo que debía ser la reconstrucción de la Alemania destruida por la Segunda Guerra Mundial. El título bajo el que se tenía que desarrollar era "El ser humano y el Espacio", y se pensaba que alternaran en sus intervenciones arquitectos y pensadores. Acudieron la generación de arquitectos que por la misma no habían podido desarrollar su carrera y los que en el periodo de entre guerras habían tenido una actividad arquitectónica importante. Entre las nuevas obras estaban las de Willem Markus Dudok, Max Taut, Hans Scharoun, Franz Schuster, Rudolf Schwarz, Ernst Schweizer, representando un cierto clasicismo estaban Paul Bonatz, Ernst Neufert, Grund y Kreis, lo jóvenes con Egon Eiermann, Sep Ruf, Mäckler y Giefer. Todo fue moderado por el arquitecto Otto Bartning.

El anterior encuentro en Darmstadt del año 1950 con el tema "La imagen del ser humano en nuestro tiempo". La polémica vino con la presentación del libro "La perdida del centro" publicado en 1948 por el historiador del arte Austriaco Hans Sedlmayr. Al que se acusaba de haber sido un participante activo del Nacionalsocialismo. Hombre religioso, teocéntrico, que rechazaba de lleno el arte moderno y la arquitectura funcionalista. La polémica de este primer encuentro marco de alguna manera el segundo encuentro.

La moderación de Otto Bartning, y para evitar fuertes discusiones, dejo fuera a los representantes mas radicales de la nueva modernidad como Mies van der Rohe, Walter Gropius, Alvar Aalto, y el mismo Oud.

\section{.Heidegger y Ortega}

Como pensadores estaban los sociólogos Alfred Weber y Dorf Sternberger, filósofos como Martin Heidegger y el español José Ortega y Gasset.

En la Alemania de entreguerras había una serie de arquitectos que se habían opuesto de forma clara al dogmatismo del funcionalismo. Defendiendo con un cierto romanticismo centro europeo la recuperación de lo autóctono, indagando en las raíces mas profundas. No eran, por supuesto, seguidores a ultranza del nacionalismo mas radical, simplemente estaban en la línea de arquitectos escandinavos como Asplund o Lewerenz, o a las corrientes inglesas. Estos arquitectos interesados en la conexión con lo tradicionalmente suyo eran Franz Pölzig, Hugo Häring, Bruno Taut, Frank y Behne. 
Esta discusión fue claramente interrumpida con la llegada de los nazis y la polarización política. Pero en este segundo encuentro el arquitecto Rudolph Schwarz aprovechó la ocasión para lanza una ponencia crítica que se llamó "la demanda del Baukunst" en la que analizaba la definición de ciencia: "

"Las ciencias (...) de aquel entonces sólo quieren abarcar el mundo, lograr dominarlo, poder cogerlo. Sólo se cuestiona si algo tiene eficacia. La pregunta acerca de la verdad no juega ningún papel. Quizás es la más grandiosa prisión que el espíritu humano haya sido capaz de construirse (...). De la misma manera la técnica nace como la continuación conforme al sentido gótico, una forma que originalmente había tenido la intención de lograr una unidad de las formas del mundo de manera superior y noble, (...) con la única intención de dar más ligereza a la materia del mundo. Surgida de estos anhelos y especulaciones nobles la técnica fue originalmente considerada como una verdadera y extraordinaria forma de un mundo más común y posible, pero el siglo XIX se había dado cuenta que con esta forma de mundo podía someter la tierra (...) lograr subordinar sus formas, y así la técnica se transformó en una verdadera garra y pertrecho para agarrar, descuartizar y maltratar el mundo". ${ }^{1}$ 


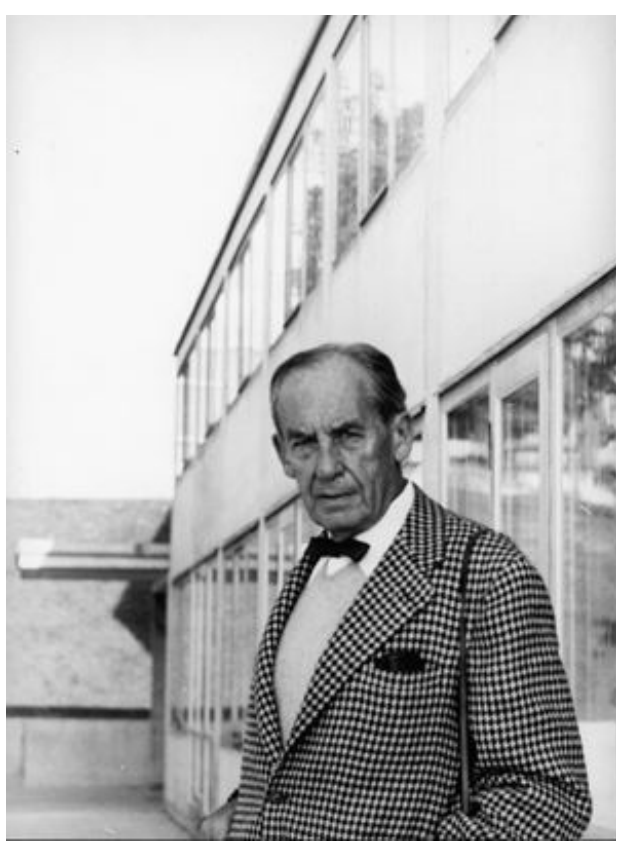

\section{2 figura}

\subsection{1 la elección de Bill}

a partir de 1930 max bill fue miembro de la Werkbund suiza, una institución que siguiendo el modelo alemán reunía a los autores más progresistas del país. bill había destacado por sus trabajos tipográficos, y publicitarios en el ámbito de las neues Bauen, y por el pabellón de la trienal de Milán del 36. finalizada la II guerra mundial se empezó a prestar atención a los bienes de consumo y objetos cotidianos. como siempre aparece el problema del estilo, algo que se tuvo muy claro durante la guerra donde dominaba el Heimatstil, falsamente autóctono, pero por otro lado de estados unidos llegaba el streamline, estilo que se rechazaba. según bill en ambos casos había un desarrollo erróneo de la producción industrial y artesanal. bill centró su atención en la forma más que en el utilitarismo del movimiento moderno. a max bill le surge organizar una exposición en la feria de muestras de Basilea el año 1949 con el título Die gute Form, esta exposición significaba para bill y la Werkbund suiza una forma de objeto natural, desarrollada a partir de su función, las condiciones técnicas y además es bella. para la exposición bill utiliza un gimnasio que reviste paredes y techos con paneles blancos, y en el medio una estructura de listones que definen una determinada curva exenta. esta malla contenía 80 paneles cuadrados y en cada panel figuraban tres imágenes y un pequeño texto explicativo. la exposición funcionaba como una cinta continua de imágenes con cuatro rincones dedicados a las formas de la naturaleza, la ciencia, el arte y la técnica, a las formas del urbanismo y la arquitectura, a las formas de las necesidades habitacionales, así como a las formas de los distintos utensilios y sistemas de transporte. a partir de esta exposición nació un concurso con la etiqueta de calidad del gute Form, premiándose por primera vez en 1952.

la exposición se había pensado para que fuera itinerante, después de Basilea viajó a otras ciudades suizas y después a Alemania, Austria y Holanda. siguiendo el ejemplo suizo el MoMa de NY distinguió con la etiqueta de good design a bienes de consumo industriales con un alto grado de calidad.

Ya en 1948 bill expreso en una conferencia su idea sobre la nueva primacía de la forma: "la belleza a partir de la función y como función" exigía para la belleza el mismo rango de importancia que a la función.

en mayo del 48 cuando una comisión de profesores de la VH viajaron a la provincia de Zürich para un curso de maestros de escuelas primarias. es allí donde Aicher y Scholl tienen un primer encuentro con 


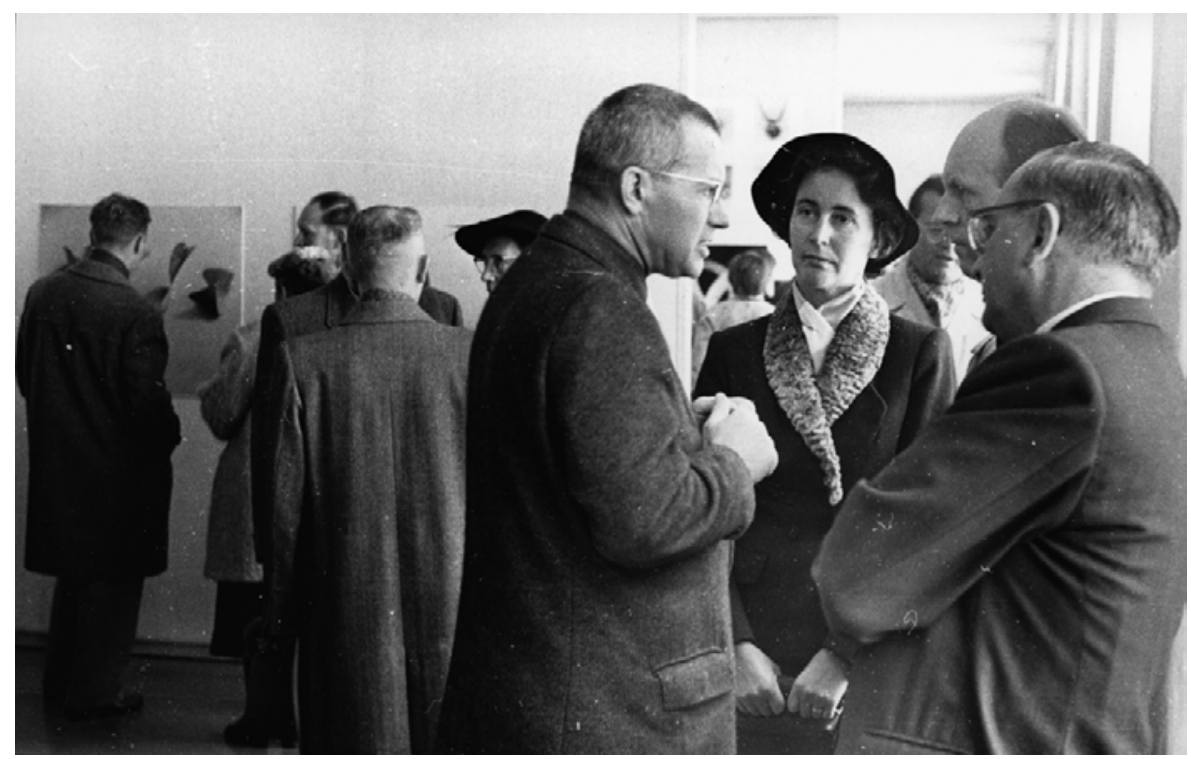

Max Bill. lo siguiente fue una visita de Bill a Ulm y después el montaje, en la ciudad, de la exposición de la Werkbund suiza comisariada por el mismo "die gute Form".

Desde una perspectiva histórico-cultural, la división creciente del trabajo que vino con la industrialización fue el prerrequisito básico para el surgimiento de la actividad proyectual Es sólo en la etapa transitoria del artesanado a la industria cuando esta actividad se separa de la producción: el pensar y el hacer objetos de uso diario - herramientas o artefactos - no era ya el logro de un gremio determinado. Se convirtió en una especialidad, que hoy en día lleva el nombre de "diseño".

la dirección que max bill quiso darle a la escuela, el experimento pedagógico más importante de Bill, es bastante simple "to shape a better postwar wordl". en contraste con la Bauhaus de lo años 20 que se mantuvo al frente de la teoría de Bill en los 50, mas que la función, el aspecto estético de la forma era lo importante. Significativamente, combinó con ella el deseo "de que usted entonces tiene la voluntad de, 20 años después, ser como la 'Bauhaus' (pero no en el futuro, sino por delante) 3 Brief von Max Bill an Inge Scholl vom 6. März 1950 (Archiv Bill). Qué se entiende exactamente por esta formulación, Bill estaba abierto. Por lo tanto también Inge Scholl y Otl Aicher pudieron ponerse de acuerdo de alguna manera. en efecto, el concepto "Weitersein" en el sentido de la Bauhaus como concepción política y literaria, como era para Hans Werner Richter y Carl Zuckmayer, debería ampliarse.

Definitivamente Hans Werner Richter no fue sino hasta finales de abril de 1950 nombrado como un "designatus rector". Al igual que antes, también contenía la Geschwister Scholl Hochschulle una mezcla de intenciones, que varía de las clases de educación cívica hasta las ayudas económicas para las empresas de Ulm. Aunque Bill ejerció cada vez más presión sobre las decisiones sobre la claridad y las decisiones personales, todo quedó como ya había sido indicado en el "programa amarilla". Esto cambió radicalmente cuando se invitó a los emprendedores de ulm el 25 de abril 1950 por Shepard Stone a un cóctel en Bad Homburg, al norte de Frankfurt.

A pesar del marco informal de una fiesta, se esperaba que los americanos anunciaran una decisión final sobre su participación en Ulm. En un hotel en Frankfurt, los diversos colaboradores del grupo de construcción de Ulm se reunió por primera vez en esta ocasión juntos al completo. Además de Inge Scholl y Otl Aicher apareció Hans Werner Richter, Max Bill y el abogado Hans Jürgen Soehring. cerca de hessen los americanos hicieron saber, que no quería ver tantos alemanes. Así Inge Scholl y Otl Aicher fueron solos a Bad Homburg acompañados de un número de especialistas del HICOG (high comission 


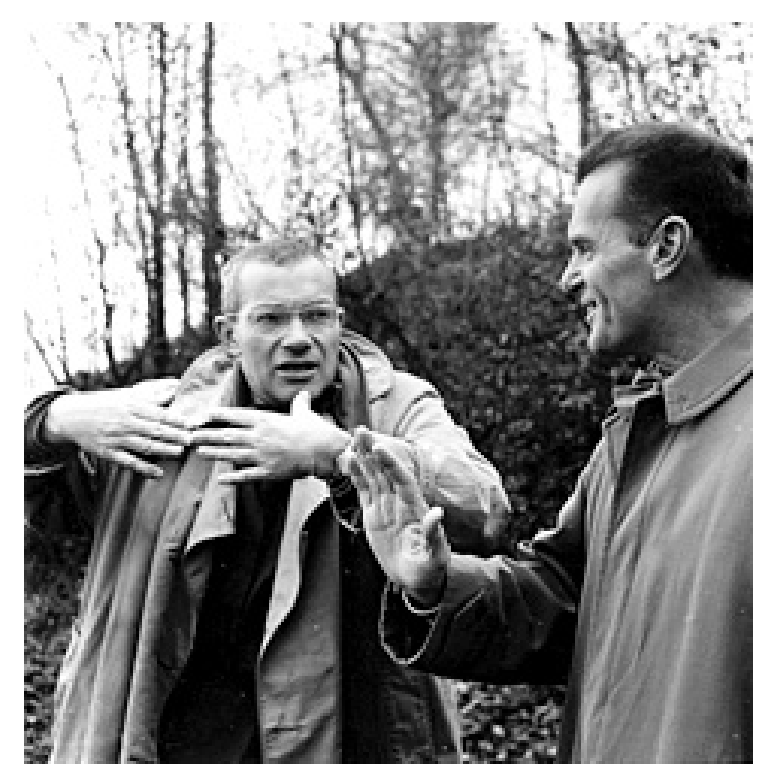

for Germany, con competencias educativa y con el objetivo de reorientar la educación alemana), especialmente los del Departamento de Educación. Las negociaciones llegaron a su fin cuando los dos de Ulm dijeron que no podían aceptar una Escuela de Política en el sentido McCloy. por otro lado querían no obstante desarrollar un plan propio, que también fuera de gran relevancia política. Entonces Bill fue convocado a Bad Homburg, al tiempo que Shepard Stone ya tenía un mensaje telegráfico de Walter Gropius, en el que expresaba su completa confianza en Bill. Él vino a sentarse detrás de Inge Scholl y Otl Aicher y de repente les dice que él estaría dispuesto a tomar la dirección del establecimiento y la gestión de la escuela. Con la promesa igualmente espontánea de Bill comenzó un nuevo capítulo en la historia fundacional, y otro,el de Hans Werner Richter como director terminó. El grupo fundacional había entonces a ser reformado para crear el núcleo de Inge Scholl, Otl Aicher y Max Bill.

La decisión de los estadounidenses para Bill y por tanto indirectamente contra Richter dependía, sin duda, porque eran contrarios a la posición política de este último, que como editor del diaro "Der Ruf" ya molestaba anteriormente. Pero hay que tener en cuenta el hecho de que Bill era capaz de presentar una obra de fama internacional como artista. Además se llevó a cabo con Gropius como referencia y pieza clave en el triunfo. Decisivo, sin embargo, eran para el campo del arte en lugar inexpertos autoridades estadounidenses referencias menos sustantivas a la Bauhaus, sino más bien que Gropius y Bill eran de una institución que se ha cerrado bajo los nazis y ahora reclamar volver a reclamar algún significado para el prestigio político y hacia la Nazi fundación Scholl venía bien.

Decisivo, sin embargo, no eran las referencias de la Bauhaus en el campo del arte sino que Bill y Gropius eran de una institución que fue cerrada por los nazis y esto venía bien para reactivar el prestigio político de la considerada nazi fundación Scholl.

Walter Gropius,

Richard Neutra

Marcel Breuer 


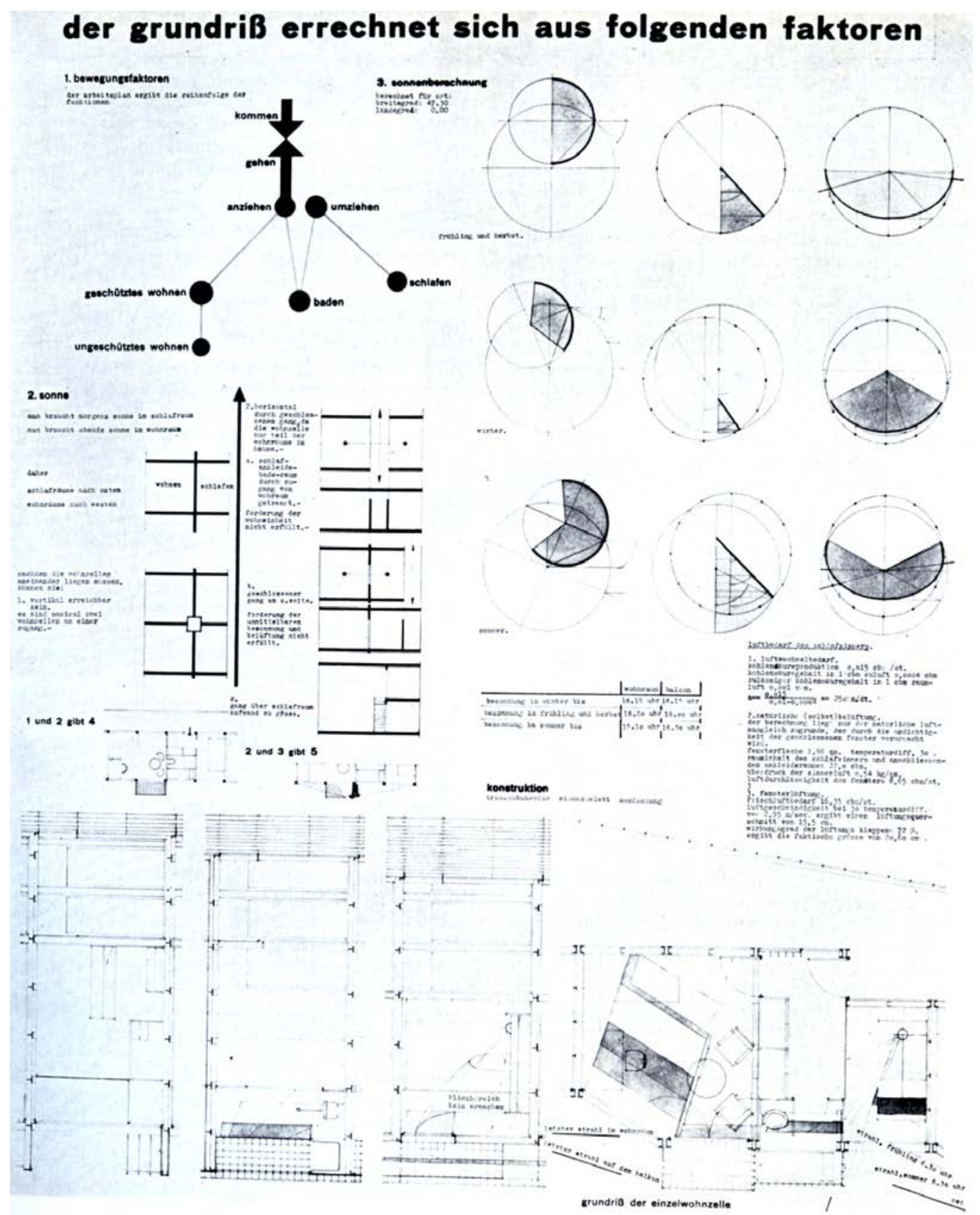




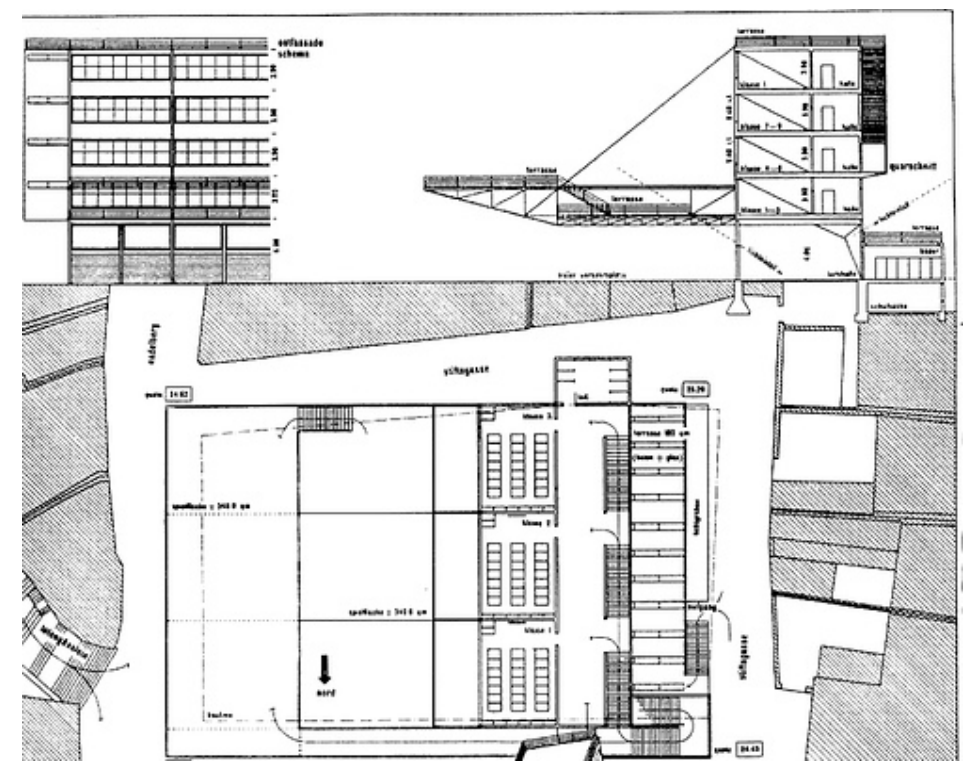

\subsection{2 las influencias de Bill 1. Europa en Europa}

Desde una perspectiva histórico-cultural, la división creciente del trabajo que vino con la industrialización fue el prerrequisito básico para el surgimiento de la actividad proyectual Es sólo en la etapa transitoria del artesanado a la industria cuando esta actividad se separa de la producción: el pensar y el hacer objetos de uso diario - herramientas o artefactos - no era ya el logro de un gremio determinado. Se convirtió en una especialidad, que hoy en día lleva el nombre de "diseño".

Bauhaus estuvo en el origen del proyecto de la escuela. Pero en la medida que el proyecto se concretaba, la identidad de la hfg se distanciaba cada vez más. Al menos de aquella que dirigió Walter Gropius. Porque se estudió con interés la gestión pedagógica y principalmente el ideario de Hannes Meyer, que alentaba »un funcionalismo basado fundamentalmente en la exaltación del productivismo, del antiesteticismo, el realismo, el colectivismo y el materialismo«. (6) Se manifestó abiertamente contra el arte, "en clara oposición a las tesis sostenida por su predecesor, principalmente a aquella relativa a la unidad entre arte y técnica«.

meyer empezó en la bauhaus en abril de 1927, empezó como docente y siguió dirigiendo el departamento de arquitectura. había 15 estudiantes, los principios fueron difíciles, los alumnos protestaban. solo un año después cuando Meyer llegó a ser director de la bauhaus el departamento ganó en prestigio y por tanto adeptos. el número de profesores pasó de 4 a 9 y la duración de 7 semestres a 9. el curso preliminar duraba 1 semestre y se obligaba a los estudiantes a pasar por uno de los talleres, de madera, metalista, vidrio, yeso. la semana se organizaba un día dedicado a los conocimientos artísticos, otro conocimientos científicos y los otros tres al trabajo práctico en los talleres.

para meyer la creación de la cultura del día a día no es solo un problema formal, también el problema de la unidad entre arte y técnica. si el creador quiere representar un papel socio cultural útil debe aliarse con el movimiento obrero y luchar para la transformación de la sociedad. la tarea del creador no estará dedicada por más tiempo a la forma, deberá analizar con métodos científicos las necesidades de los menos favorecidos "estudiar la sociedad para servirla". las principales asignaturas fueron las ciencias sociales, la sicología y la organización del trabajo, disciplinas impartidas desde el exterior con un sistema continuo de conferencias, principalmente de ideología marxista. el concocimiento transmitido tenia que contribuir al desarrollo de una cocepción del mundo material y un método empírico. 


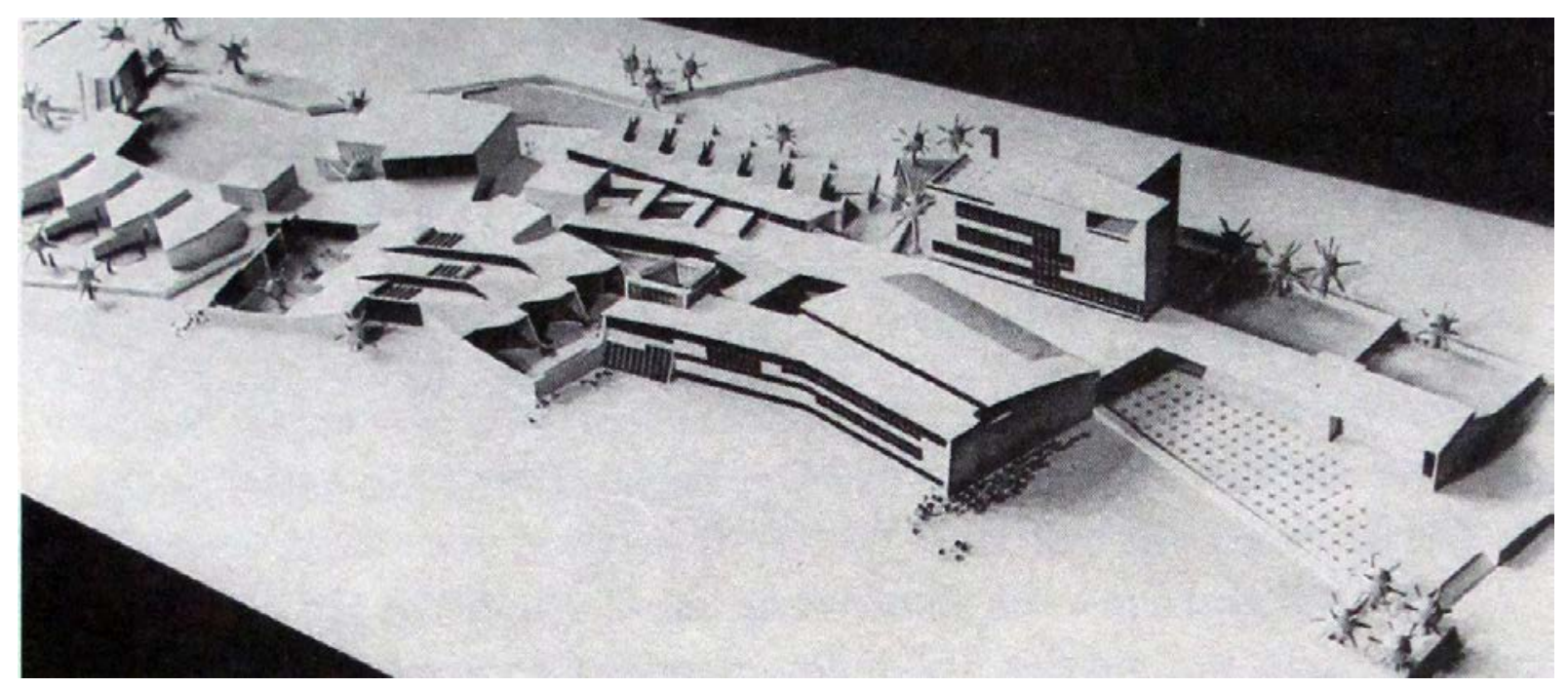

la filosofía educativa de Meyer se articulaba alrededor de las siguientes 4 nociones: armonía, el específico trabajo o tarea, las acciones colectivas y la incorporación a la sociedad. una vigorosa e intelectual transubstantación debía tener lugar en la bauhaus desde donde una harmonioso hombre surgirá. meyer aumento el número de asignaturas a enseñara e introdujo el deporte intensamente. desde el primer orden del material a la numérica verficacion final al estudiante no se le perdona nada. el acento sobre todo lo social producirá la aparición de un coproductor para la cosa nueva y estará ligado a la realidad de la colectividad. esto significa una aproximación al mundo de los trabajadores y un entendimiento de sus problemas, intereses, y participación en sus combates políticos.

nuestra actividad está condicionada por la sociedad y esta a su vez regula nuestros deberes. la alemania del momento demandaba miles de escuelas, jardines, casas para la gente, cientos de miles de viviendas sociales y millones de piezas de mobiliario.

el nuevo hombre será educado por la bauhaus en la colectividad, los estudiantes de los diferentes niveles son reagrupados en equipos verticales que funcionan como colectivos para la autoeducación, también para la transmisión de conocimientos de arriba abajo y al revés. para Meyer a nadie se le puede negar el acceso a la Bauhaus.

"la nueva escuela de constructores se posiciona como un establecimiento educativo para la organizaci'n de la vida, no forma una élite. se preserva así misma del sectarismo: endogamia, egocentrismo, ignorancia del mundo, indiferencia hacia las cosas de la vida. en cualquier lugar, en cualquier persona hay una actitud que necesita ser puesta en uso. la vida no rechaza a nadie" meyer, hannes, Bauhaus und Gesellschaft. first appearance: Bauhaus. Dessau, 1929.

seis semanas antes de su elección Meyer escribió a Gropius "la fundamental tendencia de mi enseñanza será funcional, clolectiva y constructiva". Meyer, Hannes, carta a Gropius 16 Febrero de 1927. los tres determinantes de la concepción arquitectónica de Meyer son: método material del proyecto, relación entre arquitectura y sociedad, trabajo racional inventivo y edificante. la enseñanza de Meyer tenía una visión muy amplia del presente y el futuro. meyer estará muy atento a las necesidades de las esferas de población para quien nunca se ha hecho arquitectura. los problemas se establecen en términos de economía, sociología y avances tecnológicos. se buscan métodos y procesos tecnológicos para conseguir buenos precios. la arquitectura es la respuesta a las necesidades del momento. es parte de un proyecto global de sociedad. Meyer busca que la forma no 

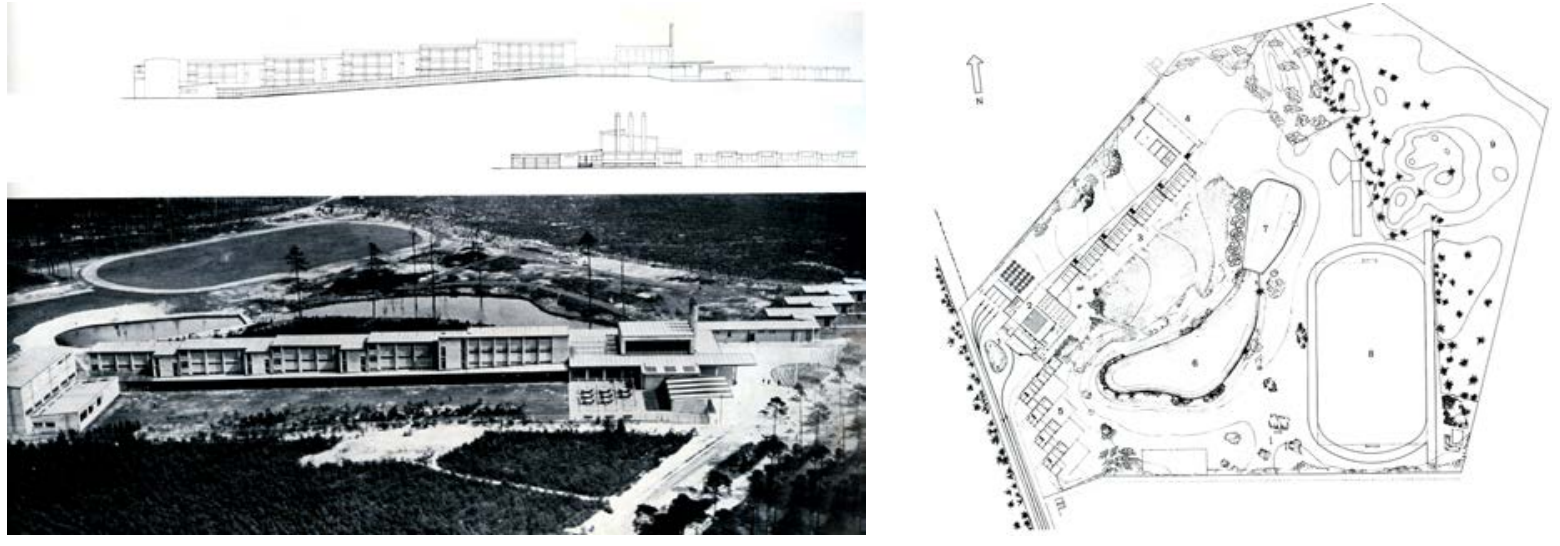

sea predeterminada, ni como referencia al pasado ni siquiera como próximo futuro, huyendo de la banalidad del arte y la arquitectura burguesa. el método de proyecto aplicado y enseñado por Meyer busca ser completamente científico e integra los últimos descubrimientos tecnológicos.

El estudio del comportamiento diario del vecindario nos provee de un conocimiento del perfil del padre, de la madre y del resto de las personas de la casa. la determinación de las variaciones del sol, la temperatura, las perdidas de calor con las ecuaciones de conductividad térmica harán que la forma, la estructura, el color del material y la textura de las superficies salgan de si mismos. según los estudiantes meyer era un profesor que dejaba evolucionar los proyectos en la reflexión sobre los mismos, no imponía una idea preestablecida.

además de la tarea práctica cada estudiante era invitado a proponer ejercicios y a discutir sobre sus resultados. esto servía para educar la autonomía autocrítica y también examinar las contradicciones entre diferentes ponentes. con este sistema docente se incitaba a los estudiantes a exponer abiertamente los problemas y a tomar parte activa en resolverlos.

las tareas llevadas a cabo por Meyer era interrelacionar los edificios con los seres humanos desde el punto de vista bilógico y social y la naturaleza. asignaturas tales como "the periodicity of vital space", "cronología de las actividades de una familia", "cuánta cantidad de sol hay en las premisas". la visualización de los resultados es la finalidad, los estudiantes aplicaban los procedimientos de representación gráfica sobre estadística usados por Otto Neurath, una de los profesores invitados en la bauhaus. meyer y taut quienes impartían cursos en la escuela politécnica de Berlín fueron los primeros en enseñar arquitectura basándose en sociología. Meyer estaba de acuerdo con Gropius que el aprendizaje de la arquitectura debía estar en relación a la práctica, no como un ejercicio teórico.

Retrospectivamente, Meyer pudo orgullosamente escribir_

era en la sección de arquitectura donde los principios de enseñar a través de la práctica con trabajo real era más evidente. la práctica fue cotejada por un equipo internacional de arquitectos: el holandés Mart Stam, el alemán Hilberseimer, el austriaco Anton Brenner y los dos suizos Hans Witwer y Hannes Meyer. la ciudad de Dessau nos cedió varios proyectos: la oficina del sindicato de iniciativas, modelos de casas para la clase media, una ciudad de 15000 habitantes y propuestas para la reconstrucción del mercado municipal. desde fuera recibimos la tarea para construir una casa para un doctor en Eifel, proyectar un sanatorio y una colonia para pescadores cerca de Berlín.

Eran los tiempos en lo que floreció lo que se llamó the new Education, educadores de todo el mundo 


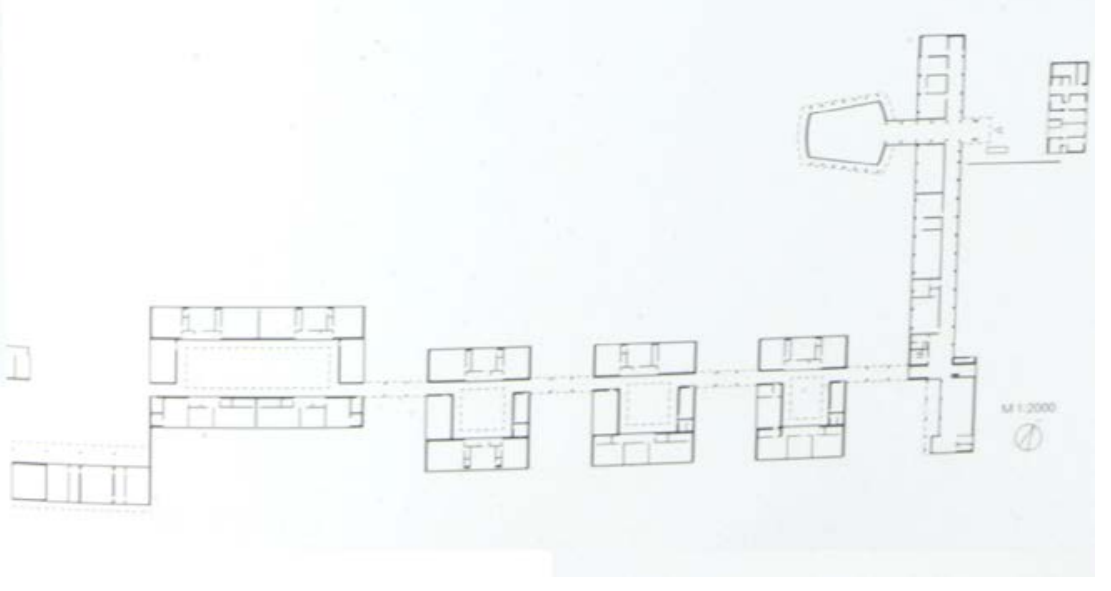

habían lanzado la expresión "copernican Revolution" que muestra que el centro alrededor del que la escuela se mueve la escuela debería ser el adulto, sus necesidades, su programa, pero también el niño y sus intereses. la cuestión era saber quien era la persona a educar y provocar que sus recursos internos afloren, por tanto adaptarse a su propia evolución natural. los estudiante no fueron más tiempo considerados un recipiente donde ir echando conocimiento. en la nueva escuela el estudiante no espera pasivamente recibir desde el profesor, el libro etc, sino jugando, creando, y haciendo. por tanto lo importante era crear una atmósfera educativa donde el edifico era fundamenta para la new school. la bauhaus es un mero episodio en esta aventura. y dentro de ella casi todos los profesores estaban de acuerdo pero fue Meyer el primero en entender los límites de una educación basada en una directa, sensitiva, espontánea, pragmática aproximación a la realidad.

no hay una educación práctica sin una teoría de la educación.

un hombre atesorando conocimiento científico no puede comprender el mundo de hoy y es incapaz de transformarlo, el humanismo de nuestro tiempo debe ser científico y politécnico, por lo tanto se deben objetivar las disciplinas en las escuelas.

la bauhaus no fue cerrada tres veces en 14 años no por los métodos, que estaban muy en boga en Alemania, si no porque sus contenidos fueron considerados subversivos. bajo el pretexto de lo no predecible de la arquitectura del futuro las escuelas se habían convertido en bazars, en donde los malos hábitos se consideraban parte de la libertad creativa.

La bauhaus tenía claro que la educación conectada a la producción nunca significaría que la escuela era una fábrica. es evidente que las escuelas no tienen éxito en la relación con lo que se llama realidad, pero no es un error considerar exclusivamente la realidad percibida. ovide Decroly eligió como lema de su escuela: pocas palabras, muchos hechos.

los alemanes del oeste estuvieron unos años en la esperanza del Projekthesogenes Studium (estudio subordinado al proyecto). un ficticio proyecto regula el proceso de adquirir conocimiento. la mesa de dibujo hace al estudiante que se de cuenta de las lagunas que tiene y estimula su necesidad de aprender. en ese momento cuenta con los profesores para satisfacer sus dudas. cultura y utilidad, teoría y práctica se reconcilian aquí. el conocimiento se limita a las tareas esenciales de la doctrina, el conocimiento es reducido a su utilitaria función. el estudiante permanece en el círculo que puede explorar por si mismo.

La máxima efectividad de la bauhaus fue adquirido en 1929: 197 estudiantes y una docena de 


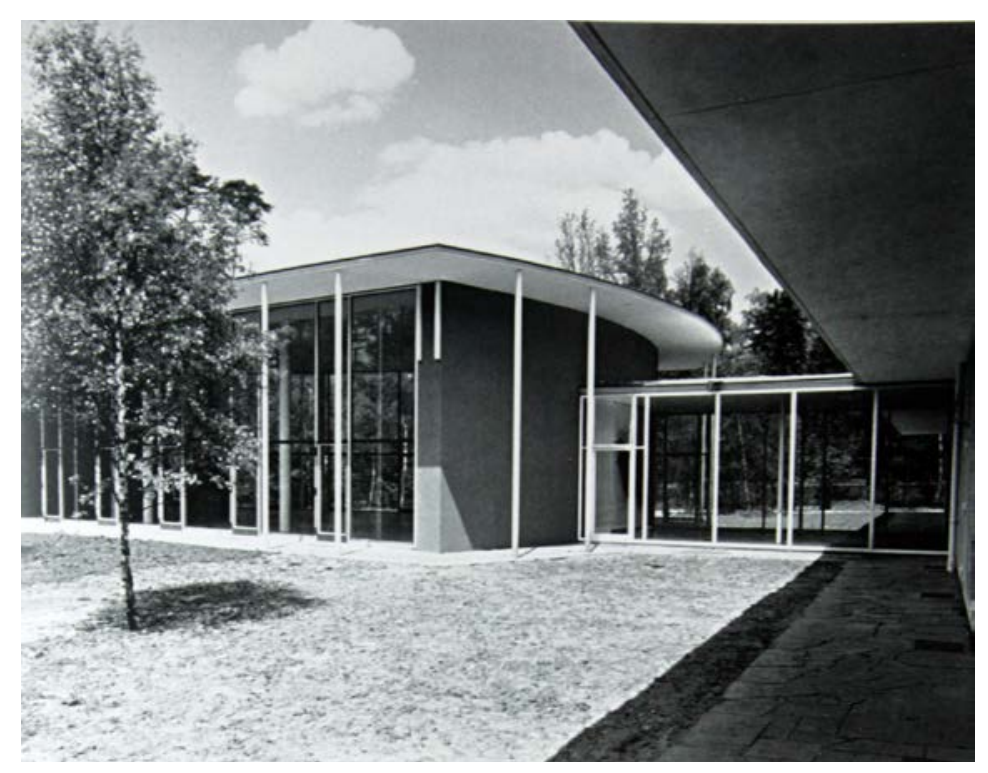

profesores a tiempo total, 5 becarios, así como esporádicos conferenciantes. en una esculea así todo el mundo se conoce, los problemas personales se tienen en cuenta, la transmisión de información no encuentra obstáculos, la burocracia se reduce al mínimo, el peso del contenedor no supera el del contenido. por encima de un cierto tamaño las escuelas encuentran imposible constituir un cuerpo homogéneo, si se desea constituir una escuela conectada a la vida, y que aproveche al máximo los recursos de su país, es necesario que los estudiantes trabajen en la región que ellos conocen bien y los problemas que desean resolver.

No hay una educación sin un adecuado medio para que el acto educativo tenga lugar. una escuela sin un marco estructural viable no es más que un elemento de transmisión de direcciones administrativas.

Desde la muerte de Meyer en 1954, nuevos problemas han surgido. una gran parte de las escuelas rechazan educar más de un único tipo de arquitecto, un proyectista que es capaz de asumir la mayoría de los diversos tipos de trabajo. 


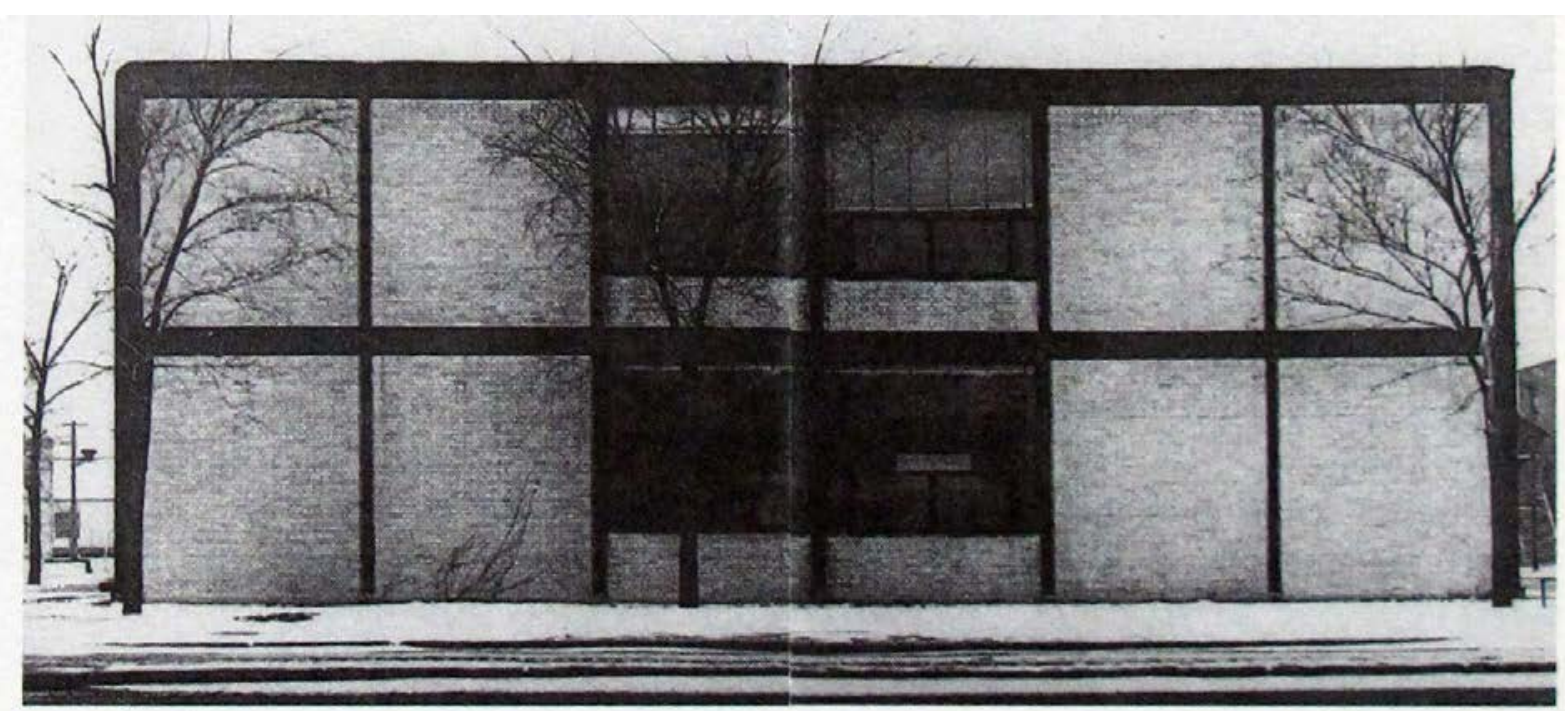

1.2.3 las influencias de Bill 2. Europa en América

américa américa. Frank Lloyd Wright Taliesin west

Illinois Institute of Technology y the new Bauhaus

Walter Gropius, Richard Neutra, Marcel Breuer 

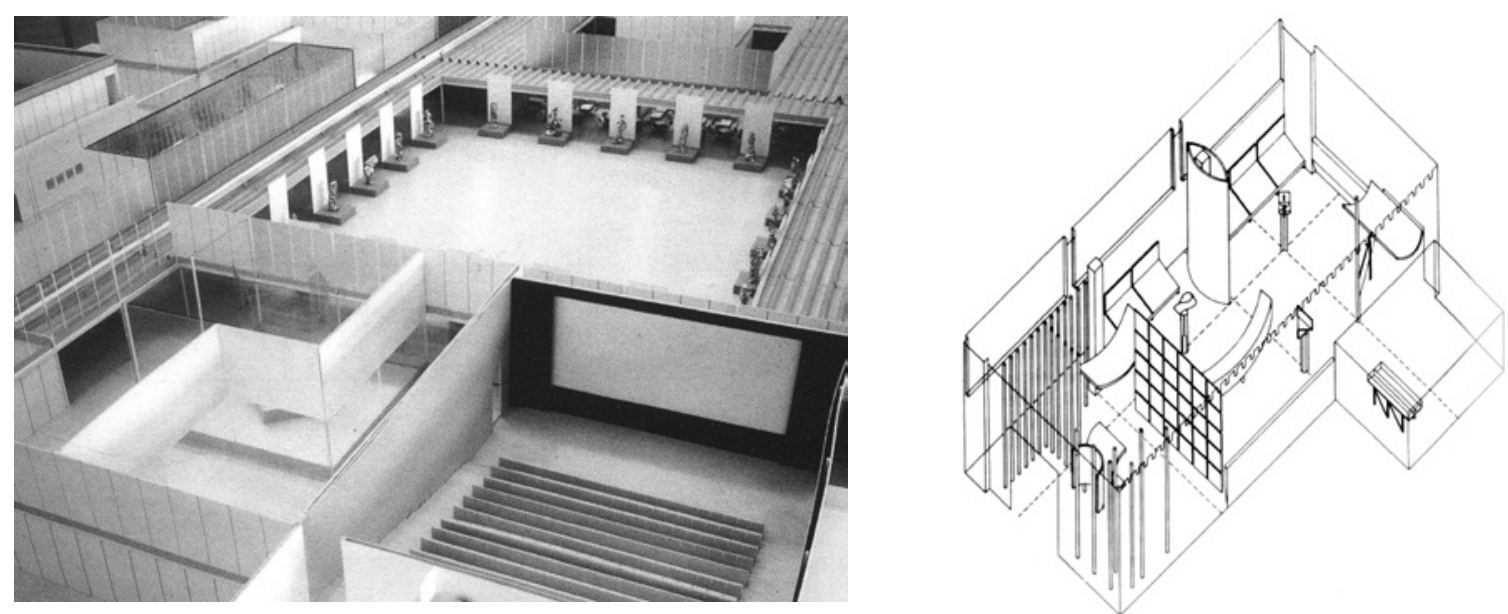

\subsubsection{Max Bill arquitecto}

Stanislaus von Moos: max bill. A la búsqueda de la "cabaña primitiva"

El etnólogo e historiador del arte Martin Héller describió el diseño concreto como el "proyecto con más talento en la historia del arte suizo hasta el momento", ya que "mediante el gusto, conquistaron tanto las paredes de los grandes espacios de oficinas de los bancos y compañías de seguro, así como las salas de estar de la clase culta, llegando incluso a los estantes de los grandes almacenes más elegantes".

Von moos plantea varias preguntas interesantes:

¿consiguió max bill en suiza lo que no consiguió ni la bauhaus en Alemania ni Vladimir Tatlin y Rodchenko en la unión soviética?

¿pueden entenderse suiza constructiva y su creencia en la castidad visual como una "escultura social" llevada acabo en el sentido al que se refiere Joseph Beuys?

¿o se trata de una "fata morgana" en las mentes de un élite de artistas liberales, en la medida en que el culto a la limpieza y la sencillez no ha sido sustituido por otras referencias?

En la década del 70-80 max bill, cuya postura se encuentra más cerca de Rodchenko que de Beuys, llegó a ser uno de los artistas suizos más importantes, junto a Ferdinand holder, paul klee, Alberto giacometti y le Corbusier.

Max bill apareció siempre como arquitecto en las páginas amarillas de zurich, no como escultor ni pintor, dando a entender que él sobre todo era un arquitecto que dedicaba su tiempo libre el arte. Aunque es evidente que bill simultanea diferentes técnicas visuales toda su vida.

De las artes aplicadas a la arquitectura

En suiza no había escuela de bellas artes, por tanto la forma de entrar era a través de las escuelas de orfebrería. El propio le Corbusier adquirió su formación artística como grabador de cajas de reloj, en 1926 asistió bill a una conferencia del maestro suizo, y de la noche a la mañana decidió dedicarse a la arquitectura. Ya con 17 años había visitado la expo de artes decorativas en parís del año 25, tres de cuyos edificios le produjeron una gran y duradero impacto: el pabellón de l'esprit nouveau" de le Corbusier, el de la Urss de melnikov y la ciudad en el espacio de Frederick Kiesler en el pabellón austriaco.

A continuación se traslada a la bauhaus de dessau (1927-28) y vuelta a suiza sin haber obtenido ningún título. En aquel entonces la werkbund 
suiza estaba construyendo la siedlung neubühl (1928-32), bill participa diseñando el cartel publicitario, que junto con él de la exposición vivienda en Neubühl son los mejores de la década de los 30, para ello se basa en unos carteles que había hecho kurt schwietters para la algo anterior siedlung dammerstock en karlsruhe (1928. Con 28 años proyecta y construye el pabellón suizo de la trienal de Milán, extraordinaria instalación que le coloca con la vanguardia del diseño moderno de espacios de exposición, junto con lissitzky y lázslo moholy-nagy.

A partir de este momento bill trabaja en diferentes frentes, por un lado elaboró la teoría del "arte concreto", como artista gráfico avanza en las nuevas leyes de comunicación visual y de retórica de la imagen. Como arquitecto se hace su propia casa en höngg (1932) a partir del estudio de la villa stein/ de monzie en garches de le Corbusier. En el 39 proyecto el pabellón de la expo de nueva york, no lo llega a hacer, si retícula espacial cuadrada tiene una referencia directa en la ciudad en el espacio de Kiesler. Para von moos la hfg es la obra maestra como arquitecto de bill, con referencias a la lógica tectónica de mies van der rohe, mientras que la geometría entretejida de la planta y la inclusión en el paisaje le aproximan a Hannes meyer, incluso una cierta sensibilidad orgánica a hugo häring o mario ridolfi (tengo dudas), y podríamos encontrar un relación con schinkel a través de la tradición pintoresquista del neofuncionalismo suizo-alemán.

La casa Villiger en Bremgarten la proyecta y construye durante la segunda guerra mundial, a la vez que recopilaba una auténtica enciclopedia de sistemas prefabricados (bill, max, Wiederaufbau, Verlag für Architektur, Erlenbach-Zürich, 1945.) bill estaba fascinado por la sencillez en la construcción producida por elementos estándar. El sistema de prefabricación lo utiliza en ulm, por la imposibilidad de utilizar acero, y porque el apoyo económico que da la empresa de cementos de ulm a la escuela lo hace con el material. También lo utilizará a gran escala en Lausana (1964) en la exposición nacional suiza "educación y creación". A partir de este momento la arquitectura fue adquiriendo más valor en al vida de bill, aunque realmente no tuviera más encargos. Bill había publicado en los 50 más monografías sobre arquitectos que edificios había construido.

Bill realizó la primera escultura pabellón, propiamente dicha a partir de 1969, en otras palabras es la obra de un artista maduro. 
Hablando de la escultura pabellón en la Bahnhofstrasee en Zürich, en una entrevista que le realiza Hans Ulrich Schlumpf, dice que más que una escultura, la obra se debe considerar como un tipo de arquitectura, "como un edificio en el que se entra" incluso como "un antiguo recinto de templos" por qué no? Como una pérgola proyectada por Friedrich Gilly.

Para Hans Frei llamo la "transversal de los temas formales desde la pintura hacia la arquitectura". Utilizando comparaciones interculturales -la limusina Adler junto a una escultura de Georges Vantongerloo, o un puento de Maillart junto a sus cintas sin fin-

Mas bill creía que la tareas a que se enfrentaba sólo permitían un manejo sensato de los sencillos medios al servicio del sentido común.

Lo que los Smithsons y Bill tenían en común era una opción por una arquitectura pragmática, sin disparates, es decir, una arquitectura carente de cualquier sentimiento utópico. Consideraban que la "modernidad" era menos un objetivo a alcanzar que una realidad a interpretar. "cuando nuestros estándares los establecían la iglesia o los reyes y, mas tarde, la política local y la banca eran tiempos para edificios que anunciaban su poder en voz baja. Hoy cuando una gran cantidad de factores nos influyen, se ha terminado el tiempo para cualquier forma de retórica en los edificios indivuales; esto es lo que pensamos de la HfG ulm: de su facilidad, su cualidad de "lo ordinario", que es una especie de lirismo subestimado lleno d potencial que no perturba la paz de la colina sobre la que se coloca. Para nosotros Chandigarh, Lafayette park(mies) chase Manhattan(bunschaft??) y Ulm son edificios bisagra." (smithson, Alison y Peter, without rhetoric. An architectural aesthetic, lartimer, Londres, 1973, pag. 14-19). Esa modernidad eficiente y carente de heroísmos que fascinaba a los Smithson, poco después sería interpretada por Richard Hamilton.

Max bill tenía poca afinidad con el arte pop de manera que quizá resulte más acertado hablar sobre el modus humilis de su Sachlichkeit desencadenada en términos tales como la puntualidad, la honradez, el ahorro y la limpieza. En este sentido el arte tiene que ser compatible con el sentido común. La demostrabilidad matemática o geométrica, es un homenaje al buen hacer suizo.

Bourdieu nos hizo conscientes del papel que juega el ascetismo" como dogma estético, especialmente en sociedades en las que su propia opulencia produce un problema de honradez, causado por la acumulación de riqueza. 
El compromiso ético de bill con la sencillez, la transparencia lógica y la razón, debe considerarse simultáneamente como una carga y un desafío.

concurso biblioteca nacional de berna.

mientras que la axonometría (aparentemente no presentada al concurso pues aparece firmada por bill) se inspira claramente en de Stijl y el suprematismo ruso, los dibuos de las fachadas, con las cristaleras pintadas de negro se refieren claramente al proyecto de gropius para la bauhaus. aparentemente este proyecto lo hizo bill poco después de inscribirse en la bauhaus en abril del año 1927, cuando aún no tenía 19 años, claramente estimulado por sus profesores Kandinsky, Klee Abers y Moholy Nagyde esta manera describe bill el edificio de la bauhaus la primera vez que lo vio: "todavía recuerdo cómo, aquella mañana, justo antes de llegar a la estación de tren de Dessau, de repente, enfrente apareció la fachada del edificio de la bauhaus. no había nada parecido: paredes de un blanco sorprendente y grandes fachadas de vidrio y, en primer plano, el edificio de la residencia de estudiantes, con balcones y puertas de minio.

casa estudio Bill, Zürich-Höngg

cuando en otoño de 1928 max bill vuelve de la bauhaus, quiere ser arquitecto, quiere construir y aprender. creo un sello que se llamó "bill-Zürich". sus amigos arquitectos le encargaban rótulos en edificios de vanguardia, así creó lo de la Zetthaus o el cine teatro corso, así como la tienda de muebles que fundaron Gropius y Breuer Wohnbedarf. en el 31 se casa con la fotógrafa Binia Spoerri. se construyen una casa con un presupuesto muy limitado. destaca lo compositivo de sus fachasdas, ordenadas en cuatro columnas y tres filas, destacando el contraste entre huecos y el blanco brillante del acabado de la fachada. el arquitecto Carl Hubacher dio a conocer a bill el sistema Kieser de prefabricados de hormigón, piezas de alveolo abierto con un tamaño de 283 altura, 20 ancho, 7 de grueso. con los que se construye tanto la estructura portante, como la fachada y la cubierta.

Zürich: la ciudad jardín junto al lago, 1937

Zürich: die gartenstadt am see. nombre original del proyecto. es una excepción porque es la primera y última vez que tuvo la ocasión de un encargo puramente urbanístico. también es la primera vez que como arquitecto afronta la ciudad, aquí no hay diseño solo proyecto. forma parte de una serie de 
trabajos con los que Bill intenta afianzarse como arquitecto moderno en la ciudad. en Zürich durante el mandato del alcalde progresista Emil Klöti y como responsable urbanístico el progresista Hermann Herter, se convocaron numerosos concursos públicos, como el de la remodelación de la zona ribereña del lago.

El telón de fondo era la Exposición Nacional Suiza de 1939, que siguiendo el modelo de la de Estocolmo de 1930, aprovechaba la fantástica ubicación de la ciudad a orillas del lago. se buscaba dar forma a la relación entre lago y ciudad en la cuenca inferior del lago, es decir entre el teatro municipal en la orilla derecha, y el edificio del auditorio en la izquierda (buscar posición de proyecto de utzon para la ópera de Zürich). en el concurso los proyectos presentados hacían hincapié en la creación de paseos ribereños, miradores y zonas de baño. max bill plantea algo mucho más radical, consiste en sustituir las fachadas del XIX por una sería de edificaciones modernas sobre pilotis, con cubierta ajardinada, alineadas y organizadas. de los antiguos solo conserva el banco nacional y el auditorio. se hace un tratamiento de borde dedicados a los peatones, con accesos en rampa directos al agua. como elemento importante aparece una piscina flotante de madera. el proyecto de bill fue desestimado en segunda ronda. max bill daba continuidad al proyecto realizado cuatro años antes por Karl Moser (primer presidente de los CIAM) que planteaba el derribo de toda la zona antigua de la ciudad situada a la derecha del rio Limmat, sobre la que se construyó siguiendo los principios del funcionalismo. en la propuesta de bill se ve claramente la influencia de le Corbusier, coincide que en ese momento estaba preparando la edición del tercer volumen de las obras completas.

es una propuesta arriesgada y creo de calado, aquí bill se comporta claramente como arquitecto.

restaurante Neue Waid, Zürich, 1937

la propuesta de concurso de bill, no se ajustaba a las formas de la antigua fonda rural cuya reforma era objeto del concurso. el proyecto consistía en un volumen colocado sobre la pendiente y dividido en tres partes: gran salón a doble altura, terraza cubierta y restaurante. a la derecha aparece una gran terraza restaurante-jardín con vistas. hay dos elementos formales que resultan llamativos, el primero el muro ondulado de vidrio, que funcionando como pared portante, tuviera nichos a la zona de comedor y por otro lado una fina marquesina ondulada apoyada sobre finos pilares que se inspira en le Corbusier. es muy interesante lo bien organizada que está la planta, con todos los servicios la fondo. muy bonito el acceso a través de una pérgola hasta el restaurante pasando tangente al restaurante jardín. todo rematado con el final de la gran 
sala. sigue siendo un proyecto demasiado heterogéneo y dubitativo, algo que en el pabellón de la triennale le había funcionado, aquí no.

pabellón suizo, exposición internacional de París, 1937

el nombre era Exposición internacional de las Artes y las Técnicas en la vida moderna, y en cierta medida era un continuación de la de artes decorativas del año 1925. en principio bill no formaba parte de los 32 arquitectos invitados al concurso de 1936, por tanto se sintió libre de dibujar un pabellón sin ningún requerimiento. el concurso lo ganaron unos arquitectos famosos de la época, con oficina en Basilea Bräuning, Leu y Dürig. se situaba en la orilla izquierda del sena entre los pabellones de Italia y Bélgica. los bocetos muestran una malla estérea, con referencias directas en las ciudad en el espacio de Kiesler. sobre esta estructura cuelga una secundaria que serían cubos o cajas en diferentes colores. la estructura le permite solucionar el apoyo de escaleras y mobiliario, toldos etc. proyecto bastante infantil pero con bastante interés.

pabellón suizo, exposición universal de Nueva York, 1939

es un desarrollo más detallado del concurso para el pabellón suizo del 39. tampoco este proyecto se acabó presentando al concurso porque el proyecto se encargó directamente al arquitecto suizo residente en Nueva York, William Lescaze, quien a raíz de la construcción de la torre PSFS en Filadelfia con George Howe, había adquirido renombre en la década de los 30 como uno de los arquitectos del estilo internacional. cabría destacas su casa estudio en NY. el proyecto de bill vuelve a ser una estructura estérea en forma de malla cuadrada de $8 \times 13$ pilares que alberga cubos de diferentes dimensiones con programa diferente, en este caso presta especial atención a la disposición de los volúmenes y la forma de ensamblarlos. la planta baja del edificio contaba con tres alturas y estaba subdividida con vidrio, se había pensado como vestíbulo y albergaría el restaurante. a las zonas de exposición de las plantas superiores se accedía por una escalera en el extremo oeste que conducía a los visitantes desde el primer espacio a una sala de exposiciones a doble altura. el proyecto está en la habilidad de bill en definir un espacio de circulación en la malla tridimensional, aquí aparece otro concepto heredado de Corbu de la promenade architecturale. parece ser que al edificio se entra por otro colindante que no pertenece al sistema de bill. este edificio hace de entrada, una especie de estómago con una escalera en el centro que te elevaba hasta una pasarela que cruzaba la 
calle y llegaba a la planta alta del pabellón expositivo. el recorrido por el edificio es muy curioso, se entraba por el edifico adyacente al otro lado de la calle, al subir la escalera llegabas a una pasarela que pasaba por encima de la calle que daba a la primera planta de la estructura espacial, donde enlazaba con un corredor que en diagonal entraba al primer cubo, con el número 2 en el programa, de ahí por una escalera circular se subía al segundo nivel, también marcado en el programa con el número 2, de ahí por otra pasarela a la sala número 3, sucesivamente por otro paso a la número 4, la más grande y alargada, para acabar por otro puente en la número 5 por la que se bajaba al nivel inferior por otra escalera circular y por esa misma escalera a la planta baja que directamente era un espacio abierto y público entre los propileos formados por los pilares.

realmente hay una cosa curiosa, pues el primer croquis de bill son dos paraboloides que flanquean una semiesfera, que a su vez son la antesala de otra semiesfera mucho mas grande. un mástil en el centro del conjunto con la bandera suiza.

otra de las propuestas que no coincide exactamente con la perspectiva dibujada es la planta de la cruz helvética levantada sobre pilotis, se intuye la malla estérea soportándolo todo.

casa para una pareja de artistas, ascona, 1949

de forma diferente a la casa Villiger, esta casi si se adapta a la tipología canónica de planta en L. se entra por el encuentro de los dos brazos, a la derecha la zona pública, compuesta de cocina, comedor y estar, a la izquierda la zona privada compuesta de dos baños, uno abierto al vestíbulo de entrada, el otro a salita que distribuye las dos habitaciones con la que cuenta esta vivienda. el avance con respecto a la casa Villiger es bastante grande, de alguna manera bill se ha ido convirtiendo en arquitecto. el edificio cuenta además con una planta superior a la que se accede por el exterior. la casa exteriormente presenta tres volúmenes, la dos partes de la L, con una cubiertas a dos aguas, con un lucernario corrido en el encuentro de los dos faldones, consiguiendo de esa manera modular la luz superior de los espacios interiores. estos dos volúmenes presentan, por otro lado, diferente altura. los dos tienen una galería corrida en ese planta, lo que mejora la protección solar. recuerda de alguna manera a la escuelita en Suiza de Hannes Meyer. 

>2 construcción vertical (finite 
Zirkulationsgraph mit vorgegebenem Plan.f Circulation graph including original plan. Studenten/Students: Karel Links, Robert Couch, Jürgen Böttcher.
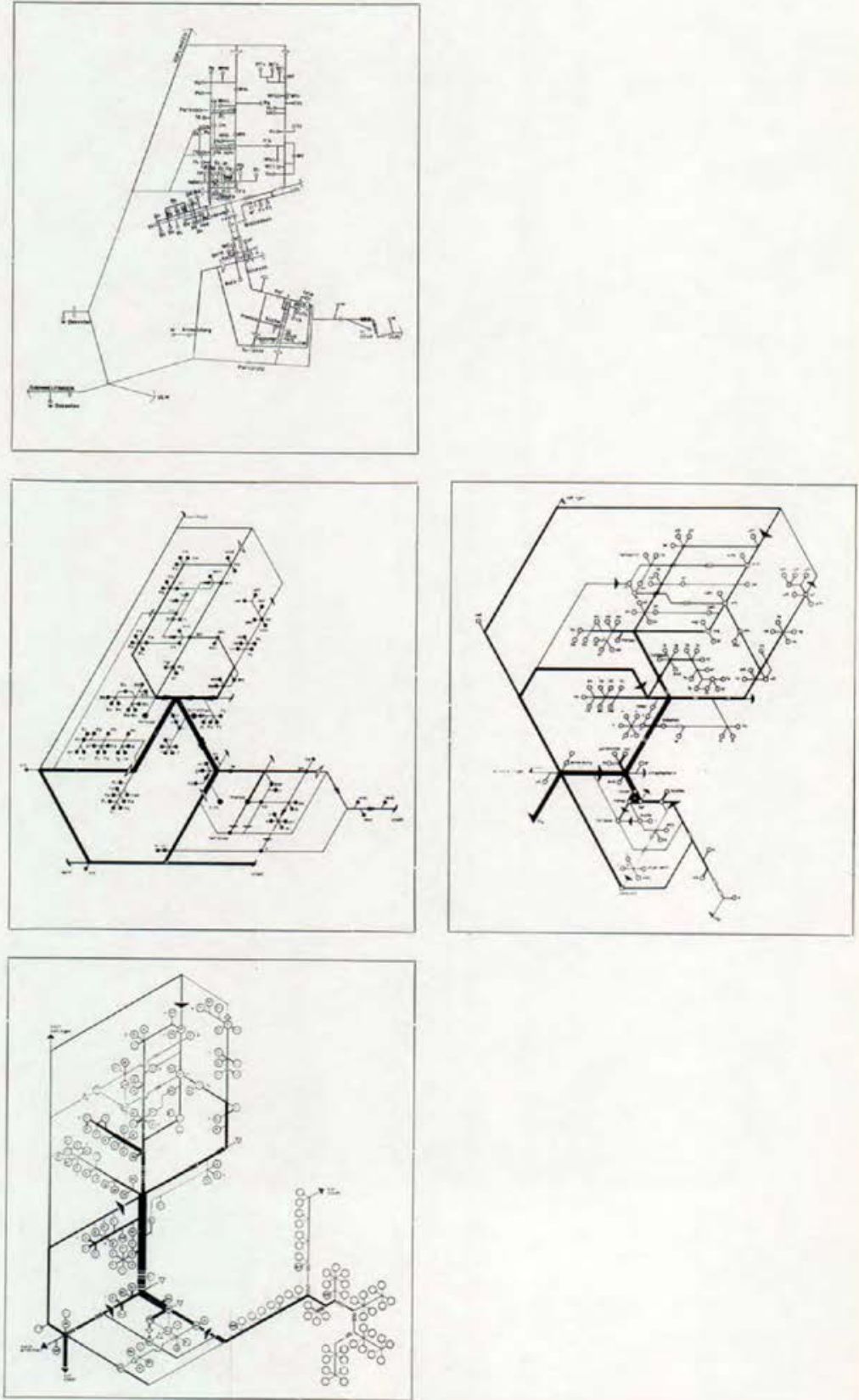


\section{>2 construcción vertical (finite}

\section{1 fondo}

2.1.1 la generación de un programa

.verano 1950 - agosto 1952, un recorrido epistolar Sholl-Bill

Max Bill opinaba, que en la era tecnológica, el diseño es un medio para impulsar la cultura. si embargo Tomás Maldonado abogó así mismo por la necesidad de llevar a cabo estudios fundamentales en el campo del diseño y especificó para ello los temas de investigación, como estudios de combinatoria y sistemática formal de los productos o investigaciones sobre la complejidad estructural y funcional de los artefactos técnicos. Esta última temática había sido ya tratada por Abraham A. Moles;12

Las ideas de esta corriente llevarían a un concepto de diseño en el que los productos no sólo dieran la apariencia de ser nuevos, sino que realmente se renovaran en su función o en su estructura. La gran preocupación de Maldonado por relacionar las cualidades estructurales y funcionales de los productos, significa que la forma de un producto no ha de ser definida meramente por sus características externas.

A mitad de 1950 los programas de la universidad prevista en Ulm se pueden clasificar de acuerdo a cómo paso a paso se han eliminado aquellas materias de formación, que no tienen nada que ver con el diseño. Con Walter Gropius, fundador de la Bauhaus, Bill tomó inmediatamente después de la fiesta de cóctel en contacto Stone y le pidió un informe adjunto para la"HochschulefürGestaltung" además de unirse al consejo de administración ${ }^{1}$.

Una solicitud similar fue también Henry van de Velde, que había fundado en 1906 los Kunstgewerbeschule en Weimar y que dirigió hasta 1914, fue Gropius (el camino a la sugerencia de Van de Velde) quien se hizo cargo después de la Primera Guerra Mundial y la convirtió en la legendaria Bauhaus. en la carta que acompañaba a la de Gropius había una de Bill donde tambien hablaba de la Bauhaus, de la cual la Ulmer Hochschule debería ser heredera. acto seguido se volvía a hablar del espedífico carácter del nuevo proyecto: 


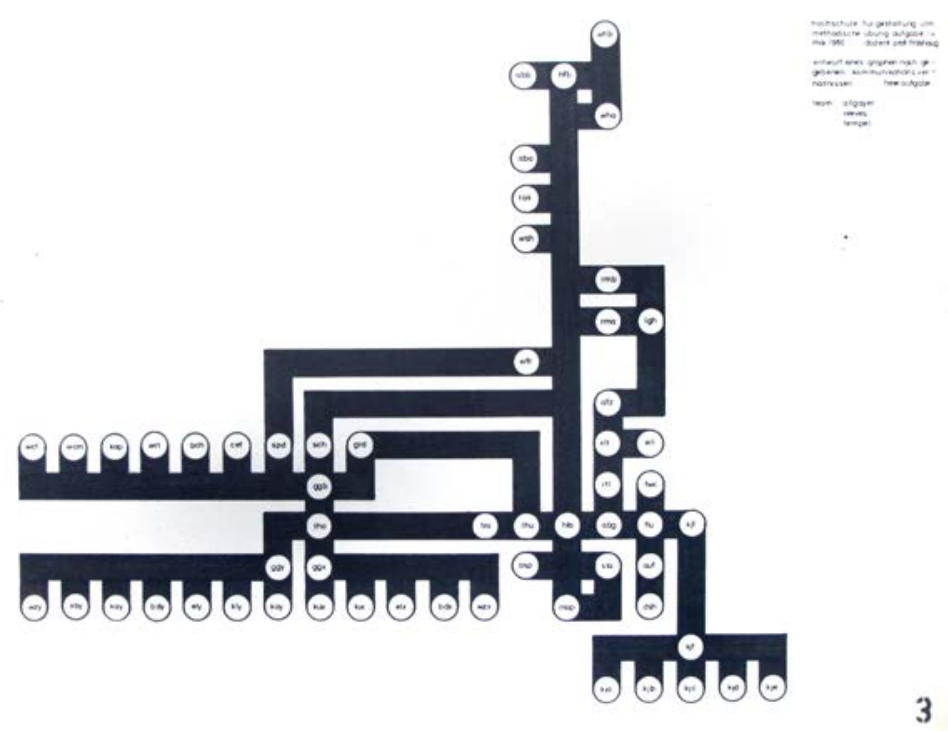

Es "sumamente importante para nosotros y también para los americanos la formación política, además de técnica y las humanidades. hemos presentado a la opinión de que ahora es necesario proporcionar en Alemania unas pocas personas por todos los medios, que les permitan ser políticamente efectivo sobre una base democrática².

El nuevo informe era ya un borrador elaborado por bill. la importancia se ha desplazado significativamente hacia una escuela de diseño. En lugar de los ocho temas de formación sólo siete se enumeran, aunque al mismo tiempo se llegará un nuevo especialista en el Departamento de Arquitectura. Pero estaban "Presse" y "Rundfunk" además de "cine" y "fotografía" conectados entre sí para formar una departamento. Además, un estudio de "artes plásticas" debe establecerse para los más talentosos. Los dos pioneros de la reforma de la educación artística, Gropius y Van de Velde, respondieron básicamente positivo - por lo menos expresado su interes pero rechazando ser nombrados miembro del consejo de administración. Van de Velde, en particular, elogió el proyecto como algo más que lo que Gropius y él mismo han ofrecido previamente. Porque en Ulm el diseño sería uno de los pilares de una educación creativa. Van der Velde escribió literalmente:

"La gran visión y claridad, que se expresan en la concepción de este programa, son la mejor garantía de la fuerza de los cimientos sobre los que se construyó la formación profesional y la educación moral de la nueva escuela. (...) Bueno, ya ha sido utilizado por las escuelas anteriores, el principio de la subordinación de los factores sociales y culturales entre los factores profesionales y artesanales; aquí, sin embargo, es considerado por primera vez como la piedra angular, sobre la que se basa la "filosofía de vida", que corresponde a este principio ${ }^{3}$.

El programa que me presenta Bill, excluye lo que es obsoleto, ampliado el anterior, se está preparando para llegar a nuevas etapas y empuja unos límites que ni Gropius ni yo pudimos superar." Van de Velde llegó a un punto por así decirlo, que será para el carácter independiente de la la HfG de suma importancia y al mismo tiempo marcó una distancia crítica con la Bauhaus. La idea central

2 Brief von Max Bill an Waller Gropius, 2. Mai 1950. (Bauhaus-Archiv Berlin)

3 Übersetzung des in französischer Sprache abgefassten Briefes von Henry van de Velde an Max Bill vom 26. Juni 1950. (HfGArchiv UIm) 


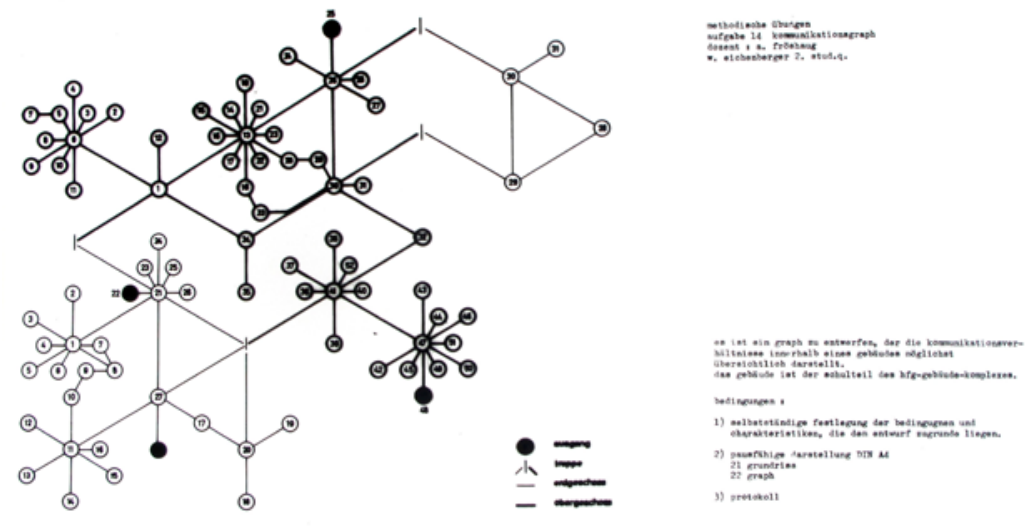

de sus conclusiones antes citadas está expresado en otras palabras: el diseño se había recubierto de contenidos sociales y culturales y directamente de la naturaleza construida del objeto. hacia esto sin embargo sigue siendo muy amplia la interpretación que van de Velde habría tenido que sostener y probablemente no habría llegado por sí solo a la redacción de la expuesto. Van de Velde, sin embargo, se había establecido desde el final de la Segunda Guerra Mundial en Oberägeri en Suiza, en una construcción de estructura de madera diseñada por Alfred Roth, y con frecuencia fue visitado allí por Bill. Se puede suponer que no tenía más información sobre lo planeado para la Ulmer Hochschule que una conversación personal con su "amigo Bill". estaba preocupado? Así que es probable que para Bill tampoco han sido muy sorprendente que el viejo maestro al final de su informe se refiera tanto al departamento de "Metodología Política" y "Difusión / Prensa" y expresó, que no estaba de acuerdo en incluirlas en el contexto de una escuela de diseño.

En el mismo sitio asentó Walter Gropius su crítica. Él, sin embargo, hizo sus reservas a este respecto al punto de partida de la preocupación fundamental: “"Cuanto más me ocupo de este problema cuanto más tengo la impresión de que la iniciativa proviene de interés político y no del diseño artístico. No creo que sería correcto si este último como un apéndice se construiría. El desarrollo de la creación artística debe ser completamente libre. Política, prensa, publicidad deberán someterse a ella, no a la inversa. (...) Por favor, entiéndame. El arte no se puede construir en el espacio vacío; necesitamos toda su vida como un fondo, pero no tendríamos un instituto de política y otro de artistas mezclados en una institución, porque no estamos en esa etapa, donde estas dos áreas se toleran directamente entre sí. ${ }^{4}$

A diferencia de van de Velde Gropius vio en el proyecto para la Ulmer Hochschule el riesgo de que los sujetos políticos dominen el diseño. En este sentido, él estaba sensibilizado por las experiencias personales. Después de que Gropius hubiera transladado en 1925, la Bauhaus de Weimar a Dessau por insultos políticos, se quedó fuera de cualquier disputa política. Antes de que Hannes Meyer le sucediera el 1 de abril 1928 etuvo que comprometerse con esta postura políticamente neutral. Gropius acusó a Meyer de traición más tarde porque no había cumplido su promesa y por lo tanto la Bauhaus se fue a la ruina ${ }^{5}$.

\footnotetext{
4 Brief von Walter Gropius an Max Bill, 28. Mai 1950, (Bauhaus-Archiv Berlin)

5 Brief von Walter Gropius an Maldonado vom 24. November 1963. (Abgedruckt in: Schnaidt: Hannes Meyet; 1965, S.120.)
} 
Fue de alguna manera lógico que Gropius ahora también recomendara a la Ulmern estructurar el rango previsto de temas de modo que los sujetos creativos están en el primer lugar. A modo de ejemplo, se refirió a la "Nueva Bauhaus", que ha sido fundada por Laszlo Moholy-Nagy en 1937 en Chicago y que en 1944 se transformó en "Instituto de Diseño". De acuerdo con Gropius se ha desarrollado "la distribución de los estudios en sociología, historia y economía (...) allí correctamente

6 Brief von Walter Gropius an Max Bill, 28. Mai 1950. (Bauhaus-Archiv Berlin) 


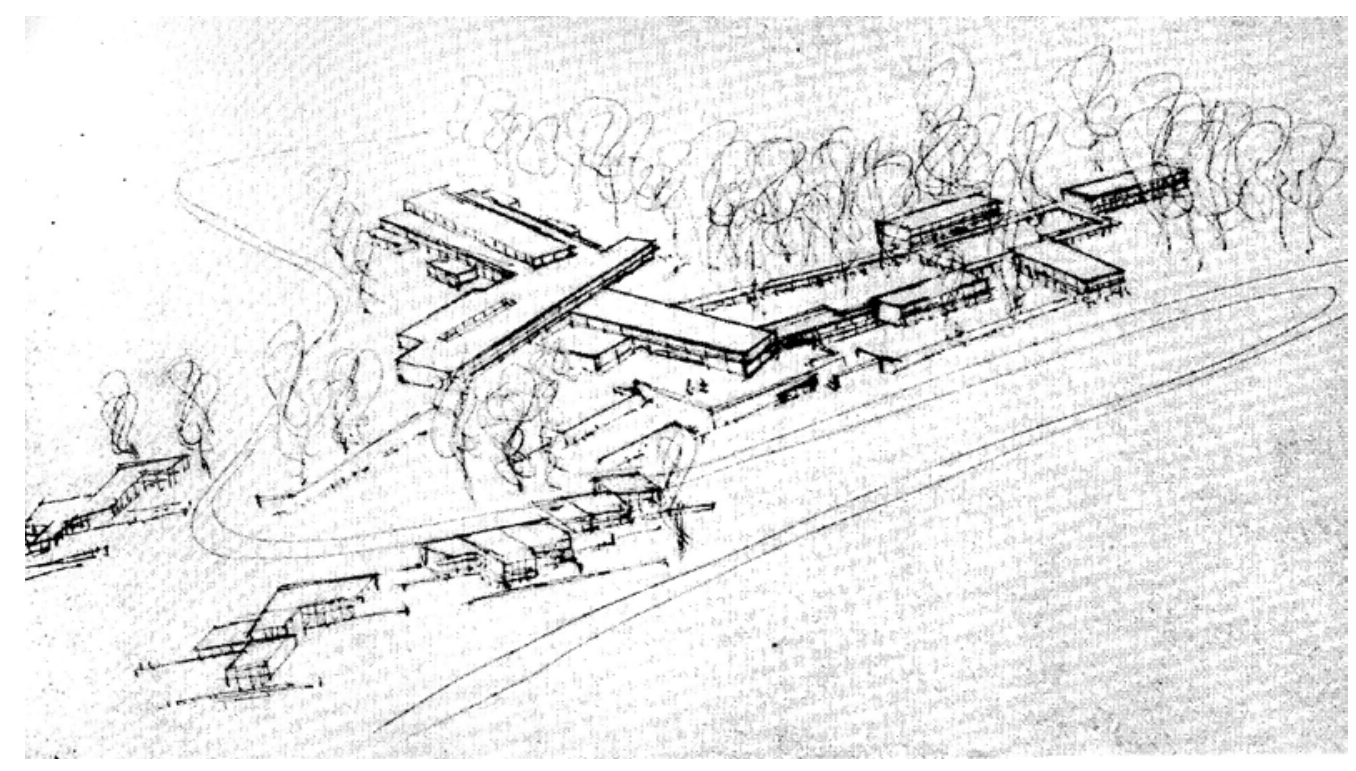

\subsection{2 die vorprojekte}

Desarrollo de los proyectos y su realización

En comparación con lo que en las diferentes secciones de hfg, la edificaciones no solo son la mayor en volumen si no también lo más significativo. Sin embargo fue la proyecttación se cerró cuando la escuela en agosto de 1953 empieza sus clases.

La tarea de proyectar y programar la escuela recayó en las manos de una sola persona. Hubo una gran interaccione entre el contenido del enfoque y la forma construida. Esto se demuestra el dia de la de la fiesta de aprobación de la construcción de la escuela, fiesta que organiza Shepard Stone y después de la fiesta bill piensa que el puede aunar más competencias con la relación al programa de funcionamiento interior.

La interacción entre forma y contenido no sólo generó un sentido funcionalista en el uso si no determinó el proyecto arquitectónico. Lo implica que bill ya no se ha quedado con la primera impresión que le produce el lugar de implatación.

Aparentemente las piezas se comportan de forma uniforme en el terreno cuando en realidad son unas construcciones cristalinas que se adaptan al lugar. La arbitrariedad del orden y la forma no se cierran a las diferentes funciones nos permite un análisis más claro del proceso del proyecto y del resultado.

.vorprojekte 1. 22_06_1950

La historia de un proyecto arquitectónico empieza con las reglas y el deseo de construir del promotor y se encuentra con el arquitecto. El 26 de mayo de 1950 Inge Scholl le envía una carta a bill en la que le informa que entre otras cosas le gustaría que construyera la nueva escuela. Sobre el ya mencionado programa que viene en la carta, se dice que tiene el lugar donde construirlo que está en la explanada pegada al fuerte y mas o menos a quince minutos andando de la ultima estación del tranvía. También sobre el programa espacial ya había algunas ideas que vienen en el siguiente resumen.

“por la gran escasez de viviendas no es posible encontrar ningún edificio válido. La ampliación de las 

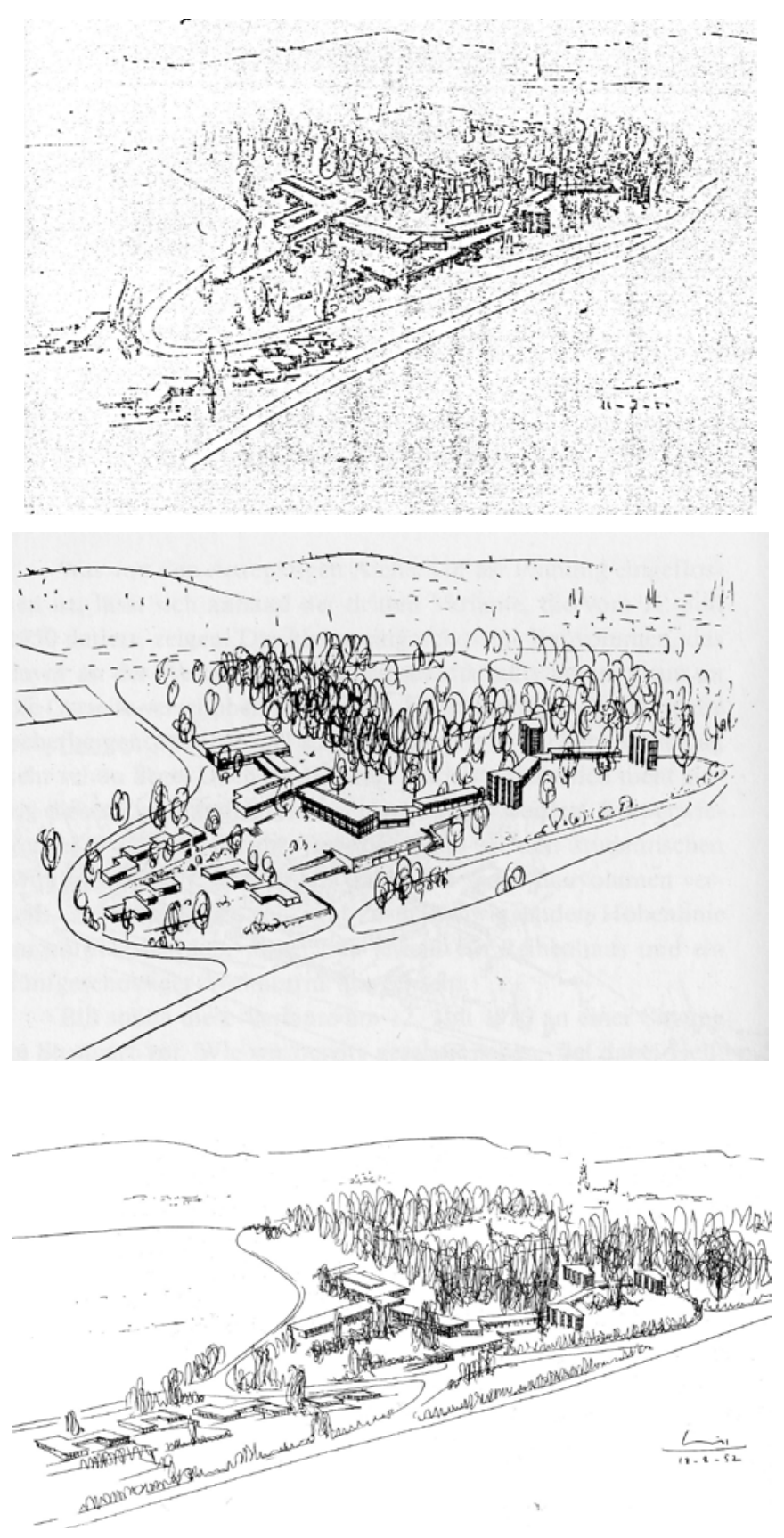
ruinas sería más que una nueva construcción, por tanto se decide alzar una nueva escuela. Se ha llegado a la conclusión que la forma exterior debería hablar de su espíritu para la formación de los alumnos. La fortificación tal y como está hoy no es posible utilizarlo como escuela, pero permitir la inclinación a la posibilidad de cualquier ampliación".

El edificio de la escuela se formará por una gran sala, que se pueda transformar en sala de cine o parecidos, la cual sirva de la misma manera, de sala de club y salas menores. Esta última debe estar al servicio de la vida y del desenvolvimiento de debates libres.

Además, deberá contener 15-20 espacios (habitaciones) a disposición de las diferentes pequeñas clases o equipos de trabajo. Aparte se le proporcionara, con espacios para estudios, para cada uno de las clases de formación profesional, que puedan montarse/configurarse/amueblarse poco a poco. También debe disponerse de una pequeño espacio deportivo, después debe buscarse todo, para que los alumnos se protejan de la limitación (desequilibrio), y para estimular una actitud ante la vida fresca y optimista/confiada.

Como es difícil obtener habitaciones individuales en la ciudad, deberá contener el internado pequeños espacios habitables para alrededor de 100 estudiantes. Al igual que el edificio de la escuela el exterior del internado deberá respirar el espíritu de la escuela, el espíritu de la amplitud de miras, la libertad y la simple belleza, no la fuerza/violencia y el miedo?

Especificar para las primeras intenciones del <circulo de ulm> es la exigencia de que en la arquitectura tiene que reflejarse el espíritu de la escuela. En este sentido ha desarrollado realmente una primera idea Otl Aichers. El existente pequeño restaurante de excursión, que se puede encontrar en el fuerte desde la guerra, debe ser reconstruido como Mensa( comedor de la universidad) y las casamatas deben utilizarse como aulas. Lo mas importante del plan de Aichers eran dos torres de filigrana, hechas de acero y vidrio, que se levantarán como fénix sobre la masa de piedra del refuerzo de la esquina ${ }^{8}$.

7 Geschwister-Scholl-Hochschule. Eine Aktive Schule für Kultur und Politik (Ulm 1949/1950), S.27/28. Archiv Bill

8 Bill Anmerkungen, 1957, S88. Ebenso in: Heimbucher, Michels: Bauhaus, Hfg, lup, 1971, S70

>2 construcción vertical ( finite / 71 
Esta visión de la relación con el antiguo fuerte, que se utilizaba pocos años antes del gobierno nacionalsocialista como centro de concentración, incluía una simbólica reutilización de histórica sustancia constructiva.

Bill, como arquitecto encargado de los planos, oyó por primera vez, con motivo de una conferencia en febrero de 1950, sobre esta <architecture parlante> para el proyecto del Kuhberg. Sin embargo, negó categóricamente cualquier intento de recargar las formas arquitectónicas como personajes simbólicos, e interpretó la propuesta Aicher está en camino: "el fuerte visto como tren fantasma o casa del terror, para eso sería bueno, pero no en el sentido de la nueva vida aflorando sobre las ruinas; porque si usted posiciona la nueva escuela justo encima y las habitaciones en un antiguo campo de concentración, usted está actuando de una forma un poco extraña, especialmente visto desde el extranjero. de algo fundamentalmente malo (dice Bill) nunca saldría nada bueno"9.

Entre las propias ideas, que emplea Max Bill en este momento, digamos que sólo se mantienen para completar la nueva construcción, aquellas que contrastan con la fortificación existente, pero lo existente que se quede como está.

No hay mucho tiempo para discutir sobre las diferentes variables, porque el proyecto, junto con la solicitud de apoyo financiero deberá estar, en el primer Ejercicio del HICOG, entre 30 de 06 de 1950, que se presentará al Oficial Residente en Ulm. Por el contrarió a Bill le pidieron a la mayor brevedad los planificación necesaria "sin mirar otra vez hacia las torres de la edificación"10.

Antes de que se enviaran los primeros dibujos a Ulm informó por escrito Bill sobre su posicionamiento ante el proyecto. Le parece; desde la urgencia de las fechas, no estar particularmente impresionado; porque él anteriormente había estado aplicado en sus deberes. Por ese motivo, tuvo lugar la deseada y precisa indicación para hacer el proyecto.

9 Carta de Bill a Inge SCholl, 17 febrero 1950 und 6 de Marzo de 1950 (ArchivoBill) 


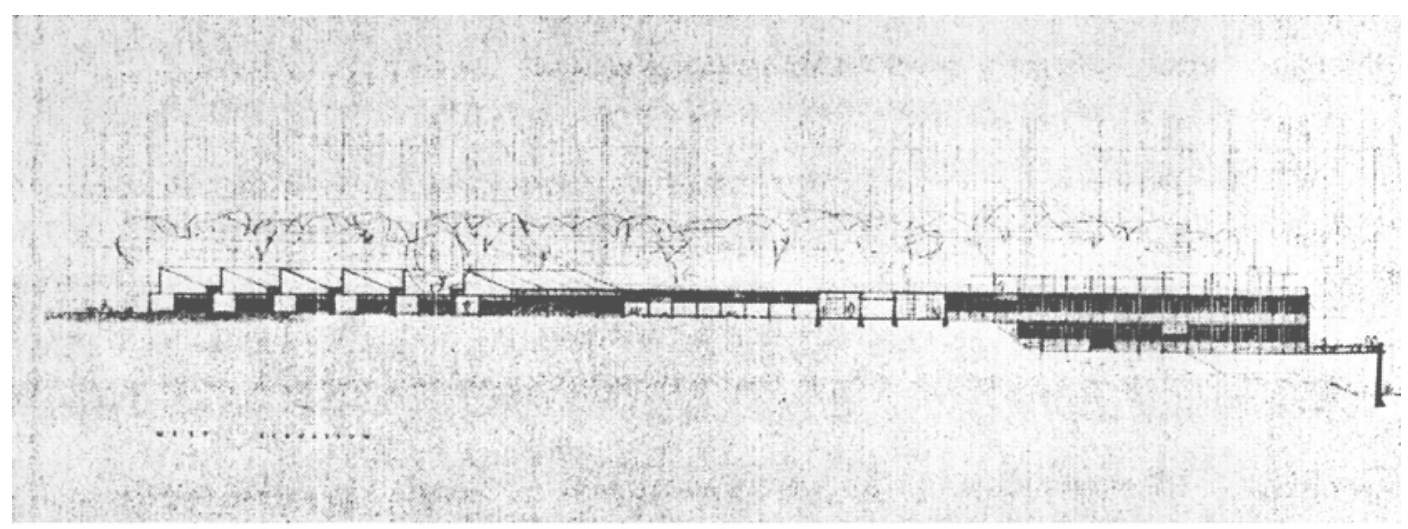

C.W. Voltz: Stahl-Variante des

Billschen Entwurfs, 1951,

Flugperspektive und Westfassade

Bill escribió marzo 1950 lo siguiente:

"He llegado a la conclusión de que la escuela de los estudiante debe construirse a si misma, esto condicionaría una organización muy diferente. También la propia construcción de la escuela debe ser dirigida por estudiantes, o por lo menos deben colaborar en ello. ... mi plan comienza con los primeros talleres en la fortaleza, y de allí salir y construir la nueva escuela después de una concepción global, el curso se debe establecer en primer lugar." ${ }^{\prime 1}$

En la concepción global MaxBill en realidad pudo trabajar desde el 25. 04 1950, ya que en esa decisiva Reunión con Shepard Stone la competencias sobre el contenido del programa fueron redistribuidas. Durante los próximos dos meses en paralelo con el trabajo de los esquemas y también surgieron estudios sobre la clasificación funcional y la ubicación espacial de las construcciones.

Lo que los estadounidenses finalmente en este momento por vía oral recibieron sobre el proyecto, que los dejó más bien escépticos, fueron los informes de Inge Scholl, y eran únicamente una organización puramente funcional y apenas trataban sobre la relación entre los diferentes usos.

Como Inge Scholl, el 5 de Junio escribió a Bill, los americanos se habían planteado una "aldea universitaria", tal vez en Memoria de los famosos American Colleges en New Haven, Cambridge, etc, tal vez sólo, porque se habían planteado unas relaciones más racionales con los volúmenes de construcción.

"Ellos (los estadounidenses; AdV) se plantean un pueblo escuela de arte, que es pequeñas casas en las que los estudiantes pueden vivir 20 a 25, con un espacio público grande, que es durante el día, al mismo tiempo se utiliza como sala de la escuela. Así que no hay separación entre la escuela y la vida, si no están estrechamente conectados. Además opinan que se podían introducir los talleres en el sótano de las misma casas.

Así que, le repito otra vez, que seguro que lo entiende, lo que los americanos opinan básicamente es lo que queremos ${ }^{12}$.

11 Carta de Bill a Inge Scholl 22 de marzo de 1950

12 Carta de Inge Scholl a Max Bill 
Bill se decantó en cambio por un conglomerado homogéneo de los diferentes cuerpos de la construcción ${ }^{13}$. Subrayó por primera vez su intención de desarrollar una forma desprovista de cualquier referencia a su función.

Es cierto, él también habló después de la escuela como un pueblo, pero esta declaración no se relaciona con la forma arquitectónica, sino más bien de un método de convivencia entre el arte y la vida. Como ya simbólicamente proponía Aicher, la idea del pueblo-escuela provocó también la reacción de Bill, como si para él cada definición contenida fuera un asedio inadmisible a la forma.

Interrumpido por largas pausas, desarrolló durante más de dos años - a partir del verano 1950 a agosto 1952- un total de cinco diferentes variantes dibujadas por Bill. Otro adicional vino de Aicher, mientras C.W. Voltz, que fue empleado como arquitecto del grupo de construcción de Ulm desde mediados del 1951, contribuyó con dos revisiones. Cada uno de estos proyectos preliminares por medio de dibujos de plantas esquemáticas, en los cuales es evidente el tamaño y la disposición de los espacios.

Para mayor detalle, se hace una vista de pájaro del conjunto, en la que de fondo llama la atención la aguja de la torre de la catedral de Ulm destacándose sobre otros edificios de ulm como referencia al lugar.

El 22 de 061950 envió MaxBill un "primer esbozo" de su proyecto de Ulm. Aunque todavía no había podido encontrar la solución, pero se puede captar la esencia de lo que es, en comparación con los siguientes niveles de revisión que acompañan. Para la construcción se utilizó la parte de lo que fue campo de tiro, que se extiende a lo largo del borde sur de la Kuhbergs y luego detrás de la fortaleza, de espaldas a la ciudad, se levanta una cima suavemente abovedada, en este sitio, pero a una distancia segura de la fortaleza, deben surgir los edificios de la Universidad. El plateamiento de Bill dividido en cuatro alas es el siguiente: primero aquel con los estudios y talleres, segundo el ala de servicios comunes, tercero residencia de estudiantes y cuarto casas de profesores. y en cuarto lugar, las casas de los profesores.

13 Carta de Max Bill Gropius un 12 junio 1950 

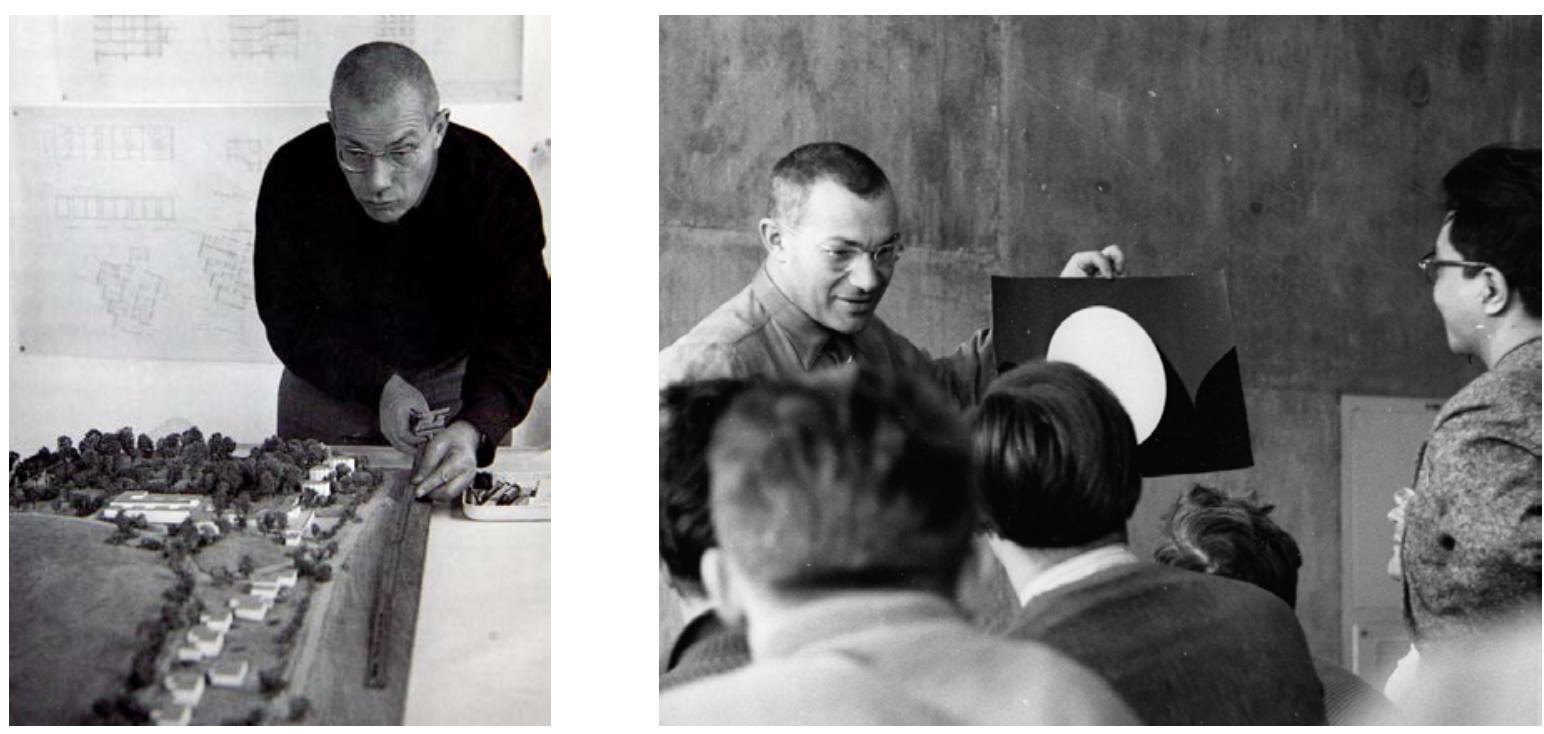

En la descripción ya se pueden identificar las características esenciales del sistema construido. En cualquier caso no hay la mas mínima indicación en las primeras propuestas de que Bill planteara un cuerpo construido monolítico, como Aicher - y después de él muchos otros - habían afirmado en 1975 en el número de la revista de la HfG "Archithese"14.

No obstante, Bill también señala en la carta que acompaña que él no consideró definitivamente los primeros bocetos y mencionó especialmente, que la casa de los estudiantes debería estar más diferenciada:

"se trata de un primer esbozo, en el que a mí me parece que todo el sistema representa gran parte de nuestras necesidades. En cambio, lo específico, por supuesto, aún no se tienen en cuenta. por lo que las diferentes partes sólo se pueden ver como un esquema, sin su disposición real. Algunas cosas son todavía un poco demasiado grandes, y que no están unidas entre ellas. Me imagino también que la casa de estudiantes todavía debe estar más diferenciada, pero no en el sentido en que escribió usted en su carta de fecha 06/05/50. me parece imposible que en cada una de las casas vivan 20-25 estudiantes, con las grandes salas para vivir dar clase y ser utilizadas como talleres, esto daría lugar a un violento enfrentamiento de actividades. Y tampoco sería deseable desde el punto de vista de la economía de medios. Puede que haya un campo de investigación en ese sentido, pero más en la zona norte de la casa de los estudiantes"15.

14 Otl Aicher: Die Hochschule für Gestaltung. Neuen Stufen ihrer Entwicklung, 1975, s 13>. 


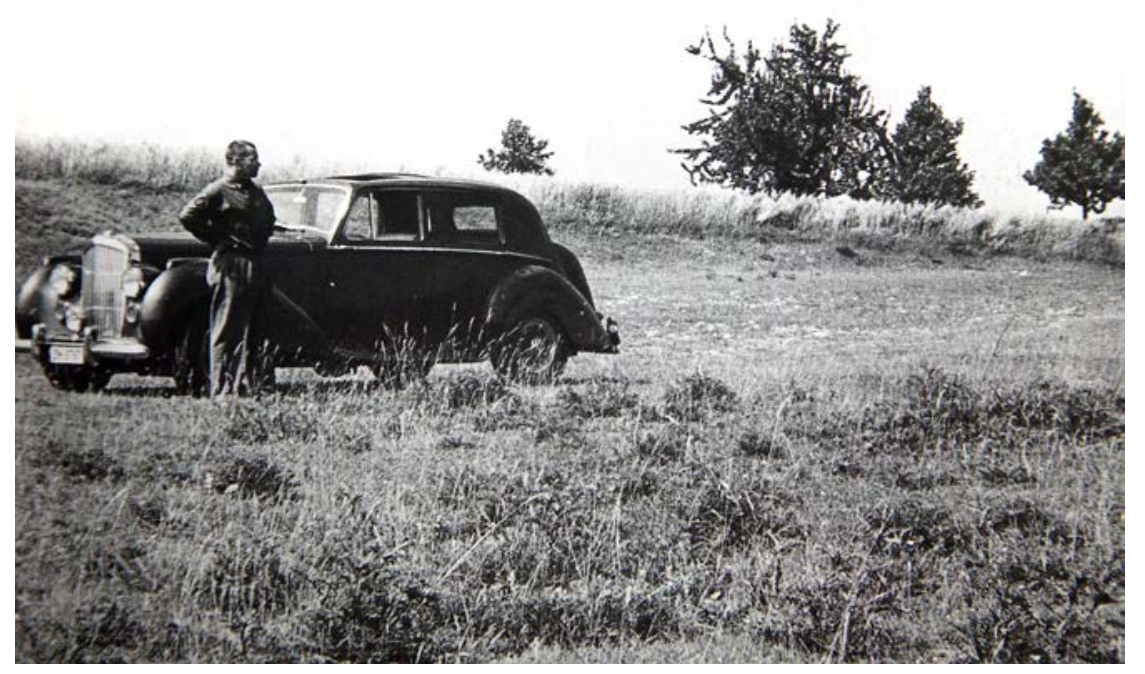

.vorprojekte 2.23_06-10_07_1950

La aquí anunciada segunda variación puede tener su origen en los próximos 14 días entre el 23 de junio , y el 10 de julio. De hecho se puede encontrar en la redacción de la "solución Descrita» para los pisos de los estudiantes. El solitario edificio inicial se divide en cuatro casas una al lado de la otra de dos plantas, y conectados por pasarelas.

Bill se dejó influenciar por un dibujo anterior que solo un par de meses antes vio en la revista I'architecture d'aujourd'hui abierta en el estudio que trataba de proyectos para la universidad Hua-Tung en China entre los que el estudio de Gropius tenía el proyecto llamado "the architects collaborative" con el estudio chino de I.M.Pei. I'architecture d'ajourd'hui febrero 1950, s 28/29.

Dicho esto, no hay más rotundas inconsistencias en comparación con la primera descripción. Como todavía estamos en el proceso de establecer lo rotundo, ahora tenemos que trabajar con diferentes pequeños volúmenes cristalinos, alineados y cuidadosamente situados en el territorio. De algunos de estos conjuntos sacamos una forma de la planta simplificada y de ahí un ala única con los estudios y talleres. Esta se eleva sobre el planta en "L" añadiendo los pequeños volúmenes adicionales. Las dos ramas también deben distinguirse por medio de la sección del tejado y su propia construcción. Al oeste del edificio de la escuela están posadas más casas de invitados y docentes, que también están compuestos a partir de diversos cubos simples y unidos entre sí en grupos pequeños.

En el mismo tiempo en el que Bill proyectaba la segunda variante Aicher le mandó una contra propuesta a Zürich porque estaba descontento con la primera propuesta de bill. También estos croquis actualmente no se pueden encontrar, pero hay suficientes indicios para saber la dirección de Aicher, a través de lo que le contestó Bill en una carta, donde discutía las diferencias fundamentales entre la propuesta de Otl y la suya. A partir de esta diferencias bill concreta su tercera propuesta, en donde hay algunas concesiones a la propuesta de Aicher pero no son importantes en el conjunto de la propuesta. Sobre la propuesta de Aicher Bill escribe lo siguiente a Inge Scholl <carta de Bill a Scholl el 6 de julio 1950>:

"he estudiado el proyecto de Otl para kuhberg. Tengo algunas objeciones, pero tiene algunas cosas que me gustan, sobre todo que los planos son muy bonitos y muy claros. Yo mismo soy un viejo aficionado del "aligeramiento" en los últimos tiempos he llegado a la conclusión de que el aligeramiento tiene un 


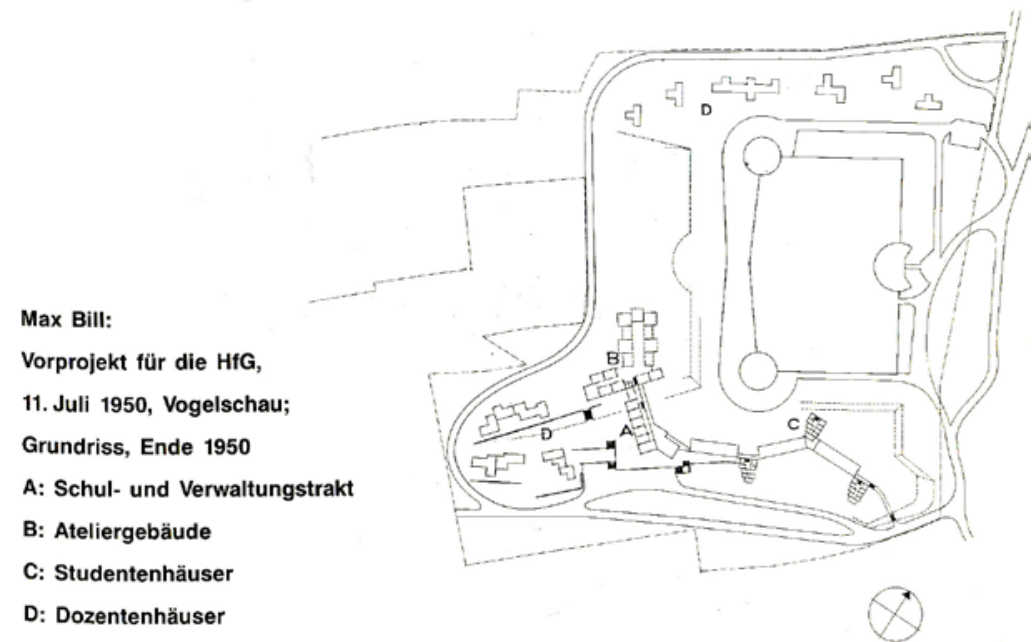

gran fallo, incluso en la construcción de la ciudad. Hoy soy del parecer de que hay que concentrar, y que la concentración debe ser tan multiforme como sea posible, pero igualmente tan flexible. Por eso mi gran espacio de trabajo es una cosa que después de muchos y queridos cambios internos se puede volver a cambiar internamente sin gran esfuerzo. He llegado a la misma conclusión de que lass cosas, que son muy diferentes y especiales no son practicas para la vida y a menudo se vuelven inútiles. Por ello la posible gran flexibilidad y no implica un aligeramiento individual. Pero todo ello influido por las circunstancias, la finalidad y las condiciones. Creo que mi próxima propuesta estará bien, pero tendrá otra vez terrazas. Creo que Otl ha decidido dejar vivir a los conejos que corren gustosamente y libremente. Encuentro que las terrazas son algo espléndido para la convivencia de las personas. No hay nada más bonito para construir y también es fantástico. Ahí pueden construir los alumno tanto como quieran y más.

En el proyecto de Otl me gusta la situación de la cocina, desde ahí se tiene una esplendida vista y eso está bien así."

Estos pensamientos te recuerdan a ese famoso debate de los años 20 en el que los dos arquitectos y compañeros en el estudio Mies Hugo Häring tenían posiciones contrarias que provocaron el argumento del libro de Adolf Behne "der Moderne Zbeckbau": la posiciones separadas de los racionalistas y los funcionalistas de la forma. La serenidad racional del sentido de Mies se refirió a la forma general validada por los tipos. El parecer funcionalista, como lo entendía Häring estaba más relacionado con recortar la escala para llegar a la unidad de lo orgánico.

Bill vio en la propuesta de Aicher tendencias funcionalistas en el trabajo y criticaba según su opinión la amplia diferenciación y el aligeramiento entre partes. Significativamente eligió él para sí la mitad de camino, donde deja abierto un método tanto racional como orgánico.

En el sentido "tanto como también" en el que se entienden todos sus siguientes propuestas. El contenedor, recibió una aumento de la forma con la misma estructura mientras que los trozos del cerramiento se convirtió en una adulta espina dorsal orgánica. para la Gestaltung de los cuerpos y la integración de la construcción se formulan dos sistemas que desarrollaremos a continuación. 


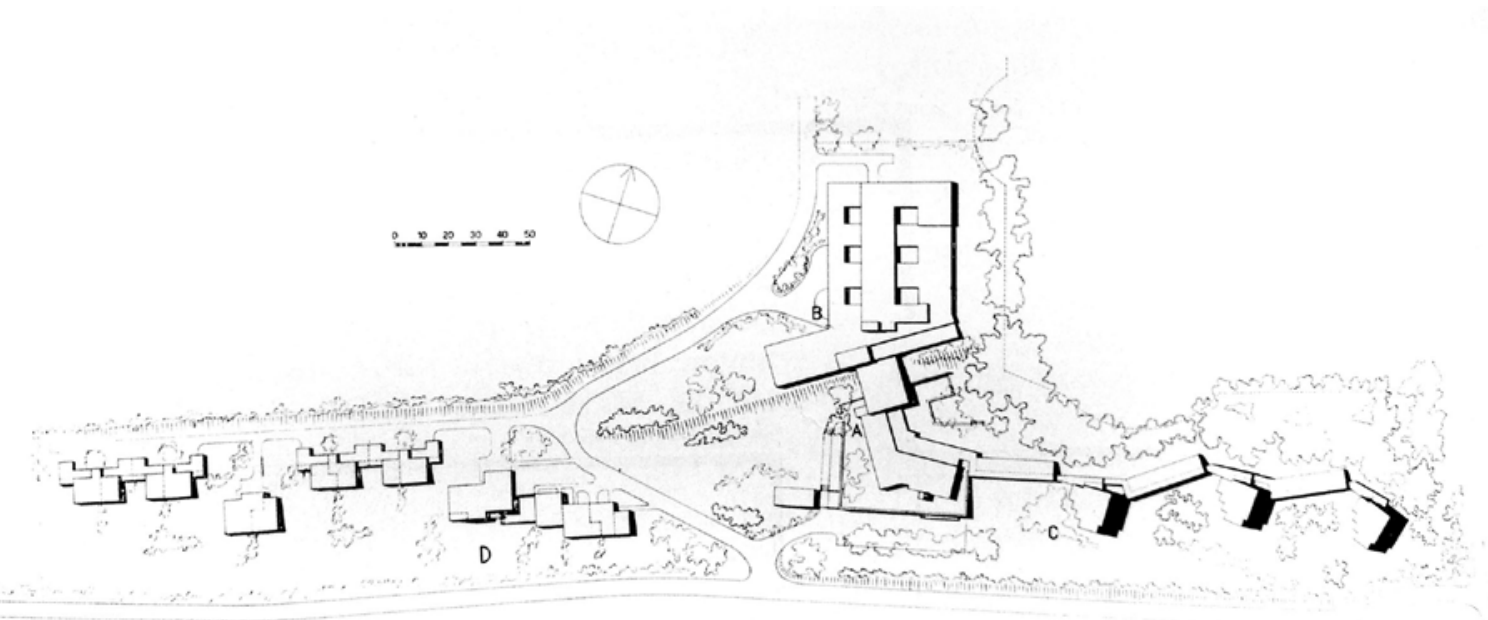

.vorprojekte 3. 11_07_1950

De las sugerencias que venían inspiradas de los planos de Aicher surge la tercera variente, que data del 11 de julio 1950. El pequeño volumen de construcción de un piso que antes estaba posado en la parte oeste del ala común se movió hacia el ala este para poder alojar la cocina, sobre lo que escribió Bill que en la propuesta de aicher estaba muy bien situada. No sólo se dibujó esta concesión en la tercera variante, de mucho fueron los cambios y cambios sobre las viviendas de estudiantes. Se distribuyeron en total en 6 volúmenes que oscilaban ordenadas a lo largo de una línea larga, los cambios ibas desde una casa adosada a una torre de vivienda de cinco pisos.

Bill propuso esta variante el 12 de julio de 1950 en una reunión en Stuttgart, como podemos ver Helmut Becker, el abogado de los Ulmer falló de inmediato que el presupuesto previsto nunca alcanzaría para realizar un proyecto de este tamaño. Ahí los americano no tenían nada que decir en contra de este proyecto, de que la búsqueda de financiación de la Fundación hermanos Scholl se tenía que calcular sobre esta base. Según La valoración de bill debería costar dos millones de marcos, a partir de ahí se calculó cada millón de marcos que los ulmish solicitasen de los americanos, más tarde se supo que este cálculo de costes más que caro era barato.

Todavía cuando el proyecto fue analizado por la administración americana desde diferentes puntos de vista las diferencias eran notables. Así viene la cuarta variante que bill dibujo, el 18 de agosto de 1950 y en la que hay un deslizamiento de la calle existente al borde de la HfG dentro de la parcela. A partir de esto las casas de los profesores deberían estar un paso más cerca de las construcciones de la escuela, mientras que las restantes se designaron a la parte norte del fuerte.

.vorprojekte 4. 18_08_1950

Las dos siguientes variantes que quedaron sólo como episodios proceden C.W.Voltz, que desde mayo de 1951 participó activamente en el grupo de trabajo de ulm. Ambas fueron directamente a través del comentado donativo de la "asociación del hierro y el acero".

El trabajó por una parte en dibujar la propuesta de bill en acero y por otro lado para dibujar una detallada variante a escala 1/200. Los planos para el proyecto de acero no sólo no iban en la línea de los anteriores proyectos de bill si no que iban en otra línea completamente diferente. Voltz intentó 


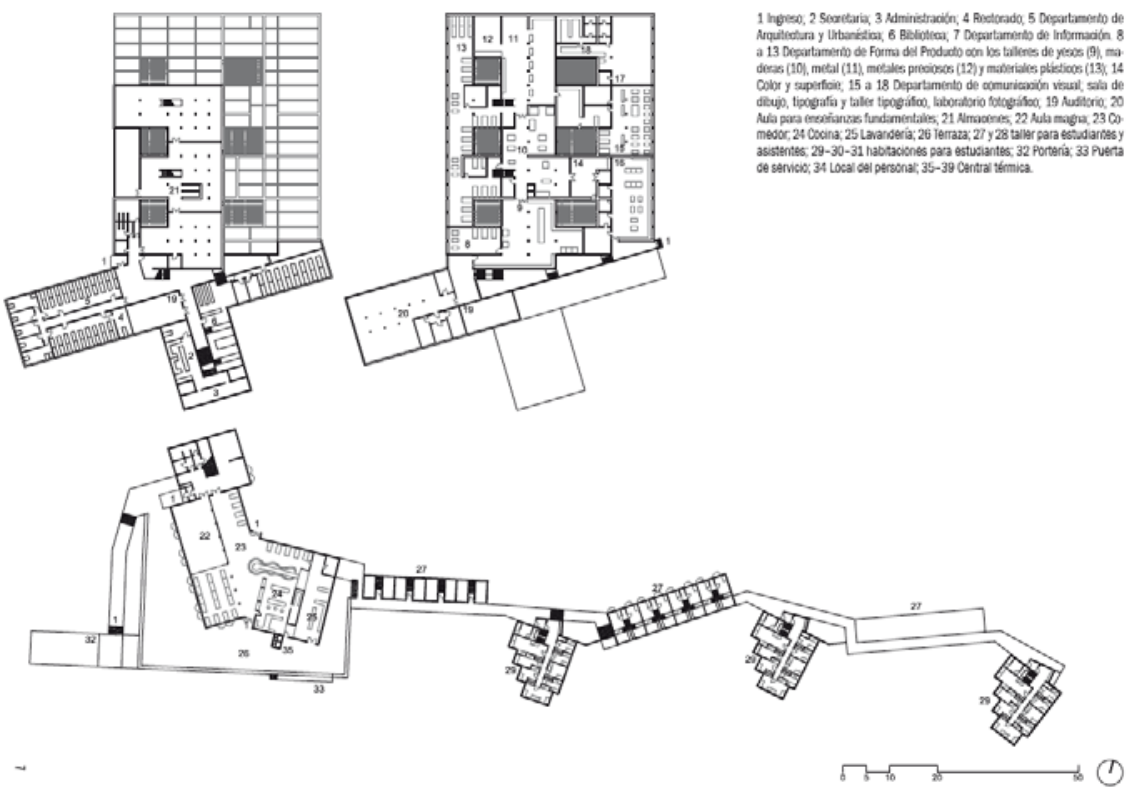

como algo especial con motivo de estas nuevas propustas constructivas, darle forma interesante de forma retórica. Materiales y funciones dieron motivo a que las construcciones estuviesen equipadas por formas específicas. Por ejemplo los talleres tenían un tejado de cobertizo de acuerdo a la apariencia del nivel social. Por lo que el donativo de acero se desvaneció. Todas esta variaciones tomadas al respecto se desvanecieron por el tema económico y se quedaron sin limitación para las futuros propuestas.

.vorprojekte 5. 18_08_1952

Con la quinta y última variante fechada el 18 en agosto de 1952, de acuerdo el hilo anterior desarrollado de nuevo por Bill <el motivo por el que dos proyectos anteriores se datan el 18 de agosto se clarifica porque ese era el día del cumpleaños de Binia Bill y se permitió correr la fecha. 'En el mismo año que la perspectiva aérea fue publicada en la revista "Form" por primera vez Bill: Form 1952 s 164. Resultó que mBill presentó la propuesta de la HfG en Ulm como una institución la cual venía obligada por la tradición de la reforma en la educación artística. En general, mencionó cuatro precedentes. Dos de ellos, a saber, la Escuela de Artes y Oficios de Henry van de Velde y la Bauhaus de Walter Gropius en Weimar, eran de primordial importancia debido a su orientación pedagógica. Más estrechamente relacionado con la concepción arquitectónica de la HfG, sin embargo, fueron el Instituto de Tecnológico de Illinois, cuyo campus fue planificado en los años cuarenta por Ludwig Mies van der Rohe, y el construido en 1938 por Frank Lloyd Wright el Winter Camp "Taliesin-West" en Arizona.

Estos dos ejemplos se representan dos estructuras de construcción, las cuales caracterizan las propuestas proyectadas por Bill, análogamente a las construcciones de Wright, bill utilizará la división de volúmenes y la cuidadosa integración en el territorio. Estas características son, en el tratamiento de algunas partes específicas, constituyen el consideración orgánica del conjunto, y la unión entre sí de la piezas esparcidas. Al mismo tiempo y en contraposición la uniformidad de los volúmenes desde el exterior hace referencia a Mies van der Rohe. De la misma manera las torres de viviendas se pueden entender como volúmenes simples, que a través de la sustracción escalonada de las cubiertas, quedan deformadas. Se puede decir por el contrario, que la forma de los contenedores de uso viene sometida por la medida a la que obliga la escala, y estos organizados en espina forman la sustancia que distingue. 


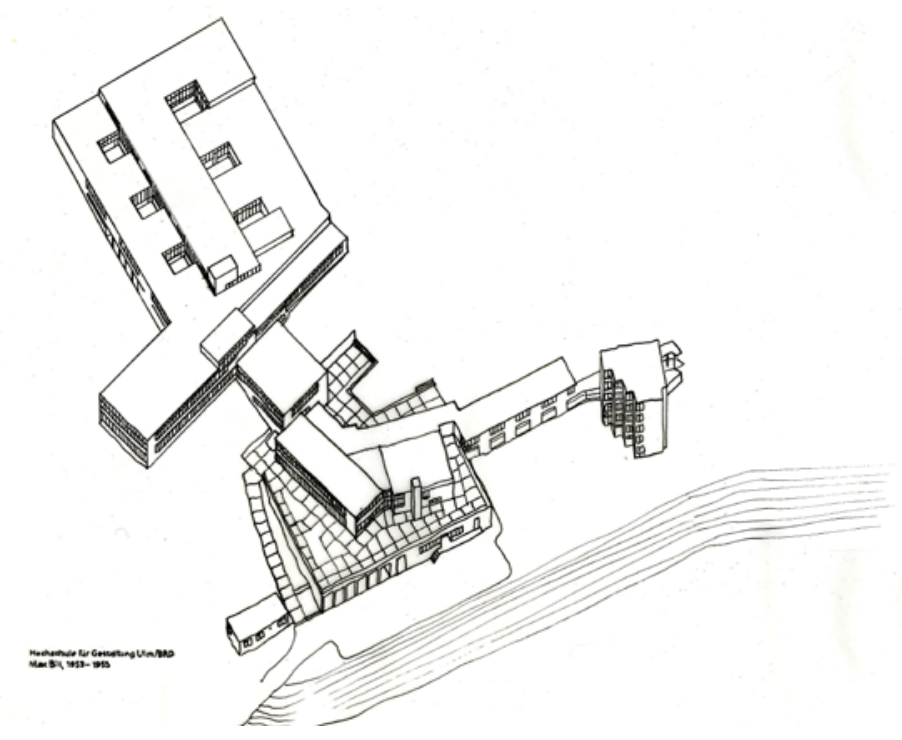

En este punto del desarrollo es la evidente analogía conceptual al proyecto de escuela de sindicatos de Hannes Meyer en Bernau. Aquí como allí se reconoce la radical y funcionalista prolongación, que por un lado repercute en la descomposición de los volúmenes constructivos posados uno al lado del otro y por otro lado en el respectivo montaje a lo largo de un elemento de conexión. Aquí como allí destaca en la solución la directa transmisión" que viene de la aplicación directa de los diagramas funcionalistas, igual que Meyer utilizo explícitamente <Schnaidt: Hannes MEYER, 1965, S.40>. sin decirlo directamente, es en este contexto digno de mención que bill de 1927-29 estudiaba en la Bauhaus, cuando bajo la dirección Meyer el departamento de construcción dibujó los planos para el edificio de sindicatos. La colaboración de bill en el proyecto de ese edificio es importante tanto conceptual como biográficamente. Hay relativizar está aseveración en el sentido de que las diferencias predominan. La diferenciación es más notable en el desarrollo de la estructura del cerramiento. Por ello los volúmenes se arriman cariñosamente sobre el terreno, mientras que los de la ADGB lo hacen a lo largo de una galería. En lo que se refiere al comportamiento en si mismo la forma se determinará en bernau según una diferenciación funcional, mientras que en ulm en contraposición de bernau hay una tendencia a la uniformidad. Para terminar, pero algo importante que hay que mencionar, el desarrollo funcionalista del proyecto de la HfG será una solución intermedia que superará la diferenciación funcionalista.

A medida que el objeto principal se puede eliminar del hasta ahora trabajo de proyecto, es por lo que el anterproyecto consta de dos estructuras heterogéneas, que se encuentran en varios lugares. A ambas se le asignan diferentes áreas funcionales y se proyectan formalmente de acuerdo a sus propias leyes. La heterogeneidad de ambas estructuras destaca con mayor claridad en el curso del proyecto -como consecuencia de seguir literalmente la máxima de que "la forma sigue a la función", también por la influencia de los proyectos en los que se inspira.

Se puede considerar la diferenciación entre elementos como una traducción del programa en una forma arquitectónica. Sin embargo, lo que si los proyectos preliminares HFG tenían es que la forma estaba visiblemente concentrada en una contraposición de dos estructuras, es un tema que no deriva tanto desde el programa, pero que surge durante el desarrollo del proyecto después. 


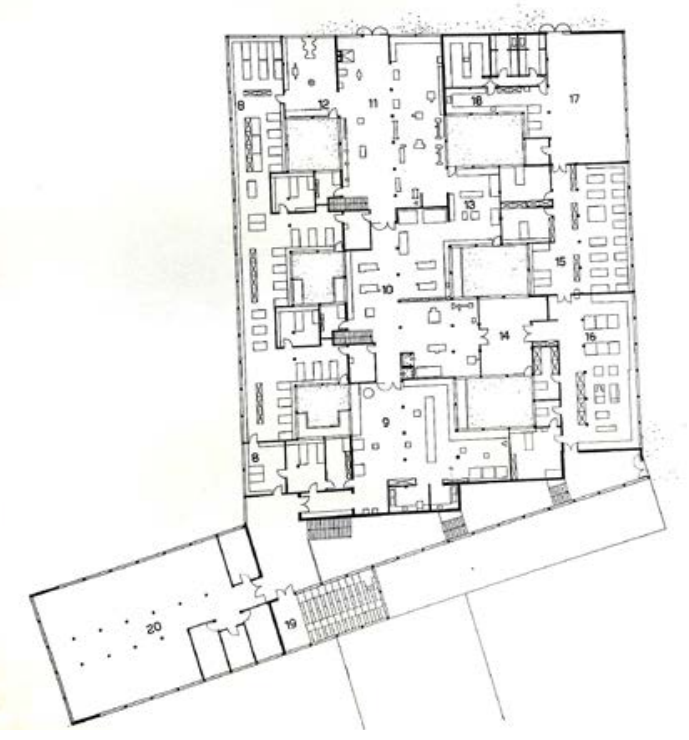

\section{2 figura}

\subsection{1 desarrollo final Zurich}

En el otoño de 1952, la dirección del HICOG les admite un pago anticipado de una sola vez en la cantidad de 75.000 marcos, a Bill se le encargó de desarrollar el proyecto de construcción de inmediato. Voltz trasladó su trabajo de Ulm a Zurich, a el taller privado de Bill, donde con René Haubensak y Edwin Walder se ocuparía de seguir dibujando. El 5 de Mayo de 1953, después de más de medio año, se presentó la solicitud oficial de planificación en Ulm, que contiene un plan de sitio (1:500), así como diez planos del edificio (1:100).

El mapa te da una visión general de todo el conjunto planificado, aunque ya se había decidido desarrollar sólo una parte en el proyecto de ejecución. Esta incluye toda la zona central con las instalaciones escolares, talleres, administración y zonas comunes. Todos los edificios de viviendas con la excepción del de la puerta de entrada, el taller y una de las torres de viviendas desaparecen.

Bajo la dirección de Fritz Pfeil, que estudió con Bill en la Bauhaus, el 8 de septiembre 1953 empezaron a levantar los edificios, pero sin todas las decisiones tomadas. Un mes antes se abrió en la ciudad el primer curso básico. Además de las clases se les hizo a los alumnos involucrarse en el proyecto dibujando los planos de detalle con ayuda de los directores de obra. En octubre se escavaron las cimentaciones y se empezó a armar. Los trabajos se vieron interrumpidos por un duro invierno que duró mucho. La fiesta de cubrir aguas tuvo lugar, sin embargo, fue el 5 julio 1954. Pasó el siguiente medio año hasta que estuvieron montadas las aulas de trabajo en la zona de talleres y en el ala de la escuela. Así se pudo empezar el curso básico para el segundo año en curso, en el cual a principios de enero de 1955 entraron 30 nuevos estudiantes, en la Hfg del Kuhberg. Sin duda se adhirieron las circunstancias financieras fundamentales a eso, que las medidas constructivas se tuvieron que limitar a lo completamente necesario. El mismo Bill acentuó en un comentario posterior que construir en estas circunstancias se ordenaba en relación a los medios económicos y de utilidad. Y sigue: "más barato y más primitivo no puede ser, se había llegado a estar absolutamente por debajo del límite de lo posible. Lo único divertido, que me quedaba como arquitecto era la disposición de las construcciones en el sitio, la armonización de las funciones internas de las partes del edificio, la lógica sistemática de la construcción primitiva, para ello la elección de sólidos y baratos materiales, que en su naturaleza mantuvieran la calidad y así se burlaran de los precarios medios aportando su belleza pura. Esta 

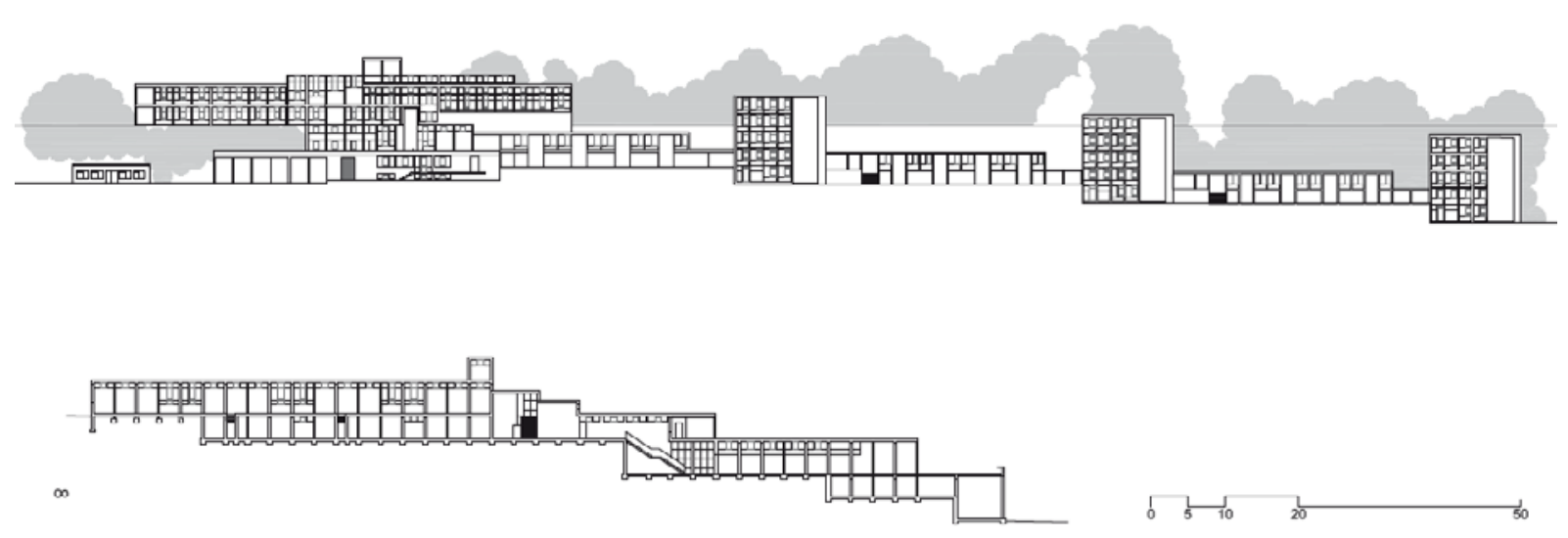

precariedad, escasamente conocida, no se hubiese dado si hubiera existido otra opción. Para el dinero que teníamos a nuestra disposición, solo se hubiera podido construir hoy sólo una casa de campo."<Max bill, vom bauhaus bis ulm 1976 s18-19>

La actitud pragmática también la habían tomado los arquitectos Alison y Peter Smithson de la la HfG.

Así escriberon los protagonistas del nuevo Brutalismo en su biografía profesional titulado "sin retórica" que los edificios en Ulm por su ligereza, su naturalidad y normalidad, se entendían por si solos". $<1$ Smithson: Without Rbetoríc, 1976. Zit iert nach der ljbersetzung ven Sranislausvon Moos in: Werk/ Archilhese: Januar 1977. 5.11. vergleiche dazu auch: Hamilton:Not quite orcñíteaure. U-L-M soeus Hf G. 17. Iuli 1958.> 'En este sentido, Stanislaus von Moos ha subrayado en uno de sus primeros artículos sobre Bill como arquitecto que la simple forma de los edificios no sólo es una imagen externa, sino tiene que ver también con la disposición interna que habla del método de proyecto:

"La 'normalidad de esta arquitectura incómoda. En esta "normalidad", se transluce una gran actualidad. El era un arquitecto adelantado a su tiempo: adelantado era hacer lo más sencillo, sin que la pobreza afectara a la limpieza del diseño»<

Stanislaus von moos: Bemerkung über Max Bill als Architekt, Nov/Dez 1978 s.81>

Como tal, forma parte del proceso de diseño de mBills que desde el exterior, el hecho inevitable desarrolla una virtud formal interior y así inextricablemente entrelazado con la Pragmátismo formal. De esta manera, las necesidades funcionales reciben una justificación formal. Se puede hasta ese momento se puede hablar con toda la razón del formalismo de Bill, siempre y cuando uno entiende los Temas formales no como el exterior estilístico o alegórico si no como los medios propios necesarios. La diferenciación funcional en este sentido tendría Sentido, por tanto, una sustancia para enlazar con el sentido puramente estético. En este último caso, además de la mencionada disposición mBill de volúmenes y espacios están también los procedimientos que se refieren a la relación entre las partes heterogéneos y el conjunto.

El orden de los volúmenes

La uniformidad, el diseño uniforme de los edificios, especialmente visible en las zonas comunitarias y en la parte de aulas estaba dibujada ya en los proyectos anteriores. Es finalmente en este sentido realizada la construcción, los elementos constructivos para los diferentes de tamaños de volúmenes 


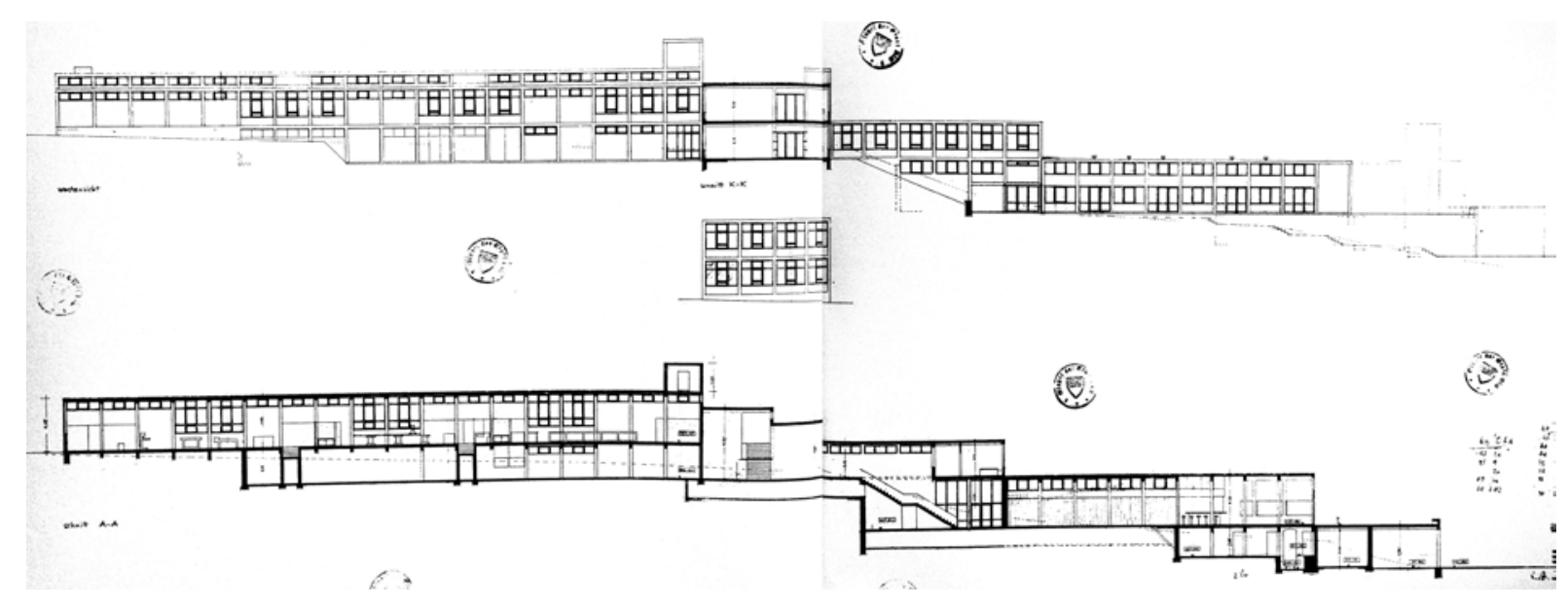

constructivos se combinan según los requisitos, como tatamis en la casa tradicional japonesa. En particular, esta combinatoria se utiliza de manera especial en la parte de talleres, donde hay una malla de rectángulos de gran tamaño, los módulos se han dispuesto de manera que forman seis patios pequeños interiores

De esta manera se construyen todos los cuerpos. Los elementos principales constructivos siguen la regla de $6 \times 6 \mathrm{~m}$. Consta de cuatro pilares y dos vigas en la dirección principal de la carga. Sobre las vigas reposa una construcción secundaria de techo, que consta de elementos de hormigón

prefabricados. La altura de la luz del armazón se eleva desde el suelo hasta la parte de abajo del canto inferior de la viga, que mantiene el módulo de 3 metros.

Como siempre también al combinar estas unidades unas con otras, no se puede eludir que unas con su parte ancha y otras con su parta larga quedan embebidas en el plano de fachada. La fachadas forzosamente tienen que dividirse por pilares que están separados una vez tres y a continuación 6 y así. Realmente las fachadas de la zona central son todas uniformes, la distancia entre pilares son siempre tres metros. Esto quiere decir que algo no se da por hecho: se tienen que encontrar de los pilares construidos algunos, que bajo la estructura de cargas sean innecesarios.

Para alcanzar este resultado, tuvo bill que superponer un segundo orden sobre la malla constitutiva de volúmenes. Esta segundo orden es únicamente válido para el ámbito de la fachada y rompe la malla principal en estos puntos.

Bill rompe la malla principal por una decisión pragmática: y esto es para conseguir un sistema regular de fachada que permita, con los mismos elementos, definirlas todas. Esta aclaración es suficiente en la mayoría de los sitios hasta que donde los volúmenes en limitan un espacio interior y por lo tanto no hay que construir fachada, paredes de división que son más simples a veces tapiadas con bloque de hormigón y otras disfrazadas de madera. Pero también en estos puntos se queda la estructura de pilares intacta. Se objeta que para ello hay que encontrar un motivo. Esta concesión, se dibuja en la concatenación de determinadas decisiones de comportamiento de la forma. Para cada problema hay que encontrar un solución específica, desarralló bill una única regla para la manipulación estructural de los volúmenes, por lo cual diferentes problemas que se resolvía de un solo golpe.<hay en el interior de toda la construcción sólo cinco situacione, donde la estructura de pilares exterior no se quedan 


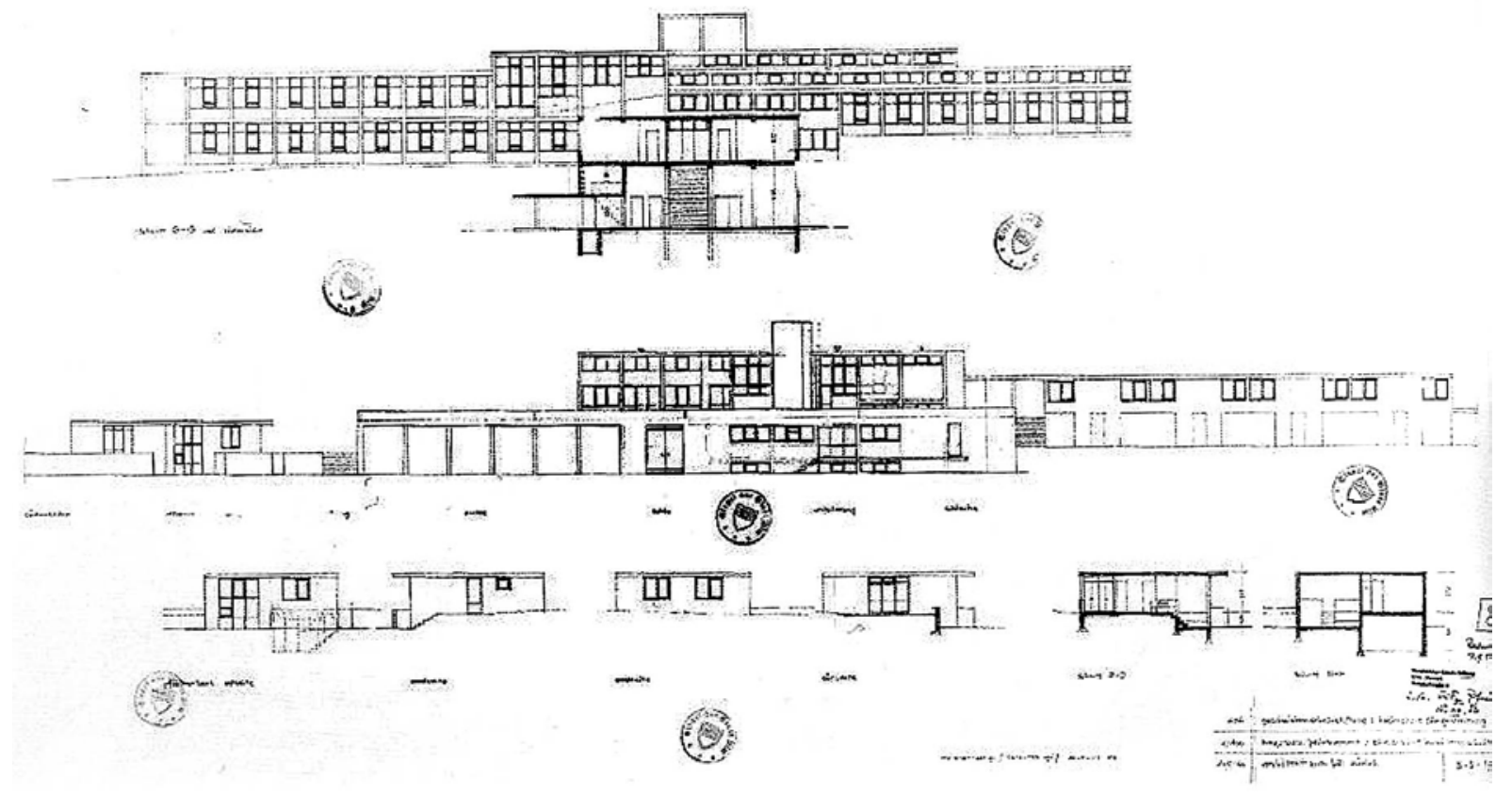


intactas en algunas cajas de uso. Estas se encuentran todas en la zona central alta, las así llamadas "dientes de sierra". Para esta aparente incongruencia se pueden dar dos situaciones. en algunas que en el proyecto inicial aparecían reforzadas con paredes de hormigón, cuando uno lo mira se da cuenta de que por motivos constructivos no eran necesarias, se han quitado durante la construcción pero no se han cambiado lo planos de forma correcta. Y el otro se pueden aclarar estas incongruencias en las uniones espaciales de los dientes de sierra y en la parte alta de la entrada principal>

La construcción del HfG consta para ello de una cantidad de volúmenes, que a través de su invulnerable unión sucumben a un estatus autónomo. Su uniformidad no se corresponde con la construcción interior, sino que sigue a la superposición de la estructura secundaria. Esto permite divergentes posibilidades de la forma: dentro permite una completa libertad en la ordenación de la planta al mismo tiempo que mantiene uniformidad en el exterior. Siendo purista, entonces -perdón por la paradoja- es esto una inversión suplementaria y no una reducción.

Junto a la gestaltung de las cajas se puede por lo tanto continuar la diferenciación inicial, esto se comporta, en un primer momento, en sentido contrario no tiene un análisis continuado hasta la meta, cuando ahora hay muchas en el análisis de la construcción.

Para el relleno de los marcos de fachada con bloques de hormigón desarrolló bill un esquema geométrico, por lo cual la apertura cuadrada de tres metros en el lado largo se divide en cuatro partes vistas horizontales y tres verticales. Cada celda se asienta en un antepecho y elemento de ventana juntos. Este coge siempre un conjunto de ancho de una celda y proporciones que cambian de lado de uno 1:4 y respectivamente 3:4. Los cantos de todos los elementos de hormigón se achaflanan y dan como resultado en la fachada de la parte superior un fina red en fuga. Los elementos grandes de fachada experimentan las siguientes subdivisiones, basadas en un triángulo pitagórico $a 2+b 2=c 2$. Reciben de forma análoga las hojas de la ventana comportamientos de lado las más grandes 1:2 las pequeñas 3:4. por elementos de ventana una ventana de ventilación dimensionada como la mitad del grande que el ala, lo que el comportamiento de lado es tumbada 3:8.

Traducido a otra escala son los principios generales de la división de la fachada, los que se dan en toda la construcción de la HfG, igual, donde se establece otro sistema de construcción. En todos los casos se separan por una fina malla de líneas rehundidas que se soportan sobre un entramado de hormigón. 

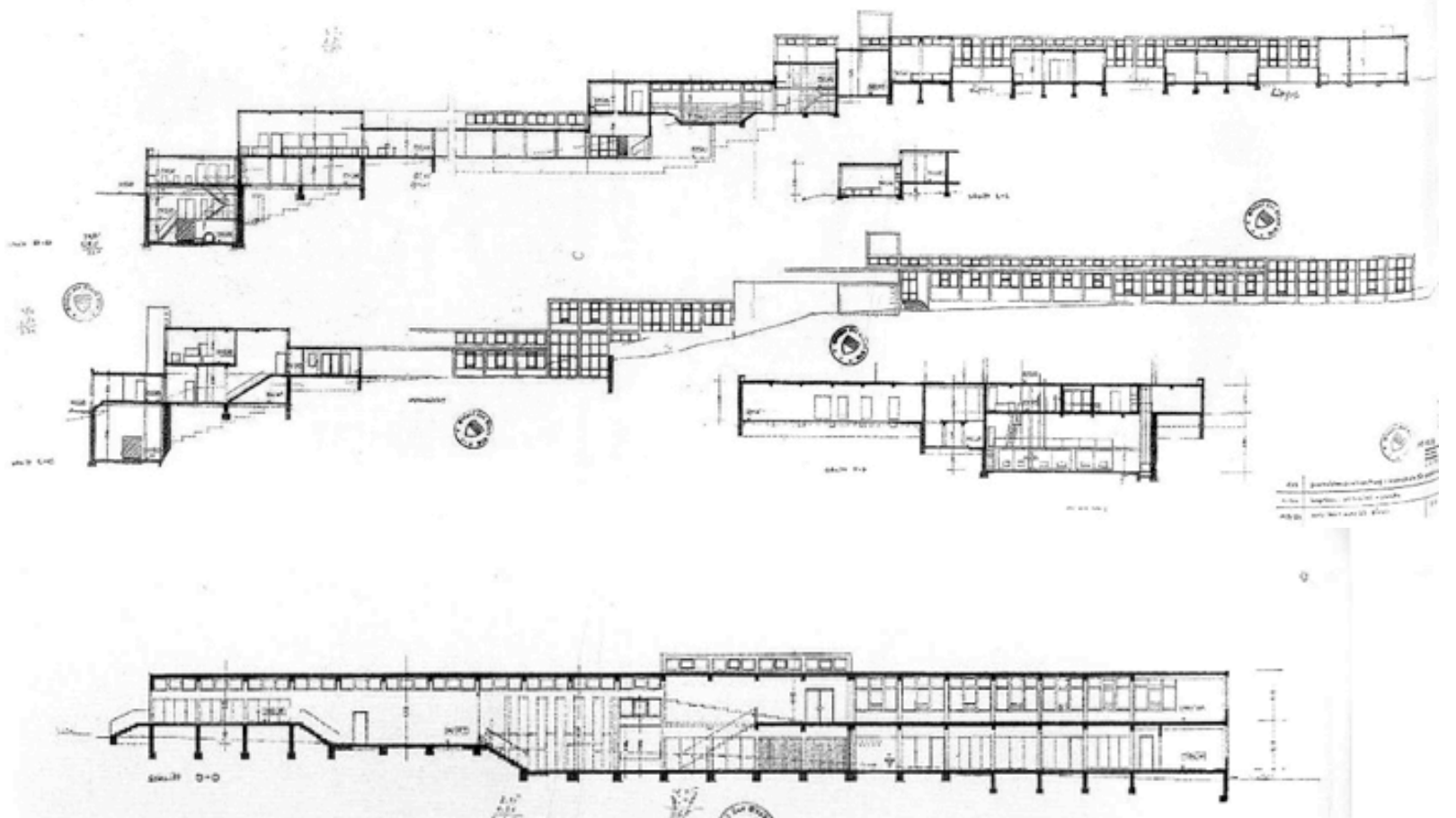

(9)
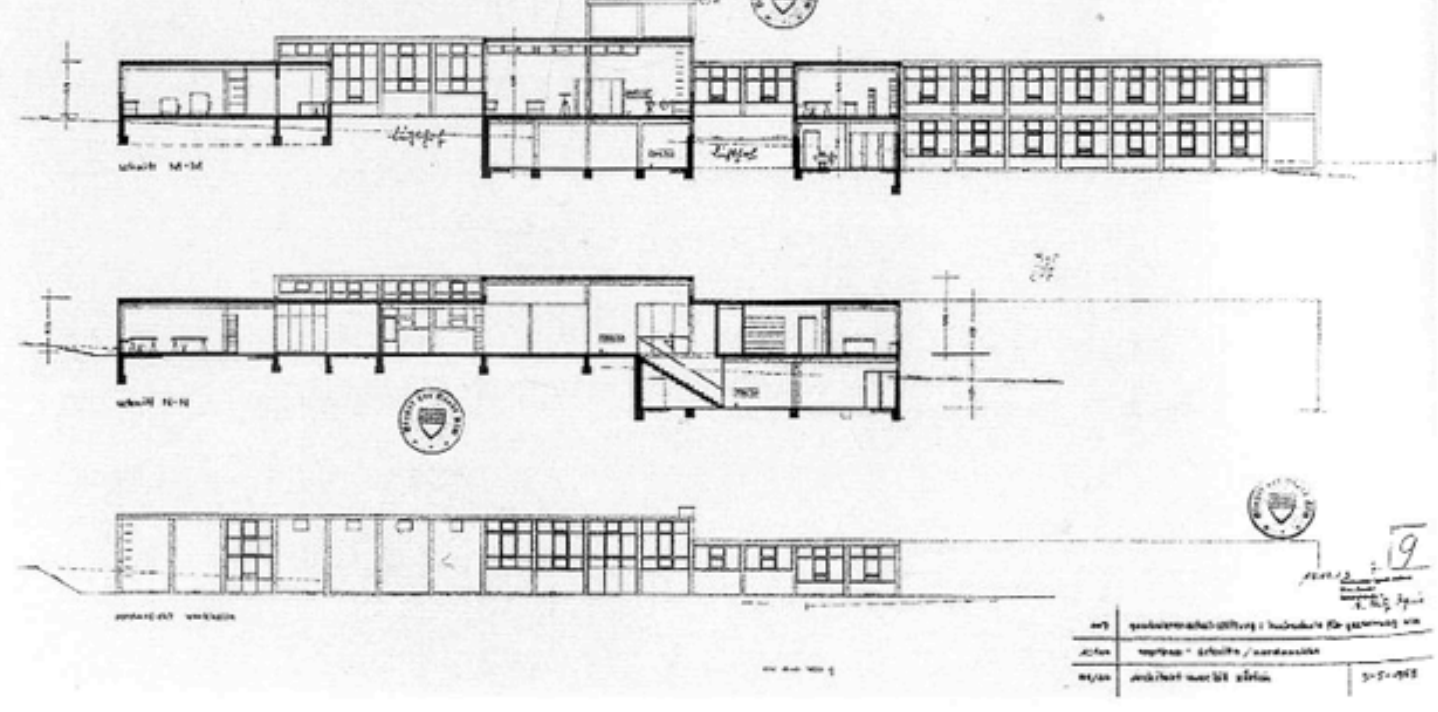
Así sigue válido para el entramado de ventana y elementos de antepecho, que toman toda la luz entre dos partes que cargan.

\subsection{1 desarrollo del proyecto}

sobre la primera propuesta de Aicher para la HfG:

...dijo efusivamente a mí que las casamatas podrían funcionar como talleres e incluso podrían tener una pequeña mesa para los excursionistas, como si fuera una expansión de la cafetería. el tenía pensado también en la propuesta construir una torre de vidrio en uno de los cubos de la muralla. "El edificio de la escuela, así como el embarque deben Exteriormente el

El espíritu escolar respirar, el espíritu de apertura al mundo, la libertad y simple

Belleza, no el de la coacción y el miedo

max bill dice:

En marzo de 1950, los dos habían acordado entonces, sin embargo ; junto a la fortaleza debe surgir un nuevo edificio. Hasta la finalización de las instalaciones

caso de que los grupos de enseñanza están trabajando en el antiguo Fort . Sin embargo, este plan no puede materializarse debido a que la Fundación sólo una parte del sitio destinada recibido. La parte en la que se encontraba la fortaleza ella fue negada. La ciudad de Ulm dio sino una suroeste mayor. Localicé este pedazo de tierra .

Después de la concesión de fondos por parte de los americanos, por los donantes públicos y privados, se estableció en agosto de 1953, la primera fase de la construcción

la HfG comenzó . El 5 de julio En 1954 se celebra la ceremonia de cubrir aguas.

En agosto de 1954, los primeros talleres se crearon .

En diciembre de 1954, la administración se trasladó.

Desde principios de 1955 las lecciones se celebraron en las instalaciones terminadas provisionalmente en la parte superior Kuhberg . En octubre de 1955, se completó la primera fase, el segundo, dos estudiantes más torres residenciales y una línea de estudio, no se pudo iniciar por falta de dinero Arquitecto Fritz pfleil coordinó los trabajos de construcción. Arquitecto Fritz Flecha coordinó los trabajos de construcción. Fue el responsable de la Programación de los materiales donados y son responsables de el trabajo de la oficina de construcción de los estudiantes. Bill tenía la idea de que la escuela debe ser construido por los estudiantes acerca de sus planes, esencialmente, 
En marzo de 1950, expresado ya En una carta a Walter Gropius, se basó en el método pedagógico de Frank Lloyd Wright, cuya pupila

Desde 1937, el "Campamento de Invierno Taliesin West ", cerca de Phoenix / Arizona incluso construido.

“"'Estoy totalmente de acuerdo que sólo el trabajo práctico para el requisito departamento de arquitectura debe ser, pero no necesariamente para que lleve a la escuela, porque la propia escuela será una obra de construcción . los edificios están todavía no que la propia expansión se deben construir. Tiene que haber algo del espíritu ( en otros aspectos peligrosos ) Frank Lloyd Wright con en los jóvenes piensan que pueden sentarse en un mundo terminado.

también con el uso de los estudiantes es, por supuesto se ahorraron costos. La oficina de construcción bajo la dirección de Fred Hochstrasser, arquitecto de formación que quería estudiar en la HfG, fue exclusivamente ocupada por Los estudiantes. Esto funcionó desde el otoño de 1954 bajo la dirección de Walter Zeischegg en la adecuación interior del edificio. El costo de la construcción todo el sistema fue extremadamente bajo, que ascendió a 60 por DM m espacio cerrado. En comparación, el estudio de Bill en Zurich / Höngg, Construido en 1932-1933, a pesar de los costos de construcción económica 67,40 sfr por $\mathrm{m}$.

El esqueleto, todas las superficies externas y muchas paredes interiores fueron expuestos hormigón vertido en un encofrado liso. Bill tenía para superficies lo externo una Agua rechazan la pintura estaba previsto, pero que hasta el día de hoy no ha sido instalado. Como el hierro para techos reforzado pómez se colocaron láminas de hormigón del muro. Las casas de estudiantes y profesores se utilizó el "Kluge-techo para el nombre de su inventor Ulmer, Dr. Heinz Kluge. Los tapajuntas son galvanizados. Las ventanas eran de madera natural, pintadas y equipadas con rieles de aleación ligera.

El sistema consta de cinco edificios contiguos HFG

y el fuera de mentira tres casas adosadas para los profesores. Los edificios escolares se encuentran en una longitud total de unos 400 metros, orientado hacia el noroeste y noreste, alternativamente, a tres niveles diferentes a la "Oberer Kuhberg". Además de los estudiantes de cinco pisos edificios torre residenciales no tienen más de dos plantas. En los departamentos individuales extractos fueron desde 1954 ocupa el siguiente: El 54 × 54El tracto de medida 54 ×54 m al norte ubicado en el lado oeste de las oficinas longitudinales del Departamento "Produktforrn", en medio de la escayola talleres, 
madera, metal, metal fino, plásticos, pintura y de superficie y Lateral de los espacios de trabajo del departamento de "comunicación visual" patios tranquilos dentro del edificio y claraboyas proporcionan el ruido necesario y una iluminación adecuada. En el sótano de la construcción son trasteros. Cultivado en el taller en un ángulo obtuso, proyectando un tratado con las dimensiones de $24 \times 15 \mathrm{~m}$. al sudoeste Contenía en el piso superior de los departamentos »Arquitectura, - . y" Urbanismo "y la sala de rector en la parte oriental de la biblioteca eran y el Departamento de Información El siguiente edificio perpendicularmente adjunta contenida en la primera biblioteca de piso, la administración y la secretaría y en el sótano. la luz del pasillo. avanzado hacia el oeste, es una extensión de (18 × 15 $\mathrm{m})$, en el que se acomoda el espacio comunitario. Con acceso a una amplia terraza estaban aquí en el auditorio lado suroeste y cafetería, cocina y lavandería cerradas al este de. En la terraza y los espacios comunes es (todavía) el aparato de suministro de toda la planta: la entrega, sala de profesores, actualizar, armario de cableado, escorias y depósito de carbón. El Oriente en la línea de estudio adjunto (48 $\mathrm{m}$ de largo) se compone de ocho unidades residenciales. Tu aguas arriba es un pasillo cubierto que conduce a la torre residencial.

Mientras que Bill había proporcionado en su primer proyecto describe la separación de la inversión en "Instituto de la forma del producto" y los edificios escolares, las áreas se fusionaron en el diseño ejecutado. Bill ordenó cada función de un edificio; estos volúmenes no están unidos de forma aditiva, sino que se entrelazan y superponen. La planta de manera refleja el concepto educativo, cuyo objetivo era la integración de la enseñanza y la investigación, los diversos departamentos, las áreas de trabajo teórico y práctico y la esfera pública y privada.

„»Der strukturelle aufbau der schule ist ähnlich einem freien zusammenschluß sich ergänzender institute, studios und labors mit den dazugehörigen werkstätten zu gemeinsamer arbeit.«195(“El diseño estructural de la escuela es como una libre asociación instituciones complementarias, estudios y laboratorios asociados a la talleres de trabajo en conjunto)

El mismo principio: la disección del edificio de la escuela en, funciones individuales diferentes, pero las alas contiguos de construcción, también persiguieron Walter Gropius en el diseño del edificio Bauhaus Dessau (1925-1926). El complejo incluye cinco estructuras de los edificios en las cinco funciones: estudios residenciales, talleres, espacios de la escuela de formación profesional, oficinas de arquitectura y administrativas y áreas comunes. Incluso Gropius enfatizó arquitectónicamente el contexto de las áreas, por volúmenes di e fusionados juntos. Sin embargo, la asignación de partes 


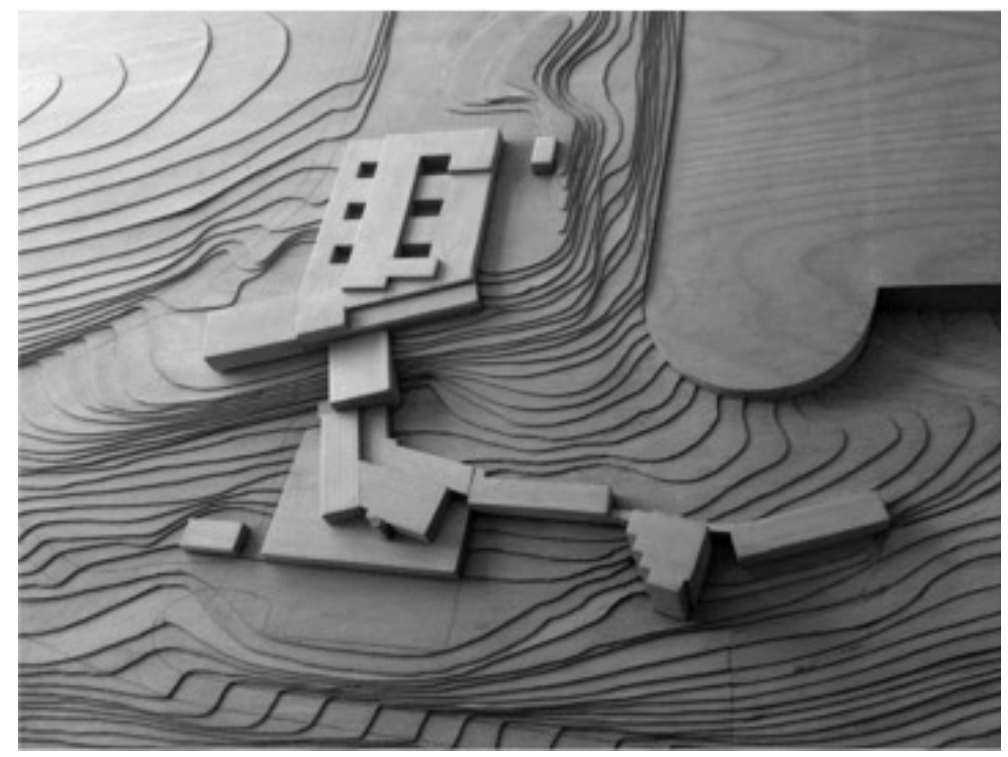

siguió esquemáticamente - que siempre se unen en ángulo recto. El sistema parece sólido porque los edificios son por lo general tres o cuatro plantas.

construimos esta casa de estudios con un mínimo de esfuerzo, es decir, queremos salvar dependiente. Podemos hacer lo que sólo necesitaba ser realizado si evitamos lo superfluo y nos limitamos a los todo lo esencial, que es el significado de esta construcción, que podría llamarse casi primitivo, si dentro de sus posibilidades aún no un alto nivel de la artesanía identificaría. Así que el problema es simple, eficiente, sólida - que tenemos que resolver de una manera intentado que participen todos ellos superado por los costes adicionales para las consideraciones y cuidados tenía que ser bill „la diversidad que todavía forma una unidad ... el paralelo, se cruzan ... y al lado de la plaza en toda su fuerza ... los justos, de no ser la relatividad nublada ... todas estas cosas que parecen no tener nada que ver con las necesidades diarias de las personas están siendo de la mayor importancia en el momento en que se convierten en arte. estas fuerzas, con los que interactuamos, son las fuerzas fundamentales que subyacen a toda institución humana, la reconocibles existen cada uno de nosotros para" bill

El puritanismo casi exagerar de la arquitectura parece educar a los monjes de la era tecnológica. Gris monocromo dentro y fuera de los muros de hormigón en bruto se ponen juntos - un juego modular de los niños gigantes. Una casamata de la cultura - un sanatorio de la técnica

"Dieter Hoffmann-Axthelm cuenta el lado de la HfG Schneider-Eslebens Gran garaje en Düsseldorf (195 1) y la Sala de Conciertos de Baumgarten de la Academia de Música de Berlín (1952) a los "presentables" edificios alemanes

Arquitectura de los años cincuenta. Él ve en su floración tardía una generación arquitectura que "durante los años del fascismo sobre la construcción se habían tomado ". Hoffmann-Axthelm honra el juego de "rigor constructivo - y" más flexible Forrn.

Tras dar la bienvenida a los invitados y los discursos, siguió la representación de una composición de Vladimir Vogel((Moscú, 1896-Zurich, 1984) Compositor suizo de origen ruso. Discípulo en Moscú de Skriabin y, desde 1918, de Busoni en Berlín, abandonó Alemania en 1933, estableciéndose en Suiza un año más tarde. De su producción, dominada por la importancia del ritmo marcado por los instrumentos de percusión, destacan el oratorio Thyl Claes (1937-1945), la composición Siete aspectos 


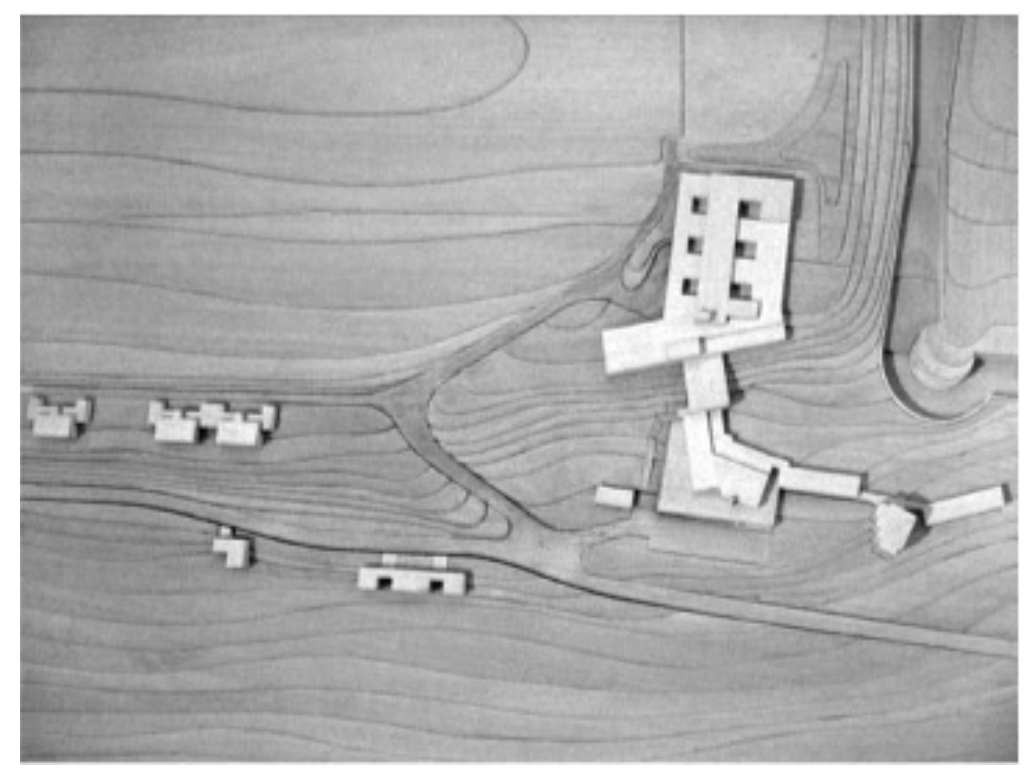

de una serie dodecafónica (1950), la cantata surrealista Arpiade (1954), el Concierto para violonchelo (1954) y las Meditaciones sobre las máscaras de Modigliani (1961)).

después del recorrido por la arquitectura se inauguró la exposición de los trabajos de los departamentos. Una merienda terminó la parte oficial de la ceremonia de apertura.

Además Inge Aicher-Scholl y Max Bill, que se presentaban como miembros de la escuela en sus discursos y Walter Gropius, que aparecían como garante moral, formularon a los emisarios de las instituciones del Estado sus peticiones y esperanzas sobre la escuela. La primera linea de la vida política no estaban como ponentes. Presidente Heuss, había pedido un ex hombre Werkbund desesperadamente hablar, así como el Ministro Federal de Economía Ludwig Erhard.

Si concurrieron: el alcalde de Ulm Pfizer, el representante de la Ministra de Cultura de BadenWürttemberg, Christmann, el secretario por el Ministerio Federal de Economía Hirsch y el Presidente del Comité de Asuntos Culturales de Baden-Wuerttemberg.

enumerando los clientes más importantes y dio la bienvenida: representantes de los ministerios federales y estatales, el parlamento federal y estatal, oficinas consulares extranjeras, el gobierno provincial, ciudades y distritos del país, universidades, academias en el país y en el extranjero, el Consejo Alemán de Diseño y el grupo de trabajo para dar forma , la Federación de la Industria Alemana y Economía. Pfizer expresó su esperanza de que "los hombres de la economía" pueden venir a la universidad en estrecha relación, ya que los objetivos de la la HfG significaron beneficios inmediatos para la economía. 


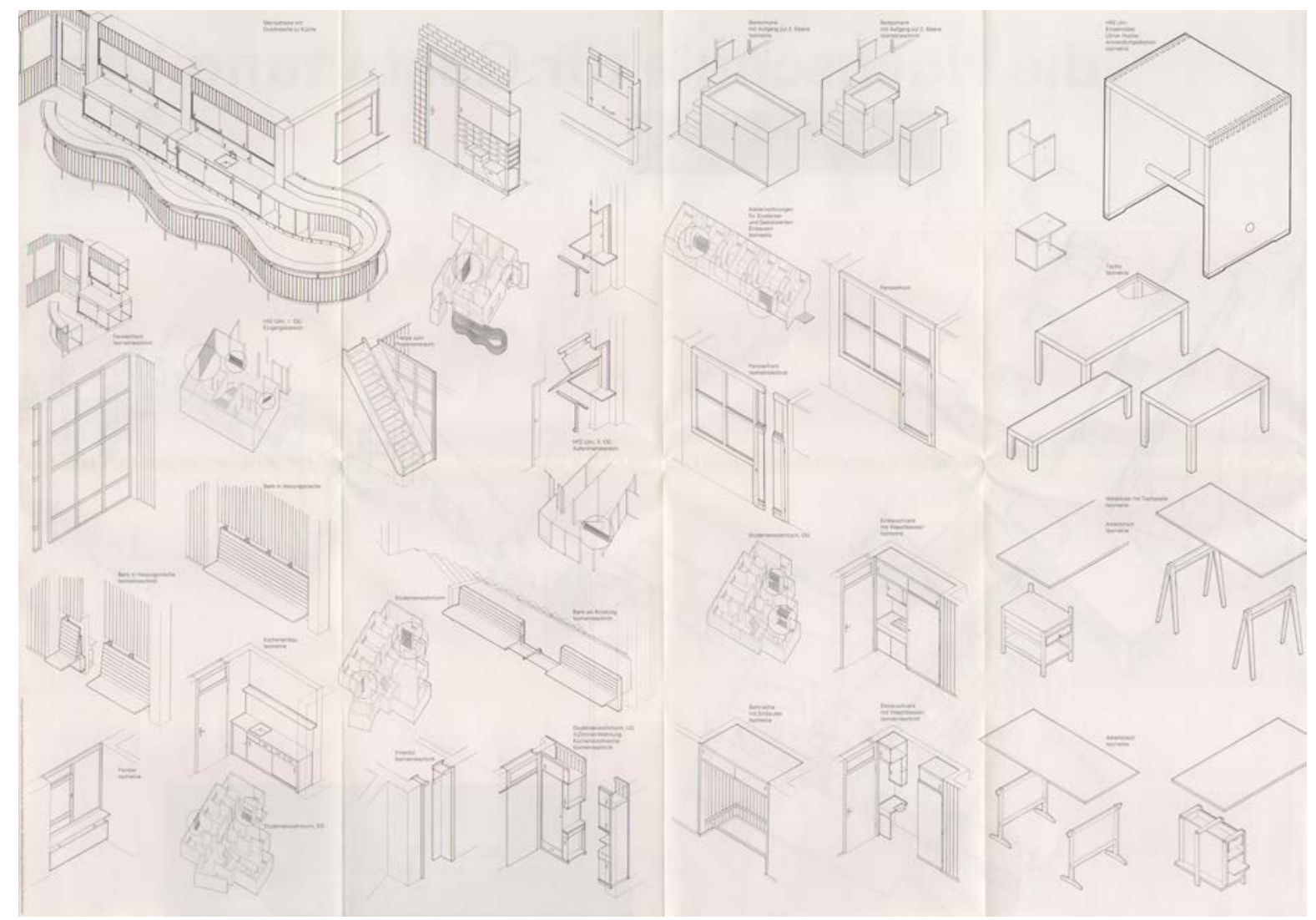




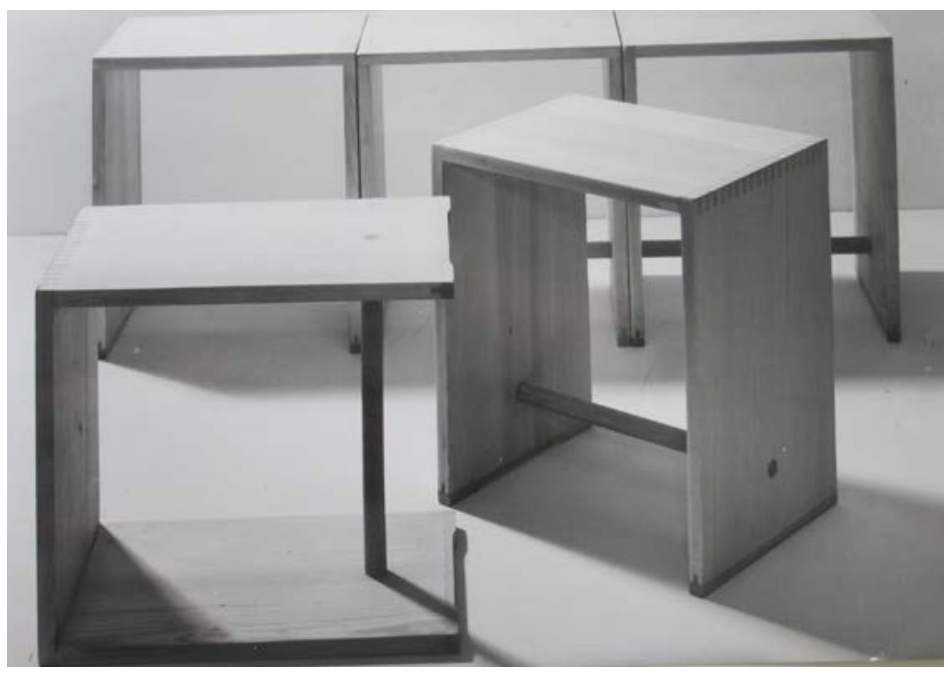

2.2.2 la construcción del edificio

\subsection{3 las otras arquitecturas}

Hans Gugelot

Walter Zeischegg 

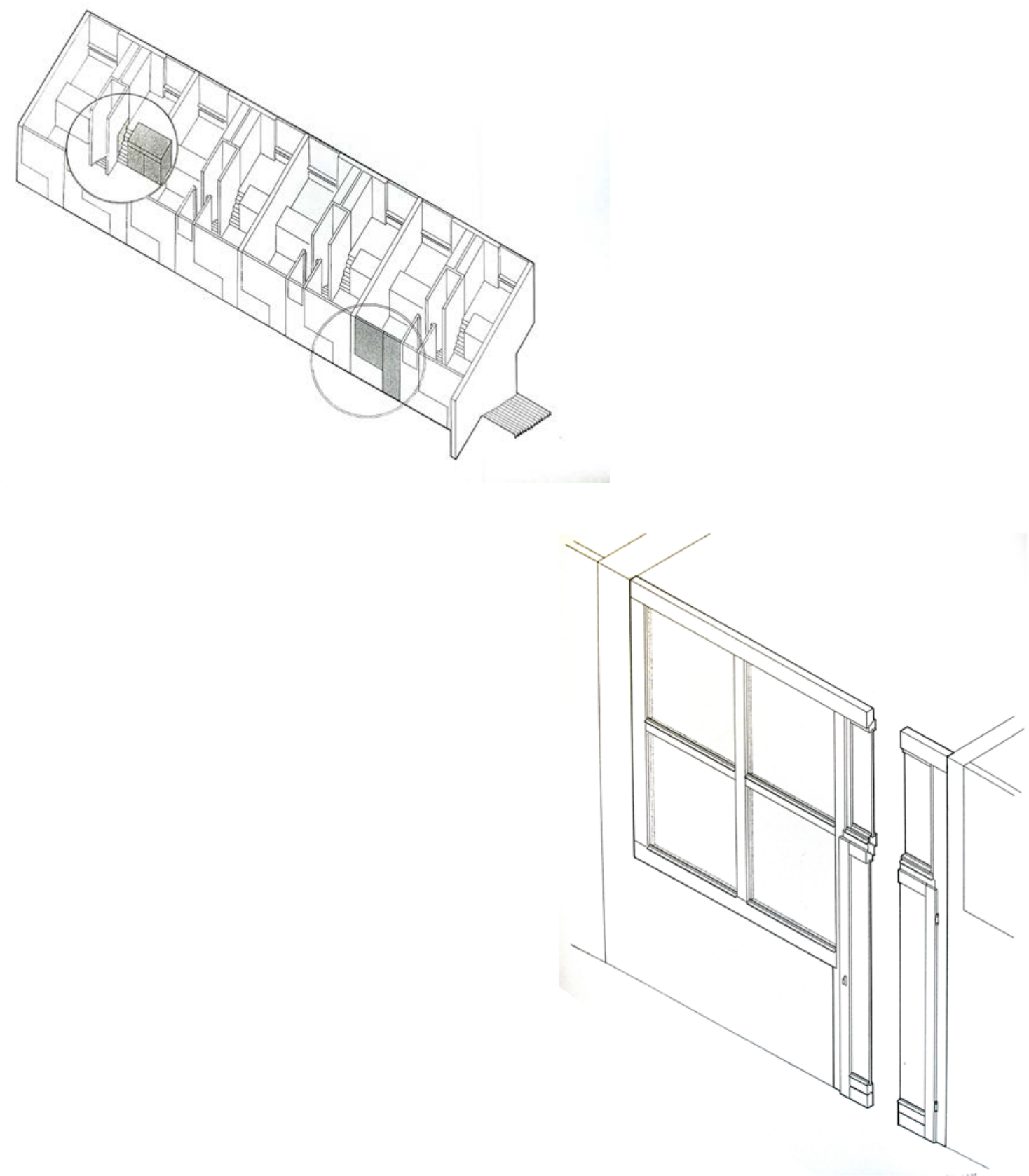

>3 construcción emotiva (infinity-finite 


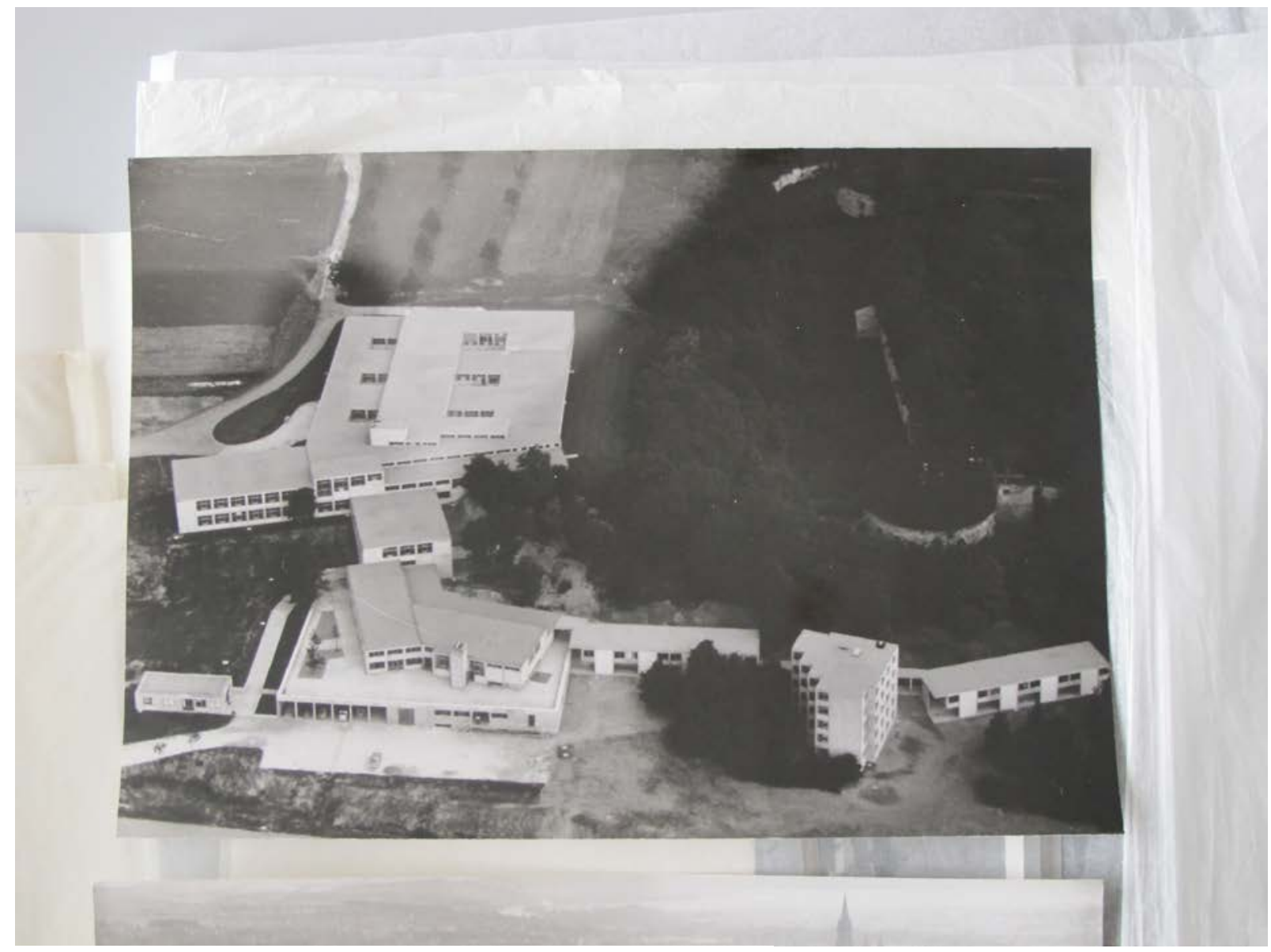

foto aérea HfG desde el sur. 02.08.1955. Ernst Hahn 


\section{$>3$ construcción emotiva (infinity-finite}

El capítulo analiza la formalización espacial del edificio como una configuración puramente emotiva a pesar de su rigor constructivo. La lejanía o proximidad de la infinitud, la limitación sin límites exactos.

En el fondo de este capítulo está el interés por la matemática que Bill maneja en esos años y su relación con la superposición de espacios, las relaciones de tensión, bucles, etc. Su atención a la relación hombre-espacio.

En la figura está el análisis espacial de la realidad del edificio, la continuidad, los recorridos, compacidad, conectividad y metricidad.

\section{1 fondo (el espacio como anhelo}

Desde la experiencia de sus otras arquitecturas, viviendas de pequeña escala, pabellones expositivos, Max Bill anhela la gran escala. Ha hecho el concurso de "Zúrich: la ciudad jardín junto al lago"1 (f1, los concursos para los pabellones de la Exposición internacional de París del año 1937(f2 o el Pabellón suizo de la Exposición universal de Nueva York el año 1939 (f3. La Hochschule für Gestaltung le ofrece la oportunidad de pensar en la articulación de espacios en relación al hombre. En el posicionamiento extensivo sobre el terreno. En el papel de la matemática en este tipo de operaciones. Bill estaba muy interesado en el concepto de Kontinuität desde el año 1935, cuando hace su primera cinta de Moebius². Por otro lado según Stanislaus von Moos: "La razón de ser de la forma conceptual en Bill es estética: la impulsión creativa de la intuición artística, y en ningún caso la forma sigue a la función.”3

Bill está más allá de cualquier funcionalismo, ni siquiera por la exposición die gute Form se le ha reprochado que haya sido una vuelta atrás, hacia el utilitarismo del neue Sachlichkeit, que sea una vuelta a lo sin nada de Mies, a la exactitud y el amor al orden. Estaba en un momento de pensamiento donde el arte era igual que la ciencia, y la precisión se consideraba un fin en sí mismo. En palabras del propio Max Bill "el razonamiento humano necesita un soporte en el ámbito visual. Este soporte se encuentra a menudo en el arte, incluso para el razonamiento matemático"4.

1 Proyecto de concurso. 1937

2 Unendliche Schleife. 1935-53

3 Max Bill, "De la Surface a' I'Espace, XXe siècle, nr. 2, 1951

4 Artículo introductorio de Stanislaus von Moos "Max Bill: entre arte frío y ciencia cálida". Revista Faces, no15. 1990 


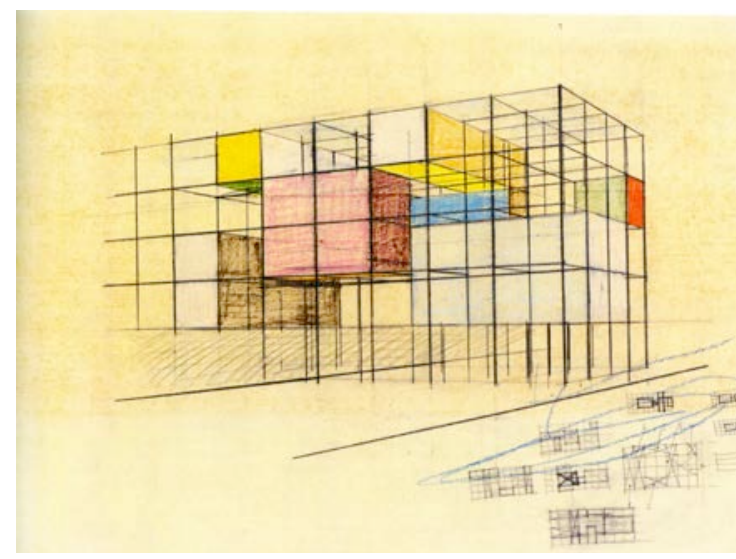

(f2. Pabellón suizo exposición internacional París. 1937

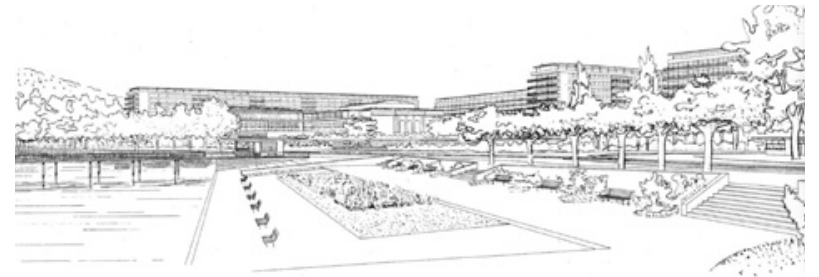

(f1.Zúrich: la ciudad jardín junto al lago. Concurso. 1937

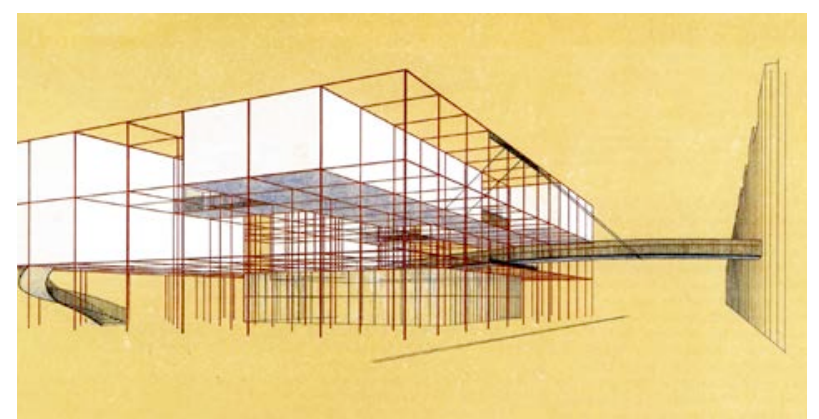

(f3. Pabellón suizo exposición universal Nueva York. 1937

\subsection{1 la nueva relación hombre espacio}

La interpretación psicológica de los deseos individuales no pasa por el conocimiento de la estructura individual del yo, ni por la explicación de su formación, tampoco por la elaboración de actividades compensatorias, sino a la efectiva satisfacción del deseo. Para André Frankin "es una especie de planificación individual de la experiencia que, si se diera el caso, permitiría bosquejar una filosofía de la presencia espacio-temporal en la cual las sensaciones y los sentimientos no dependerían ya de la memoria, sino de la dilatación de todas la virtualidades del ser mediante la multiplicación y la renovación de experiencias, ya no aisladamente colectivas ni aisladamente personales" ${ }^{\prime \prime}$. Demuestra así que la nueva concepción espacio-hombre de la posguerra europea no puede mira más que al futuro, la memoria aparece distorsionada por la guerra. Por tanto el nuevo hombre crecerá atendiendo a las sensaciones que las nuevas experiencia vitales le van proporcionando, desde lo más colectivo a lo puramente individual. Según el pintor Asger Jorn, fundador del Movimiento Cobra y perteneciente a la Comité psicogeográfico de Londres "la situación es el dominio individual y la valoración social del espacio-tiempo, es decir, la variabilidad del comportamiento público del individuo en relación a los demás." ${ }^{6}$ Entendiendo situación como un suceso que se manifiesta en el plano de la vida cotidiana.

\section{. el hombre como dimensión variable (factor dinámico}

La relación que el hombre mantiene con el espacio se fundamenta en los elementos de un proceso que tiene lugar en el propio espacio, en él el otro factor que existe ya, es el hombre entendido según Bill como "el nuevo factor de dimensión varible" . El propio Frederick Kiesler en la descripción del espacio de la Endless House(f4 "La concepción espacial elástica ha de ser capaz de satisfacer de modo óptimo, incluso en una casa pequeña, las aspiraciones sociales más heterogéneas de sus habitantes"7. En relación a esto Kiesler acuña el concepto de la Time-Space-Architectur con el que aludía a la capacidad de modificación del tamaño y forma de los espacios de acuerdo con la función asignada a estos.

\footnotetext{
5 André Frankin. Critique du Non-Avenir. Guy Debord and the Situationist International: Texts and Documents 6 En Guy Debord and the Situationist International: Texts and Documents

7 Frederick Kiesler. Inside the Endless house, Nueva York 1964, pag 566

100 / la arquitectura de la hfg ulm. de la objetividad a la revolución
} 


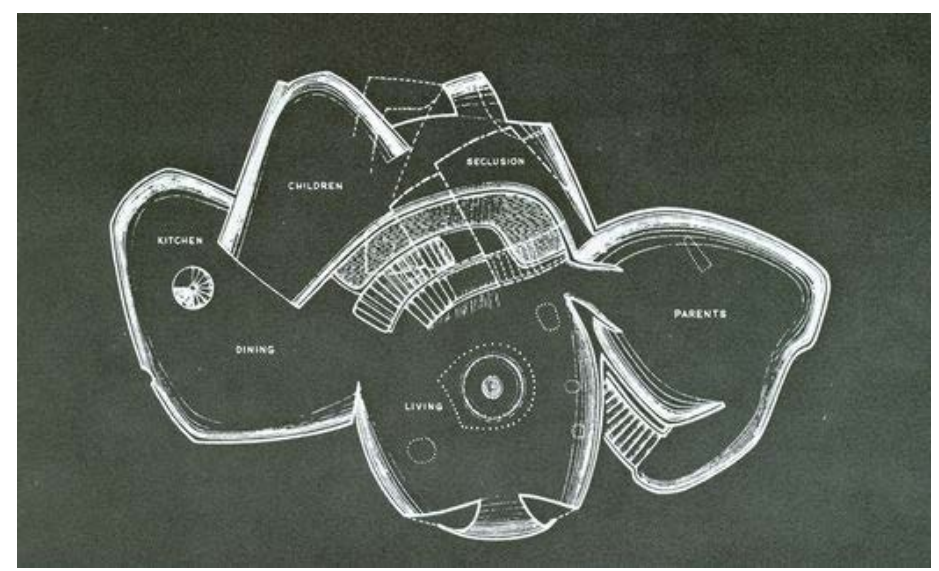

(f4. Frederick Kiesler the Endless House. 1964

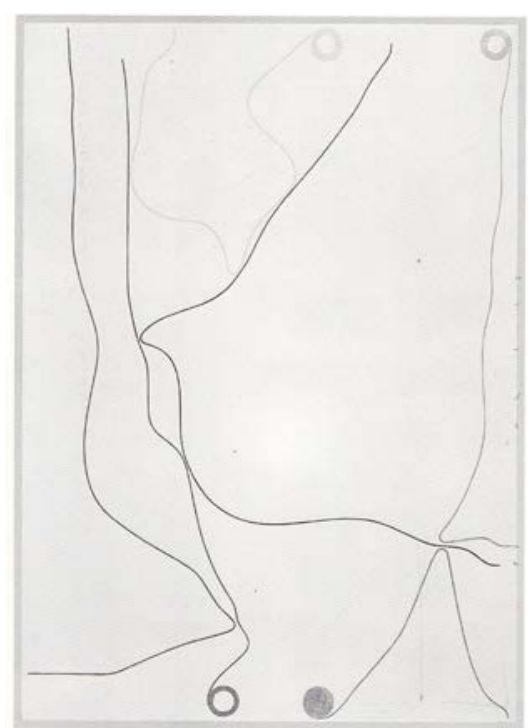

(f5.Max Bill. Sechs gleichlange Linien. 1947

. superposición del espacio real (espacio cambiante por el movimiento del hombre) y el espacio psíquico (estado en el que el hombre se encuentra)

Según Mario Perniola ${ }^{8}$ ha habido una tendencia en la posguerra europea de abandono de lo que se conoce como psicogeografía, que se había iniciado con las derivas surrealistas en el periodo de entreguerras. Es decir se intentaba dejar de lado "el estudio de los efectos precisos que el ambiente geográfico, conscientemente ordenado o no, ejerce directamente sobre el comportamiento afectivo de los individuos"9. Fue Gilles Ivain desde el seno de la internacional letrista, año 1956, el que avanzó, o en realidad puso sobre la mesa algo que había en el ambiente del momento, la hipótesis de una nueva aproximación a lo urbano que tenía que ver con la experiencia perceptiva del espacio. Se llamo psicogeografía y su herramienta fundamental para la investigación es la deriva que la Internacional Situacionista define como "la forma de comportamiento experimental ligada a las condiciones de la sociedad urbana", "la técnica de transito veloz a través de distintos ambientes"10. Claramente la deriva presenta diferencias frente al viaje o el paseo. Atiende a los efectos psicológicos producidos por el contexto urbano. La acumulación de coches o personas, el tránsito rápido o lento, la capacidad de orientación, producen efectos perceptivos sobre el individuo. A mayor velocidad se produce una reducción inevitable del recorrido, a medida que reducimos la velocidad hasta el límite de parada el espacio se elonga, se estira. La deriva presenta un doble aspecto: pasivo y activo" "por un lado, comporta la renuncia a cualesquiera objetivos y metas fijadas de antemano así como el abandono a las solicitaciones del terreno y a los encuentros ocasionales y, por otro lado, implica el dominio y el conocimiento de las variaciones psicológicas." Nada que ver con el deambular surrealista que al final se desarrolla desde la absoluta subjetividad que acaba reflejando las situaciones urbanas desde experiencias tan arbitrarias como el aburrimiento o el interés. 


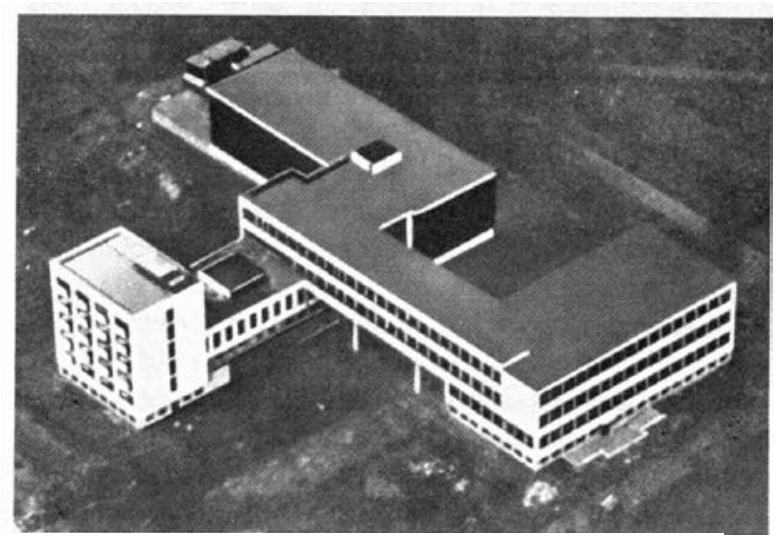

(f1. Vista aérea Bauhaus Dessau, hacia 1927

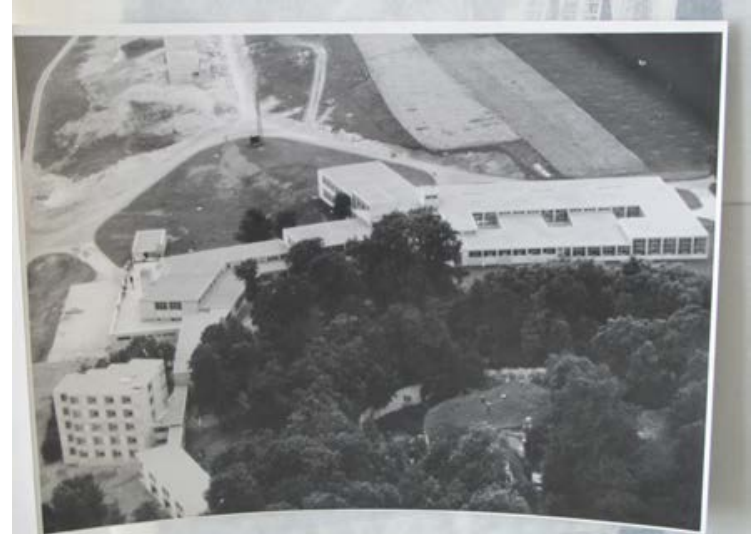

Vista aérea HfG, 1955. Ernst Hahn

Esta forma de transito por el espacio tendría su estructura ambiental más estimulante en el laberinto. Tradicionalmente y desde el punto de vista de la geometría euclidiana se ha asociado con el trazado discontinuo de una espiral(f5, en la que en su aproximación hacia el centro el recorrido aparece afectado por interrupciones que provocan en el individuo desvíos a otros niveles de la espiral que provocan en él una desorientación ${ }^{12}$.

. las imágenes de la memoria y su interacción con el espacio real

Según Bergson en su libro Matière et mémoire ${ }^{13}$ se establece una clasificación de la memoria con la distinción entre el recuerdo-imagen (souve-nir-image), la memoria como un mecanismo de activación de nuestras capacidad de hablar o de retener conocimiento y la memoria como recuerdo puro (souvenir pur) que tiene que ver con la primera vez que ocurre algo y se mantiene ese recuerdo de forma precisa, por ejemplo la primera vez que viajé en coche. Bergson afirma que «la percepción nunca es un simple contacto del espíritu con el objeto presente, sino que está impregnada de recuerdos-imágenes que la completan interpretándola» ${ }^{14}$. Vemos lo que ya hemos visto, entendemos los espacios que ya hemos visitado.

En su aproximación al hecho de Ulm Bill actúa así visitando sus recuerdos-imágenes para adquirir el estado perceptivo suficiente que le permita proponer. Bill desde fuera de la arquitectura, utilizando sus recuerdos imágenes propone una articulación de espacios sobre una topografía dada. Ha vuelto atrás, a su primera impresión del edificio de la Bauhaus(f1 cuando el 20 de abril de 1927 llega a Dessau. El propio Bill escribió años después sobre la primera sensación al bajarse del tren y recorrer la ciudad. Sus edificios grises y antiguos. La gente contemplaba el devenir del tiempo a través de sus pequeñas ventanas y de repente me encontré con sus volúmenes puros, blancos. Era una bocanada de aire fresco. Los volúmenes puros, blancos permanecen en una de las capas de su memoria. La Bauhaus está sobre un lugar casi plano, él se encuentra con un sitio inclinado. Alejado de la ciudad pero con la presencia de una fortificación muy impresionante. "Al visitar el terreno me fije en que el entorno del fuerte era muy bonito y pregunté a quién pertenecía. Me contestaron que a la misma persona que el anterior, pero esa persona ya no existe"15.

\footnotetext{
12 Mario Perniola. Los Situacionistas. 1972. pag 26

13 Henri Bergson. Materia y Memoria. 1896

14 Henri Bergson. Materia y Memoria. 1896

15 Max Bill, documental canal 3 Sat. Max Bill, ein Film von Ernst Scheidegger. 1998

102 / la arquitectura de la hfg ulm. de la objetividad a la revolución
} 

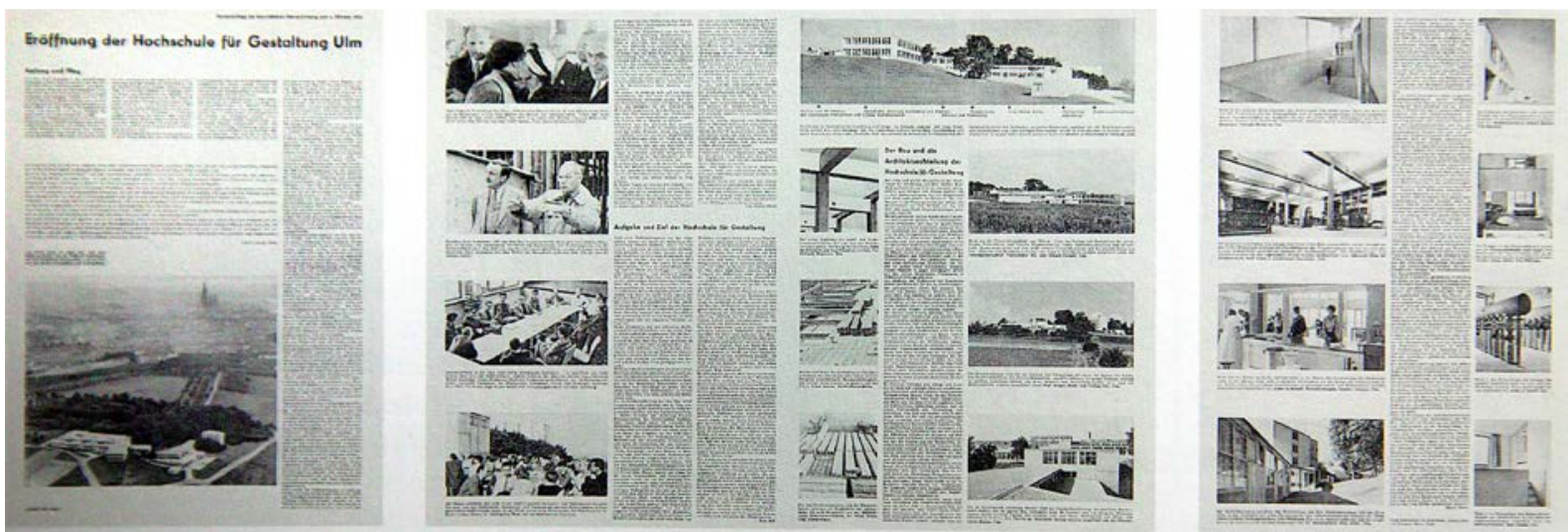

Reseña en la prensa local del día de inauguración de la HfG. 1955

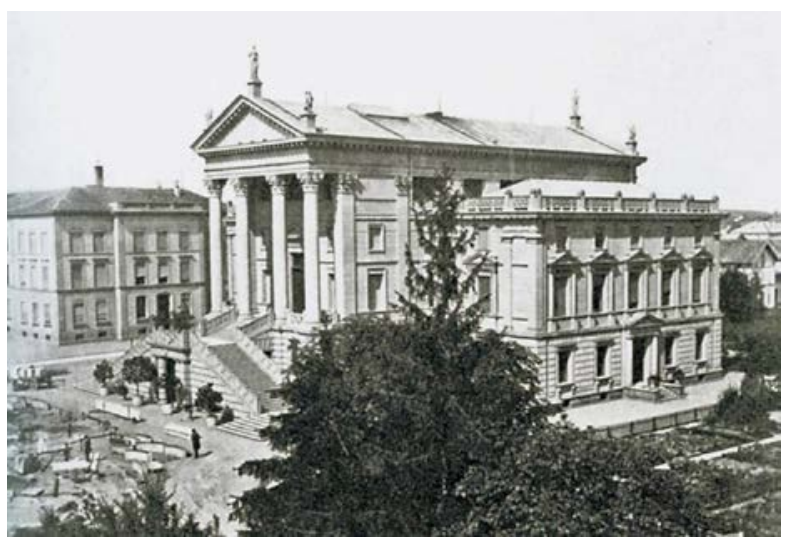

(f1. Gottfried Semper, Ayuntamiento Winthertur, Suiza. 1871

Un momento anterior de aproximación a la arquitectura por parte de Bill fue en su ciudad natal: Winterthur, el ayuntamiento era de Gottfried Semper. Según comenta, pensaba que era un templo griego, en ese momento estaba muy interesado en la plástica, los vasos, los templos. Con el tiempo se dio cuenta que Semper era un gran arquitecto clasicista y lo demostraba esa imponente construcción(f1, pero bastante alejado de la arquitectura griega. En 1925, visitó París: la Bolsa, la Madelaine, el Louvre. En sus comentarios dice, que cada casa, cada balcón le parecía que se adaptaban bien al canón griego. Luego en 1926 Roma, san Pedro, la puerta Pía, la columnata de Bernini. Berlín, el Reichstag. Hasta que de repente llegó a sus manos el libro de Le Corbusier "Vers une Architecture" donde escribía a la vez del Partenón y de un coche. "En este tiempo nos habíamos convertido en unos jóvenes racionalistas. También le Corbusier nos abrió los ojos, también de los esencial de la arquitectura griega.

En verano de 1928 vi, con no mas de 20 años, las primeras construcciones griegas. Paestum: la basílica, el templo de Neptuno. Me impresionaba más que su geometría, su masa, la materialidad. De el renacimiento, pasando por el clasicismo, hasta el hormigón clásico de auguste perret era más ligeros que las masas que había experimentado.

En 1931 vi el templo de la concordia en Agrigento, me impresionó su concepción técnica y su consecuencia arquitectónica.

En 1965 estuve por primera vez en la acrópolis." ${ }^{16}$ 


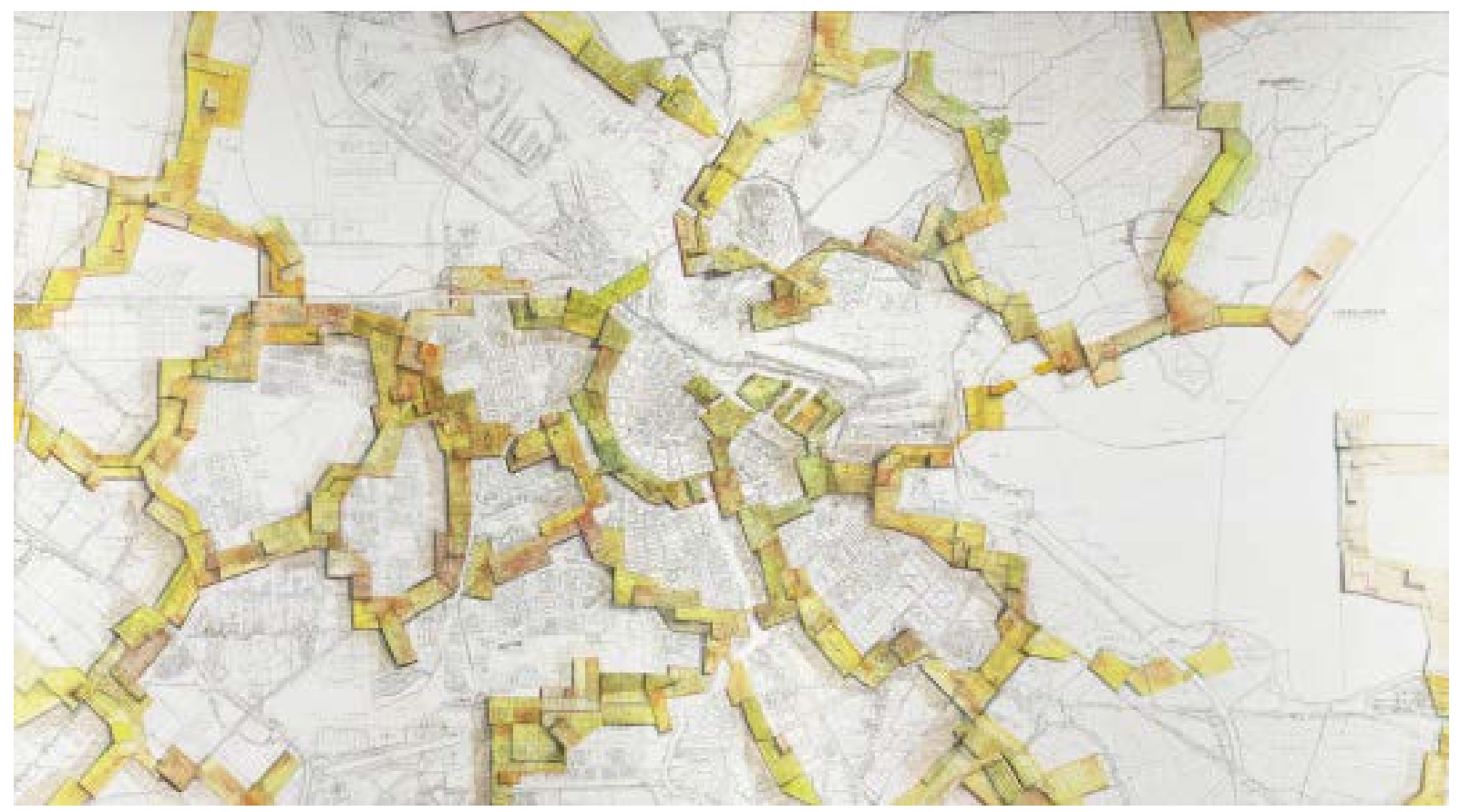

(f1. Constant. New Babylon-Amsterdam. 1968

\subsection{2 el espacio unitario como aspiración}

La psicogeografía constituye una premisa de conocimiento para el entendimiento del nuevo espacio unitario, entendido como un deseo en el que el comportamiento del usuario es el que le introduce la medida, la forma y la posibilidad de utilización . "La teoría de la implicación del conjunto de las artes y las técnicas en pos de la construcción de un ambiente ligado dinámicamente a las experiencias de comportamiento." 17

El espacio unitario representa una posición polémica frente al funcionalismo, donde lo idóneo en relación al programa, el uso y la propio construcción ocupa el papel más importante y ha acabado convirtiéndose en el contenedor de la sociedad burguesa y de su miserable idea de felicidad.

La arquitectura más importante de la reconstrucción europea no sufre de ese funcionalismo burgués. La falta de medios y la urgencia permitió a arquitectos y planificadores urbanos huir de una idea meramente funcionalista del espacio para la vida. Además de "una nueva concepción positivista que nace a partir de una visión de conjunto de la sociedad y que tiende a una creación global de la existencia."18 Esta misma concepción unitaria la aplicaría Constant al urbanismo(f1: "la actividad artística tradicional, que no puede siquiera considerarse como una creación propia y verdadera, debe abandonarse sin dilaciones por el urbanismo unitario.

"A través de él el artista deja de ser el artífice de formas inútiles e ineficaces para convertirse en constructor de ambientes y de modos de vida integrales." ${ }^{19}$ El juego, el nomadismo, la aventura se acaban convirtiendo a final de los 60 en una forma de existencia revolucionaria en todo el mundo. Desde la revolución cubana, los movimientos hippies americanos al mayo del 68 europeo. 


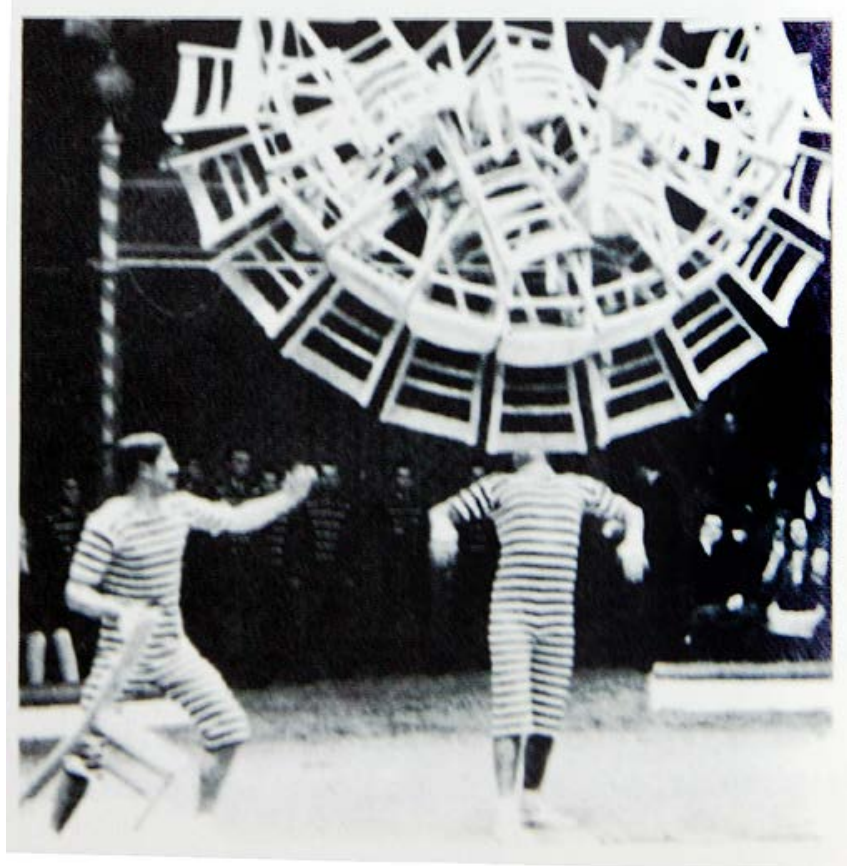

(f1. El malabarista Fred Lony, en un ejercicio de equilibrio. Del libro de Tomas Maldonado, Vanguardia y Racionalidad. 1977

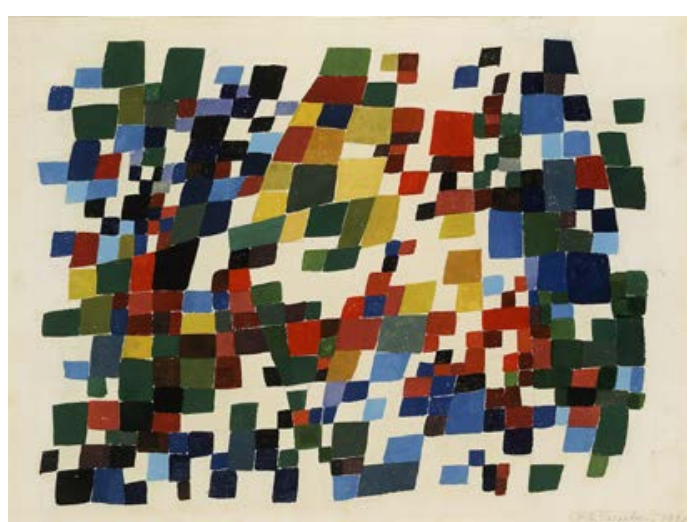

(f2. Sophie Taeuber-Arp, Composition in Dense. 1921

. el nuevo efecto espacial resultado del intersecado del espacio interior con el exterior

La relación del hombre con el espacio natural, con el de la vivienda, el ocio y la enseñanza se sometió durante el siglo XX a un profundo cambio. En realidad sufrió una avance tan importante como el del mundo del arte. Pero es el arte el que sensibiliza al hombre con el espacio y provoca que se relacione con él de una forma nueva.

En el arte anterior la superficie del cuadro se preconcebía antes, la decisión venía valorada por otros elementos, el cambio supone una especie de metamorfosis, donde esa superficie interactúa con el espacio y además con el hombre, con el visitante. El factor dinámico de lo humano en muchos casos se incorpora a la obra. Ocurre también en la nueva música, el espectador ya no permanece más sentado, ahora es parte de la obra: "cualquier pintura previamente considerada como una superficie bidimensional, se va a convertir en parte de un fenómeno multidimensional en el que el siempre cambiante espacio real (por el movimiento del hombre)(f1 y el espacio psíquico (el estado en el que el hombre se encuentra) se superponen" ${ }^{20}$.

Una pintura no va a ser mas algo de dos dimensiones, la entendemos por su efecto, y su acción, no como algo encerrado en si mismo. La pintura ha dejado de ser un compendio de imágenes de la memoria, dejo de representar para convertirse en ella misma. De alguna manera al espacio de la arquitectura le ha pasado lo mismo. No es imitativo de nada, ni siquiera de un orden, es y debe ser en sí mismo. El arte ha adquirido una función dinámica, un cuadro tiene una función espacial, al igual que la tiene la luz o de color, que se acaban convirtiendo en radiadores. Para Bill las obras fundamentales creadas en este sentido pertenecen a Jean Arp, Kurt Schwitters, Moholy-Nagy y Sophie Taeuber(f2. Este intento de explotar la superficie plana provoca una acción no frontal en un espacio que no lo es. 


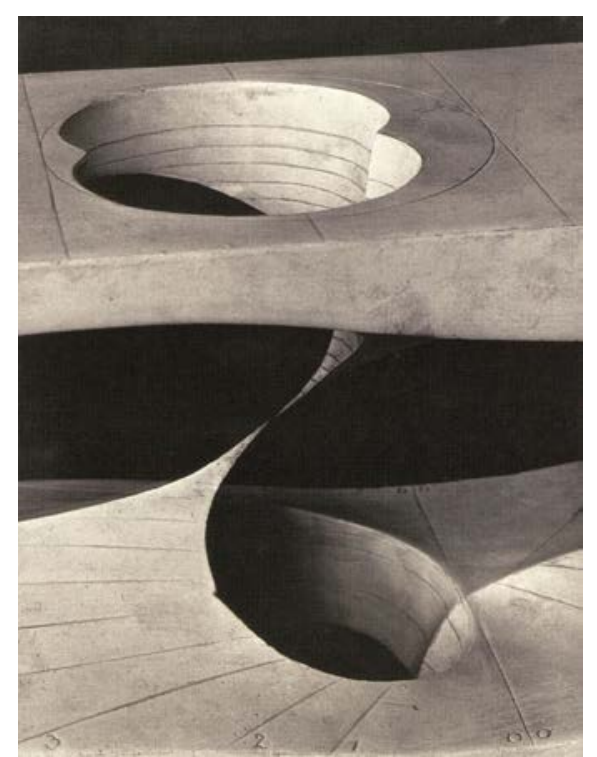

(f1. Man Ray. Equation. Construccion en yeso de una función. Instituto Henri Poincaré de París. 1928

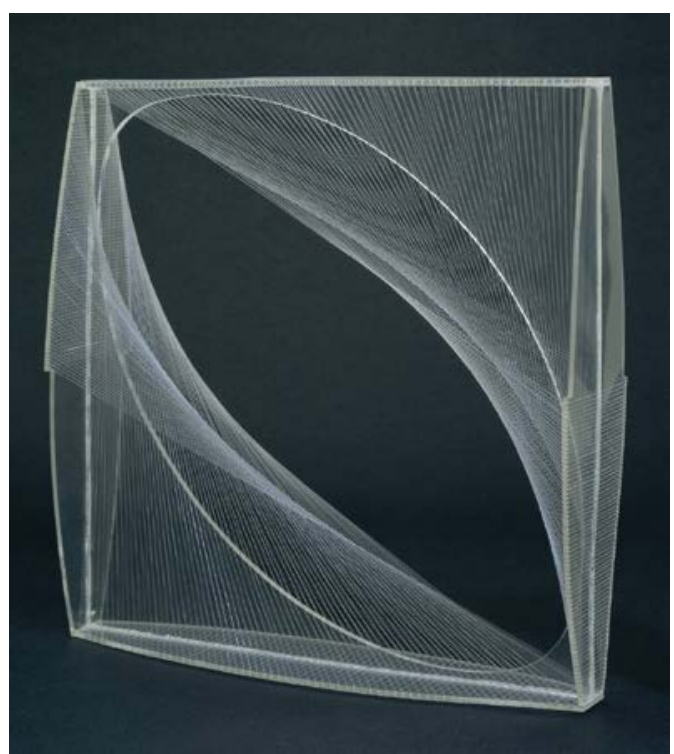

(f2. Naum Gabo. Construcción lineal no1. 1943

. la combinación del espacio interior y exterior para dar lugar a un tercera totalidad

En el siglo XX el espacio se convirtió en parte de la expresión del arte. "En el debut de esta evolución, de forma mas o menos análoga a la función desempeñada por el arte negro en el inicio del cubismo, aparece la influencia de las representaciones espaciales de funciones matemáticas" ${ }^{\prime 2}$.

Efectivamente las obras creadas no proceden directamente de este tipo de representaciones, pero sí el pensamiento matemático ha sido la base de muchas de estas obras(f1. Hay formas contemporáneas representadas de una manera arcaica, masivamente, obedecen a otras leyes que quedan implícitamente ocultas, enlazabilidad, proximidad, consistencia. Aunque en realidad las principales tendencias formales han sido y son la rejilla tridimensional, la línea en el espacio, la superficie de un cuerpo transparente, la superficie en el espacio y la generación de espacio por la luz. Hay una tendencia a la desmaterialización, a la reducción de la escultura a una línea, o la reducción a un sola superficie, "lo que podríamos llamar una conversión a lo ilimitado de la sola energía"22. Por ejemplo la topología condujo al descubrimiento de la superficie desarrollable, tal como han usado escultores como los hermanos Antoine Pevsner y Naum Gabo(f2. Son obras generadas por superficies que se compenetran las unas en las otras, su sustancia material no responde a la necesidad de generar volumen, sino obtener una construcción en el espacio.

Matemáticos como Moebius ${ }^{23}$ permitieron concebir la existencia de entidades matemáticas que consisten en una sola superficie, por tanto son idea pura y carente de volumen, es una única superficie. Con la línea y la teoría de nudos ocurre algo similar, la línea enrollada, anudada no configura un volumen, sigue siendo pura línea.

"El hexágono en el espacio de lados de igual longitud (cuyo material depende solo de la necesidad estática de la construcción). Esta escultura lineal dibuja un espacio no localizable y no presente ni dentro ni fuera, al igual que el hexágono en sí no pertenece al espacio euclidiano. Esta escultura se podría también definir como un dibujo en el espacio."24

21 Max Bill, "De la Surface a' I'Espace, XXe siècle, nr. 2, 1951

22 Max Bill, "De la Surface a' I'Espace, XXe siècle, nr. 2, 1951

23 August Möbius, 1970 Sajonia, 1868 Leipzig, Alemania. Matemático y Astrónomo teórico. Descubre la que se conoce como banda de Moebius junto al matemático Listing. Fue el primero en introducir las coordenadas homógeneas en geometría proyectiva. Es conocido sobre todo por sus estudios en topología.

24 Max Bill, “De la Surface a' I’Espace, XXe siècle, nr. 2, 1951

106 / la arquitectura de la hfg ulm. de la objetividad a la revolución 


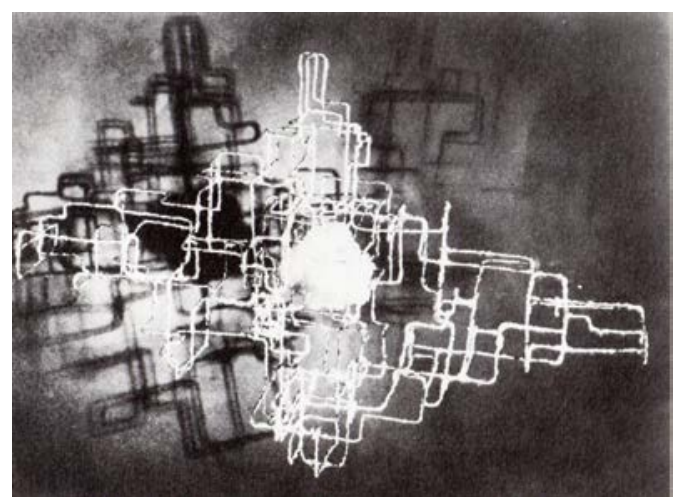

(f1. Ibram Lassaw. Original Santuary Ner Tamid. 1953

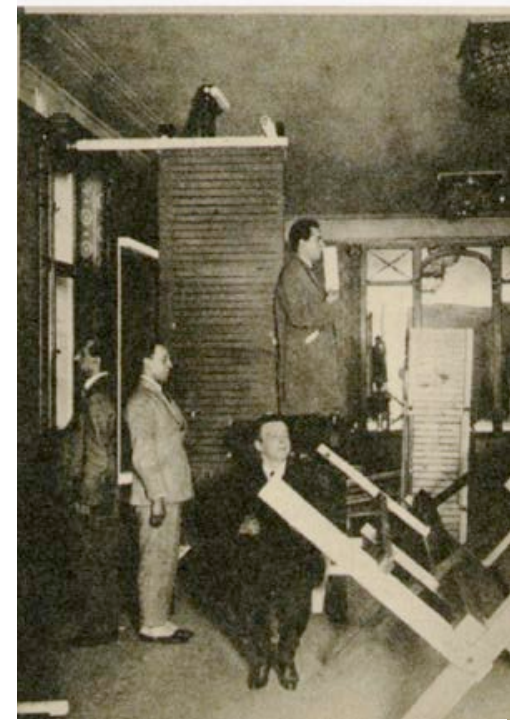

(f3. Theo van Doesburg y Frederick Kiesler

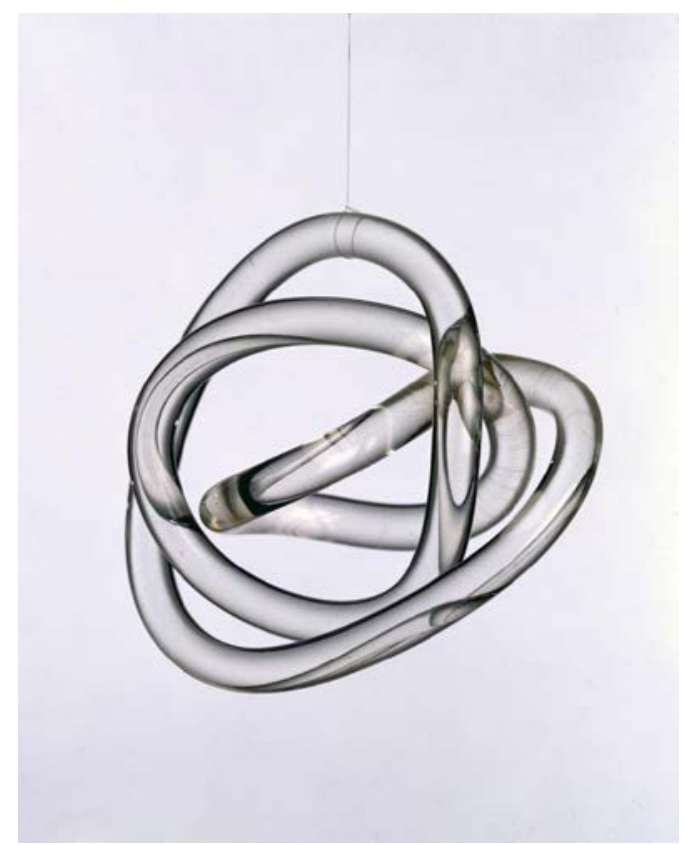

(f2. George Vantongerloo. Cocon, chrysalide, embryonaire. 1950

. la descomposición del volumen de Ibram Lassaw . la transparencia y la limitación en Vantogerloo

Escultores como Ibram Lassaw(f1 que no diluye, ni descompone el volumen, lo transforma en una red, donde el espesor del material contrasta con los espacios intersticiales, no delimitados. El caso de la escultura de Vantongerloo(f2 es similar, un volumen transparente que contiene una longitud y una superficie, también un interior visible. La transparencia y la escueta limitación generan un efecto espacial nuevo, en el sentido de que el espacio interior se corta con el espacio exterior.

La materia a la que nos enfrentamos es mucho menos masa que un soporte de energías. En arquitectura ocurre algo similar, los edificios reflejan posibilidades sin precedentes para crear espacios arquitectónicos. Losas en voladizo sobre paredes de cristal, consiguiendo que el espacio interior y exterior se compenetren. Aunque fueron Theo van Doesburg y Frederic Kiesler(f3 los primeros en ensayar esta compenetración espacial, Mies van der Rohe representó este principio con toda su pureza. Adolf Loos también formula la espacialización del concepto arquitectónico en unos términos muy similares al hablar del Raumplan. En realidad se hace evidente la existencia de un espiral ascendente que, por supuesto, estaba ya en algunas escenografías de Kiesler. No hay niveles uniformes, el espacio se compacta tridimensionalmente al máximo . Lo que permite abrir espacios de relación en un mismo volumen, con el mínimo material constructivo. 

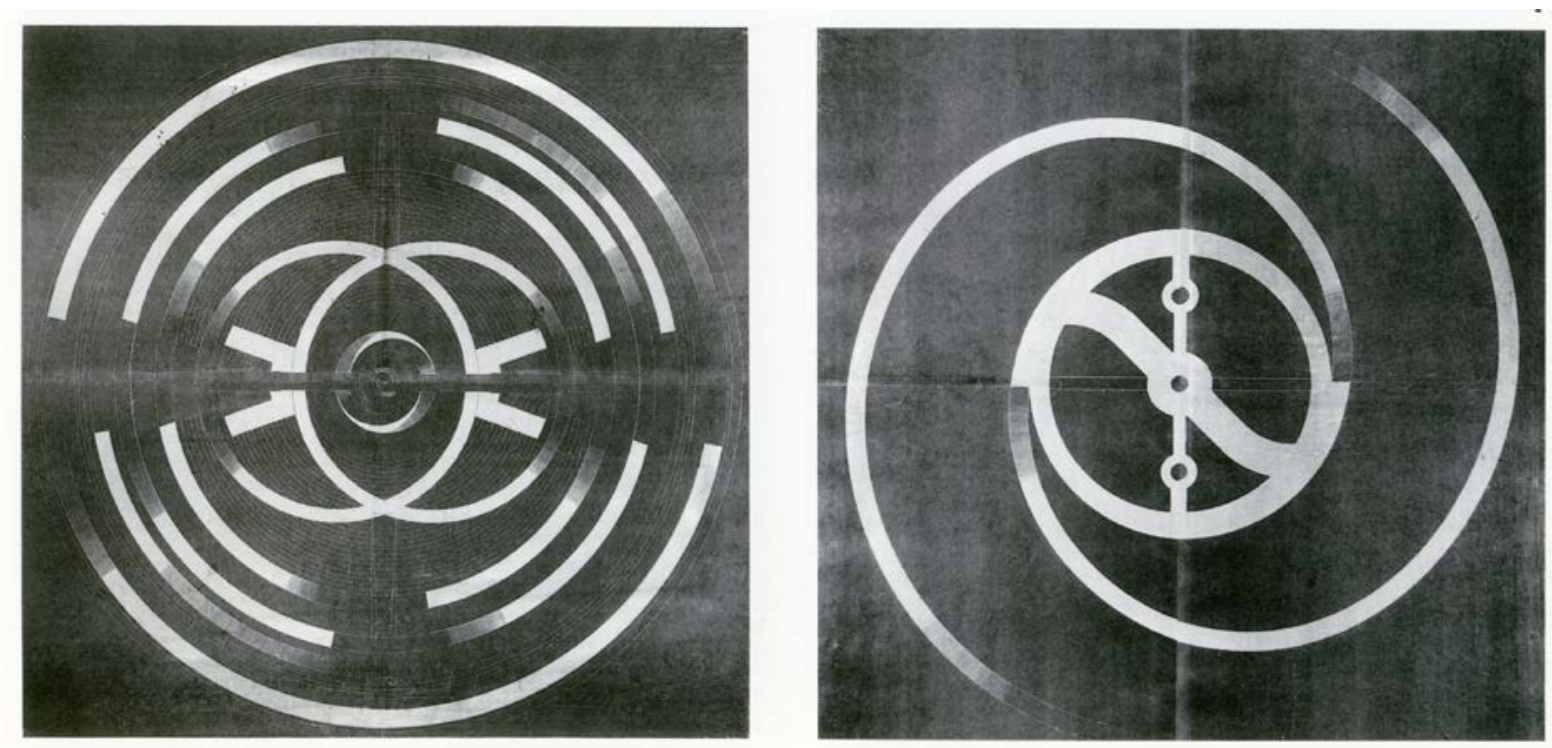

Frederick Kiesler. Planos y maqueta para el endless theater. 1925
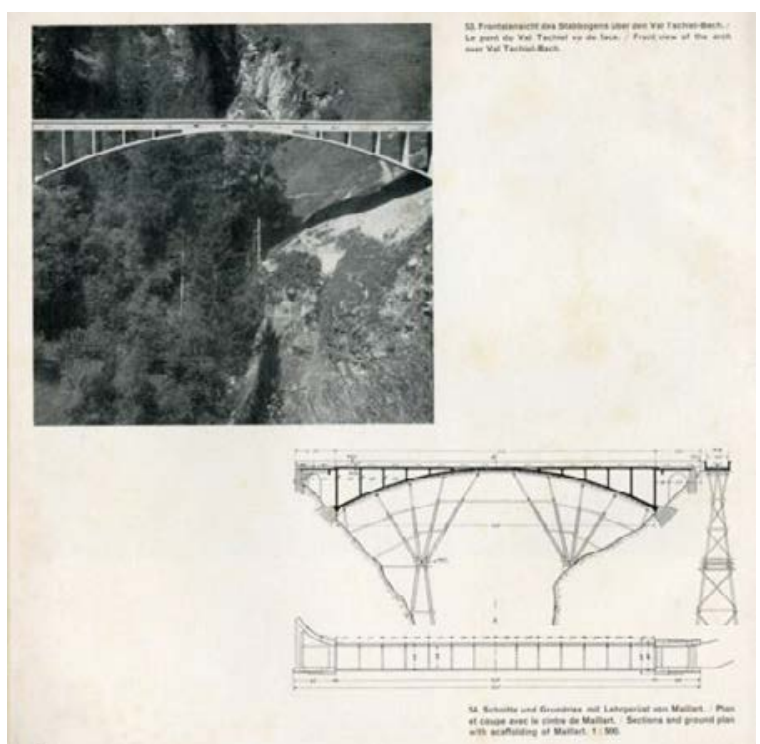

Robert Maillart. Puente sobre el Valtschielbach. 1925. Del libro sobre Maillart diseñado por Bill

La economía de medios consecuencia de la precisión geométrica y del cálculo preciso de tensiones, produjeron ejemplos audaces como el puente en Schwandbach de Robert Maillart. La construcción perfecta, la constitución de un sistema de placas horizontales y verticales complementarias y mutuamente equivalentes, generaron una realización de una extraña perfección, con una transparencia inusual. "Una vez más el ensayo de combinar el espacio interior y el espacio exterior, a fin de dar lugar a una tercera totalidad, todo un ensamblaje abierto y cerrado."25

"El artista que puede unir en sí mismo la pintura, la escultura y la arquitectura, sabe ver el espacio en su conjunto y en su relación con el hombre. Es a esta unidad a la que aspiramos." 26 


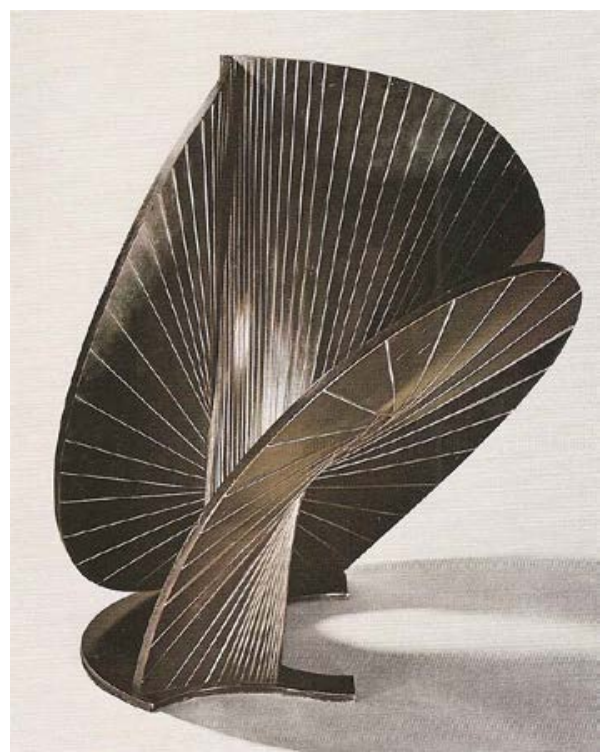

(f1. Antoine Pevsner, Constructie, 1938

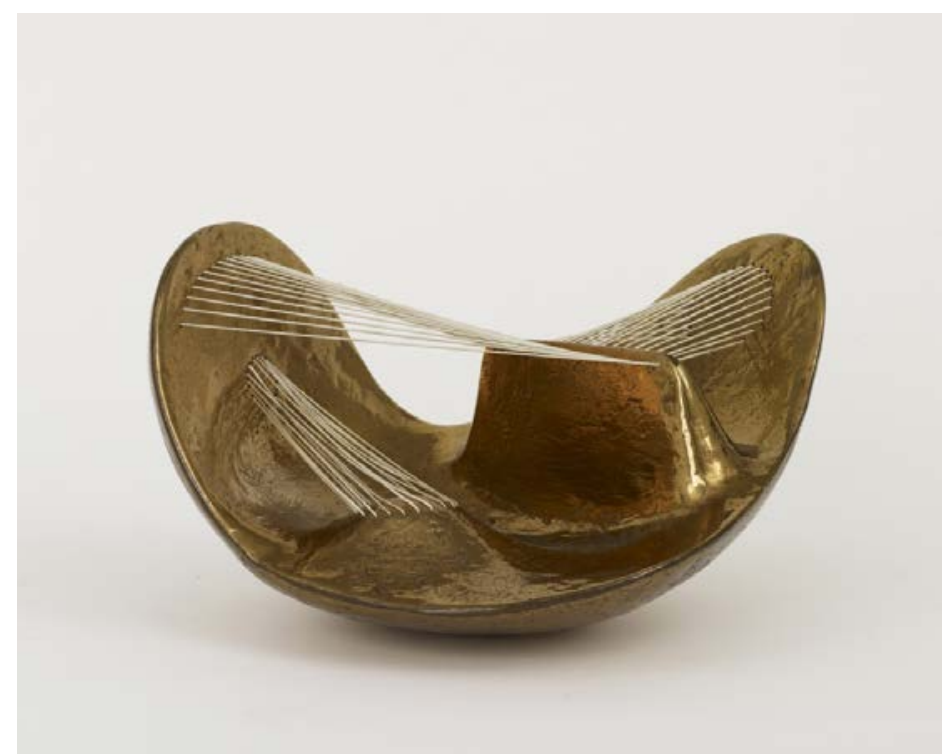

(f2. Henry Moore. Stinged Figure. Bronce y cables. 1938

. los hermanos Pevsner

Los dos hermanos, Naum Gabo y Antoine Pevsner(f1 procedentes de Rusia, que en 1920 publican el "manifiesto realista"27, utilizaron la línea como forma de sombreado en sus esculturas. Crearon conchas transparentes con superficies compuestas de hilos paralelos. Sistema que después utilizaron otros artistas, entre los más importante destacaríamos a Henry Moore(f2 y al propio Picasso.

El referente para todos fue en el siglo XVIII William Hogarth, quien en su Analysis of Beauty la interpretación de volúmenes mediante líneas. Un cuerpo sólido representado de esa manera, sin dejar de ser el mismo, se muestra más espacial, conserva su posicionamiento y dimensión en todas las posiciones. Este tipo de presentación aporta al objeto una variabilidad formal que depende de otras circunstancias como son la cantidad de luz y la dimensión de la misma. ¿no está el volumen de un depósito o las características de un casco de barco en su propia estructura? . "En nuestro entorno material, las avenidas de árboles, las hileras de postes de telégrafo, las empalizadas, las persianas venecianas y sus sombras, así como las diversas retículas arquitectónicas, combinan unidades lineales en esquemas similares." 28

\section{MANIFIESTO REALISTA o CONSTRUCTIVISTA Naum Gabo y Antoine Pevsner 1920}

En el torbellino de nuestros días activos, mas allá de las cenizas y de las ruinas del pasado, ante las cancelas de un futuro vacuo, nosotros proclamamos ante vosotros, artistas, pintores, escultores, músicos, actores y poetas, ante vosotros, personas para las que el Arte no es solo una mera fuente de conversación, sino el manantial mismo de una real exaltación, nuestra convicción y los hechos.

Hay que sacar al Arte del callejón sin salida en que se halla desde hace veinte años.

¿Cómo contribuye el Arte a la época actual de la historia del hombre?

Los intentos realizados por cubistas y por futuristas para sacar a las artes figurativas del fango del pasado solo han producido nuevos desencantos.

Nosotros decimos:

Espacio y tiempo han renacido hoy para nosotros.

Espacio y tiempo son las únicas formas sobre las cuales la vida se construye, y sobre ellos, se debe edificar el Arte.

No medimos nuestro trabajo con el metro de la belleza y no lo pesamos con el peso de la ternura y de los sentimientos.

1. Por ello, en la pintura renunciamos al color como elemento pictórico:

2. Renunciamos a la línea como valor descriptivo: en la vida no existen líneas descriptivas

3. Renunciamos al volumen como forma espacial pictórica y plástica:

4. Renunciamos a la escultura en cuanto masa entendida como elemento escultural.

5. Renunciamos al desencanto artístico enraizado desde hace siglos, según el cual los ritmos estáticos son los únicos elementos de las artes plásticas

Quien hoy se ocupe del mañana se ocupa en no hacer nada.

Y quien mañana no nos dé nada de lo que haya hecho hoy no es de ninguna utilidad para el futuro.

El hoy pertenece al hecho. Lo tendremos en cuenta también mañana. Dejemos el pasado a nuestras espaldas como una carroña.

Dejemos el futuro a los profetas.

Nosotros nos quedaremos con el hoy.

28 Rudolf Arnheim. Arte y percepción visual. Nueva Visión. 1979. Capítulo el espacio, pag 229 


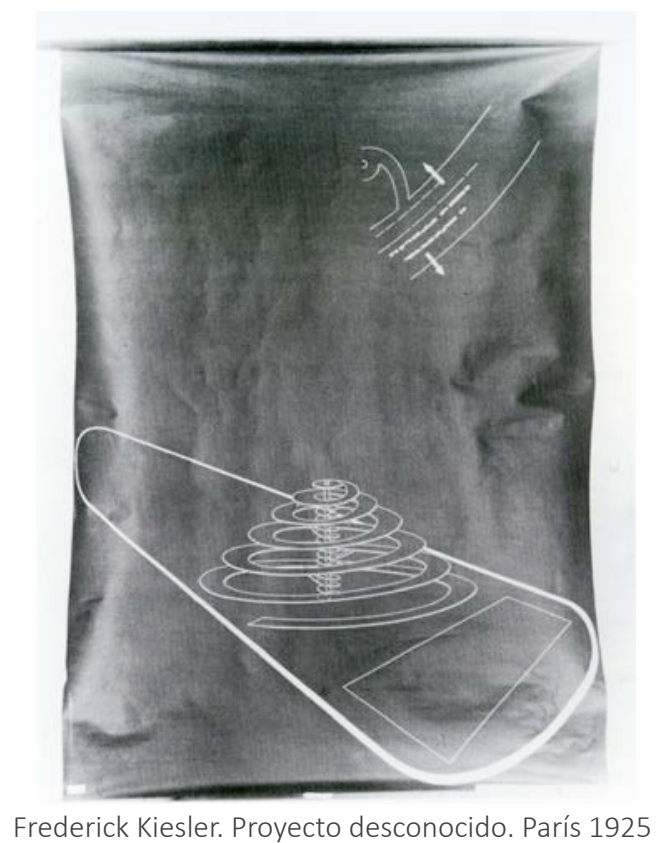

Frederick Kiesler. Proyecto desconocido. París 1925

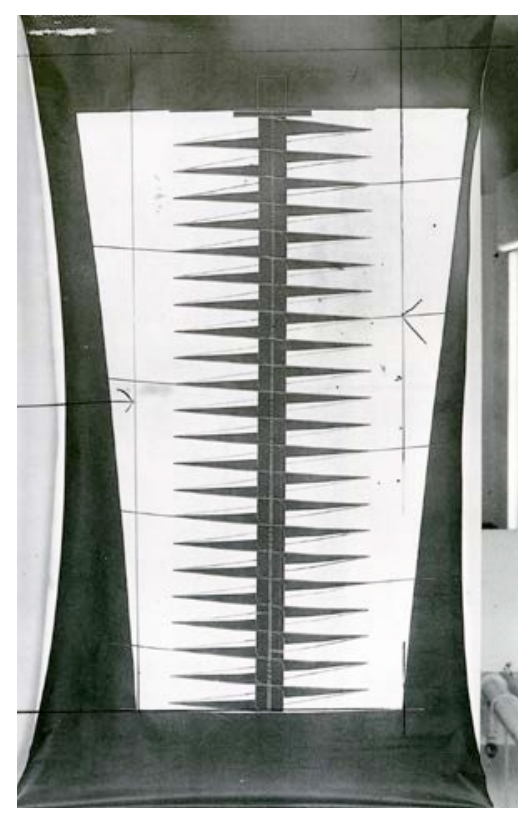

Frederick Kiesler. Proyecto para grandes almacenes. Nueva York 1925

. ensayos de compenetración espacial. Frederick Kiesler

"La idea de Endless se convertiría para Kiesler en un concepto central de su creación tanto arquitectónica como teórica y gráfica." ${ }^{29}$ Durante todo el proceso de desarrollo de proyecto que supuso la endless house, el espacio de la casa es para Kiesler la posibilidad de ruptura con el funcionalismo radical que fundamentaba todos los desarrollos formales en el rectángulo. La posibilidad de diseñar una vivienda unifamiliar supuso para el artista la oportunidad de desarrollar un discurso teórico sobre el espacio de vida para una familia.

Existen referentes anteriores en su propia obra, ya en los años 20 concibió el Raumbühne vienés, donde el espacio tridimensional continuo del escenario era el protagonista. Después vino el

Raumstadt de París, donde Kiesler concive una ciudad a gran altura, suspendida del cielo, y lo hace con decorados vieneses colgados de un estructura de listones de madera. Durante esta exposición "echó mano de las numerosas experiencias derivadas de su actividad para construir una concepción global que gira en torno a una idea central que ha condicionado toda su vida artística: la coordinación de elementos/fuerzas/tensiones heterogéneas en un continuum espacial interminable." ${ }^{\prime 30}$

Kiesler habla en muchas ocasiones de una concepción espacial elástica. Con la que se pretende resolver la heterojaneidad social de sus habitantes. Pequeños espacios para uso individual y grandes espacios para el uso común. La relación de proporción entre ellos marcará las posibles diferencia entre clases. En relación a esto Kiesler acuña el concepto de la Time-Space-Architectur con el que aludía a la capacidad de modificación del tamaño y forma de los espacios de acuerdo con la función asignada a estos. $^{31}$

\footnotetext{
29 Frederick Kiesler 1890-1965, en el interior de la endless house. Catálogo de la exposición homónima en el IVAM 1997. Pag 10. Dieter Bogner

30 Frederick Kiesler 1890-1965, en el interior de la endless house. Catálogo de la exposición homónima en el IVAM 1997. Pag 10. Dieter Bogner

3131 Frederick Kiesler 1890-1965, en el interior de la endless house. Catálogo de la exposición homónima en el IVAM 1997. Pag 14. Dieter Bogner

110 / la arquitectura de la hfg ulm. de la objetividad a la revolución
} 


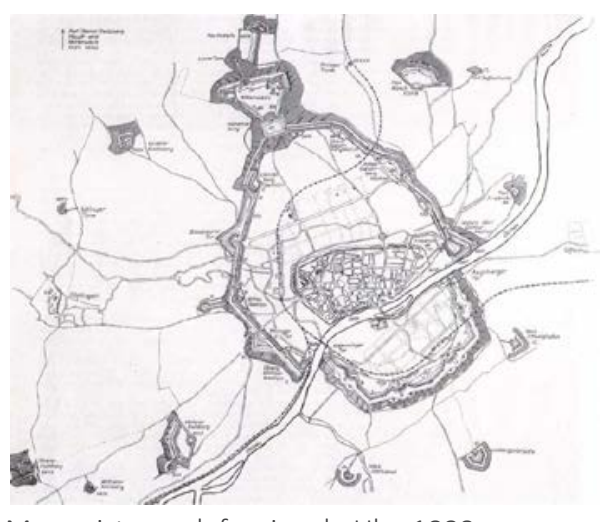

Mapa sistema defensivo de UIm 1888

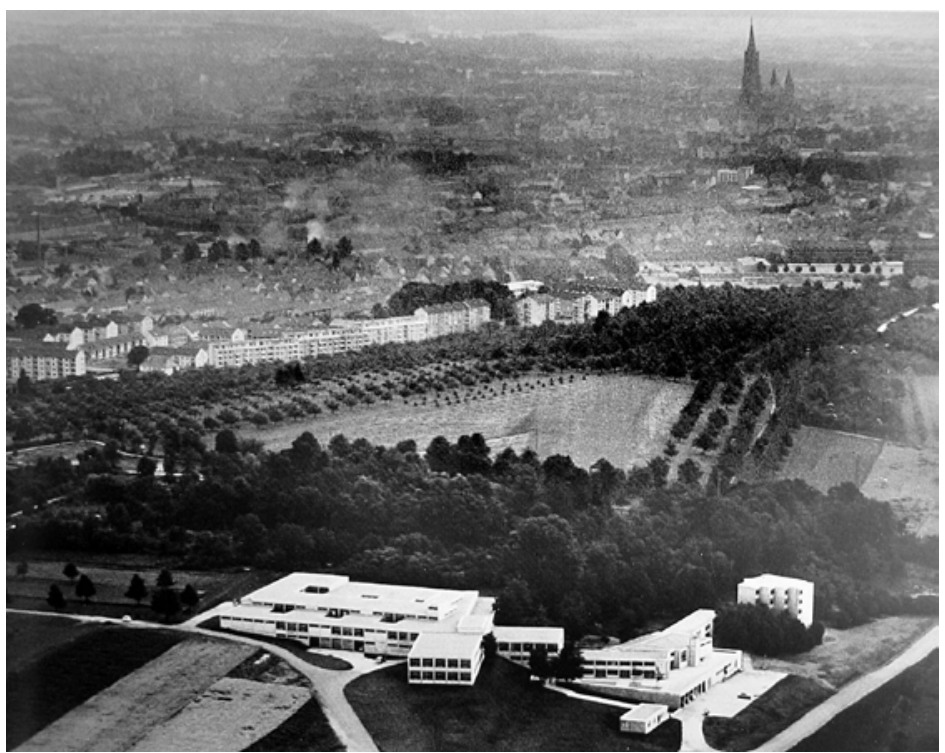

Otl Aicher. Foto aérea de la HfG. 1955

\section{2 figura (el espacio en la HfG}

La aparición de la Figura en lo que antes era el lugar de la Fortificación, un sitio para la defensa de la ciudad que además fue carcel política con el nacismo ${ }^{32}$. Por lo tanto no es la escuela la que primero viene a estar en el lugar, sino que, por la escuela misma y no antes, sólo por ella surge el nuevo lugar. La escuela coliga en el modo de otorgar (hacer sitio a) al paraje y desde este se determinan los de otros pueblos y caminos donde el espacio general se hace espacio de lo concreto. Raun (espacio), su viejo significado Rum, que significa lugar franqueado para población y campamento. El capítulo continuará analizando las leyes de articulación y ritmo implícitas en el edificio, introducidas por una aproximación a la visión de la cosa. La conciencia de que el edificio presenta una proporcionalidad constante a la vez que un irregularidad aparente lleva al análisis de unas ocultas, pero existentes, mallas matemático constructivas. El mundo de la matemática nos llevar a relacionar las irregularidades con el interés del autor en la matemática topólogica. De este planteamiento obtenemos dos consecuencias, la primera una estructura espacial continua sobre una horizontalidad inclinada. Y la segunda o corolario viene definida por el título de un artículo de Bill "la belleza nace de la función y existe como función”33, a traves de los comentarios, también, de Margit Staber ${ }^{34}$.

«Una imagen aérea. como la maqueta de una ciudad. En primera plana delante de un bosque oscuro, edificios blancos, cúbicos, chatos. cristales con ventanas, muchas ventanas, como si bloques de construcción en ángulo recto hubiesen sido ajustados sobre una pendiente. al fondo, nebulosa, desordenada y gris sobre gris, la enredada ciudad. sobre ella, como una sombra ante la brillante cinta del danubio, la masa de la catedral, a lo lejos, desapareciendo. Transitorio pasado.Adelante, blancos, los bloques del futuro. Un glorioso castillo del futuro..135. La foto aérea de Aicher es definitoria, habla de lugar pasado, del futuro y su relación con la ciudad. Describe la figura del edificio de la HfG en relación a los elementos que la conformaron como presencia.

32 Fort Oberer Kuhberg. El fuerte construido entre 1842-1857 pertenece a un sitema de fortificación federal de la ciudad de Ulm. De difícil construcción por deslizamiento de tierras, debido a la aparición de armamento más moderno el fuerte fue continuamente modificado. Entre 1933-1935 fue usado como carcel preventiva por delitos políticos por el régimen nazi. Allí estuvieron los hermanos Scholl hasta sus translado a Berlín para ser ajusticiados.

33 Max Bill: "Beauty from function and as function. 1949. Conferencia impartida por Bill en el encuentro de la Swiss Werkbund que tuvo lugar en Basilea entre los días 23-24 de Octubre de 1948.

34 Margit Staber. Alumna de Bill en Ulm. "La Scuola di Ulm". Casabella Continuitá, Enero 1962

35 Bernd Rübenach, 1959. Comentario sobre la foto aérea de Otl Aicher del año 1955 


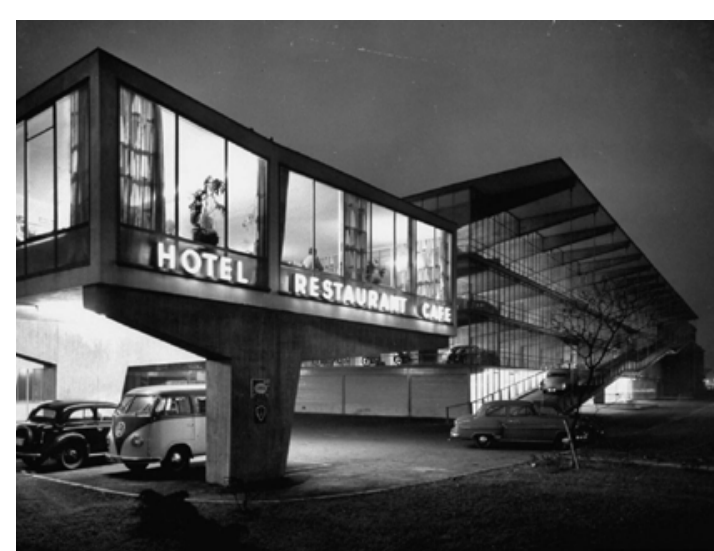

(f1 Paul Schneider-Esleben. Aparcamiento-motel Düsseldorf. 1951

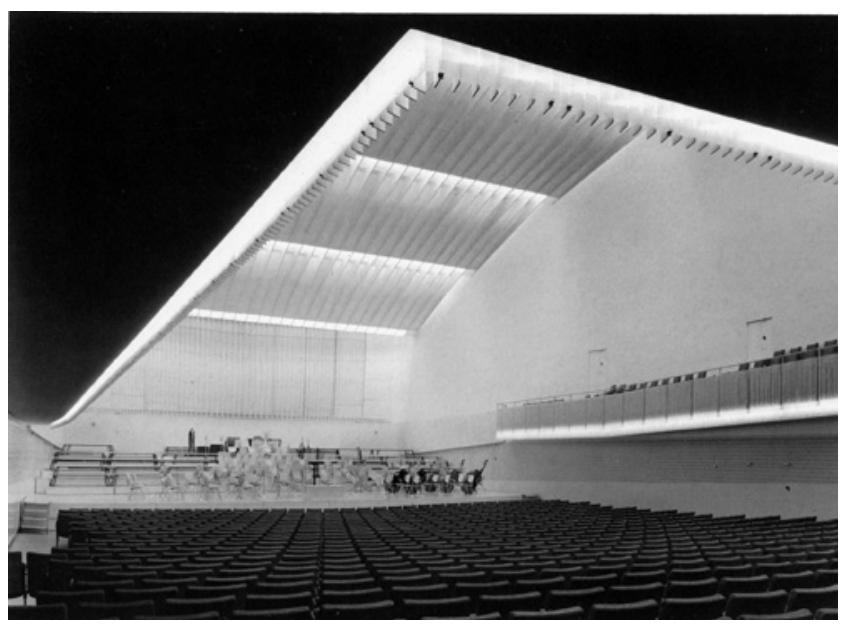

(f2 Paul Baumgarten. Sala de conciertos en la Hochschule für Musik. Berlín, 192. 1951

El mismo principio: la disección del edificio de la escuela en funciones individuales pero diferentes. Un edificio que se extiende en sus alas de función es un objetivo que también persiguió Walter Gropius en el diseño del edificio Bauhaus Dessau (1925-1926). El complejo incluye cinco estructuras que definen los edificios en sus cinco funciones: vivienda-estudio, talleres, espacios para la docencia de los diferentes departamentos, zona administrativa y áreas comunes. Incluso Gropius enfatizó arquitectónicamente el contexto de las áreas, por volúmenes fusionados juntos. Sin embargo, la conexión de las diferentes partes siguió un esquema completamente diferente, siempre se unen en ángulo recto. El complejo parece compacto porque los edificios son, por lo general, solo de tres o cuatro plantas.

El edificio de la HfG se construyó con el mínimo número de elementos. Se hizo lo necesario evitando lo superfluo y se limitaron los esfuerzos a lo esencial, generando un resultado casi primitivo, en el sentido más esencial de la palabra. Aunque en el edificio se cuida hasta el último detalle, como un testimonio representativo de la artesanía que finalmente lo identifica. El problema parece simple, es una construcción eficiente y sólida, que salva con absoluta solvencia el problema del lugar. Pero a la vez la diversidad es conformadora de la unidad. La relatividad nublada del edifico tiene que ver con las necesidades diarias de las personas, de su cambio de posición, de su concienciación hacia el trabajo. No vale con ordenar, hay que relacionar. Se actua con unas fuerzas que subyacen a toda institución humana y son reconocibles en cada uno de nosotro.

"Para Bill el puritanismo exagerado de la arquitectura parece educar a los monjes de la era tecnológica. Gris monocromo dentro y fuera de los muros de hormigón en bruto se ponen juntos, un juego modular de los niños gigantes. Una casamata de la cultura, un sanatorio de la técnica." ${ }^{136}$

Dieter Hoffmann-Axthelm coloca al lado de la HfG el gran garaje en Düsseldorf (1951) de SchneiderEsleben(f1, y la Sala de Conciertos de Baumgarten en la Academia de Música de Berlín (1952)(f2 como los edificios mas importantes de los primero años 50 en alemania. Ve en ella el florecimiento final de una generación de arquitectos que "durante los años del fascismo habían crecido alrededor de unos edificios que apreciaba el rigor constructivo a la vez que la forma flexible ". ${ }^{37}$

36 Eva von Seckendorf. Comentarios sobre la construcción HfG Ulm, en Die Hochschule für Gestaltung in UmI. Jonas Verlag 1989.

37 Dieter Hoffmann-Axthelm en Eva von Seckendorf Die Hochschule für Gestaltung in Uml, pag 83

112 / la arquitectura de la hfg ulm. de la objetividad a la revolución 


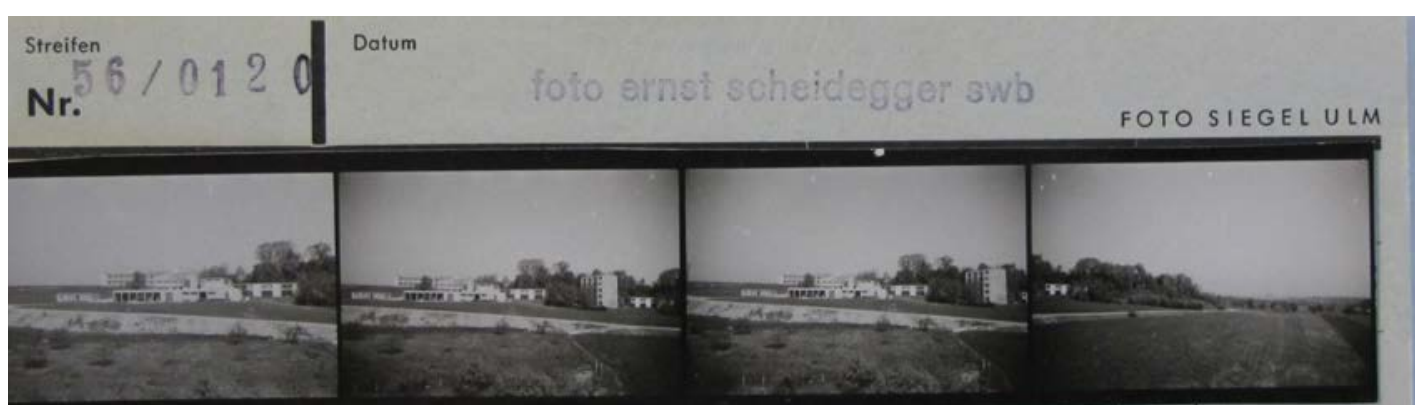

\subsection{1 leyes de articulación y ritmo}

La aproximación al edificio de la HfG nos produce una situación desconcertante, sobre la que debemos llamar la atención. Cuando nos vamos acercando al edificio este aparece casi desprovisto de importancia. La naturaleza, el paisaje que lo rodea, la ciudad atrás, nos produce un profundo latido, qué lugar. Cuando en un último bucle nos vemos inmersos en un diedro formado por la plataformaterraza y el talud-barbacana ${ }^{38}$ con el aulario encima, nos sentimos obligados al enfrentamiento con lo cerrado, con lo que más allá de su función, aparentemente no atesora nada. "el campo de experiencia ha quedado transformado, y la naturaleza de los estímulos a los que uno se veía sujeto se ha hecho, sistemáticamente, más concentrada y despiadada"39, diría Colin Rowe en referencia a la Tourette y que podríamos aplicar a la sensación de aproximación a la HfG.

Una vez atravesada la puerta, el objetivo visual no es un muro, más o menos perforado por ventanas, ahora vuelve a ser el horizonte próximo del patio de atrás, definido por la arboleda y el castillo, y al fondo, tal vez, la torre de la catedral de Ulm. Volvemos a la naturaleza, el edificio vuelve a quedar en segundo plano. "Pero el visitante se halla en tal posición que no tiene ningún medio de dar coherencia a su propia experiencia. Se ha convertido en un sujeto de excitaciones diamétricas; su conciencia se haya dividida y, al encontrarse privado de un soporte arquitectónico y ver que se le ofrece otro, se siente ansioso, por no decir obligado, si quiere resolver su situación, en permanecer en el edifico. No tiene otra posibilidad de elección"40. Esta descripción de la entrada a la Tourette vuelve a ser válida para la promenade de aproximación a la HfG. La escuela aparece agazapada en el paisaje. Los árboles puede con ella, convirtiendose en la puerta de salida a otro tipo de paisaje, el agrícola de los terrenos circundantes.

. proporcionalidad constante, irregularidad aparente

La uniformidad, el diseño compacto de los edificios, especialmente visible en las zonas comunitarias y en la parte de aulas, estaba dibujada ya en los proyectos anteriores. Es, en este sentido, realizada la construcción, los elementos constructivos para los diferentes tamaños de los volúmenes constructivos se combinan según los requisitos, como tatamis en la casa tradicional japonesa. En particular, esta

38 Se ha llamado talud-barbacana a los refuerzos de estabilización del terreno que se tuvieron que hacer durante la construcción del fuerte, pues el terreno se deslizaba pendiente abajo, hacia el Danubio.

39 Colin Rowe, Manierismo y Arquitectura Moderna y otros ensayos, Gustavo Gili, 1978. pag 181

40 Colin Rowe, Manierismo y Arquitectura Moderna y otros ensayos, Gustavo Gili, 1978. pag 182 


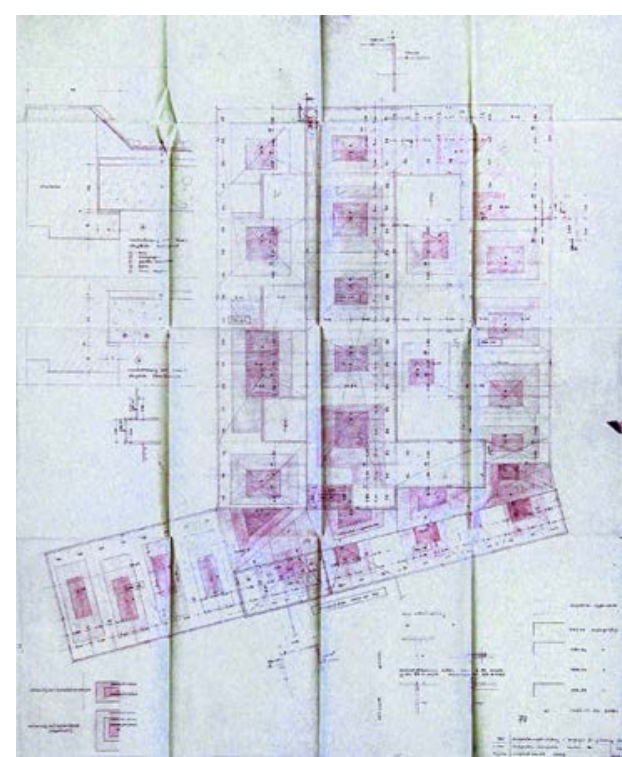

( $\mathrm{f1} \mathrm{HfG}$, plano de obra, cubiertas de zona talleres, diente de sierra y volumen de aulas

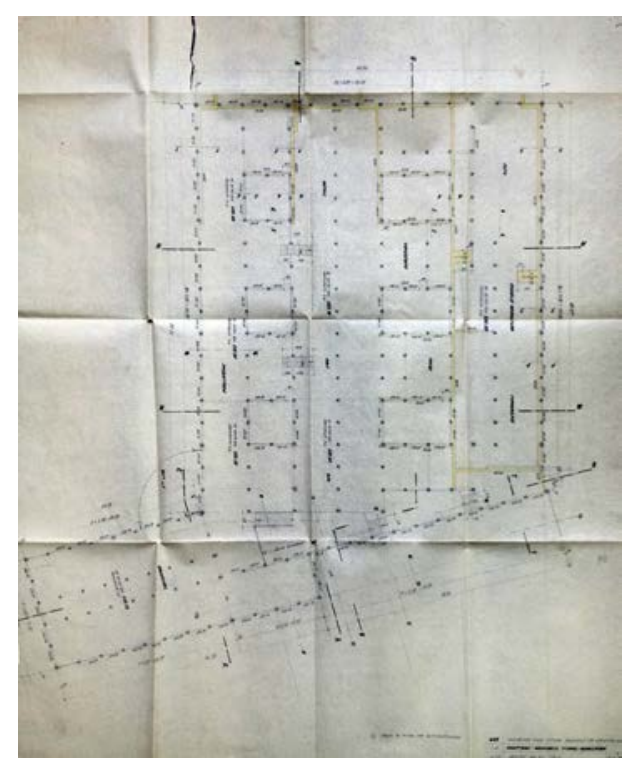

(f2 HfG, plano de obra replanteo talleres

combinatoria se utiliza de manera especial en la parte de talleres, donde la malla se constituye de rectángulos de gran tamaño (f1, los módulos se han dispuesto de manera que forman seis patios pequeños interiores.

De esta manera se construyen los cuerpos de talleres, aulas y comedor-aula magna. Los elementos principales constructivos siguen la regla de $6 \times 6 \mathrm{~m}$ (f2. Consta de cuatro pilares y dos vigas en la dirección principal de la carga. Sobre las vigas reposa una construcción secundaria de techo, que consta de elementos de hormigón prefabricados de $16 \mathrm{~cm}$ de canto. Unicamente en las zonas donde la geometría de la arquitectura no se corresponde a la constructiva, por ejempo en el espacio del diente de sierra, se resuelve con nervios de hormigón de $30 \mathrm{~cm}$ de canto y 9 de ancho. La altura de la luz del armazón se eleva desde el suelo hasta la parte de abajo del canto inferior de la viga, que mantiene el módulo de 3 metros.

Como siempre al combinar estas unidades unas con otras, no se puede eludir que unas con su parte ancha y otras con su parta larga quedan embebidas en el plano de fachada. La fachadas forzosamente tienen que dividirse por pilares que están separados siempre 3 metros. Realmente las fachadas de la zona central son todas uniformes, la distancia entre pilares es siempre la misma. Esto quiere decir que hay algo que no se da por hecho: se tienen que encontrar los pilares que bajo la estructura de cargas sean innecesarios con los que modulan las fachadas. Estos se ve claramente en la estructura del volumen de aulas, que mantiene un orden de vigas de 6 metros de luz y $60 \mathrm{~cm}$ de canto; cuando llegan a la fachada paralela al plano de los pórticos, tienen que reducir la luz a 3 metros para recuperar la modulación de fachada, por tanto las vigas reducen su luz a 3 m y el canto pasa a $40 \mathrm{~cm}$.

Para alcanzar este resultado, tuvo Bill que superponer un segundo orden sobre la malla constitutiva de volúmenes. Esta segundo orden es únicamente válido para el ámbito de la fachada y rompe la malla principal en esos puntos.

La malla principal se rompe por una decisión pragmática: y esto es para conseguir un sistema regular de fachada que permita, con los mismos elementos, definirlas todas. El orden de fachada se mantiene hasta cuando un volumen se cierra hacia el interior de otro, como en el caso del vestíbulo de entrada. Pero hay dos casos donde este sistema se rompe claramente y es en el encuentro entre el volumentalleres y el volumen biblioteca-departamento de información- dirección, resuelto por Bill con el vacio 


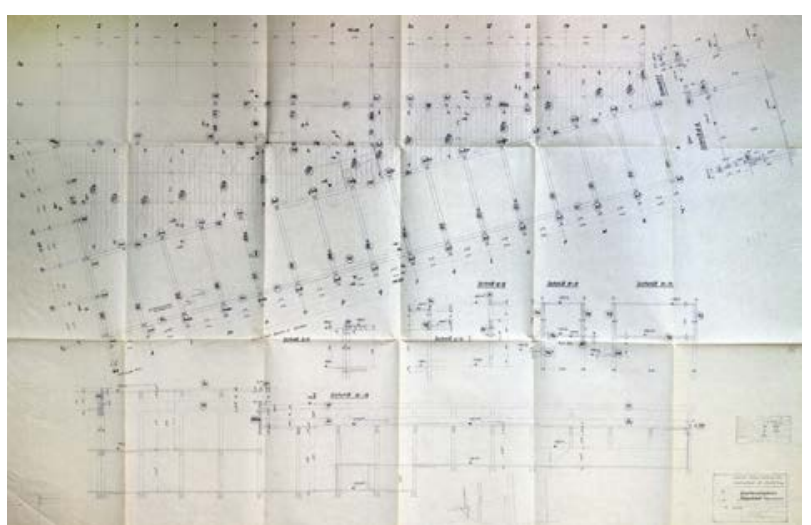

(f1 HfG, plano de obra, estructura forjado diente de sierra. 1953

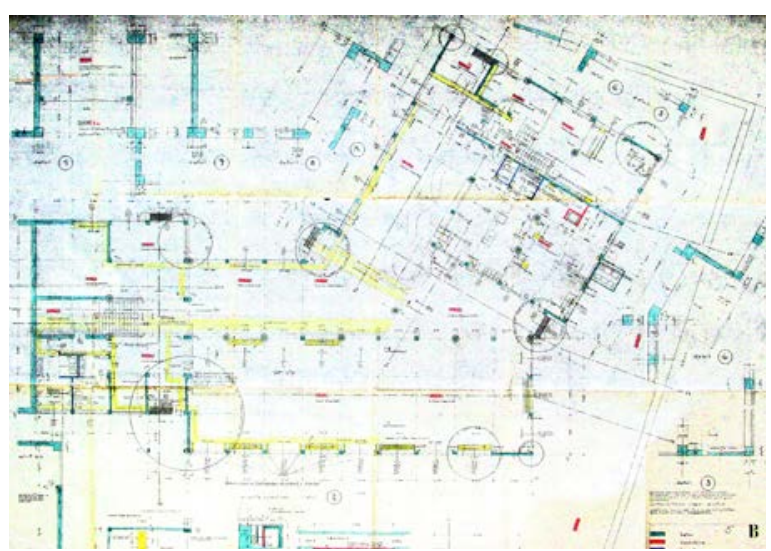

(f2 HfG, plano de obra, encuentro entre zona cocina y comedor-aula magna. 22.10.1954

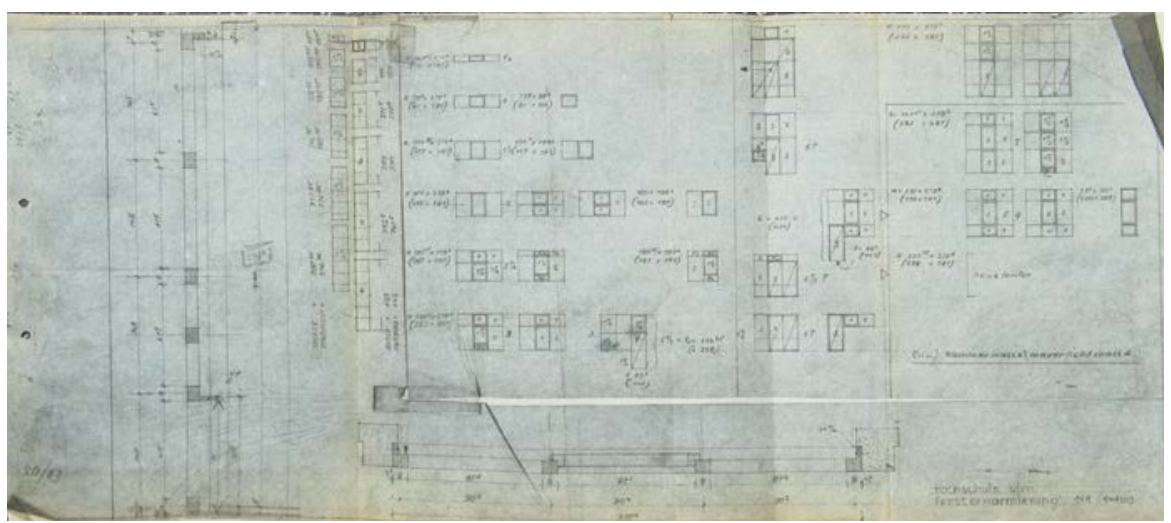

(f3 HfG, plano de obra, modulación de paños de fachada en relación a las ventanas. 1954

del llamado diente de sierra (f1. El otro caso es en la unión entre el aula magna-comedor con el area del bar-cocina donde los pilares aparece exentos y su tramado geometrico sufre trastornos fuera de sistema (f2. Las paredes de división a veces van tapiadas con bloque de hormigón y otras forradas de madera. Pero también en estos puntos se queda la estructura de pilares intacta. Para cada problema hay que encontrar un solución específica, para lo que Bill desarrolló una única regla que le permitiera la manipulación estructural de los volúmenes, por lo cual diferentes problemas se resolvían de un solo golpe.

La construcción del HfG consta para ello de una cantidad de volúmenes, que a través de su invulnerable unión sucumben a un estatus autónomo. Su uniformidad no se corresponde con la construcción interior, sino que sigue a la superposición de la estructura secundaria. Esto permite divergentes posibilidades de la forma: el tener dos tramas posibilita una completa libertad en la ordenación de la planta, al mismo tiempo que mantiene uniformidad en el exterior.

Para el relleno de los marcos producidos por la estructura Bill utiliza un tramado geométrico que usa tanto al interior como al exterior, por el cual la apertura cuadrada de tres metros de lado, menos los $12,5 \mathrm{~cm}$ de la mitad de los dos pilares se divide en cuatro partes horizontales y tres verticales. El ancho de las verticales es $90.2 \mathrm{~cm}$ y el de las horizontales $70.5 \mathrm{~cm}$. La medida de 12.5 se repite en los despieces de bloque de hormigón, siendo el espesor del bloque $11.5 \mathrm{~cm}$ y el de la llaga-tendel $1 \mathrm{~cm}$. Lo mismo ocurre con los paños forrados de madera, el despiece es a $12.5 \mathrm{~cm}$. En las fachadas cada ventana se asienta en un antepecho, aunque a veces ocurre que la cristalera baja hasta abajo como en el caso del vestíbulo. Bill maneja siempre las mismas proporciones que van desde 1:4 hasta 3:4. Los cantos de todos los elementos de hormigón se achaflanan y dan como resultado en la fachada de la parte superior un fina línea de sombra. Los elementos de fachada experimentan las siguientes subdivisiones, las más grandes 1:2 y las pequeñas 3:4. Por elementos de ventana se pueden llegar a 5 módulos de altura siempre por 3 de ancho.(f3 


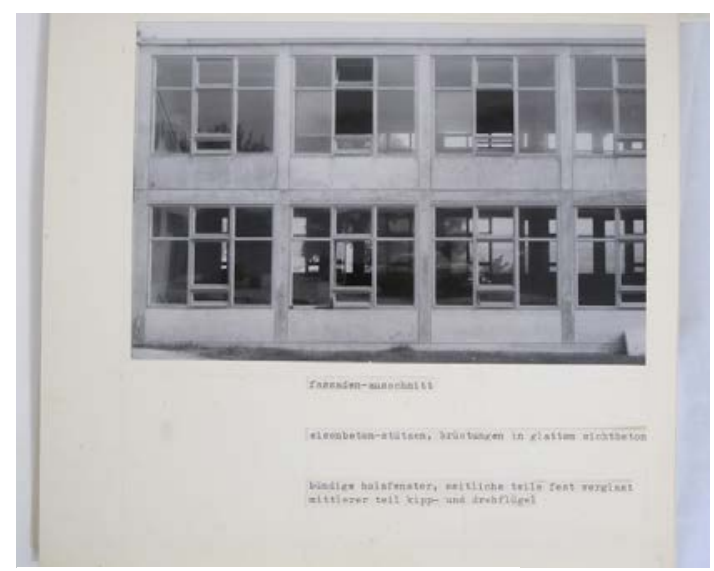

Foto fachada aulario. Ernst Hahn. 1955

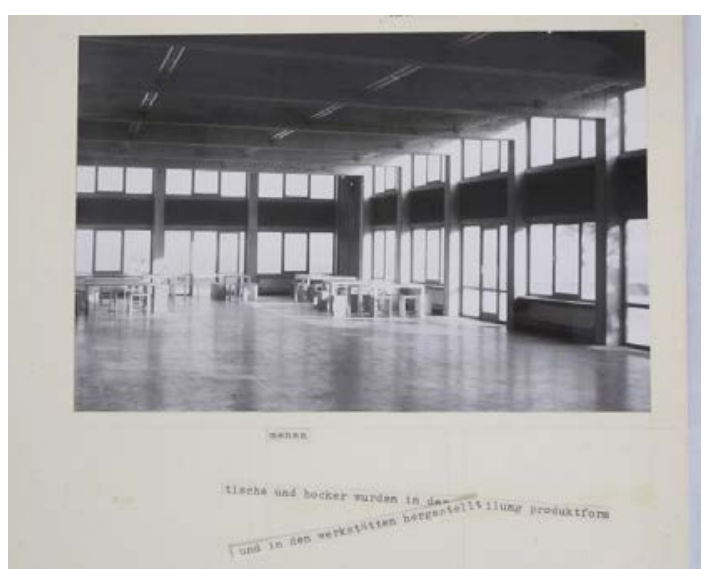

Foto interio aula magna, comedor. Ernst Hahn. 1955

Se ha tratado el tema de la proporción, que evidentemente tiene que ver con lo constructivo y no con lo puramente arquitectónico. La aproximación al hecho arquitectónico, a la arquitectura que le interesa lo hace Bill a través de la geometría no euclidiana, lo euclidiano a quedado remitido a la construcción.

"Pero lo propio del técnico y del artista es, por el contrario, instituir y mantener, durante su operación, un temperamento, o cambios tan íntimos como sea posible entre lo que desea y busca y lo que le ofrece o le niega el conocimiento que tiene de su materia y del estado final y real de su obra. De estas observaciones resulta que se puede imaginar fácilmente una especie de conflicto entre la particularidad de la producción de las obras de arte, en que cada una es una solución singular de un problema que jamás se reproducirá exactamente, y la generalidad del precepto estético que representa y precisa el número phi, el cual no debe utilizarse ciega y bruscamente, sino considerarlo como un instumento que no puede prescindir de la habilidad y la inteligencia del artista. iAl contrario! Debe excitar al artista a desarrollar estas cualidades, y aquí es donde intervienen las propiedades, tan notables, del número de Oro." ${ }^{\prime 1}$

Como podemos experimentar en la aproximación al edifico, este se ha desarrollado a partir de un dominio de dos agujeros-patio multiconexo. Esto significa que cualquier curva cerrada contenida en un dominio A puede deformarse o contraerse hasta un único punto sin discontinuidades, este dominio se llama conexo. Si ocurre que la superficie tiene un agujero ya no es simplemente conexo sino su múltiplemente conexo. Podemos construir dominios de 2, 3, 4 agujeros y para hacerlos conexos cortaríamos por un radio de cada agujero lo que significa que para convertir un dominio $D$ múltiplemente conexo en otro simplemente conexo se necesitan n-1 cortes, entonces el orden de conexión es $\mathrm{n}^{42}$

Desde el punto de vista de la geometría topológica si tenemos uno o varios agujeros en una superficie,ocurre que un área definida no la podríamos reducir a un punto en todos los casos. Alrededor de cada uno de los agujeros produciríamos una interrupción en el proceso reductivo. El proceso normal hacia una superficie conexa, seria cortar los agujeros para conectarlos con el borde exterior. La nueva disciplina se llamaba "análisis situs o topología" y estudio las propiedades de las 


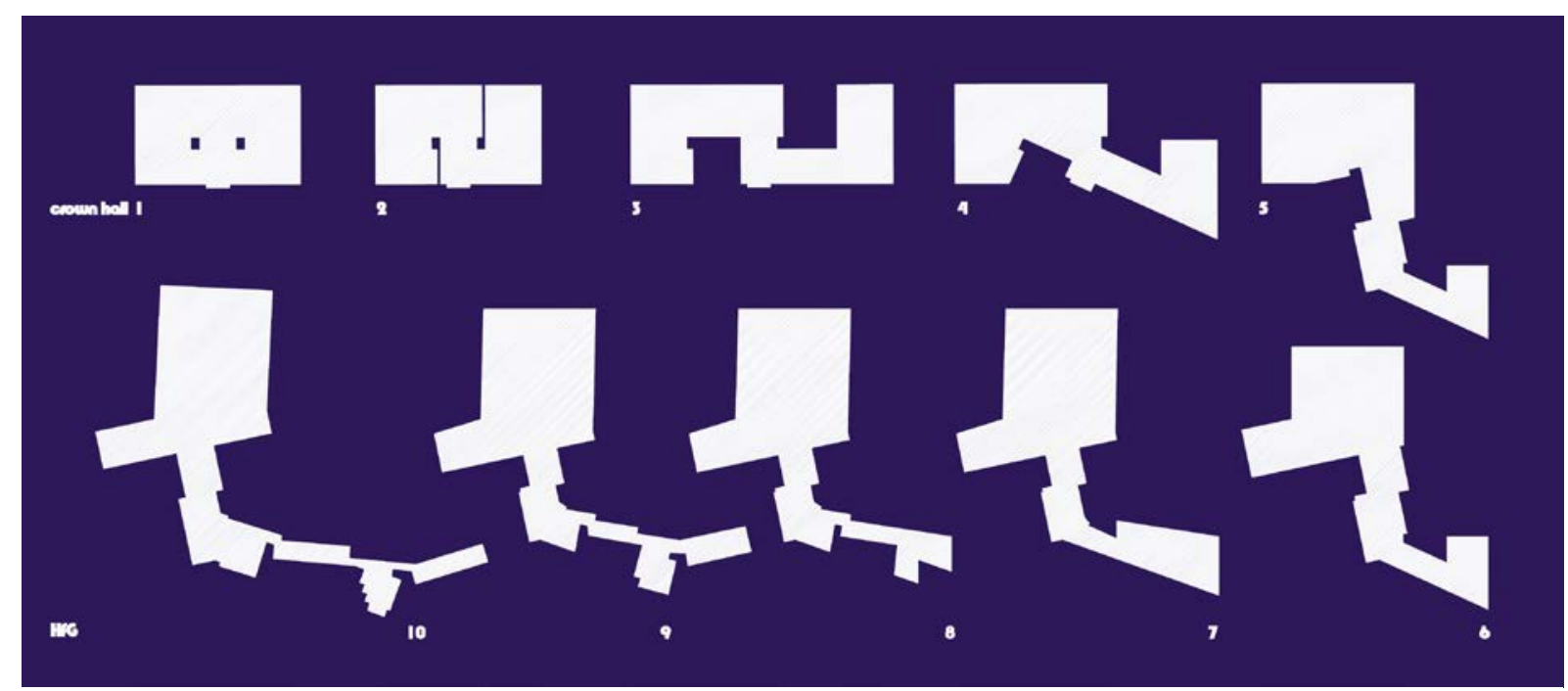

(f1.Transformación topológica del Crown Hall de Mies Van der Rohe en el edificio de la HfG en 10 pasos

figuras geométricas que subsisten aun si a esas figuras se las someten a deformaciones tan radicales que las hacen perder todas sus propiedades métricas y proyectivas. (f1

Uno de los grandes geómetras fue A. F. Möbius (1790-1868), un hombre cuya falta de seguridad en sí mismo le llevo a un observatorio astronómico de segunda en Alemania. Con 68 años sometió a la Academia de París una memoria sobre superficies de una sola cara. Por otro lado e independiente de él el astrónomo alemán J. B. Listing (1808-1882) de Göttingen hizo descubrimientos análogos y a petición de Gauss publico. Möbius descubrió la superficie de una sola cara. La más sencilla es la banda de Möbius, sólo tiene un borde y consiste en una curva cerrada única. A mediados del XIX comenzó un nuevo desarrollo de la geometría, que se convirtió pronto en una de las fuerzas mas potentes de la matemática. ${ }^{43}$

Max Bill admiraba de Mies la gran forma, la capidad de manejar la función para conseguir representación. Ningún arquitecto del siglo XX se ha acercado a la monumentalidad de Mies. Para Bill la arquitectura griega, que tanto admiraba, estaba en el arquitecto alemán. El proceso del Crown Hall es completamente paralelo al de la $\mathrm{HfG}^{44}, 1950-1956$, por lo tanto parece improbable que Bill pudiera conocer ese proyecto. Tal vez el murmullo de los arquitectos alemanes que miraban a América. Bill para ser arquitecto con mayusculas tenía que hacer el Crown Hall, además parecía lógico plantear un edificio compacto y completamente modulado. la excasez de medios para la construcción y el mantenimiento del edifico obligaba a una gran caja de zapatos con dos patios, de tal manera que fuera fácil distribuir el programa. Así pensaba cuando se dirigía en su coche $e^{45}$ hacia el oberer Kuhberg. En unas imagenes filmadas por alguien que le acompañaba se le ve bajar del coche y recorrer el terreno en pendiente. ${ }^{46}$ Evidentemente no era el lugar apropiado para la monumentalidad euclidiana de Mies. El terreno claramente tenía dos partes, pero no iba a haber dos edificios, era consciente de la concepción espacial continua que debía de tener. Partiendo del rectángulo de $67 \mathrm{~m}$ por 36m que plantea Mies en el Crown Hall ${ }^{47}$ define dos agujeros-patio en los vacios-escalera de la planta principal. Mediante dos cortes en la superficie de partida, de tal manera que los agujeros-patio queden conectados con el exterior de la superficie.(f1 De esa manera el dominio pasa a tener 0 agujeros, y

43 August Ferdinand Möbius en Enciclopedia Britannica, Micropedia, Tomo 8, pag 209 44 Hochschule für Gestaltung 1950-1955

45 Bentley Mark VI del año 1947, matrícula de Zurich 9797, con el volante a la derecha 46 Max Bill, documental canal 3 Sat. Max Bill, ein Film von Ernst Scheidegger. 1998

47 Ricardo Daza. Buscando a Mies. Actar. 2000 


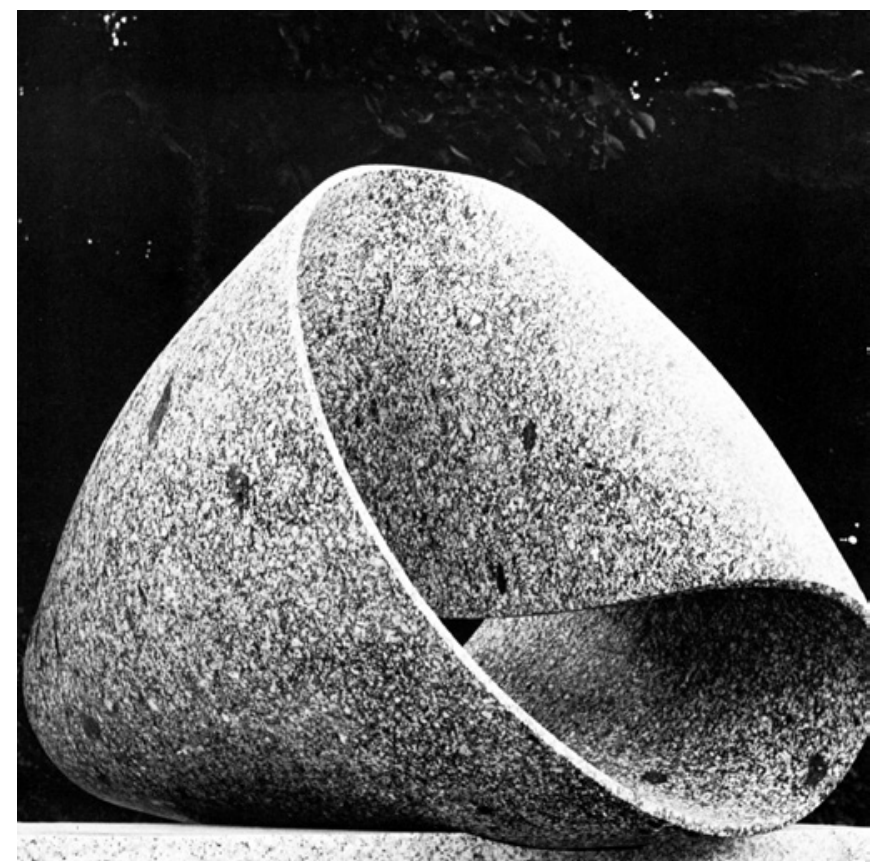

(f1. Max Bill, Cinta sin fin, granito, 150×100×120 cm. 1935-53

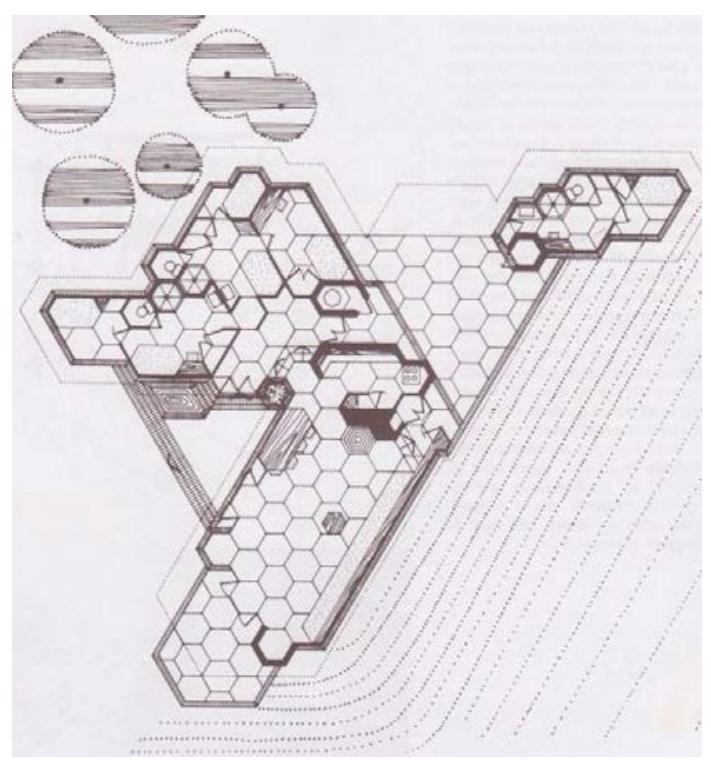

Frank Lloyd Wright, Bazett House. Hillsborough, California. 1940

dos patios abiertos al exterior, transformándose uno de ellos en el vacio de acceso y el otro en el lugar definido entre edificio y castillo. De esta forma tenemos un dominio conexo ${ }^{48}$ en todo el edificio aunque cueste entenderlo. Intuitivamente conexo significa continuo, de un continuidad espacial. El rectángulo se va abriendo por los patios, sin rupturas. Cambia su metricidad, pero topológicamente sigue siendo la misma superficie. La deformación en planta permite adaptarse al programa, y también al terreno. Max Bill llevaba desde el año 1934 interesado en estas superficies topólogícas. En ese año cuando construye su primera cinta de Möbius. ${ }^{49} \mathrm{Al}$ final la arquitectura de Mies por una lado y la deformación topológica de ese espacio ecuclidiano pertenecen a la superficie de la misma cinta de Möbius. (f1

. la estructura espacial, horizontalidad inclinada

La lucha del edificio con el lugar, con el programa, con la cocepción de Bill se produce dentro. Aparentemente no se advierte en su superficie, en sus fachadas. La complejidad perceptiva se entiende de forma poco sólita desde fuera. En palabras de Colin Rowe, "no es difícil imaginar la solución de Wright a ese programa: un gran volumen hexagonal que engendrase por su impulso interior una serie de hexágonos menores, terrazas y pasillos cubiertos. También se puede pensar en una solución al estilo Mies. Embriones a la manera de Aalto, Kahn y todas las variantes que pueden poblar la imaginación. Pero el número de elecciones de que dispone un sola persona nunca es tan grande. Al igual que una época, una persona también tiene su estilo -suma total de las disposiciones emocionales, tendencias mentales y actos característicos que, tomados en conjunto, forman su existencia." ${ }^{\mathbf{5 0}}$

Podríamos decir que la $\mathrm{HfG}$, como las construcciones de cualquier otro arquitecto se determina de forma primaria por una formulación formal que se experimenta como formulación lógica. Cualquiera de las decisiones se han ido encadenando con absoluto sentido común. La forma en L del solar, los dos niveles, el castillo, las vista al valle del Danubio, ha ido conformado una construcción horizontal

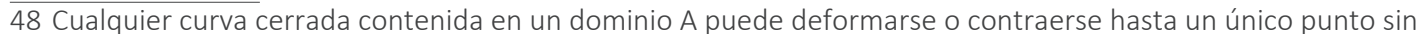
discontinuidades. Este dominio se llama conexo.

49 Max Bill, unendliche Schleife, 1935-53

50 Colin Rowe, Manierismo y Arquitectura Moderna y otros ensayos, Gustavo Gili, 1978. pag 186

118 / la arquitectura de la hfg ulm. de la objetividad a la revolución 


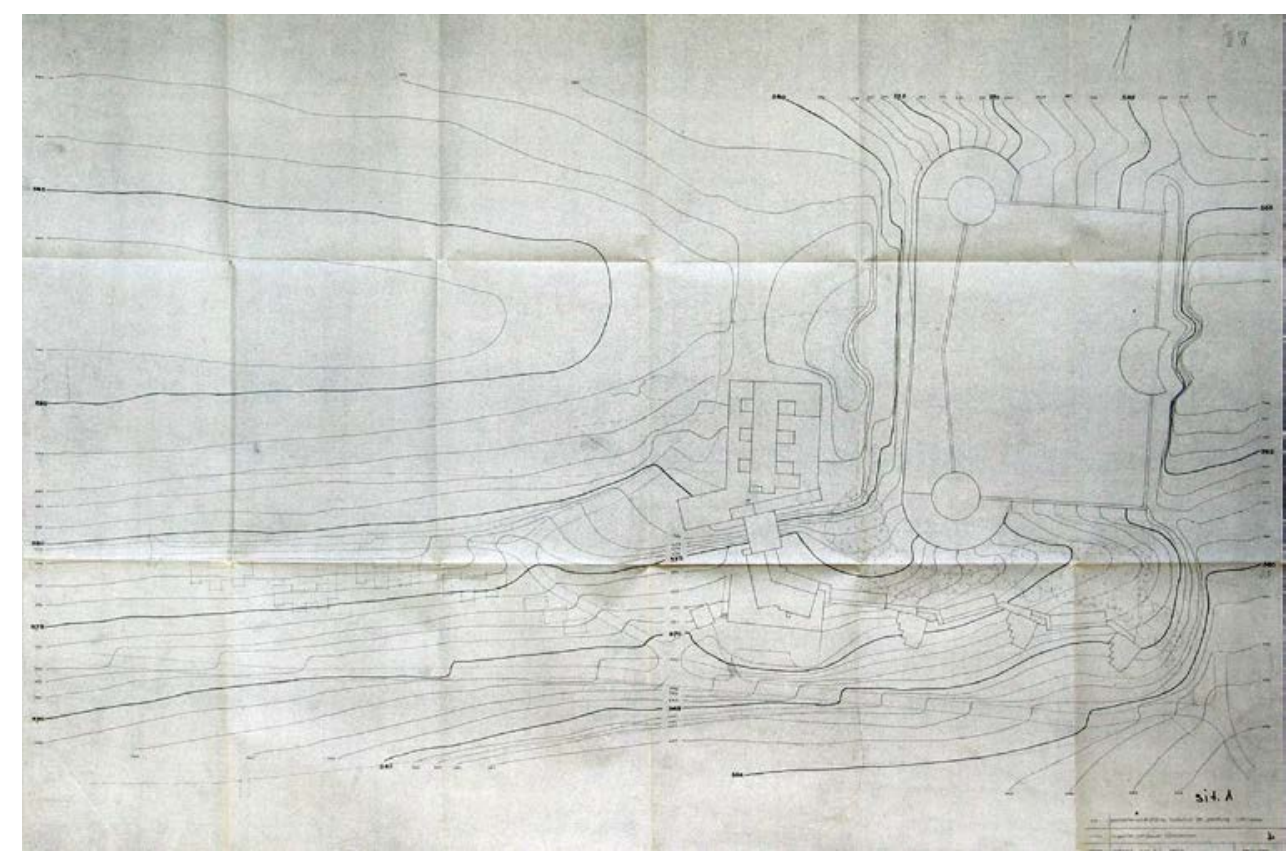

(f1. Max Bill, Plano de situación proyecto presentado a licencia, difiere de lo construido finalmente. 1953

pegada al terreno y abrazando el castillo. La planta en continuidad para los lugares comunes, se convierte en dos plantas en los volúmenes con un programa concreto: aulas, talleres, viviendastaller. Aunque en realidad al final el edificio cuente con 5 niveles. La espina dorsal, o corredor de comunicación asciende pegado al terreno, desde él escaleras conectan con la capa superior. Solo en la torre de viviendas se acumulan 5 plantas, convirtiendose en el elemento que equilibra la altura máxima de cubiertas de los talleres sobre la colina.

Desde la parte mas alta, la superficie sobre la colina, tenemos las dos plantas de talleres, el siguiente nivel sería el diente de sierra que se gira para colocarse paralelo al talud-barbacana existente, igual que el volumen de aulas. Este accidente geográfico se salva con un puente que conecta con el volumen-vestíbulo, donde se sitúa la escalera principal, que salva el desnivel en paralelo. Esta caja esta directamente conectada, y en el mismo nivel, que la del aula magna-comedor. En este caso y para mantener el nives Bill coloca la plataforma-terraza horizontal sobre el terreno inclinda. Debajo posiciona dos plantas de instalaciones. El nivel de la terraza se continua parlelo a las curvas de nivel que miran al valle, hacia las viviendas-taller, a las que se accede por un estrato inferior. La conexión es mediante las escaleras interiores de las viviendas taller y desde fuera mediante una escalera que aparece en la charnela de conexión entre este volumen y el de la cocina. Se sigue en horizontal hasta la torre-apartamentos para estudiantes, que salva el siguente desnivel hasta conectar mediante un corredor con el otro bloque viviendas-taller, que sigue descendiendo suavemente en paralelo a las curvas de nivel y mirando al valle del Danubio. (f1

. principio generador: la belleza nace de la función y existe como función

"La ley de la estructura espacial se ajusta al principio riguroso para el que la belleza nace de la función y existe como función, el vigor plástico de los edificios se encuentra exclusivamente en la proporción del volumen y la articulación con el espacio natural muy amplio: la arquitectura potencia el paisaje, y el paisaje ennoblece la arquitectura. no hay ningún recurso decorativo o se procura la ayuda de materiales valiosos." ${ }^{151}$ Margit Staber retoma de Bill el concepto de Belleza como otra de las funciones a las que debe atender un proyecto. Esto lo explica Max Bill en Basilea el año 1949 en un encuentro 


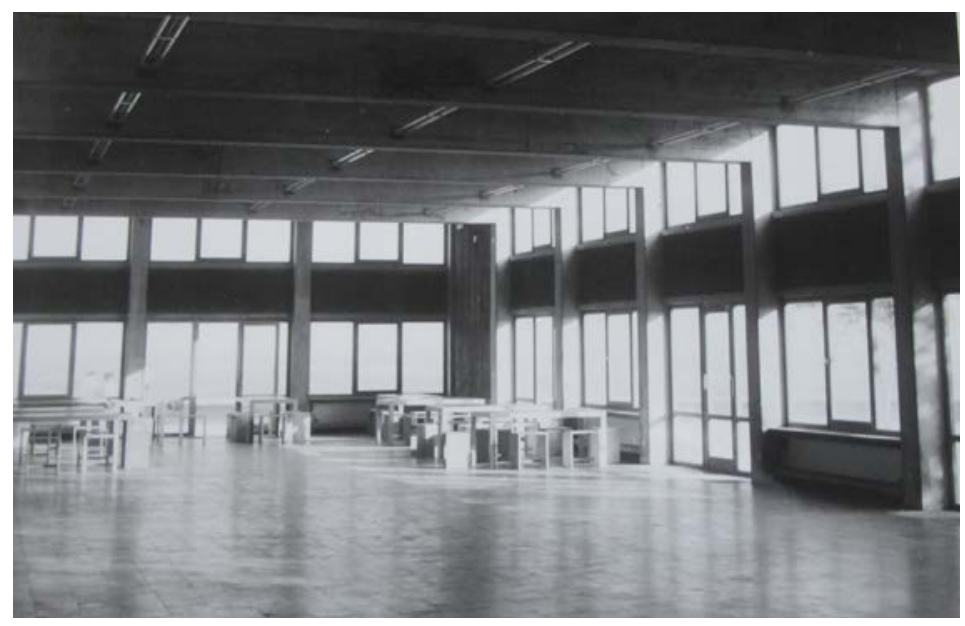

de la Werkbund suiza. Aboga por considerar la belleza como función y dice que los diseñadores serán responsables, en gran parte, de la cultura visual de la población, en tanto que los arquitectos del desarrollo saludable de nuestras ciudades y lugares para vivir ${ }^{52}$. Si bien su interés por la matemática marca algunas de las decisiones mas importantes del proyecto, el entender, desde el principio, que la belleza es parte del programa de un escuela de diseño y arquitectura. El juego de proporciones, la relación interior-exterior, el posicionamiento, la continuidad de las fachadas. Las modulaciones del interior, los objetos sobre la arquitectura: bancos, luminarias, armarios, etc, atienden al programa de solicitaciones, donde uno de los primeros requerimientos es la belleza.

\subsection{2 las funciones espaciales aplicadas a su psicodinámica}

. sistematización para conseguir la multiplicidad espacial: La disposición del edifico

"Se pueden poner en relación la fachada de la HfG con la de los edificios del IIT de Mies, pero no se puede hacer lo mismo con la planta"53. Parece una afirmación correcta. Aunque en realidad no lo sea tanto. Bill plantea, como hace Mies, varios edificios atendiendo al programa. Los dos tienden a posar sus edificios sobre la superficie del terreno. Evidentemente los terrenos son muy diferentes, uno en su totalidad plano y el otro, casi, completamente inclinado, con además una especie de falla producida por la barbacana del fuerte. Bill coloca los edificios como se ha comentado. En ese sentido Bill no tiene más remedio que colocar el volumen grande, los talleres, en la parte alta, y abajo hacer una plataforma y sobre ella, como si de la acrópolis de Atenas se tratara, colocar varios volúmenes públicos, vestíbulo, aula salón de actos y cocina-comedor. El espacio libre sobre la plataforma se convertiría en la gran terraza de Ulm y la parte hueca de la plataforma la ocuparían instalaciones. Entre las dos plataformas hay un desnivel importante, agudizado por la presencia del talud y algunos árboles. La conexión no es fácil, aunque la solución la tiene Bill desde el principio, una especie de puente apoyado sobre la primera planta del edificio vestíbulo y la baja de la gran nave de talleres.

Es esta conexión la que mancha la pureza de forma del IIT, y confiere al de Ulm una disposición

$\overline{52}$ Max Bill, Beauty from funtion and as a funtion. 1949. Publicado en Form, Funtion= Gestalt. Architectural Association London. 2010

53 Hans Frei. Konkrete Architectur? Über Max Bill als Architekt. Lars Müller, Baden. 1991

120 / la arquitectura de la hfg ulm. de la objetividad a la revolución 


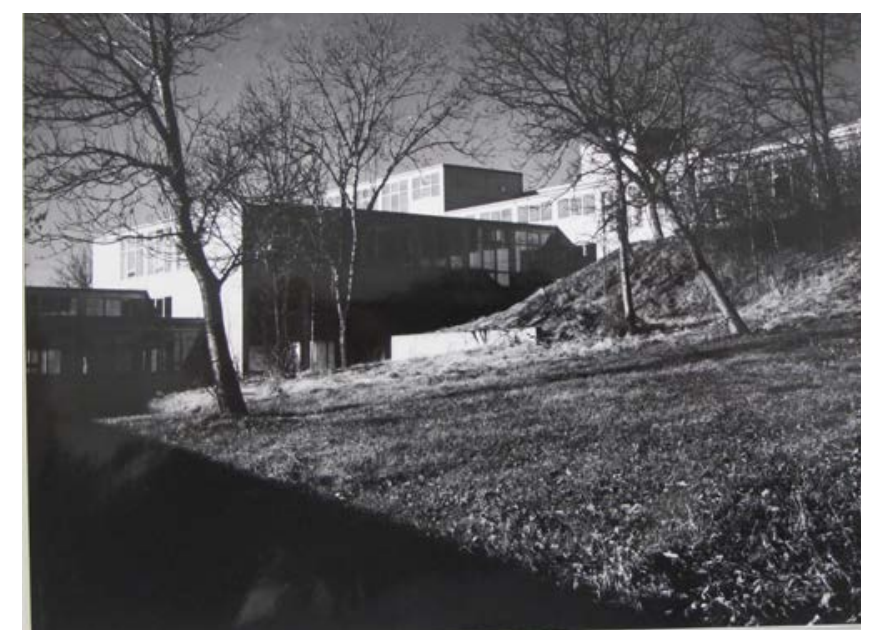

compleja, provocando vistas diferentes desde cualquier lugar.

Stanislaus von Moos escribió en Schweizer Architecture: Von der Utopie zur Realität und züruck, Jan-Feb. 1985, pag 79: “detrás de la arbitraria dispersión se esconde una precisión que podría ser comparada con los edificios en Berlín de Schinkel. Realidad que recogió Claude Schnaidt en su felicitación para el nuevo año 1957 representado el nuevo edifico de la escuela en estilo clásico romántico. La máscara subraya la categoría de lo pintoresco, la cual en Ulm es efectiva, en contraposición del racionalismo geométrico de los criterios de ordenación de Mies en Chicago. El propio Frei dice "en la búsqueda de la forma, las construcciones de la HfG se suman a lo racional y pintoresco". Tampoco parece una afirmación muy seria después de leer algunos textos de Bill. La idea de superficie única, como línea única, y su potencial artístico es defendió por Bill en el texto "de la superficie al espacio". El deseo de una superficie única, plana, a lo IIT, se mantiene como el objetivo principal. La superficie única, no orientable y de borde continuo es la cinta de Moebius.

Pero la traducción a arquitectura no es directa. Lo primero la geometría euclidiana que maneja Mies no encaja. Bill trabaja con algo que conoce hace años y que le permite desarrollar el proyecto de una forma absolutamente personal. La geometría topológica. Coloca un rectángulo Illinois sobre el terreno en pendiente y con la inclusión de dos patios, agujeros en el mundo topológico, consigue distribuir el programa de forma compacta.

Esta superficie se conoce como multiconexa pues sobre ella no se cumpliría la conjetura de Poincaré, es decir si colocamos una goma apoyada en su totalidad en la superficie, y la reducimos hasta convertirla en un punto, esta partícula sigue perteneciendo a la superficie, y esto se cumple en todas las dimensiones. En el caso de la planta de bill, el rectángulo con dos agujeros, se ve claramente que la goma reducida se colaría por uno de los puntos. Pero la superficie debe de ser conexa para ser no orientable. Para lo cual se practican dos hendiduras que conectan los agujeros con el perímetro. Esto convierte a la superficie otra vez en conexa y compacta. Sobre esta superficie topológica se puede efectuar deformaciones si cambiar sus características, o sea siendo la misma planta que las de Mies en el IIT, pero sin pertenecer al espacio euclidiano. La planta se deforma a lo largo de la topografía del lugar, con criterios de economía constructiva básicamente.

Esta superficie gorda, conexa y deformada a lo largo de la superficie del lugar genera un serie de 

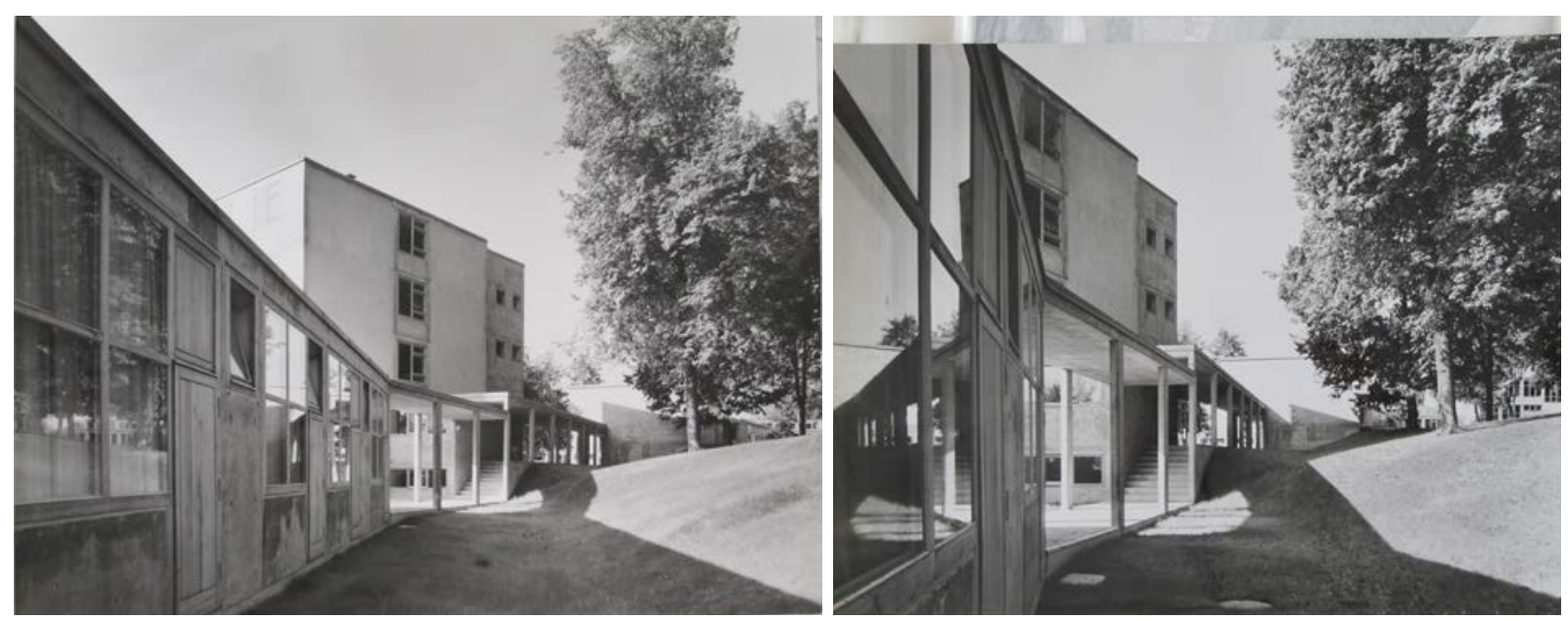

cajas interconectadas, adaptadas a la topografía existente. Las condiciones de vecindad, y entorno son parámetros que intervienen en la multideformación del sistema. Obteniendo una estructura continuada, determinada por reglas puramente matemáticas.

La relación espacial y topológica entre las cajas y los elementos que podríamos llamar de conexión genera dos lugares de intensa concepción. El lugar de encuentro entre el tramado de la cocinacomedor y el de el salón de actos, potenciado por la deformación en sección para conseguir mantener uno de los criterios de diseño del edificio, la luz natural lleva la dirección del recorrido. El otro espacio charnela interesante es el que se conoce como diente de sierra en la conexión entre la zona de talleres y el puente que viene del vestíbulo. Como dice Frei "desde fuera parecen como zonas sándwich entre los sosegados cubos primarios, de los que se obtiene una diferente impresión."

El nombre Sägeblatt (diente de sierra) proviene de los triángulos que se forman en el encuentro escalonado con el edifico de talleres. Bernard Rübenach lo compara con las piazzas italianas. En realidad este espacio resuelve el la posición del gran edificio de talleres. Desde el primer momento, y probablemente por falta de espacio, Bill decide ponerlo paralelo al castillo. El giro se produce al llegar al talud, que va a marcar la dirección de la caja de la biblioteca y de la del vestíbulo. La dimensiones de este espacio son inesperadamente generosas, convirtiéndolo en uno de los núcleos de actividad y movimiento del edificio. La dirección de la luz, y la perspectiva forzada intensifica las sensaciones.

Según Edwin Walder 54 "la Gestalt del edificio se basa en varios sistemas que Bill aplicaba a todo muy a menudo." El señor Walder se refiere, entre otros detalles, a la conexión a través del comedor con la salida que conduce a los Atelierhäuser (casas taller), mas baja que el espacio del comedor, lo que permite, por encima, una entrada de luz natural del norte hacia el comedor, también lo repite en el salón de actos de planta baja, en el vestíbulo, diente de sierra y talleres.

Kenneth Frampton vio en esta parte del edificio una posible gran deformación. "all concern for... the logic of aesthetic mesure seems o be sacrificed at this juncture, to those distortions as were considered neccesary for the accommdation of the public realm or the celebration of the genius loci of the site" ${ }^{\prime 55}$. Realmente las deformaciones vienen del planteamiento del propio Bill. La geometría topológica (ver esquemas) le permite operar estirando la planta para adaptarse a la topografía y al

54 Dibujo la construcción entre 1952-53. Conversación con él 1985)

55 Frampton: on max bill, october 1974 (s 156

122 / la arquitectura de la hfg ulm. de la objetividad a la revolución 
programa concreto.

Según Hans Frei56 "el efecto de vuelco de la forma mas superficial en las partes de conexión, que ya se podía ver desde el principio en los dibujos de los Vorprojekte, se puede observar en la escultura para el prisionero político desconocido. El concurso se desarrolla en 1952, es decir al mismo tiempo que los planos de construcción de la HfG. Bill escribió en la memoria explicativa para el jurado que el proyecto estaba marcado por dos aspectos: desde fuera es una forma elemental angulosa y cerrada, y desde dentro, sin embargo, multiforme y abierta por todos los lados ${ }^{57}$. De todas formas esto sólo se puede entender en el sentido de "equilibradas relaciones en el espacio", como Piet Mondrian dijo el año 1920 promocionando una arquitectura neoplasticista. "En las obras diseñadas por Bill se encuentran diferentes interpretaciones que van del todo a la nada en un equilibrio armonioso, en este aspecto no parecen simultáneas y cambian desde cada punto de vista del observador. Una y la mima forma (Gestalt en el original) tienen la capacidad de transformarse y desde fuera una lectura diferente a la del interior." ${ }^{158}$

Estas deformaciones acaecidas en los elementos de charnela se resuelven con un estiramiento del módulo estructural generando heterogeneidad. Lo que eran pilares se transforman en pantallas que se recortan horizontal y verticalmente para obtener una unidad plástica. Ejemplo de estas articulaciones es la unión entre el volumen de la cocina con la primera de las cajas de los Atelierhäuser, donde se produce el encuentro entre la continuación del forjado bajo de la barra del bar, que vuela hasta convertirse, sin solución de continuidad, en la cubierta del Atelier. La articulación horizontal se produce al recortarse en planta, vaciando la parte sobre la terraza-plataforma y quebrándose justo en la conexión con la cubierta del Atelier. Verticalmente ocurre lo mismo, esta deformación se produce en el primer apoyo al levantarse un pantalla como prolongación del extrados del muro soporte de la plataforma-terraza, dejando, eso sí, que vuele la losa de la cubierta como si no tuviera apoyo. También la primera pantalla vertical, de las cinco que tienen las casas-taller, se prolonga hacia la parte de atrás para recoger la losa que viene de la cocina y se recorta en un nivel más bajo para permitir el acceso al pórtico que define la Atelierhaus. (ver imágenes alusivas).

56 Cita libro de Hans Frei Konkrete Architecture pag)

57 Bill: Ein Denkmal, 1952, citado a partir de: Hüttingen: Max Bill 1976, pag 125

58 Cita Mondrian: neue Gestaltung Neoplasticismus Nieuwe Belding, 1974, pag 12. Publicado por primera vez en 1925 

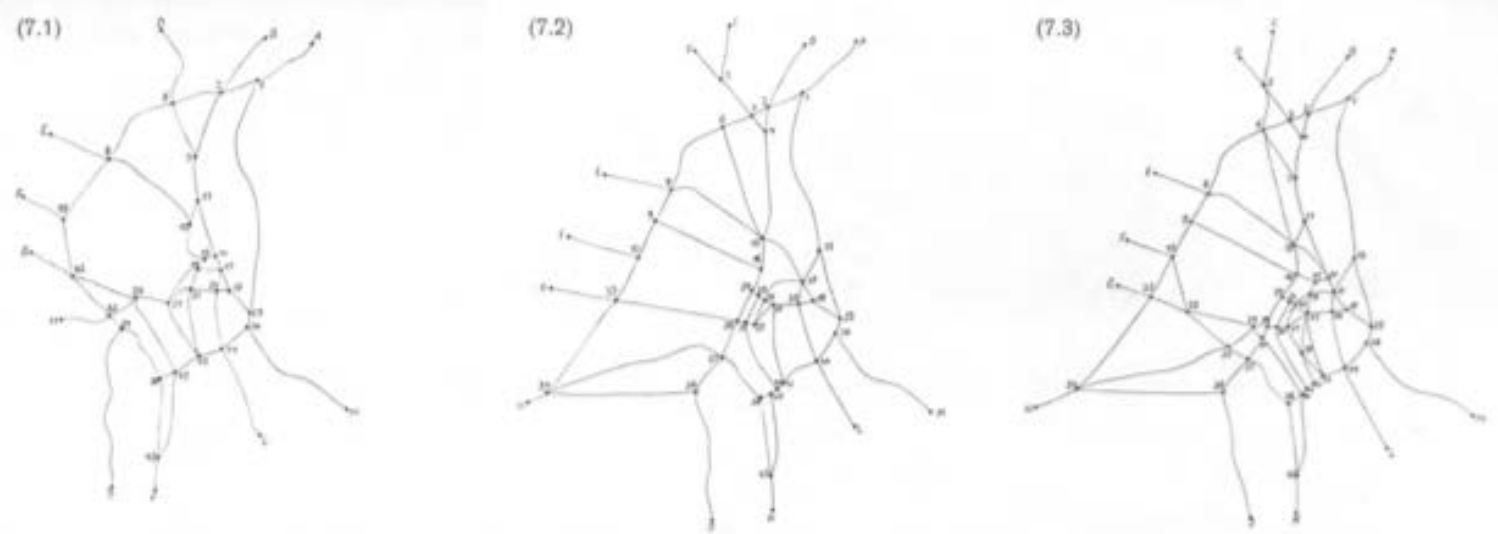

In dieses Gitter legen wir das der Matrix entsprechende Graph (7.6), das sich zet.

legen Iast in zwei Graphe $(7.4),(7.5)$, die die Situationen von 1955 und 1958 veran

The graph (7.6), which corresponds to the matrix, is bedded in this lattice; it is then partitioned into two other graphs $(7.4)$ and (7.5), showing the plans for 1955 and 1958

Dans cette grille, nous intégrons le graphe 76 gui cortespend a la matrice. On peit le decomposer en deux graphes (7.4), (7.5), qui illustrent la situation de 1955 et de 1958. schaulichen. respectivoly.

(7.4)

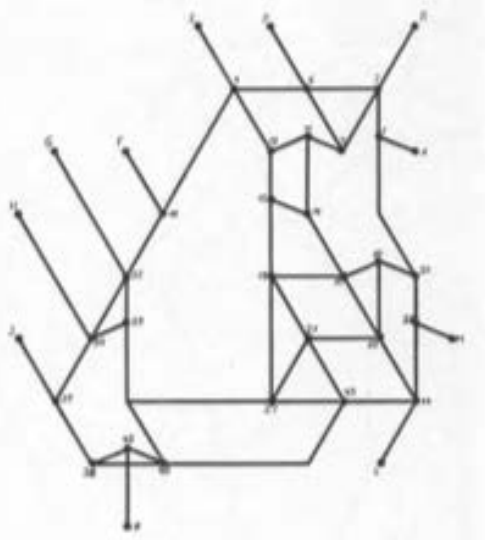

(7.5)

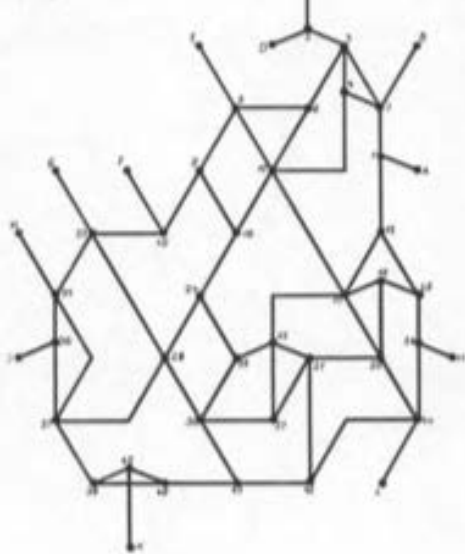

(7.6)

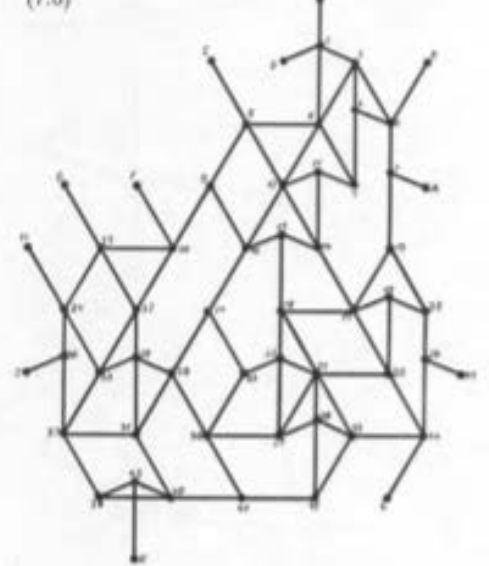


El corredor abierto de conexión en planta baja, atraviesa toda la caja de los talleres-vivienda, el piso superior se apoya sobre 5 muros pantalla que como en el caso del primero se recortan en planta baja. Por el contrario en el corredor aparecen unos pilares apantallados, otra vez deformados en la dirección de la circulación. Sin embargo, en su conexión con la torre de viviendas para estudiantes se vuelve a transformar en pilares. En este caso el claro estiramiento de la cubierta arrastra los vacíos, creciendo, hasta llevar a los pilares a su dimensión primera $(25 \times 18 \mathrm{~cm})$.

. recorridos topológicos, el intento de conseguir una superficie única, de borde único (fachada), no orientable. La representación mediante Graphos

"La costruzione esprime quindi precipuamente le concezioni spaziali tipi. che dell'architettura di Bill l'attuarsi di funzioni spaziali nella loro relazione psicodinamica, nella vita quotidiana, nelle più diverse circostanze della loro utilizzazione. Non sempre collaboratori e scolari sembrano comprendere il modo di progettare di Bill"59 .

En este texto la señora Staber se posiciona claramente del lado de Bill y afirma con gran rotundidad que Bill, ya en ese momento, tiene una forma especial de concebir la espacialidad del edificio. Bill introduce funciones (matemáticas) espaciales aplicadas a la relación sicodinámica entre el usuario y el espacio por el que transita.

Esto tiene una referencia directa a la Internacional Situacionistas (IS) y en particular por las observaciones de Gille Ivain60 "el cual ya había avanzado en el seno de internacional letrista, allá por el año 1956, la hipótesis de una nueva aproximación a los fenómenos urbanos basada en la experiencia vivida del espacio. El instrumento principal de que se sirve la investigación psicogeográfica es la deriva que la IS define como la forma de comportamiento experimental ligada a las condiciones de la sociedad urbana, la técnica del tránsito veloz a través de distintos ambientes la deriva se diferencia cualitativa mente tanto del viaje como el paseo, porque mira al reconocimiento de los

59 Texto introductorio de Margit Staber en el no 259 de Casabella: "El edificio expresa por tanto, principalmente la concepción espacial típica de la arquitectura de Bill, de las funciones espaciales aplicadas a su relación psicodinámica, en la vida cotidiana, en las más diversas circunstancias de su uso. No siempre el personal y los alumnos parecen entender cómo proyecta Bill" (traducción español carlos a wandosell

60 mario perniola, Loa Situacionistas, historia crítica de la última vanguardia del siglo XX" 
efectos psíquicos del contexto urbano. La deriva presenta un doble aspecto, pasivo y activo: por un lado, comporta la renuncia a cualesquiera objetivos Y metas fijadas de antemano así como el abandono a las solicitaciones del terreno ya los encuentros ocasionales $y$, por otro lado, implica el dominio y el conocimiento de las vacaciones psicológicas". Explicar la cita en referencia a la relación sicodinámica de la que habla Staber y que está en el edificio de Bill.

Según Margit Staber Bill “Eppure il suo principio è assai semplice: egli disegna soltanto ciò che può rappresentarsi in termini spaziali, e procede immaginativamente, quasi come in sogno. E queste sue intuizioni le traspone nella realtà, dando loro una forma sistematica, maturandole architettonicamente e tentando di sottrarre loro quegli aspetti soggettivi e personali che agli edifici di Frank Lloyd Wright, Le Corbusier, Mies van der Rohe conferiscono la forte impronta di una volontà espressiva architettonica". ${ }^{61}$

La compleja realidad espacial del edificio se entiende de forma concreta y precisa en ese recorrido sicodinámica al que hace referencia la señora Staber. Evidentemente el edificio es importante por esa concepción purista de lo que un artista entendería que tiene que ser la disciplina de la arquitectura a diferencia, por ejemplo, de la escultura, que es el espacio. El edificio es un bucle continuo, no orientable donde los elementos son la dirección de la marcha, la iluminación natural, la iluminación artificial y la sección longitudinal al recorrido. Expliquemos esto: describir uno de los graphos de los alumnos donde se especifica en su totalidad el programa del edificio. 


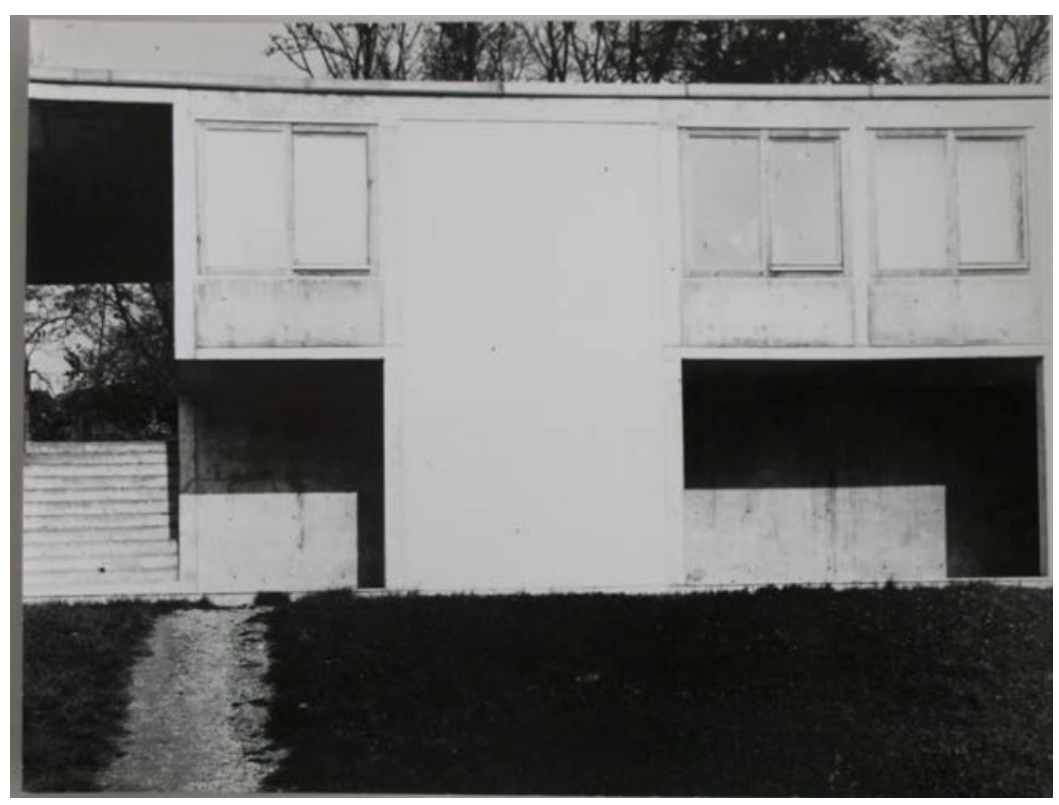

\subsection{3 topología geométrica en la HfG}

Since the 1940s - wrote Bill:

"he estado pensado sobre problemas de topología. Desde esta pensamiento desarrollé un tipo de lógica de la forma. Había dos razones por las que estaba atraído por este tema en particular: 1) la idea de un superficie infinita - que fue sin embargo finita- la idea de un infinito finito. 2) la posibilidad de desarrollar superficies que -como consecuencia de las intrínsecas leyes implícitas- dirigirían la forma en un sentido casi inevitable lo que probaría la existencia de la realidad estética. Pero ambos 1) y 2) también indicaron otra dirección. Si una estructura topológica no orientable puede existir es solo en virtud de su realidad estética, por tanto, a pesar de su exactitud. Podía no haber estado satisfecho con esto. Estoy convencido de que la base de su eficiencia está, en parte, en su valor simbólico. Son modelos de contemplación y reflexión"62.

En el texto entendemos claramente que Bill tiene dudas sería sobre el valor aplicable de la topología. Efectivamente está matemática permite conocer con precisión el comportamiento de una bandada de estorninos, desde el punto de vista de superficie única sin borde de ataque. El sistema atiende a la mejor posición conocida del sub-enjambre "circundante" al estornino-partícula en movimiento. Geométricamente es un conjunto de partículas relacionadas con independencia de la distancia que las separa. Todos o ninguno de los estorninos están delante o detrás, es la superficie la que se deforma y se dirige sin que las condiciones de cada estornino varíen, existe un vínculo de información entre cada partícula. Todos los vínculos constituyen un Grafo, una red de comunicación

62. finite-infinity (The Mathematical Approach in Contemporary Art, Max Bill, 1949, "I had been thinking about problems of topology. From them, I developed a sort of logic of shape. There were two reasons why I kept on being attracted by this particular theme: 1) the idea of an infinite surface - which was nevertheless finite - the idea of a finite infinity; 2) the possibility of developing surfaces that - as a consequence of the intrinsic laws implied - would almost inevitably lead to shapes that would prove the existence of the aesthetic reality. But both 1) and 2) also indicated another direction. If nonoriented topologic structures could exist only by virtue of their aesthetic reality, then, in spite of their exactness, I could not have been satisfied by them. I'm convinced that the basis of their efficacy lies in part in their symbolic value. They are models for contemplation and reflection." 


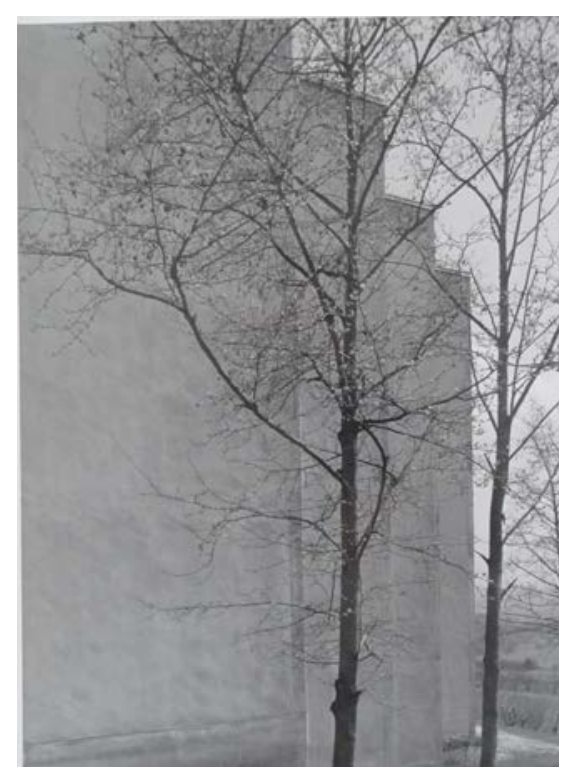

Es una situación interesante pero para Bill lo que hay detrás en un posicionamiento estético y simbólico que le sirven para reflexionar sobre el espacio. El elemento primario de actuación es la geometría que permite la ordenación de los valores emotivos. En ese sentido la matemática es un elemento esencial del pensamiento primario y como consecuencia, antes de actuar, entender el entorno que nos rodea. "Mientras que los artistas llegaban al constructivismo las matemáticas llegaban a un punto en que perdían claridad: las zonas límites son borrosas." 63

En el sentido espacial y en particular en lo referido a su concepción en la $\mathrm{HfG}$, lo interesante es entender la sorpresa de un espacio que empieza por un lado y acaba en otro, pero que a la vez es el mismo espacio, sin soluciones de continuidad o discontinuidad porque la limitación aparece sin límites exactos. Esto es una multiplicidad que a la vez es unidad. Pero en está continuidad hay elementos que acentúan diferentes situaciones, pueden ser de mobiliario -por ejemplo el banco-radiador del vestíbulo- o simplemente de iluminación, bien artificial o natural, siempre en el sentido del recorrido. "las paralelas que se cortan y la infinitud que vuelve a sí misma como presencia, además el cuadrado con toda su solidez y la recta no turbada por ninguna relatividad." ${ }^{64}$

En los planos de proyecto, analizando la planta, la impresión es que una ley oculta ordena y articula todo. Como dice en la introducción a la revista Casabella de Margit Staber, "la medida base de una unidad de masa" es el valor vinculante, al que se refieren todas las operaciones.

En las secciones podemos entender el carácter horizontal de la estructura del edificio. Una horizontal que se adapta a la inclinación del terreno. Una pieza de plastilina, que manteniendo el tamaño original se ha ido deformando para articular un programa, a la vez que se adaptaba al terreno y a la escala del paisaje, mientras resolvía de la misma forma el continuum de la espacialidad interior.

La propia Margit Staber lo expresa con claridad: "orden y ritmo, agrupación y distribución de los edificios aparecen claramente en la lógica estrictamente relacionada con el proyecto, lo que conduce a la calidad arquitectónica del complejo. La ley de la estructura espacial se ajusta al principio riguroso para el que la belleza nace de la función y existe como función, el rigor plástico de los edificios se

63 Cita Bill artículo matemáticas en el arte.

64 Cita bill artículo matemáticas en el arte. 


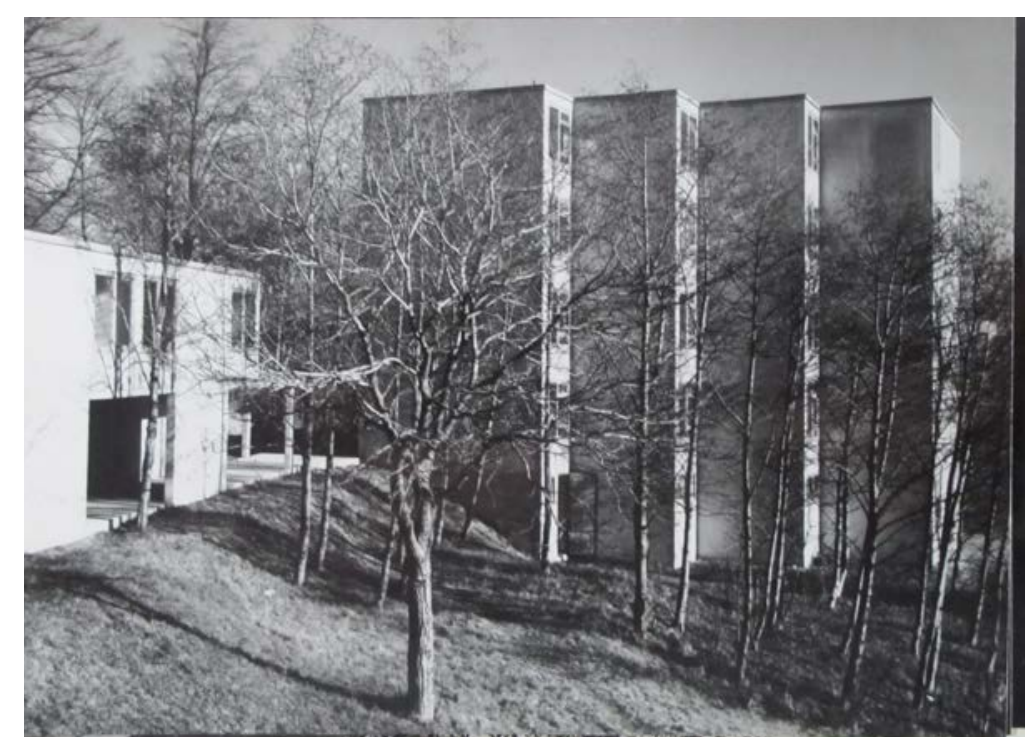

encuentra exclusivamente en la proporción del volumen y la articulación con el amplio espacio natural. La arquitectura potencia el paisaje, y el paisaje ennoblece la arquitectura." ${ }^{\prime 65}$

La malla espacial que teje Bill sobre el Oberer Kuhberg no necesita de materiales. Necesita remitirse al volumen compacto y monomaterial del que parte. No tiene razón Banham al decir que es fruto de la economía de posguerra. Es otra cosa que tiene que ver con introducir el máximo en el proceso creativo, para hacerlo con lo mínimo.

. concepto de proximidad, recorridos, consistencia

La disposición interna tiene dos recorridos fundamentales, habla de ellos Margit Staber en su introducción es Casabella, ella tenía información de primera mano pues había estado muy próxima a Bill, sobre todo durante la construcción de la obra y en sus años como director. El primero de ellos es el de los internos, es decir estudiantes y profesores que vivían allí. Empieza en el edifico torre residencia de estudiantes, se incorpora en tangencia al recorrido que viene desde el otro bloque del Atelierhaus. Al salir, y ya en el corredor tenemos miramos hacia el norte, hacia el castillo, del que apenas podemos ver la parte más superior detrás de los árboles. Lo que si percibimos es el espacio exterior del segundo patio, el conformado por la escuela y los árboles de delante del castillo.

El recorrido nos conduce directamente al corredor por debajo del primer bloque de viviendas-estudio. Desde la fachada ciega y abstracta que da al corredor, únicamente aparecen en ella cinco puertas ciegas, sin información alguna de lo que hay detrás, se incorporarán mas internos. Al final de este corredor alcanzamos una de las charnelas, espacio conformado por losas verticales y horizontales que como una unidad plástica nos resuelve el acceso al nivel superior (+575.35). entramos al volumen comedor-cocina, sin solución de continuidad pasamos de fuera adentro otra vez. Nuestro recorrido pasa tangente a los meandros de la barra del bar y continua pegado a una cristalera que sigue mirando la patio de atrás de la escuela. La descompresión del espacio justo en el quiebro de la geometría nos obliga a mirar hacia la izquierda, viendo a través de las ventanas el paisaje del valle del Danubio desde lo alto.

Ahora estamos en el vestíbulo previo al aula magna, espacio de descompresión por diferencia de nivel en la cubierta. De aquí accedemos directamente al vestíbulo principal, de frente a nosotros tenemos 


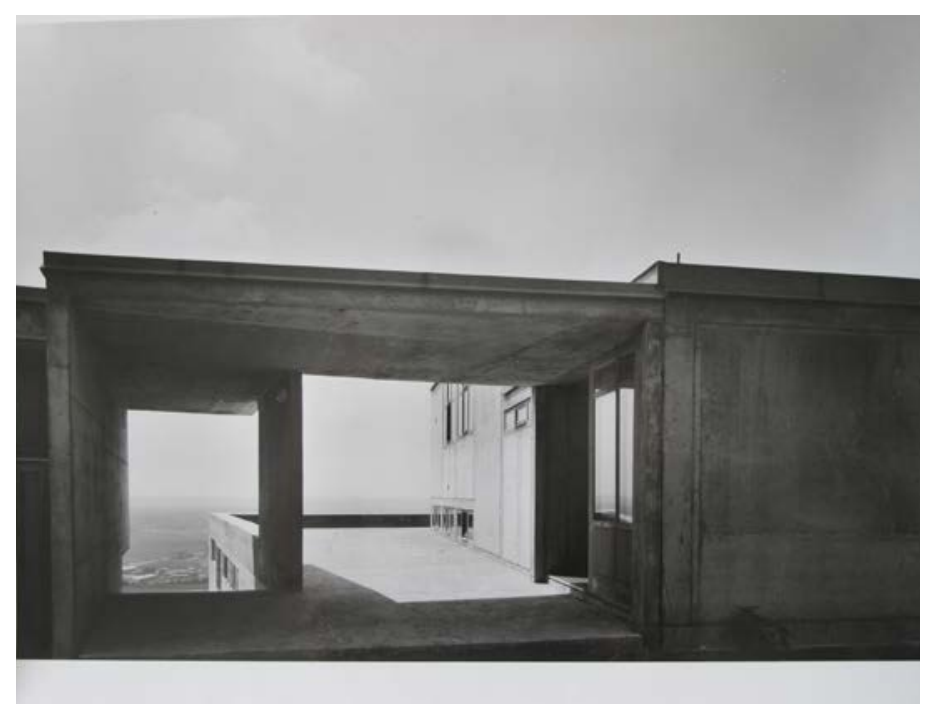

la escalera de acceso al siguiente nivel. A la derecha dos cristaleras nos siguen relacionando con el patio trasero, el delantero o de acceso se vislumbra a través del espacio comprimido del zaguán de entrada. Al subir la escalera somos consciente de varias circunstancias, la primera es que no hemos tenido que desviar, longitudinalmente, nuestra trayectoria ni un centímetro. Nuestro recorrido es perpendicular a las líneas de iluminación artificial diseñadas por Zeischegg. También, cualquier cambio de espacio viene marcado por la aparición detrás de un línea de iluminación natural. En el nivel que nos encontramos tenemos a la derecha la biblioteca, espacio puente complejo. Se encuentra suspendida sobre el talud-barbacana, y se resiente de su peso adquiriendo un sección en forma de artesa, resuelto con dos medios niveles. Este edificio puente, simbólicamente como si de un barco se tratara, tiene la dirección intelectual de la escuela representada por la biblioteca y la dirección gestora representada por el despacho de dirección, administración y secretaria. El acceso a estas dependencias es a través de un pasillo-pasarela que une la parte baja del solar con la alta. Max Bill resuelve esto con una rotundidad constructiva y conceptual impecable. De aquí accedemos al gran vestíbulo en diente de sierra que resuelve el acceso en diferentes niveles a las aulas del departamento de arquitectura, instituto de investigación y almacenes de talleres, departamento de comunicación (medio nivel arriba). En el nivel superior a la izquierda accedemos al curso básico, despacho de comunicación, oficina de forma del producto y a los talleres. Giraríamos en bucle cruzando todos los talleres y saldríamos otra vez al vestíbulo en diente de sierra. La relación con el exterior, en estas partes más estáticas ha quedado limitado a la luz natural.

El recorrido de los externos empieza en la portería, justo abajo al otro lado del pequeño aparcamiento de coche que queda debajo de la plataforma terraza. Después accedemos por la escalera rampa hasta el exterior del vestíbulo, que se remata al norte con un árbol y murete de contención que lo delimita del talud-barbacana. Al entrar estamos otra vez en el vestíbulo, con dos posibilidades ir hacia la zona pública del comedor y aula magna o girar a la izquierda para subir por la escalera principal hasta alcanzar otra vez el vestíbulo en forma de diente de sierra. 


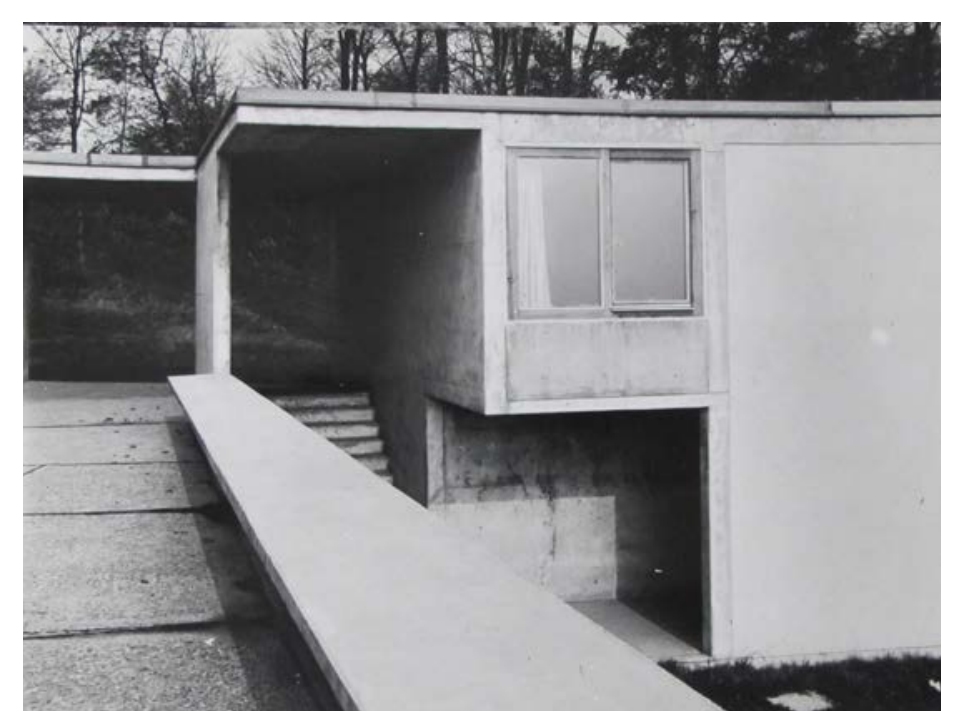

. atributos de los espacios: conectividad, compacidad, metricidad, metrizabilidad

-conectividad

La disposición interior sigue dos criterios diferentes, correspondientes a las dos formas efectivas de uso: de un lado la utilización de la escuela por los estudiantes internos; del otro el uso de los externos (en un cierto sentido incluso los profesores).

El primer movimiento por el complejo se inicia desde el edificio que acomoda estudiantes. Está conectado con una doble fila de talleres, incluyendo un corredor que conduce a la cafetería y al salón de actos, que se encuentra en el edificio principal, en el centro del complejo. Este último, junto con el jardín rodeado de edificios bajos y una amplia terraza que sobresale hacia adelante, son un lugar ideal para una vida comunitaria. el salón de actos y el comedor se encuentran junto a la entrada actual, de la que parten las escaleras; llegando a las oficinas de administración y la biblioteca, llegamos a un vestíbulo grande, desde donde nos conducimos a los distintos puestos de trabajo. En esta planta se añade, al lado izquierdo, un ala de dos plantas, proyectada para la sección de Arquitectura y el Urbanismo. Un gran auditorio en la planta superior es para el curso básico y se conecta directamente con los talleres, ubicados en el borde de la parte mas plana del terreno, un gran volumen de una sola planta, que contiene los estudios y talleres de Forma del Producto o Comunicación Visual. Se accede a la sección Forma del producto a través de una escalera en la parte superior central de la izquierda; el lado opuesto de la aurícula se extiende en forma de escalera. Aquí, a una altura intermedia está la sección de información, conectada directamente con la biblioteca, y en otro entrepiso superior está la sección de Comunicación Visual, que también está íntimamente ligada a la Sección de Información. Esta planta del complejo está fuertemente orientada hacia el interior: la razón de esta disposición es la necesidad de mantener las aulas conectadas con los talleres de diseño.

Las aulas de diseño se disponen a lo largo de los lados de los patios, que determinan un ambiente de trabajo silencioso. Talleres para la metalurgia, la madera y el yeso son accesibles desde el lado norte a través de una calle lateral. Luego, los estudiantes pueden frecuentar diferentes aulas, talleres en un ambiente común sin tener que ir al aire libre. 

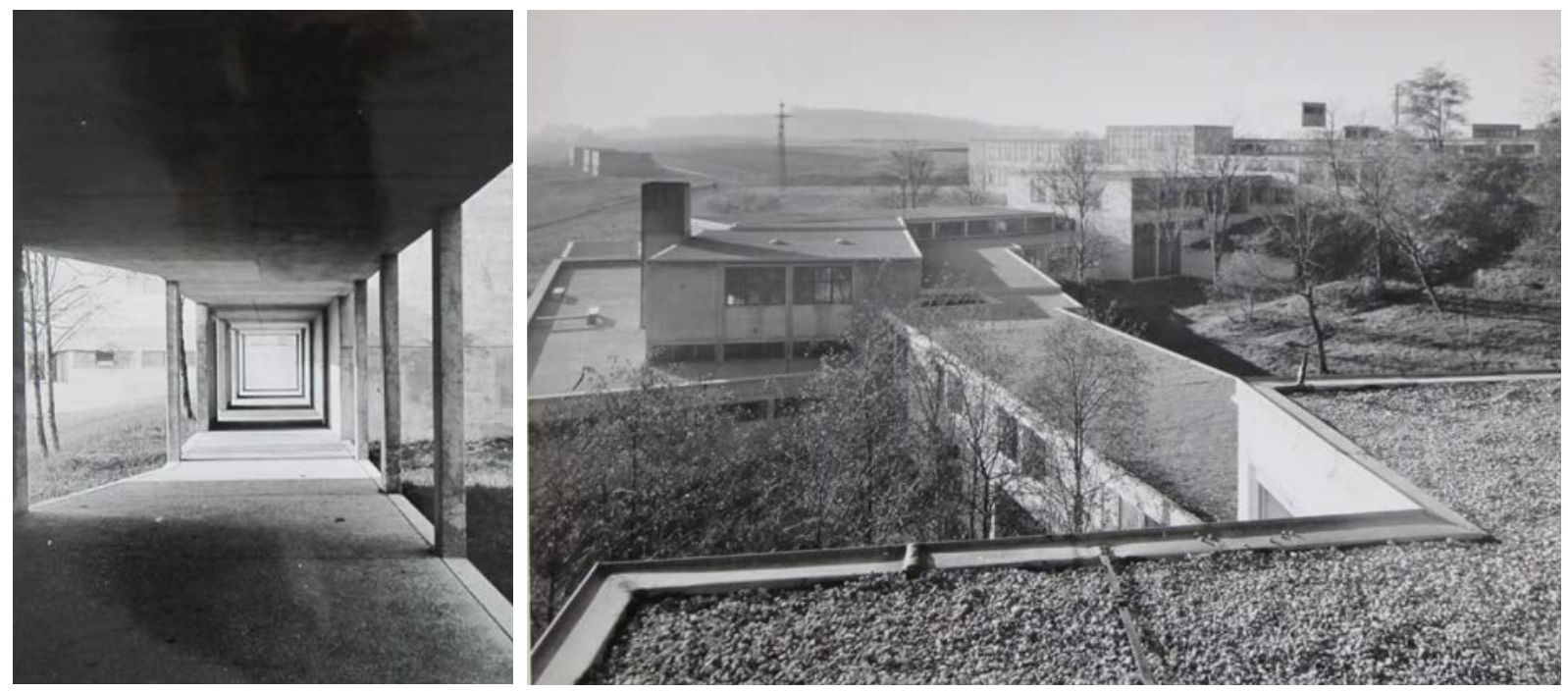
2 El visitante que viene de fuera, pasa por delante de la consejería y a través de la entrada principal entra en el vestíbulo que sirve de enlace entre los espacios comunes y la escuela. En este punto hay dos caminos: uno que conduce a la planta superior de las oficinas de la administración y el otro que conduce al aula magna y el comedor.

hay un lugar ocupado por las casas de los profesores; estas constituyen un grupo autónomo situado al suroeste de la escuela: Hasta el momento, en el primer sector, sólo hay tres casas combinadas, sin garaje intermedio, que es el único que podría dar a esta disposición un carácter unitario adecuado. los profesores viven en una zona de forma independiente, separado del entorno de la escuela, pero en cualquier caso en sus inmediaciones. Un camino conduce a la entrada principal; el acceso directo a las aulas y los talleres va por encima, en un corte plano y en otro corte siguiendo la carretera que conduce a los talleres, al norte del complejo, y desemboca en el atrio superior, que conduce a las diversas secciones de la escuela. Si hoy en Ulm se declara que el complejo de la Hochschule für Gestaltung se organizó con criterios equivocados, esto no depende del diseño del edificio, sino del hecho de que el programa y la doctrina de la escuela han sido alterados y, por tanto, los espacios han sido en parte utilizado para otros fines de los que se había esperado en un principio. 

conclusiones 
Conclusiones

Los otros son el exterior. El dentro es el. Los otros es la arquitectura, los arquitectos, alemania, el sueño colectivo de un proyecto de cambio.... El dentro es el suizo q es expulsado de las escuelas, el artista.. El el del q no hay referencias biográficas. el dentro se esconde para manifestarse el lo exterior. El edificio no es de el a pesar de serlo xq el es una cinta de moebius Las conclusiones de esta tesis las voy a organizar en cuatro bucles, en cuatro superficies no orientables de borde continuo, sin roturas ni accidentes en la superficie.

Bucle 1_ respuesta a la hipótesis de partida

Bucle 2_la vida de Bill

Bucle 3_ el encargo

Bucle 4_la naturaleza

>Bucle 1

La hipótesis de partida de esta tesis: la autoría del edificio de la Hochschule für Gestaltung no es de Max Bill a pesar de serlo. El pensamiento paradógico implícito pertenece a la lógica que propicia la existencia de una superficie continua no orientable, sin caras, sin arriba y abajo, con un borde continuo y por supuesto sin discontinuidades ni roturas sobre su superficie. Esta superficie pertenece a una geometría que entre finales del XIX y principios de XX fue desarrollada por la monumental estructura de la teoría de funciones de Riemann.

Evidentemente el edificio no es de Bill tanto como lo es. a medida que la tesis ha ido avanzando el edifico era más de Bill pero también se alejaba de él. Bill era un artista conscientemente no arquitecto, que consideraba su máxima aspiración serlo. Otra vez la cinta en la inquietudes del propio maestro suizo. El edificio se imposta de arquitectura a través de los grandes maestros reconocidos por Bill: se posa respetando la barbacana enterrada del castillo, la vegetación y la fisonomía original del sitio, a lo Wright. Bill siempre había admirado su forma de colocar los edificios, la forma de aprovechar cualquier accidente, cualquier árbol del lugar. La gran forma le viene de Mies van der Rohe. quiere una escuela como el IIT hasta en el mas mínimo detalle. Absorbe su espacio profundamente euclidiano y lo usa a través de la geometría topológica, que en ese momento en realidad es la que le interesa. Esta le permite deformar la gran forma con un resultado topológicamente absolutamente 


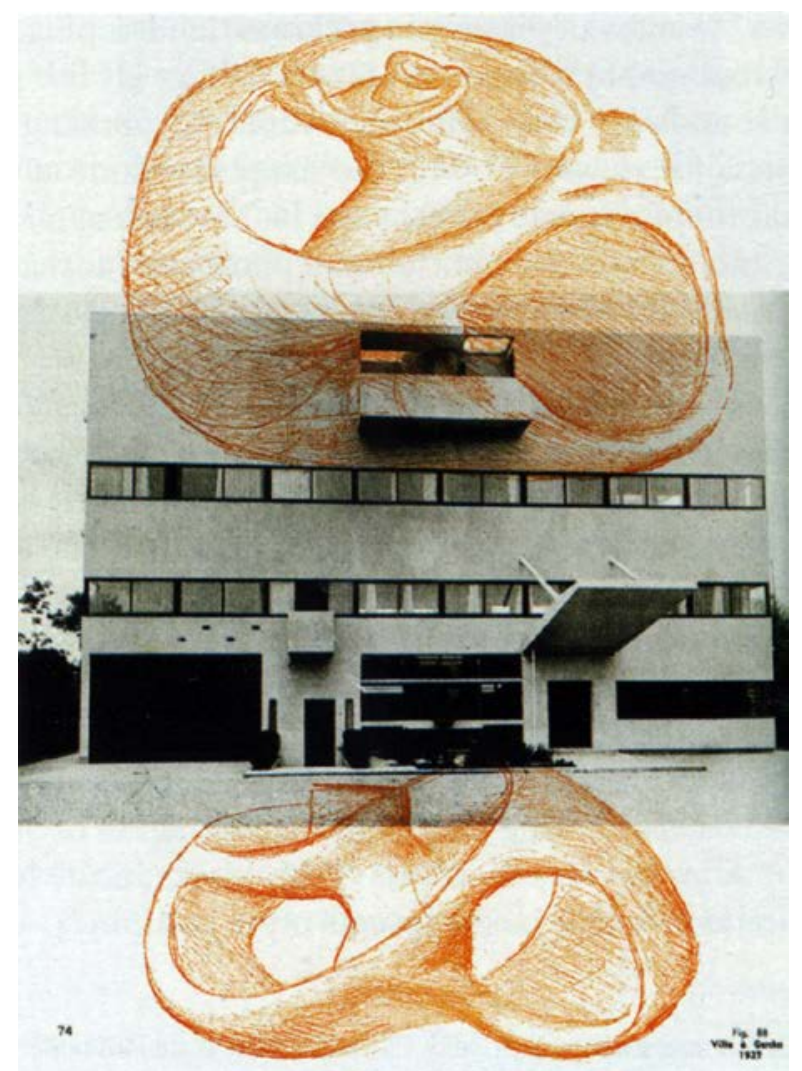


equivalente. La mirada desprejuiciada del que viene de fuera la adopta de Le Corbusier. De alguna forma el maestro suizo llega a la arquitectura desde el arte. Él desea ser un pintor reconocido que hace arquitectura. Cita libro (Le Corbusier. Betón Brut and Ineffable Space, 1940-1965. Surface Materials and Psychophysiology of Vision. Roberto Gargiani-Anna Rosellini. EPFL Press. Routledge. 2011) "en 1949 le Corbusier tiene la primera oportunidad de dar forma a las formulaciones resumidas con la síntesis de las artes y el espacio inenarrable(inefable); el puede diseñar una máquina para educar al público en la percepción del fenómeno de las artes, sin que el espace indicible pueda ser realizado en una dimensión universal". Le Corbusier sin duda aboga por el arte total, algo que Bill tiene en su sangre y que no adquirió en la Bauhaus le viene del gran arquitecto suizo-francés.

La conexión entre los dos es de ida y vuelta como aparece en el libro de Gargiani (pag 121) "esta clasificación pierde luz en la el montaje gráfico, a la manera de Soutter, encontrado en el mismo L'Architecture d'aujourd d'hui" donde le Corbusier incluye su dibujo de dos cascaras rotas sobreimpresas sobre la fotografía de la fachada de la Villa à Garches, para indicar el centro de gravedad de su evolución artística precisamente en ese trabajo. El hecho de que la cascara esté rota permite ver ese objeto no solo como el modelo de un refugio orgánico, sino también como la expresión del concepto de un inseparable continuidad dentro-fuera representada por superficies matemáticas, como la cinta de Moebius o las esculturas de Bill y Pevsner. Aunque la impresionante cavidad excavada en la Villa à Garches por el sistema de terrazas tiene el significado de un punto de inflexión en la evolución del trabajo de Le Corbusier." Este mismo dibujo lo incluye Corbu en la serie de notas sobre el espace indicible, incluyendo el dibujo de un hueso como símbolo de lo infinito, publicado en the new word of Space.

$>$ Bucle 2

en la vida de Bill está también este ida y vuelta sin discontinuidad. El quiere estudiar arquitectura en la Bauhaus y por una serie de circunstancias abandona esa escuela sin apenas contacto con el departamento de arquitectura que dirigía el gran Hannes Meyer, al que luego la historia ligará su edificio para la escuela de sindicatos con el de la HfG. Desde su vuelta a Zurich después de abandonar la Bauhaus de un forma precipitada, según algunos sufrió un accidente en la representación de un obra teatral que le afectó a la boca.

(Cita libro situacionistas pag 17) "Nosotros somos los partidarios del olvido. Olvidaremos el pasado y el presente, que son nuestros. No reconcemos como contemporáneos a todos aquellos que se contentan 


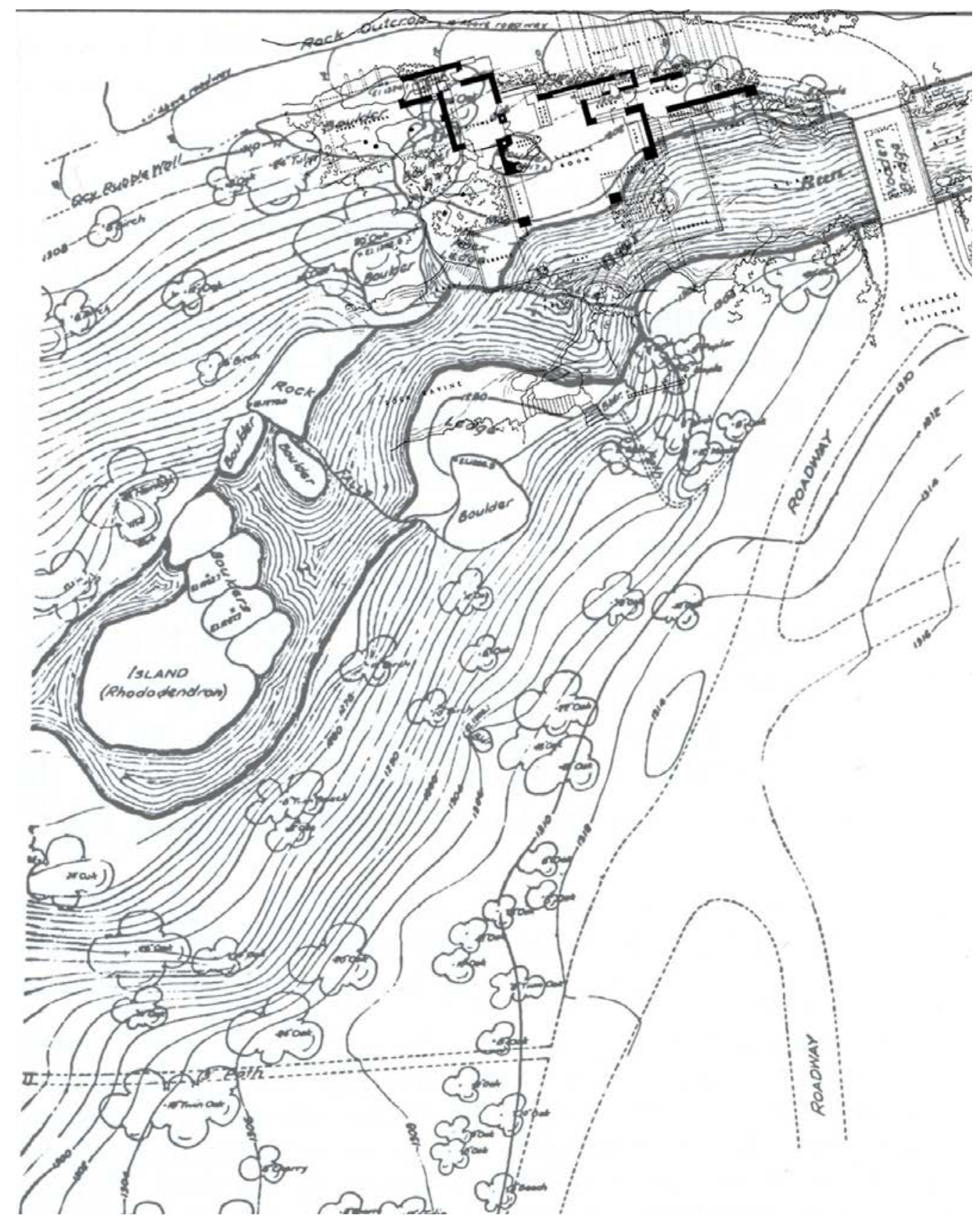


con demasiado poco". "Nosotros representamos el primer esfuerzo sistemático por descubrir, patiendo de las condiciones de vida modernas, posibilidades, necesidades, juegos superiores. Sumos los primeros en conocer algo nuevo y apasionante, ligado a la actualidad y al futuro próximo de la civilización urbana"

$>$ Bucle 3

La oportunidad de construirlo también transcurre sobre la famosa superficie. Bill usurpa un lugar en Ulm que le pertenecía a otros, a esos otros que eran los Eiermann, Baumgarten, Schwarz del momento. Ellos eran grandes arquitectos que deberían haber hecho el proyecto. La llegada de Bill se produce por ser un artista conocido y reconocido por los americanos, no ser alemán pero sí germanoparlante. Este otro bucle es el del ser y no ser.

$>$ Bucle 4

la fijación con el espacio natural como un exterior interior y al contrario 

bibliografía 

bibliografía

bibliografía comentada

bibliografía sobre max bill textos de max bill libros y revistas monográficos sobre max bill artículos sobre max bill en libros y revistas

bibliografía de la hfg ulm publicaciones editadas por la hfg ulm publicaciones y tesis sobre la hfg ulm catálogos de exposiciones sobre la hfg números especiales de revistas sobre la hfg ulm publicaciones del hfg-archiv

bibliografía general 

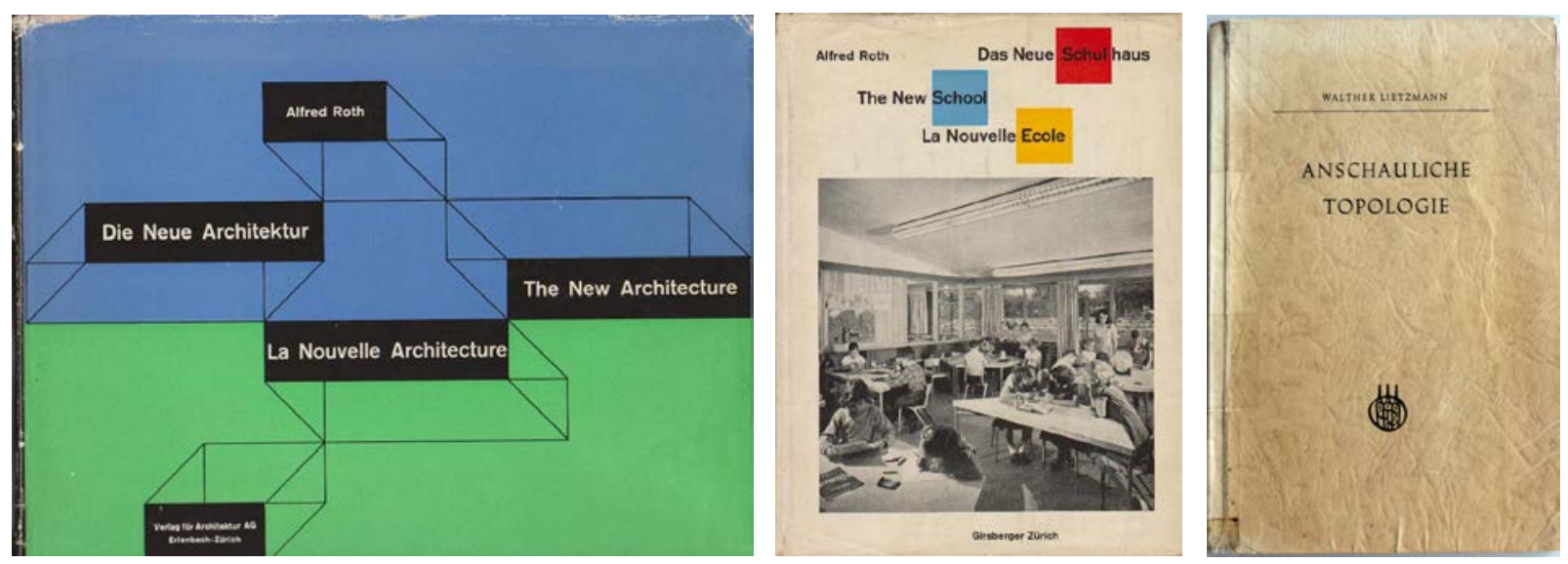


\section{Bibliografía comentada}

ROTH, Alfred. The New Architecture / Die Neue Architektur / La Nouvelle Architecture. Zürich, Dr. H. Girsberger, 1940

Alfred Roth, editor de este libro, le encarga el diseño a Max Bill. Que hace una matriz de 3x3 como estructura y la foto recortada en círculo para los autores y la foto más representativa. En la introducción del propio Roth "the Reality of the New Architecture" deja claro que pretende establecer con claridad cuál es el estado, en ese momento, de la nueva arquitectura. Se comprende, claramente, que para él el movimiento moderno está a punto de alcanzar su clasicismo. Empieza con la maravillosa Week-end House de Albert Frey, continúa con la Maison de Vacances de Le Corbusier, la biblioteca de Viipuri de Aalto. Pero para esta tesis interesan especialmente tres edificios, el Institut Héliothérapeutique en Lagnano (Italia) de Ernesto Natan Rogers, la Ecole en plein air del año 193536 en Suresnes (Francia) de E. Beaudouin \& M. Lods y la Experimental School del año 1934-35 en los Angeles de Richard Neutra.

ROTH, Alfred. The New School - Das neue Schulhaus - la nouvelle école. Zürich, Gisberger, 1950 Libro posterior al the new Architecture y, en esta caso, no diseñado por Max Bill, que le hace ser más abigarrado y menos atractivo. A destacar el texto introductorio, y claramente de posguerra, con un apartado técnico dedicado a la luz natural y artificial en las escuelas.

LIETZMANN, Walther. Anschauliche Topology. München, Verlag Von R. Oldenbourg, 1955.

Manual clásico de Topología de referencia para Tomás Maldonado que se empleaba como texto fundamental en las lecciones de topología que se impartían en la HfG. Este libro representa un importante cuerpo teórico para esta tesis.

CUNDY, H. Martin; ROLLET, A.P. Mathematical Models. Oxford, Oxford University Press, 1961 (segunda edición, originalmente editado en 1951).

La segunda edición, ampliada respecto de la primera, ofrece instrucciones detalladas para ilustrar modelos matemáticos elementales. A través de disecciones, plegados de papel, dibujos el manual guía la construcción de poliedros, teselaciones planas, y superficies regladas. Este libro ofrece herramientas para el análisis de los espacios de la HfG y para profundizar en las cuestiones de continuidad y geometría que pretende demostrar esta tesis. 

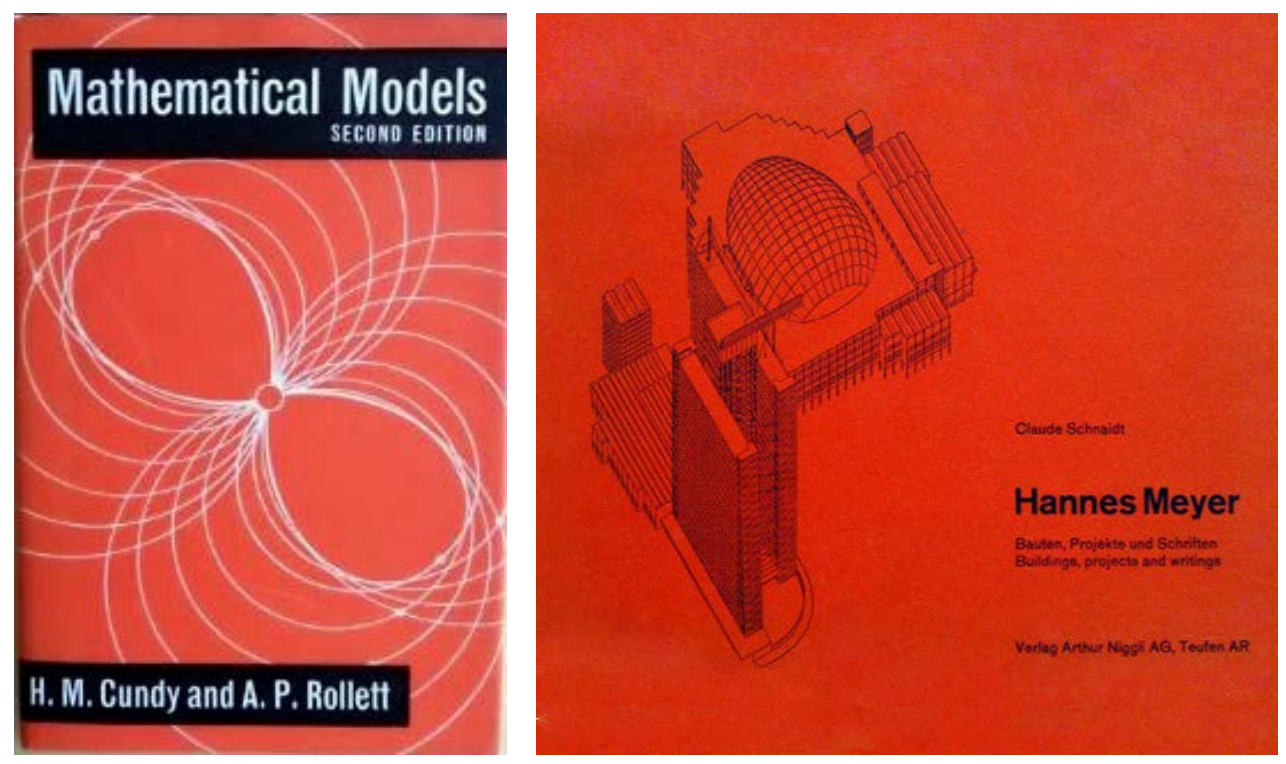

STABER, Margit. "La scuola di UIm", en Casabella Continuità, no 259, Milán, 1962

Primera publicación seria sobre el edificio de la escuela y el carácter de la nueva institución. La introducción de Ernesto Natan Rogers: Utopia della realtà. Donde comenta la importancia de las nuevas utopías en una Europa cargada de hiperrealismo. Margit Staber, desde el conocimiento directo de la escuela, hace un comentario introductorio lleno de precisión. Desde las primeras línea sitúa a este edificio dentro de un funcionalismo emotivo que le confiere una posición privilegiada en la arquitectura, que estaba por venir, del siglo XX. Muy bien documentado aporta un material de primera categoría para el desarrollo de esta tesis.

SCHNAIDT, Claude. Hannes Meyer. Zürich, Verlag Arthur Niggli AG, 1965.

Maravillosa publicación de Claude Schnaidt sobre el corpus completo de la obra de Hannes Meyer. La introducción de Maldonado posiciona para el futuro a este arquitecto, atractivo y desconocido que de alguna manera cargó con las culpas del cierre de la Bauhaus. Exquisito diseño del libro, muy en la línea de lo que se hacía en Ulm. La documentación sobre la Escuela Federal de sindicatos alemanes de Bernau de los años 1928-30 es muy importante en el desarrollo de esta tesis, pues de alguna manera aclara que la relación con $\mathrm{HfG}$ es mas tangencial que profunda.

BILL, Max, Dokumentation zur Ausstellung Max Bill. Katalog. Zürich 1976

Curioso e importante catálogo sobre parte de la obra artística de Bill editado por el mismo para unas exposiciones en Hamburgo, Berlín y Stuttgart el año 1976. Para esta tesis importa especialmente la introducción de Bill, en la que va mezclando el comentario entre la obra artística y la arquitectónica, centrando muy bien la relación entre ellos. En realidad este texto ha aportado las ideas más importante al planteamiento de la tesis.

SECKENDORFF, Eva. Die Hochschule für Gestaltung in Ulm. Gründung (1949 - 1953) und Ära Max Bill (1953 - 1957) Marburg, Jonas Verlag, 1989. Serie des club off ulm, Bd. 1.

Después de la revista Casabella, es el documento con información gráfica más precisa sobre la HfG. Con aportaciones tan interesantes como la forma de redibujar las plantas del edifico. 

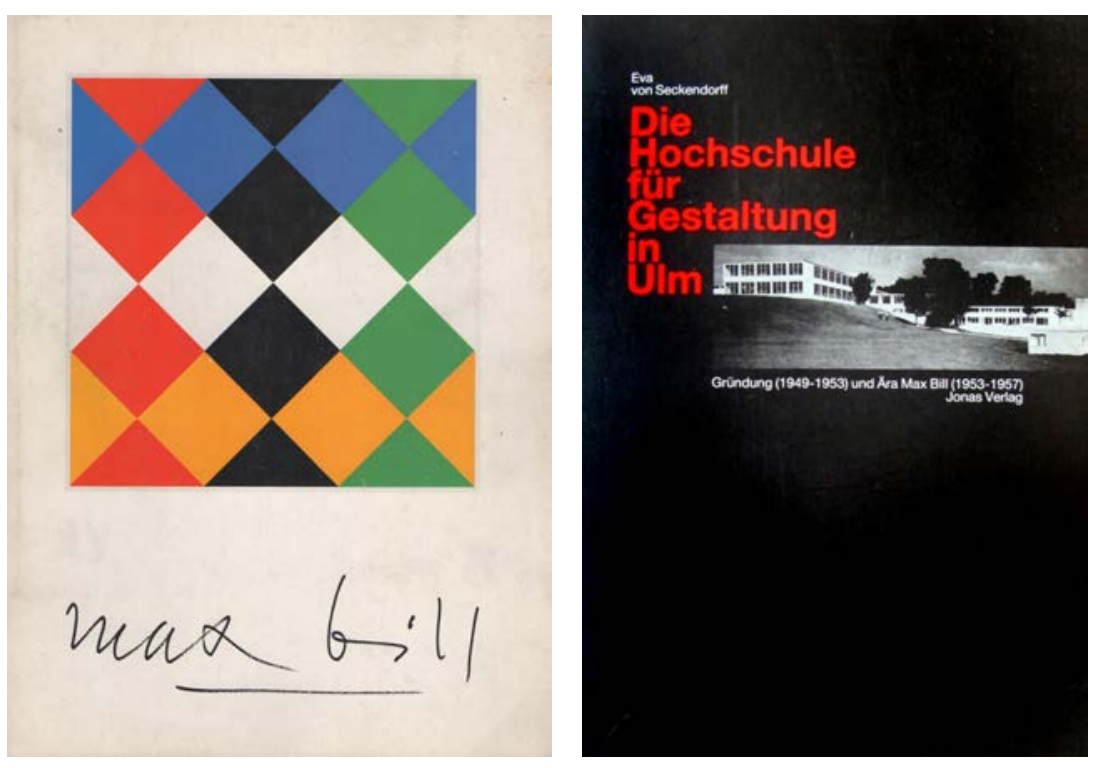

AICHER, Otl. analog und digital. Berlin, Ernst und Sohn Verlag für Architektur und technische Wissenschaften, 1991.

Texto dirigido al entendimiento pos-Descartes del concepto de fenómeno, en tanto que todo fenómeno sobre la tierra tiene como mínimo aplicada una ley, la de la gravedad. Es el propio Descartes el que duda de esta ley general.

AICHER, Otl. the world as design. Berlin, Ernst und Sohn Verlag für Architektur und technische Wissenschaften, 1991.

Importantísimo libro para esta tesis, es el que posiciona ideológicamente el enfoque de la investigación. Otl Aicher es el gran personaje después o la vez que Bill en la HfG. En este libro aparece el importantísimo texto de Aicher "Bauhaus and UIm".

FREI, Hans. Konkrete Architektur? - über Max Bill als Architekt. Baden (Schweiz), Lars Müller publishers, 1991.

Para la investigación que lleva a cabo esta tesis es el libro más importante. Hans Frei hace un trabajo concienzudo respondiendo con su texto a casi todas las preguntas que uno se puede hacer sobre la gestación del edificio de la HfG.

QUIJANO, Marcela (ed.) HfG Ulm: programm wird bau. Die Gebäude der Hochschule für Gestaltung Ulm. Stuttgart, Edition Solitude, 1998.

En este caso Marcela Quijano centra su trabajo en la justificación de la forma del edificio a través del programa. Libro interesante que aporta una mirada desde fuera de la arquitectura, con la que esta tesis, en algunas afirmaciones, no está en absoluto de acuerdo.

VV.AA. DPA 17. "max bill". Número monográfico, publicación del Departament de proyectes d Arquitectura de la Universitat

Politecnica de Catalunya. 2001.

Textos de Max Bill, Claudi Alsina, Ton Salvadó, Josep Maria Guix, Bruno Reichlin, Franz Graf, Carles Marti y Joan Llecha.

Publicación dirigida a difundir la figura de Bill. Aporta una traducción al castellano de la famosa conferencia de Bill del año 49 "die mathematische Denkweise in der kunst unserer Zeit" 

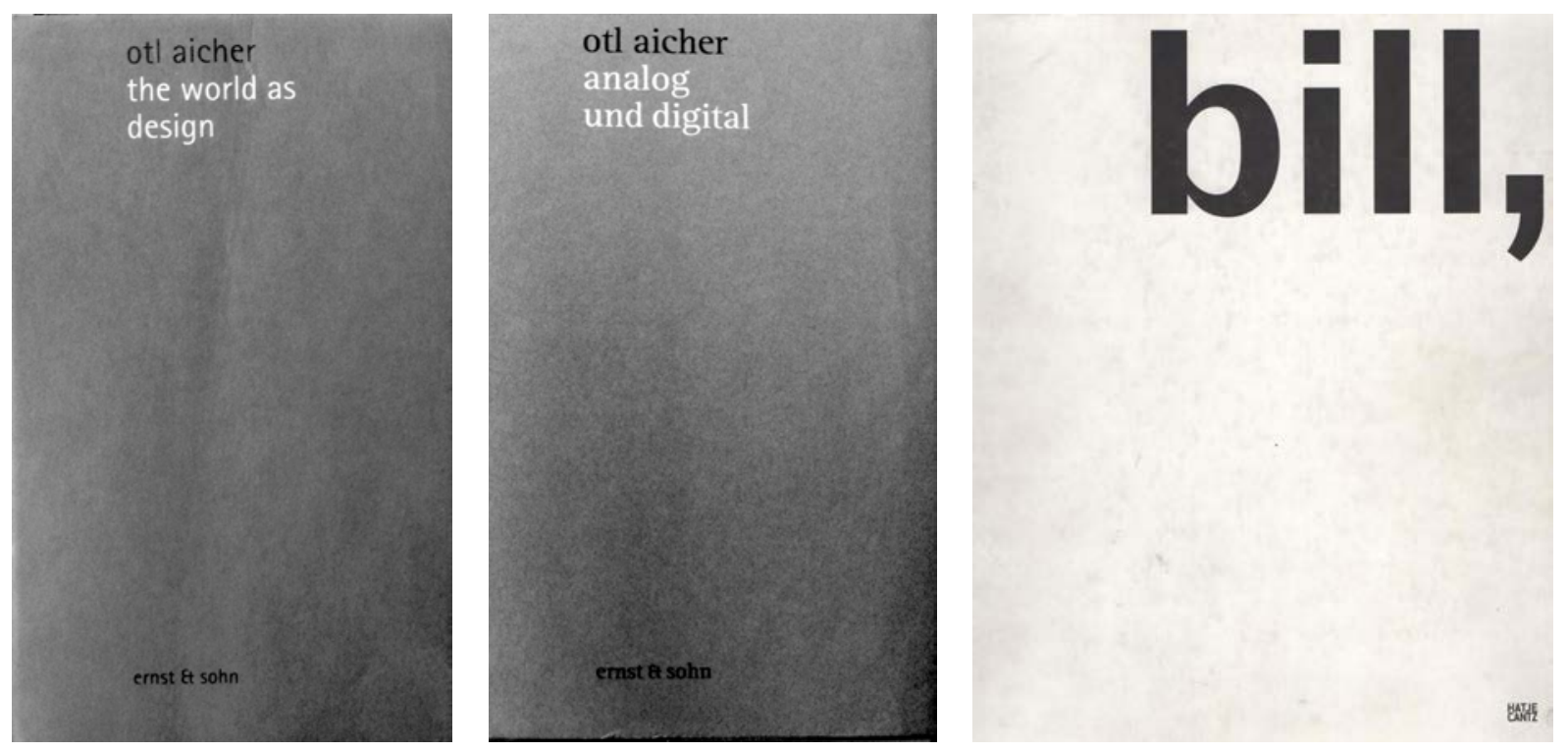

SPITZ, René. Der Blick hinter den Vordergrund. Die politische Geschichte der Hochschule für Gestaltung 1953 - 1968. Stuttgart / London, Edition Axel Menges, 2002.

Después del libro de Hans Frei, es la publicación más seria sobre el entorno ulmiano. Una investigación socio-política de lo que fue la HfG. Un trabajo de investigación de altísimo nivel que despeja muchas de las dudas.

KRAMPEN, Martin; HÖRMANN, Günther. Die Hochschule für Gestaltung Ulm / The School of Design. Anfänge eines Projektes der radikalen Moderne / Beginnings of a Project of Radical Modernism. Berlin, Ernst und Sohn, 2003.

RINKER, Dagmar; QUIJANO, Marcela; REINDHARDT, Brigitte. Ulmer modelle. Modelle nach UIm. Hochschule für Gestaltung Ulm 1953-1968. Stuttgart, Hatje Cantz, 2003. Catálogo de exposición. Catálogo de la exposición sobre la HfG que estuvo en Madrid el año 2011. Centrada en lo que fue la escuela como institución educativa. Con textos importantes de Gui Bonsiepe y Eva von Seckendorf. También la exposición y el catálogo atendía a la importancia posterior de la producción de la escuela.

SPELLMAN, Catherine (ed.); UNGLAUB, Karl (ed.). Peter Smithson. Conversaciones con estudiantes. Barcelona, Gustavo Gili, 2004. Edición española a cargo de Moisés Puente.

Pequeño libro de la serie de Gustavo Gili conversaciones. El libro presenta una conferencia y un seminario celebrados en noviembre de 2001en la Arizona State University. El interés para esta tesis está en comentario que hace Peter Smithson sobre la HfG ante la siguiente pregunta: "¿puedes hablarnos de tus ideas acerca de la cultura del consumo y explicar cómo se relacionan con el desarrollo de los medios de comunicación, la televisión y la publicidad?

VV.AA. "Max Bill Arquitecto", 2G, no 29-30. Barcelona, Gustavo Gili, 2004. Número monográfico de Max Bill con textos de von Moss, Stanislaus; Frei, Hans; Gimmi, Karin; Rüegg, Arthur.

Importantísima edición a cargo de Moisés Puente de la obra como arquitecto de Max Bill, un recorrido sobre la totalidad de su obra como arquitecto, acompañado por textos muy importantes como el de Hans Frei: "la transversal de Max Bill" en donde duda del sentido transversal de la obra de Bill, las esculturas continuas no tienen nada que ver con las esculturas pabellón. Evidentemente esta tesis quiere demostrar lo contrario. 

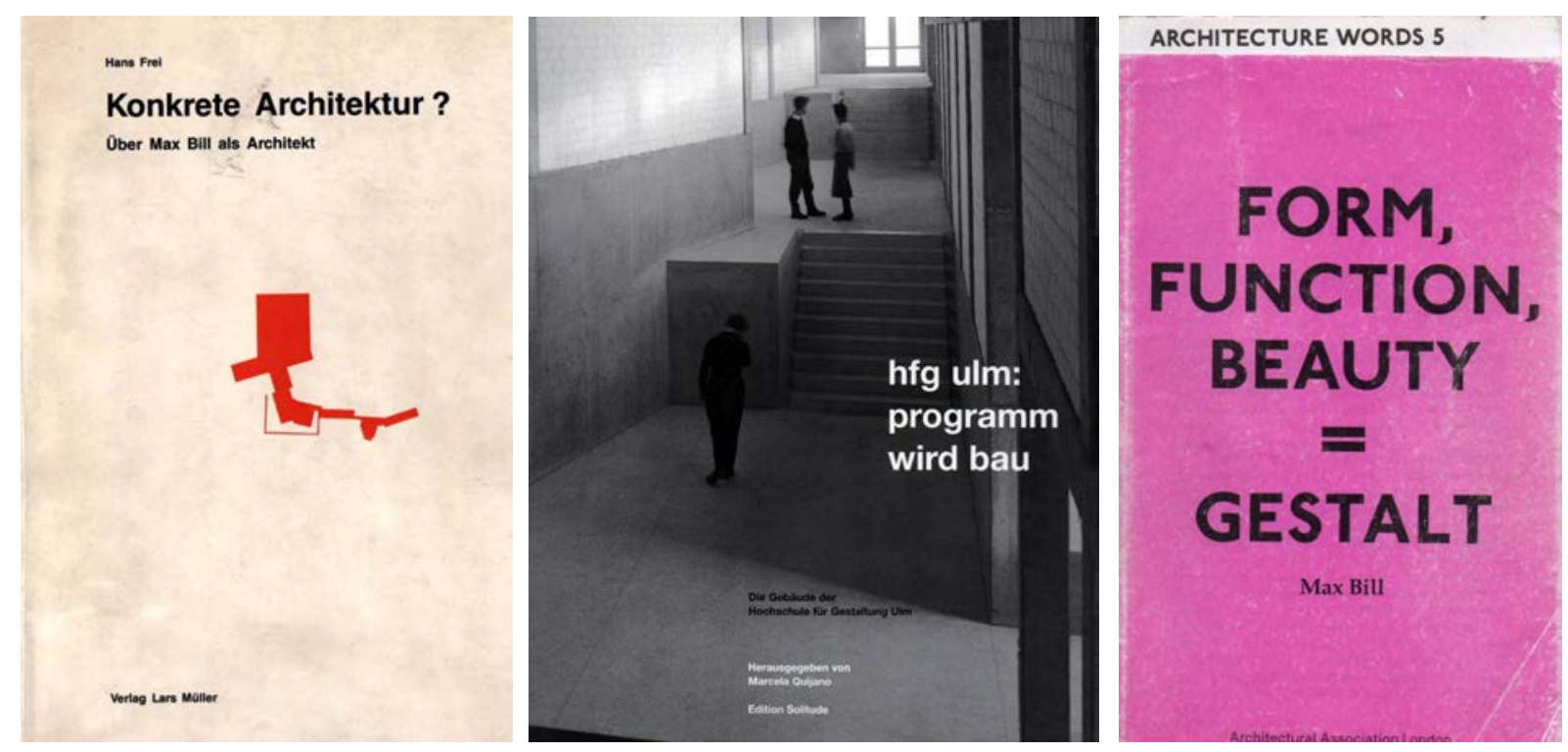

BUCHSTEINER, Thomas (ed.); LETZE, Otto (ed.). Max Bill, maler, bildhauer, architect, designer, hatje cantz verlag, 2005. textos de max bill, vivian endicott barnett, angela thomas schmid, eugen gomringer, karim gimmi, arthur rüegg, karl gestner, marion ackerman, jakob bill, gerd fleischmann, dirk scheper. Monografía que presenta a Max Bill como paradigma del artista total.

Este libro tiene fundamentalmente dos aspectos valiosos para la tesis. El primero, que contradice la hipótesis de transversalidad entre pintura y arquitectura sostenida por Hans Frei. El segundo, el capítulo dedicado a la HfG escrito por Eugen Gomringer, secretario personal de Bill y director del Instituto de arte y poesía concreta en Rehau.

BILL, Max. "Form, Function, Beauty = Gestalt". London, Architectural Association, 2011. Recopilación de textos de Max Bill.

Recopilación a cargo de la AA de las conferencias de Max Bill desde el año 1945 al 88. Bill el año 1949 imparte dos conferencias fundamentales, la primera: "Schönheit aus Funktion und als Funktion" (en: Werk, 8/1949, p. 273) y la segunda también muy importante pero que este libro no recoge: "die mathematische Denkweise in der kunst unserer Zeit" 


\section{Bibliografía sobre Max Bill}

Textos de Max Bill

1936

"konkrete gestaltung", zeitprobleme in der schweizer malerei und plastic. zurich, kunsthaus, 1936.

(catálogo de exposición). "Arte Concreto" ha sido publicado en español en el catálogo de la exposición Max Bill, Museo Español de Arte Contemporáneo, Ministerio de Cultura, Madrid, febrero 1980.

1937

"typography is the graphic expression of our time", Bill Typografie, Zürich, Verlag Niggli AG, 1937

1946

"Über typografie", schweizer grafische mitteilungen no 4, 1946. Publicado en inglés "on typography(...) with ten reproductions from the author" 1946, en "BILL Typografie" Verlag Niggli AG, Sulgen/ Zürich.

1949

"Die Gute Form", Kunstgewerbemuseum (catálogo de la exposición de la federación suiza de trabajo), Zurich. Reeditado y traducido en inglés: "The Good Form". Form, Function, Beauty = Gestalt. London, Architectural Association, max, Binia + Jakob Bill Foundation, 2011.

"La concepción matemática en el arte de nuestro tiempo", Werk no 3, 1949. Reeditado y traducido al español en MALDONADO, Tomás. Max Bill. Buenos Aires, editorial nueva visión, 1954. También en el catálogo de la exposición Max Bill en el MEAC, Ministerio de Cultura, Madrid, 1980 y en la revista 2G, no 29-30, 2004.

"Schönheit aus funktion und als function", Werk no 8, 1949. Publicado en francés: "Beauté issue de la function, beauté en tant que function". Faces no 15, 1990 y en inglés "Beauty from function and as function". Form, Function, Beauty = Gestalt. London, Architectural Association, max, Binia + Jakob Bill Foundation, 2011.

"l' expresion artistique de la construction", Robert Maillart Brücken und Konstruktionen, Zürich, Girsberger, 1955. 
1952

"Form und kunst". FORM. A balance Sheet of Mid-Twentieth- Century Trends in Design. Basel, Verlag Karl Werner, 1952.

"Vom Werkzeug zum Schleckzeug". FORM. A balance Sheet of Mid-Twentieth- Century Trends in Design. Basel, Verlag Karl Werner, 1952.

1953

"base et but de l'esthétique au temps du machinisme" Conferencia en Congreso Internacional de Estética Industrial en París 16.9. 1953, esthétique industrielle (paris), № 10, 1954. "Base y finalidad de la estética en la época del maquinismo", publicada en español en Revista Nacional de Arquitectura no 160. Abril 1955, p 5-13. y en Nueva Forma, no 92, 1973.

"El arquitecto, la arquitectura y la sociedad" Conferencia en la escuela de arquitectura de Sao Paulo 9.6.1953 Publicada en: Revista Nacional de Arquitectura no 163. Julio 1955 y Nueva Forma no 92. Sept 1973 , p. 56-57.

"Continuity and change", 1953. Conferencia dada en el 40 aniversario del Werkbund Suizo, 27.09.1953. Publicada en: max bill, funktion und funktionalismus, schriften: 1945-1988, Benteli 2008 y en: Form, Function, Beauty = Gestalt. London, Architectural Association, max, Binia + Jakob Bill Foundation, 2011.

“El lazo infinito,1935-1953", catálogo de la exposición Max Bill en el Museo Español de Arte Contemporáneo, Madrid, Ministerio de Cultura, 1980.

"Good formal design". Conferencia 26.10.1953. Publicada en: max bill, funktion und funktionalismus, schriften: 1945-1988, Benteli 2008 y en: Form, Function, Beauty = Gestalt. London, Architectural Association, max, Binia + Jakob Bill Foundation, 2011. 
1954

"Qú est-ce que l'industrial design". Conferencia en el 1er Congreso Internacional de Diseño Industrial en la 10a Trienal de Milán 30.10.1954. Publicada en: max bill, funktion und funktionalismus, schriften: 1945-1988, Benteli 2008 y en: Form, Function, Beauty = Gestalt. London, Architectural Association, max, Binia + Jakob Bill Foundation, 2011.

"vom staatlichen Bauhaus in Weimar zur Hochschule für Gestaltung in Ulm". Magnum no1, 1954, p. 59-60. Editado en inglés "The Bauhaus Idea from Weimar to Ulm," en: Architects Yearbook 5, London, Morton Shand, 1953, p. 29-32.

\section{5}

"Un monumento", 1955, (proyecto del concurso para el monumento al prisionero político desconocido). En: MALDONADO, Tomás. Max Bill. Buenos Aires, Nueva Visión, 1955.

"the beginning of a new epoch in architecture", architectural design, no 11, 1955. En castellano: "Sobre el estado actual del arte de construir", 2 G no 29-30, 2004, p. 266-269.

1956

"Forma, Función, Belleza", en el catálogo de la exposición Max Bill en el Ulmer Museum 1956.

Publicado como: "Form, funktion, Schönheit=Gestalt" en: max bill, funktion und funktionalismus, schriften: 1945-1988, Zürich, Benteli, 2008. Traducida en español en Nueva Forma no 92, 1973.

"umweltgestaltung nach morphologischen methoden", ("La configuración del entorno mediante métodos morfológicos"). Werk und zeit 5, no 11, 1956, p 4-5. Reeditado en: funktion und funktionalismus, schriften: 1945-1988, Zürich, Benteli, 2008.

"Funktion und Gestalt", 1958, conferencia en la escuela técnica federal de Zurich, 26.2.1958. funktion und funktionalismus, schriften: 1945-1988, Zürich, Benteli, 2008. Editada en inglés en: Form, Function, Beauty $=$ Gestalt. London, Architectural Association, max, Binia + Jakob Bill Foundation, 2011.

1959

"der modellfall ulm-zur problematik einer hochschule für gestaltung", Form(Köln) no 6,1959. 
1960

"L’aménagement du milieu ambient". Architecture, formes+fonctions № 7, 1960-61, p. 118-119. También publicado en: funktion und funktionalismus, schriften: 1945-1988, Zürich, Benteli, 2008. Editado en inglés en: Form, Function, Beauty = Gestalt. London, Architectural Association, max, Binia + Jakob Bill Foundation, 2011.

1961

"Über die güte der guten form", Form no 15, 1961, p. 32-33. Editado en inglés en: Form, Function, Beauty = Gestalt. London, Architectural Association, max, Binia + Jakob Bill Foundation, 2011.

1963

"Vorfabriziertes Bauen- Freiheit oder Bindung?" (Construcción prefabricada ¿libertad o atadura?). Form no 24, 1963.

"Structure as Art? Art as Structure?". En: KEPES, Gyorgy (ed.) Structure in Art and Science. Nueva York, Braziller, 1965. Editado en español "¿iestructura como arte? ¿arte como estructura?". $2 \mathrm{G}$ no 29-30, 2004 y en BAU no 15, 1997.

1964

"Are European methods of environmental design universally applicable (in art, architecture, urban planning, product design)?" Editado en inglés en: Form, Function, Beauty = Gestalt. London, Architectural Association, max, Binia + Jakob Bill Foundation, 2011.

"Sinn ohne sinn?", Form no 32, 1965. Editado en inglés "Sense without sense?" Editado en inglés en: Form, Function, Beauty = Gestalt. London, Architectural Association, max, Binia + Jakob Bill Foundation, 2011.

1965

"Responsibility in design and information", American Scholar vol. 35, oㅡ 2, 1966. Reeditado en: Form, Function, Beauty = Gestalt. London, Architectural Association, max, Binia + Jakob Bill Foundation, 2011. 
1970

"Response to the International Design Centre in Berlin", Reeditado en: Form, Function, Beauty = Gestalt. London, Architectural Association, max, Binia + Jakob Bill Foundation, 2011.

1972

"How I started making single surfaced", texto catálogo de exposición, marlborouh-godard galleries en Toronto y Montreal 1972. Publicado en:

BILL, Max; BILL; Jakob. Max Bill, endless ribbon 1935-95 and the single sided surfaces. Wabern-Bern, Benteli Verlag, 2000.

1973

"Sistema de cinco centros con cuatro colores". "El barrio vivienda como elemento urbano diferenciado", Nueva Forma, no 92, 1973.

1976

"Von Bauhaus bis Ulm". DU, vol. 36 no 6, no 424, junio 1976.

1977

"idee-konzept-Werk: über ein thema", texto del catálogo de la exposición idee koncept Werk en la akademie der kunste, Berlín, 1977. Publicado en: BILL, Max; BILL; Jakob. Max Bill, endless ribbon 193595 and the single sided surfaces. Wabern-Bern, Benteli Verlag, 2000.

1979

"vom funktionalismus zur funktion", 13.7.1979, conferencia durante su nombramiento como Doctor Honoris Causa en la escuela de arquitectura y urbanismo de la universidad de Stuttgart. Publicado en: funktion und funktionalismus, schriften: 1945-1988, Zürich, Benteli, 2008. Editado en inglés en: Form, Function, Beauty = Gestalt. London, Architectural Association, max, Binia + Jakob Bill Foundation, 2011. Publicada en alemán en "max bill, funktion und funktionalismus, schriften: 1945-1988", Benteli, 2008, y en inglés "from functionalism to function" en "Form, Function, Beauty = Gestalt", AA 2011. "Del funcionalismo a la función" es publicada en español en 2G, no 29-30, 


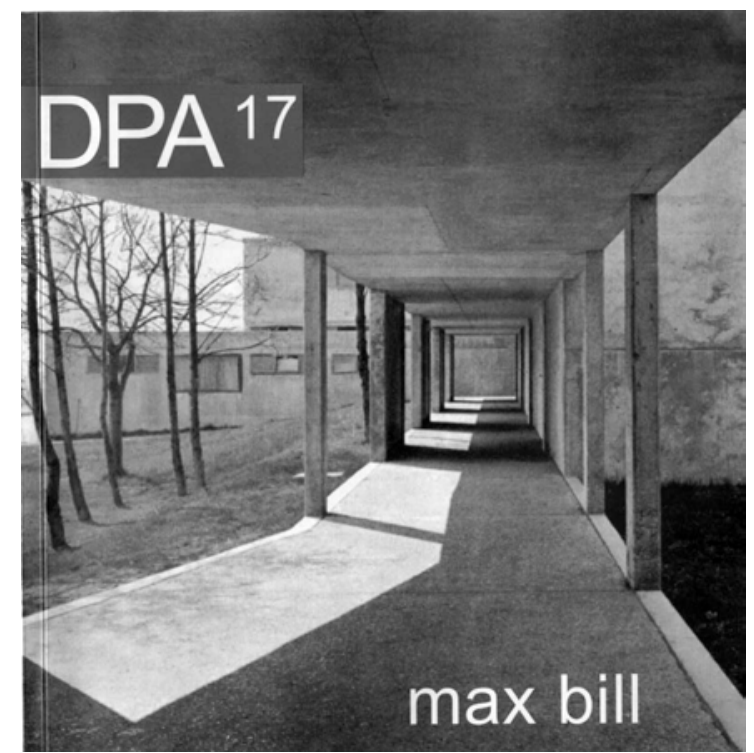

1980

"art as non-changeable fact" en: HILL, Anthony. DATA, directions in art, theory and aesthetics. London, faber\&faber, 1968. En español: "El arte como un hecho inalterable", en: VVAA. Catálogo de la exposición Max Bill. Madrid, Museo Español de Arte Contemporáneo, Ministerio de Cultura, 1980.

Libros y revistas monográficas sobre Max Bill

1945

BILL, Max. Wiederaufbau: Dokumente uber Zerstorungen Planungen Konstruktionen. Zurich, Erlenbach, 1945.

1955

MALDONADO, Tomás. Max Bill. Buenos Aires, Editorial Nueva Visión, 1955.

1964

STABER, Margit. Max Bill. London, Methuen, 1964.

1973

"Max Bill". Nueva Forma no.92 Septiembre 1973 (Número Monográfico) Texto de Juan Daniel Fullaondo.

1976

DU, vol. 36 no 6, no 424, junio 1976. Monográfico dedicado a Max Bill

BILL, Max, Dokumentation zur Ausstellung Max Bill. Katalog. Zürich 1976

1977

HÜTTINGER, Eduard. Max Bill. Zürich, ABC editions, 1977.

1979

ANKER, Valentina. Max Bill ou la recherche d'un art logique. Lausanne, Editions l'Age d' Homme, 1979. 

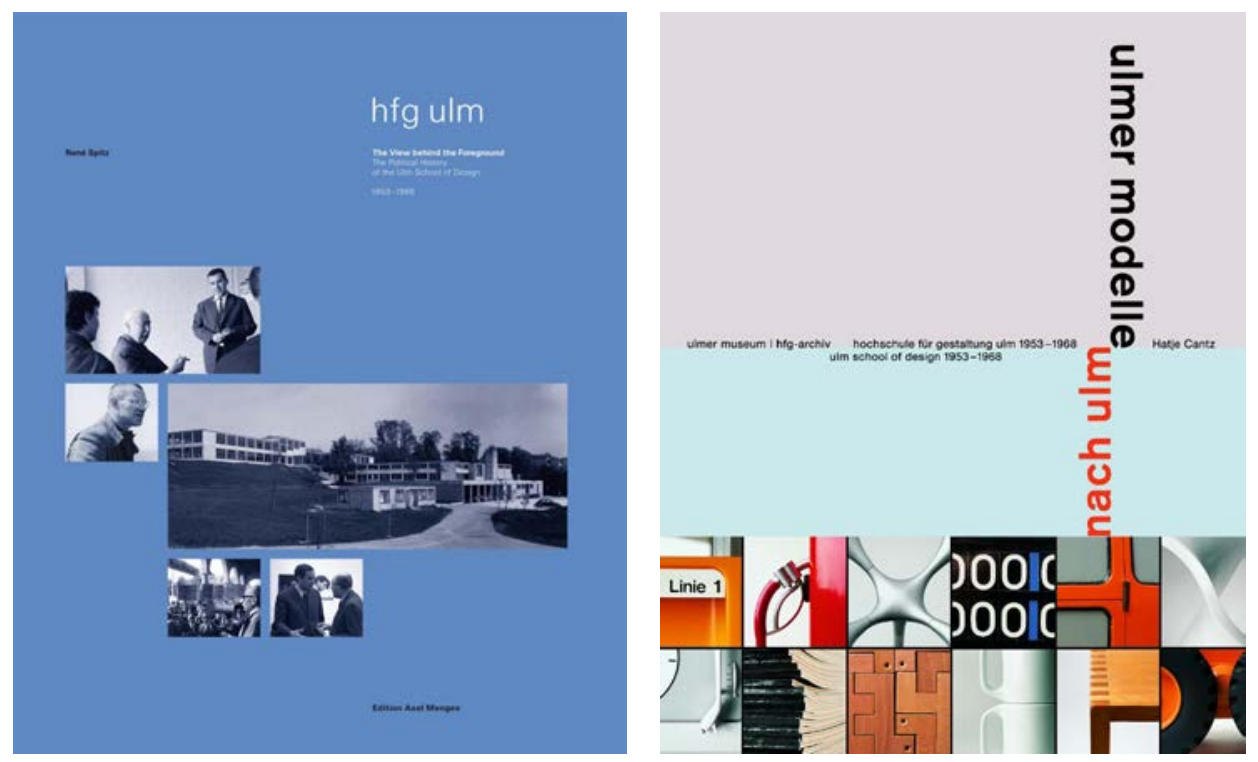

1980

"Max Bill". Catálogo exposición Museo Español de Arte Contemporáneo, Madrid, febrero 1980. Ministerio de Cultura.

1987

TANCA, Piero G; HÜTTINGER, Eduard. Max Bill. Zürich, abc verlag 1987.

"Max Bill". Grafis Edizioni. Galeria comunale d' arte moderna di Bologna, 1988. Con textos de Claudio Cerritelli y Giulio Carlo

1989

SECKENDORFF, Eva. Die Hochschule für Gestaltung in Ulm. Gründung (1949 - 1953) und Ära Max Bill (1953 - 1957) Marburg, Jonas Verlag, 1989. Serie des club off ulm, Bd. 1.

1990

"FACES, Journal d'architectures", no 15, 1990, Ginebra. Número dedicado en gran parte a Max Bill con artículos de: Stanislaus von Moss, Hans Frei, Bruno Reichlin, Daniel Spalinger.

1991

FREI, Hans. Konkrete Architektur? - über Max Bill als Architekt. Baden (Schweiz), Lars Müller publishers, 1991.

1995

BILL, Max. max bill, die grafischen rehien. Stuttgart, Hatje Cantz Verlag, 1995.

1996

BENTON, C. minimal tradition. Max Bill and simple architecture 1942-1996. Zürich, Swiss Federal Office of culture + Lars Müller Publishers, 1996.

1998

QUIJANO, Marcela (ed.) HfG UIm: programm wird bau. Die Gebäude der Hochschule für Gestaltung Ulm. Stuttgart, Edition Solitude, 1998. 

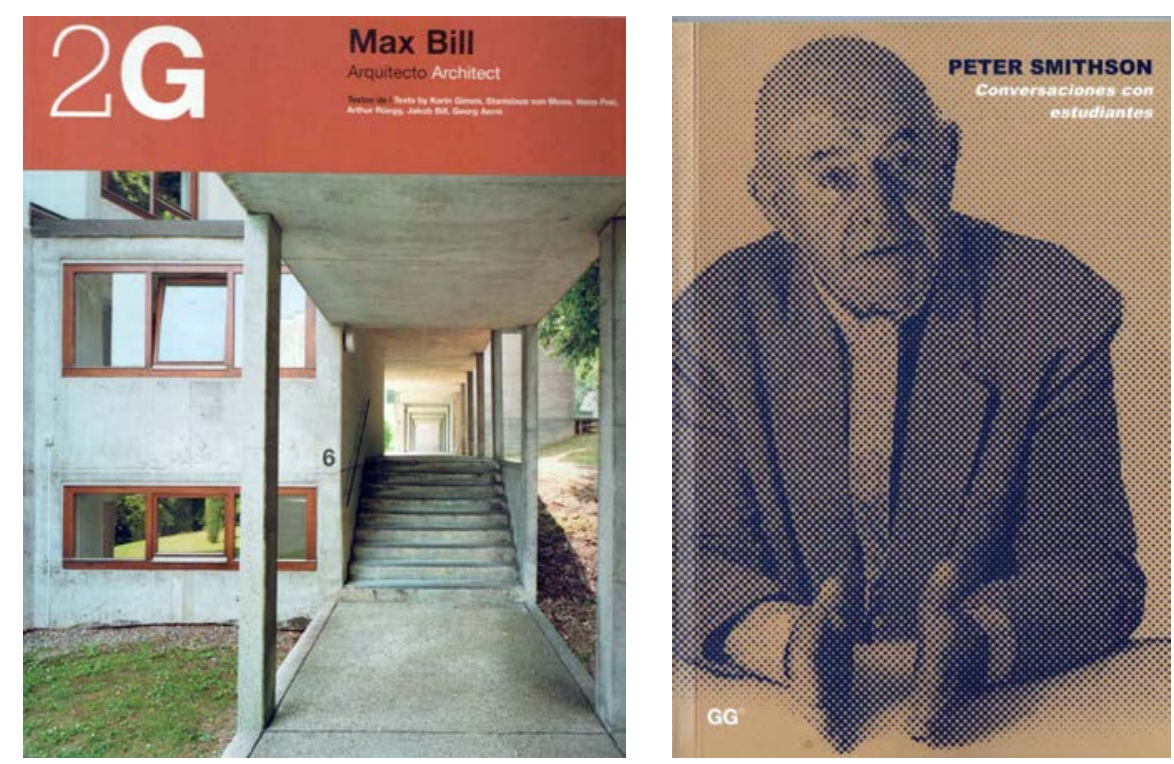

1999

BILL, Max. Typografie, reklame, buchgestaltung = Typography, advertising, book design. Zurich, Verlag Niggli, 1999.

2000

BILL, Max; BILL, Jakob. max bill. endless ribbon 1935-95 and the single-sided surfaces. Zürich, Benteli Verlag, 2000.

2001

VV.AA. DPA 17. "max bill". Número monográfico, publicación del Departament de proyectes d 'Arquitectura de la Universitat

Politecnica de Catalunya. 2001.

Textos de Max Bill, Claudi Alsina, Ton Salvadó, Josep Maria Guix, Bruno Reichlin, Franz Graf, Carles Marti y Joan Llecha.

2004

VV.AA. "Max Bill Arquitecto", 2G, no 29-30. Barcelona, Gustavo Gili, 2004. Número monográfico de Max Bill con textos de von Moss, Stanislaus; Frei, Hans; Gimmi, Karin; Rüegg, Arthur.

2005

BUCHSTEINER, Thomas (ed.); LETZE, Otto (ed.). Max Bill, maler, bildhauer, architect, designer, hatje cantz verlag, 2005. textos de max bill, vivian endicott barnett, angela thomas schmid, eugen gomringer, karim gimmi, arthur rüegg, karl gestner, marion ackerman, jakob bill, gerd fleischmann, dirk scheper.

2006

REINKE, Thomas. Max Bill: hfg Um; drawing and redrawing : atelierwohnungen, studentenwohnturm. London, Marmalade Publications, 2006

2008

VV.AA. Max Bill: no beginning, no end: a retrospective marking the centenary of the artist, designer, architect, typographer and theoretician. Museum Marta Herford, Scheidegger \& Spiess, 2008 
BILL, Max; BILL, Jakob. funktion und funktionalismus, schriften: 1945-1988, Zürich, Benteli, 2008.

2010

BILL, Max. Form, function, beauty = Gestalt. London, AA Publications, Spring 2010 (Colección AA Words) Recopilación de textos de Max Bill.

2011

FABRI, Roberto. Max Bill in Italia, Lo spazio logico dell"architettura. Milano, Bruno Mondadori editore, 2011.

Artículos sobre Max Bill en libros y revistas

1946

"Suisse cite Bocksriet a Schaffhouse", Architecture d'Aujourd'hui, no 16 (4), 1946.

1947

KAISER, Hans. "'Continuita" di Max Bill". Domus no 223-225. Octubre-Diciembre 1947, p.30-33.

1948

SCHMIDT, Georg. “Max Bills “Kontinuitat”". Werk, no 35, Marzo 1948, p.76-80.

1949

"Mathematical considerations in contemporary art: critical analysis" / article by Max Bill in Werk no.3 1949 / p.86-91 (text in German)

1953

ROGERS, Ernesto Nathan. "Max Bill”. Magazine of Art, 46 May 1953. p.226-230, 1952

"Furniture; designed by Max Bill for mass production"

Domus no $276-277,1952$, p. 44-45. 
"Studies for housing in warm climates; Architects: Max Bill and A Beer". Bauen \& Wohnen no 2 1952, p.85-86.

1954

GOMRINGER, Eugen. “Hochschule für gestaltung ulm” Das Werk, no 8, 1954.

1955

"Small pavilion for the city of UIm, Landesausstellung Baden Wurttemberg, Stuttgart, July-October 1955; Architect: Max Bill" Werk, Septiembre 1955, p.287-288.

1956

"La nuova Bauhaus di Max Bill a Ulm sul Danubio" Architecttura: Cronache e Storia, no 1 (5) EneroFebrero 1956, p.737-738.

1957

GROHMANN, Will. "Max Bill und die Synthese”. Werk, no 44, Julio 1957, p.247-249.

1959

"Hochschule fur Gestaltung Ulm; Architect: Max Bill". Bauen und Wohnen no 11, Noviembre 1959, p.400-405.

GREGOTTI, Vittorio. “Complessita di Max Bill”. Casabella Continuitá no 228, Junio 1959, p.32-39.

WALTERS, R. T. “The experiment at Ulm”. Architects' journal, Apr.16, v. 129, 1956, p. 585-587.

1962

MARGIT, Staber. "Max Bill und die Umweltgestaltung- über die Wechselwirkung von Theorie und Praxis". Zodiac no9, 1962, p.60-95.

MARGIT, Staber. "La scuola di Ulm; Architect: Max Bill". Casabella Continuitá no 259, January 1962, p.227. 
1963

"Cultural Centre for the Swiss National Exhibition, Lausanne; Architect: Max Bill". Architectural Design, no 33, Noviembre, 1963, p.526-529.

BENSE, Max. “Max Bill 1963”, Art International, vol. VII, no 3, Lugano, 1963.

1964

"Art of living Pavilion, Swiss National Exhibition, Lausanne 1964" Architectural Record, no 34, Diciembre, 1964, p.614-619

BACCHI, Anna; BACCHI, Giorgio. "Max Bill: artist and architect". Arts \& Architecture, no 81 Noviembre, 1964, p.20-23

"Expo 1964: Vorschau auf die Expo 1964: Sektor 2b Bildenund Gestalten; Max Bill, architect", in Werk, no 51 February 1964 / whole issue on Expo 1964 (text in German)

1967

"The education of the architect" (incluye ensayo de Max Bill). U I A - International Architect no 44, Abril, 1967. p.23-31

1971

"Zurigo: il giardino e la casa di Max Bill", Domus no 494, Enero 1971, p.16-21.

1973

"Max Bill". Nueva Forma no.92 September 1973 (Número Monográfico) Texto de Juan Daniel Fullaondo.

1974

FRAMPTON, Kenneth. "On Max Bill: a review of the Albright-Knox exhibition catalog" Oppositions (4) Octubre 1974, p.154-157. 
FRAMPTON, Kenneth. "Apropos Ulm: curriculum and critical theory", Oppositions (3) Mayo 1974, p.1736

1976

JOLY, Pierre. "Max Bill". Oeil no.254, Septiembre 1976, p.42-45

BILL, Max “Max Bill....architecture and art: special issue” Du vol.36 no.6 (424) Junio 1976, p. 10-69. Número monográfico dedicado a Max Bill. DU, vol. 36 no 6, no 424, junio 1976. Monográfico dedicado a Max Bill

1984

JEHLE-SCHULTE, Ulrike "Squares, artists and monuments: two fountains by Jean Tinguely and a sculpture by Max Bill". Werk, Bauen und Wohnen vol.71/38 no 4. Abril 1984, p.38-43.

1987

PEPPIAT, Michael. "Max Bill: Perpetuating the Bauhaus ideal". Architectural Digest, nำ44 Agosto 1987, p.48.

1989

KELLY, Lore. "Prinzip der Ordnung: Max Bill und sein Haus im Zumikon". D B - Deutsche Bauzeitung, 123 Enero 1989. p.94-96

1994

MULLER, Dorothea. “Max Bill 1908-1994 [obituario]”, Bauwelt, 85 (48) Diciembre 27, 1994, p.2652 1995

MOOS, Stanislaus von. "Un ricordo di Max Bill = A memory of Max Bill", Domus no 770, April 1995, p.116-118.

GREGOTTI, Vittorio. "Max Bill, un grande artista moderno = Max Bill, a great artist of the modern [obituary], Casabella, 59, Marzo 1995. p.2-3, 6. 
RAHM, Philippe. "Max Bill [obituario]". Architecture d’Aujourd’hui № 297, February 1995, p.21.

MANFREDINI, Alberto. "L'eredita di Max Bill [obituario]". Parametro no 206, Enero -Febrero 1995, p.2-3 HAGEN-HODGSON, Petra. "Max Bill (1908-1994)”. Deutsche Bauzeitung vol.129 no 1 Enero 1995, p.10

MOOS, Stanislaus von. "Beauty as function: on Max Bill". Rassegna, 17 (62) 1995, p.68-72.

1996

GIMMI, Karin "Max Bill geht ans Herz: der Schweier Beitrag zur Triennale di Milano von 1936", Archithese, 26 (3) Mayo-Junio 1996, p.48-53.

"Minimal Tradition"; Max Bill in Mailand [reseña exposición]". Archithese, 26 (2) Marzo-Abril 1996, p.62

1999

FREI, Hans. "La "Hochschule fur Gestaltung”, (Ecole superieure de Design), Ulm, 1955, Max Bill architecte". Architecture d"Aujourd"hui no 321, Marzo 1999, p.110-115.

FLEISCHMANN, Gerd, “Max Bill: I"arte della stampa”. Domus no 811. Enero 1999, p.106-113.

2001

CRISPIANI, Alejandro, "Un mundo continuo [Max Bill]". A R Q (49) Diciembre 2001, p.57-59.

2002

HEATHCOTE, Edwin, "Max Bill: simplicity and ordinariness", Architectural Design, 72 (4) Julio 2002, p.17-21.

2004

MOOS, Stanislaus von "Max Bill, arquitecto = Marx Bill, architect", 2G: revista internacional de arquitectura $=$ international architecture review no.29-30. 2002. Número monográfico dedicado a Max Bill. 
VV.AA. "Continuity: Max Bill's public sculpture and the representation of Money". Figuration/ Absraction, strategies fro Public Sculpture in Europe 1945-1986. Editado por Charlotre Benton. 2004.

2005

JANSSEN, Johan. "Max Bill architect [ed by] Karin Gimmi [book review]", Arkitektur, 105, Noviembre 2005, p.78

2006

FINESSI, Beppe. "Max Bill: una retrospectiva = Max Bill: a retrospective [reseña exposición]", Abitare no 458, Febrero 2006, p.99-100

2007

"Haerle Hubacher Architeckten: Max Bill Platz", Archithese no 37, January-February 2007

SOLT, Judit. "Virtuelle Kuben und echtes Leben: Max-Bill-Platz in Zurich Neu-Oerlikon; Architecten, Haerle Hubacher, atelier ww". DB - Deutsche Bauzeitung, 141 (8) 2007, p.26-32.

2008

“Max Bill” Domus no 916 Julio-Agosto 2008, p.10

ADAM, Hubetus. "100th anniversary of Max Bill"s birthday, two retrospectives in Winterthur", Bauwelt, vol.99, no 10 Marzo 2008, p.2-3.

BIGNENS, Christoph. "Maximal und minimal: two exhibitions in Winterhur celebrating Max Bill"s centenary" Werk Bauen \& Wohnen vol.95/62 no 4 Abril 2008, p.61-62

GRACIA, Francisco de "Belleza logica: Max Bill, 1908-1994", Arquitectura Viva no 120. 2008, p.78-79.

2009

BIGAS, Monserrat, BRAVO, Luis. "Projecting the infinite: Miralles, Max Bill, Klee”, EGA: revista de expresión gráfica arquitectónica no14, 2009, p.146-157, p.289-293 
Publicaciones editadas en la HfG

ulm. 1, Oktober 1958 - 5, Oktober 1959. Vierteljahresbericht der Hochschule für Gestaltung UIm. Hg. v. Hochschule für Gestaltung. (Revista editada por el rectorado de la HfG)

ulm. 6, Oktober 1962 - 21, April 1968. Zeitschrift der Hochschule für Gestaltung. Hg. v. Hochschule für Gestaltung.

output. 1, 1961 - 25, 1964. Hg. v. Studentenselbstverwaltung der Hochschule für Gestaltung UIm. (revista editada por los estudiantes de la $\mathrm{HfG}$ )

UIm. Hochschule für Gestaltung 1963. Katalog einer Wanderausstellung. Ulm, 1963.

Information 63. Hg. v. Hochschule für Gestaltung UIm, September 1963.

ulm report. 1, Oktober 1966 - 4, Oktober 1967. Hg. v. Hochschule für Gestaltung Ulm.

Publicaciones y tesis sobre la HfG

1971

HEIMBUCH, Joachim, MICHELS, Peter. Bauhaus - HfG - IUP. Dokumentation und Analyse von drei Bildungsinstitutionen im Bereich der Umweltgestaltung. Diplomarbeit am IUP, UIm 1971.

1982

ROERICHT, Nick (Hans) + Arbeitsgruppe HfG-Synopse: HfG-Synopse. Ulm 1982.

1983

club off ulm e.v. (Ed.): who was who an der ehemaligen Hochschule für Gestaltung, Ulm, HfG Ulm, 1983. 


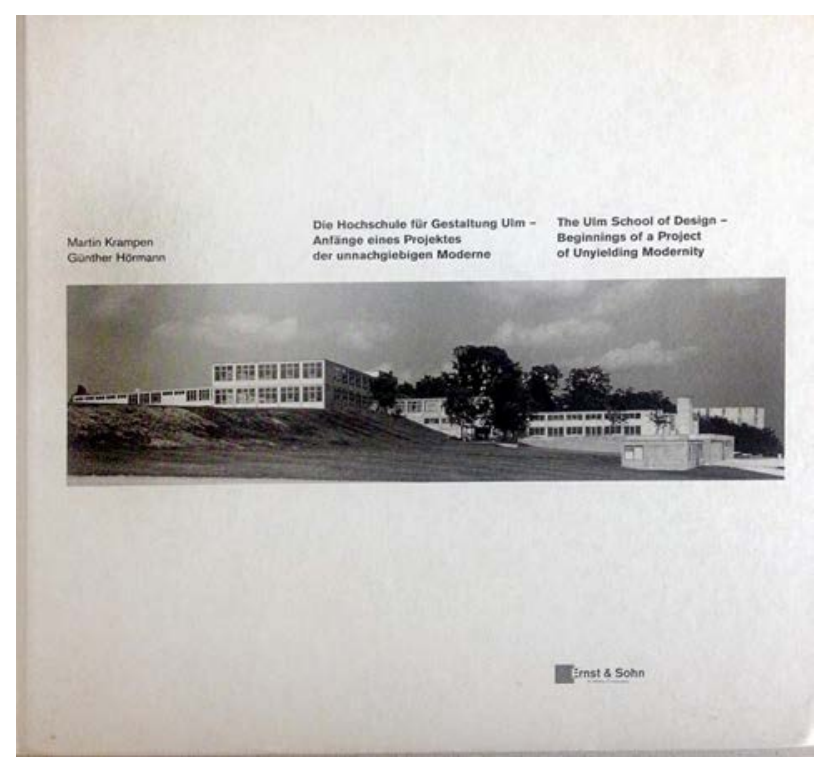

1985

SEELING, Hartmut Seeling. Geschichte der Hochschule für Gestaltung in UIm, 1953 - 1968. Ein Beitrag zur Entwicklung ihres Programmes und der Arbeiten im Bereich der Visuellen Kommunikation. Tesis doctoral. Köln 1985.

KORREK, Norbert. Die Hochschule für Gestaltung in UIm. Tesis doctoral. Hochschule für Architektur und Bauwesen Weimar 1985.

1987

RÜBENACH, Bernhard. Der rechte Winkel von Ulm. Rundfunkfeature für den Südwestfunk BadenBaden 1958/59. Darmstadt, Bernd Meurer ed, 1987.

Club off ulm e.v. (ed.): who was who an der ehemaligen Hochschule für Gestaltung, Ulm, HfG UIm, 1987, 2. Aufl.

1988

BURCKHARDT, Lucius. Das Ende der Polytechnischen Lösbarkeit. Hg. V. Club off ulm e.v. Ulm 1988.

1989

AMBERG, Elke. Der eigene Weg der Abteilung für Filmgestaltung an der Ulmer Hochschule für Gestaltung. Magisterarbeit an der Sozialwissenschaftlichen Fakultät der Ludwig - Maximilians München, Universität München 1989.

Norbert Korrek: Kontinuität und Wandel. Zur Rezeption der Hochschule für Gestaltung Ulm. Hg. V. Club off ulm e.v. Ulm 1989.

SECKENDORFF, Eva. Die Hochschule für Gestaltung in Ulm. Gründung (1949 - 1953) und Ära Max Bill (1953 - 1957). Tesis doctoral. Universität Hamburg 1986. Posteriormente publicado con el mismo título en Marburg, Jonas Verlag, 1989. Serie des club off ulm, Bd. 1. 
STONE, Dominic. The Ulm Hochschule für Gestaltung: Ideology and Methodology. Tesis de maestría, Royal College of Art London, 1989.

1991

FREI, Hans. Konkrete Architektur? - über Max Bill als Architekt. Baden (Schweiz), Lars Müller publishers, 1991.

1993

SPITZ, René. Die Hochschule für Gestaltung in Ulm. Ein Beispiel für kulturelle Bemühungen und Kulturpolitik in der frühen Bundesrepublik. Tesis de maestría en la facultad de filosofía de Colonia, 1993.

1994

KORNATZKI, Peter von; MÜLLER, Rolf. "Die Abteilung Visuelle Kommunikation an der Hochschule für Gestaltung 1951 - 1968". En: High Quality. Zeitschrift über das Gestalten, das Drucken und das Gedruckte. Heft 29/1994, S.58-77.

1997

SPITZ, René. Die politische Geschichte der Hochschule für Gestaltung Ulm (1953-1968). Tesis doctoral. Universidad de Colonia, 1997.

1998

QUIJANO, Marcela (ed.) HfG Ulm: programm wird bau. Die Gebäude der Hochschule für Gestaltung Ulm. Stuttgart, Edition Solitude, 1998.

2001

CURDES, Gerhard. Die Abteilung Bauen an der HfG Ulm. Eine Reflexion zur Entwicklung, Lehre und Programmatik. Ulm, club off ulm e. V; 2001.

2002

SPITZ, René. Der Blick hinter den Vordergrund. Die politische Geschichte der Hochschule für Gestaltung 1953 - 1968. Stuttgart / London, Edition Axel Menges, 2002. 
RATHGEB, Markus. Otl Aicher: Design as a method of action. Tesis doctoral, Universidad de Reading, 2002 (inédita).

2003

KRAMPEN, Martin; HÖRMANN, Günther. Die Hochschule für Gestaltung Ulm / The School of Design. Anfänge eines Projektes der radikalen Moderne / Beginnings of a Project of Radical Modernism. Berlin, Ernst und Sohn, 2003.

2006

CURDES, Gerhard (ed), HfG Ulm: 21 Rückblicke. Bauen - Gemeinschaft - Doktrinen. Ulm, club off ulm e. V., 2006.

2007

MÜLLER-KRAUSPE, Gerda. Selbstbehauptungen. Frauen an der hfg ulm. Frankfurt am Main, Anabas Verlag 2007.

2008

CZEMPER, Karl-Achim (ed). Hfg, ulm. Die Abteilung Produktgestaltung. 39 Rückblicke. Ulm, club off ulm e. V., 2008 .

2009

KRAMPEN, Martin. Beobachten und formulieren. Grundkurs mit Übungen, nach einem Filmskript von Josef Albers. DVD, Ostfildern-Ruit, 2009.

2010

STEMPEL, Barbara, EPPINGER CURDES, Susanne ed.), Rückblicke - Die Abteilung Visuelle Kommunikation an der HfG UIm. Ulm, club off ulm e. V., UIm 2010.

2011

PAIVA, Rodrigo. 421 Plakate der Hochschule für Gestaltung UIm. UIm, Schriftenreihe der Stiftung Hochschule für Gestaltung Ulm Bd. 1, 2011. 
2012

ABELE-AICHER, Christine. Die sanfte Gewalt: Erinnerungen an Inge Aicher-Scholl. Ostfildern, Thorbecke Jan Verlag, 2012

SPITZ, René. UIm, Internationales Forum für Gestaltung IFG UIm GMBH, 2012.

\section{3}

SPITZ, René; MÜLLER, Jens (ed.). A5/06: HfG Ulm: Kurze Geschichte der Hochschule für Gestaltung. Baden (Schweiz), Lars Müller Publishers, 2013. Número 6 de la colección A5 series.

Catálogos de exposiciones sobre la HfG

1987

LINDINGER, Herbert. ulm ... Die Moral der Gegenstände. Hg. v. Herbert Lindinger. Catlalogo de la exposición en el Ulmer Museum. Berlin, Ernst und Sohn, 1987.

1988

ALBERS, Josef. Ausstellung zum 100. Geburtstag. Exposición Ulmer Museum, 20.5. - 26.6. 1988. Ulm: Süddeutsche Verlagsgesellschaft, 1988.

\section{3}

GRAEVE, Inka. Walter Peterhans. Fotografien 1927 - 1938. Catálogo de la exposición en: Ulmer Museum, Museum Folkwang Essen, 10.10.-28.11.1993; Bauhaus-Archiv Berlin, 7.12. 1993 - 30.1.1994; Fotografie Forum Frankfurt, 12.2. - 27.3.1994; HfG-Archiv Ulm, 10.4. - 22.5.1994; Kunstverein Karlsruhe, Mai - Juni 1994; Bauhaus Dessau, 5.7. - 7.8.1994. Oberhausen, Plitt Druck- und Verlag, 1993.

UTE, Eskildsen. Ringl und pit. Grete Stern, Ellen Auerbach. Catálogo de la exposición en: Museum Folkwang, 10.10. - 28.11.1993. Bauhaus-Archiv Berlin, 7.12. 1993 - 30.1. 1994. Badischer Kunstverein Karlsruhe, Mai - Juni 1994. Bauhaus Dessau, 5.7. - 7.8. 1994. Hg. v. Museum Folkwang Essen. Oberhausen, Plitt Druck- und Verlag, 1993. 
MEGGS, Philip B. Tomás Gonda. A Life in Design. Catálogo de la exposición en: Anderson Gallery Richmond, 21.1. - 6. 3. 1994. Richmond, Virginia, Anderson Gallery, 1993.

1995

EDER, Klaus. Anschauung und Begriff. Die Arbeiten des Instituts für Filmgestaltung Ulm 1962 - 1995. Ausst. Kat. Ulmer Museum. Stadthaus Ulm, 16.9. - 5.11.1995. Deutsches Filmmuseum Frankfurt, 8.11. - 29.11.1995. Haus des Dokumentarfilms Stuttgart, 2.12 - 22.12.1995. Ulm, Süddeutsche Verlagsgesellschaft, 1995.

1998

VV.AA. L'école d’ulm: textes et manifestes. Paris, Edition du Centre Pompidou,1998. Catálogo de la exposición con textos

de Herbert Lindinger, François Burkhardt, Otl Aicher, Claude Schnaidt, Herbert Ohl, Gui Bonsieppe.

Números especiales de revistas sobre la HfG

1975

"hfg ulm, ein rückblick. une retrospective". En: archithese 15, 1975. Con textos de Claude Schnaidt, Otl Aicher, Herbert Ohl, Kenneth Frampton. Niederteufen (Schweiz), Verlag Arthur Niggli AG, 1975.

1984

"Il contributo della scuola di UIm. The Legacy of the School of UIm". En: Rassegna Heft 19, 1984. Con textos de Tomás Maldonado, Marina Bistolfi, Martin Krampen, Giovanni Anceschi, Piero G. Tanca. Casabella continuitá? 


\section{Publicaciones del HfG-Archiv}

1990

SCHOLTZ, Andrea; SECKENDORFF, Eva von; WACHSMAN, Christiane. design ist gar nicht lehrbar...Hans Gugelot und seine Schüler. Entwicklungen und Studienarbeiten 1954 - 1965. Catálogo de exposición. Ulm, HfG-Archiv, 1990. (Dokumentationen 1).

1991

VV.AA. Objekt + Objektiv = Objektivität? Fotografie an der HfG UIm 1953 - 1968. Catálogo de exposición. Ulm, HfG-Archiv, 1991. (Dokumentationen 2).

1992

ZEISCHEGG, Walter; SCHOLTZ, Andrea; WACHSMANN, Christiane. Kartoffelchips im Wellflächenquadrat. Walter Zeischegg, Plastiker, Designer, Lehrer an der HfG Ulm 1951 - 1968. Catálogo de exposición. Ulm, HfG-Archiv Ulm , 1992. (Dokumentationen 3).

\section{3}

ALBERS, Ingela; QUIJANO, Marcela; WACHSMANN, Christiane. Bauhäusler in ulm. Die Grundlehre an der Ulmer HfG zwischen 1953 und 1955. Catálogo de la exposición con el mismo nombre en el HfG Archiv. Ulm, HfG-Archiv Ulm, 1992. (Dokumentationen 4).

1994

WACHMANN, Christiane. Hotelstapelgeschirr TC 100, 1959, Nick H. Roericht. Obra del mes, Octubre 1994. Ulmer Museum. (folleto)

WACHMANN, Christiane. Wellflächenobjekt mit drei Schwingungen, um 1968, Walter Zeischegg. Obra del Mes, Septiembre 1994. Ulmer Museum. (folleto)

1996

WACHSMANN, Christiane. Plakat für die Ulmer Volkshochschule, Juni 1955, Otl Aicher. Obra del Mes, noviembre 1996. Ulmer Museum. 
1998

Bewegung. Tomás Gonda an der HfG Ulm. Un trabajo interactivo entre su trabajo y su docencia entre los años 1958-1966. Un proyecto del FH Schwäbisch Gmünd con el HfG-Archiv Ulm.

2000

AICHER, Florian (ed); RINKER, Dagmar (ed). Ein Symposion in Rotis. Zweiter Band der Rotis Schriften. München, Christian Pixis Verlag, 2000.

RINKER, Dagmar. Plakat Olympischer Fackellauf, 1971/72, Otl Aicher. Obra del Mes, Mayo 2000. Ulmer Museum.

Gebrauch und Gebräuchlichkeiten. Vom Umgang mit den Dingen und ihrer Gestalt.

2002

WAGNER, Tanja. Radio - Plattenspielerkombination Phono - Super SK 4, 1956 Hans Gugelot. Obra del mes, Julio 2002. Ulmer Museum.

KRAMPEN, Martin; RINKER, Dagmar. politische kultur. otl aicher zum 80. geburtstag. Rotis, otl aicher rotis e.v., 2002.

Vom Handeln im Netz. Dimensionen der Globalisierung.

En: form + zweck 19, 34. Jahrgang. Beiträge des 3. Rotis-Symposions. Hg. v. form + zweck verlag und HfG-Archiv Ulm. Berlin 2002.

2003

RINKER, Dagmar; QUIJANO, Marcela; REINDHARDT, Brigitte. Ulmer modelle. Modelle nach UIm. Hochschule für Gestaltung UIm 1953-1968. Stuttgart, Hatje Cantz, 2003. Catálogo de exposición.

2006

Staatliche Schlösser und Gärten Baden-Württemberg in Kooperation mit dem HfG-Archiv Wilhelm von Ockham. Das Risiko modern zu denken

Ulm 2006 
2012

MOSER, Eva. Otl Aicher - Die Regenbogenspiele. Das visuelle Erscheinungsbild der XX. Olympischen Spiele, München 1972.

(folleto de exposición). 


\section{Bibliografía general}

AICHER, Otl. analog und digital. Berlin, Ernst und Sohn Verlag für Architektur und technische Wissenschaften, 1991.

AA.VV; “L'Ecole”, L’architecture d’aujourd d’hui, núm. 6, mayo-junio 1946 (número monográfico sobre la obra de Richard J. Neutra), págs. 25-28.

AICHER, Otl. the world as design. Berlin, Ernst und Sohn Verlag für Architektur und technische Wissenschaften, 1991.

ALEXANDER, Christopher; Menéndez, Iris, El modo intemporal de construir, Barcelona, Gustavo Gili, 1981.

ARNHEIM, Rudolph. La forma visual de la arquitectura. Barcelona, Gustavo Gili, 2001. (Ed. original The dynamics of the architectural form, University of California Press, 1977.)

BAKER N; FANCHIOTTI A; STEEMERS K (ed.). Daylighting in architecture. A European reference book. London, James \& James Science Publishers, 1993.

BUSSAGLI, Mario. Arquitectura Oriental 2. Region del Himalaya, Asia Central, China, Corea, Japón. Madrid, Aguilar, 1989. (edición original Archittetura Oriental 2, Milán, Electa, 1980).

CALVINO, Italo. Seis lecciones para el próximo milenio. Madrid, Siruela, 1989.

CUNDY, H. Martin; ROLLET, A.P. Mathematical Models. Oxford, Oxford University Press, 1961 (segunda edición, originalmente editado en 1951).

FRAMPTON, Kenneth. Studies in tectonic culture, the poetics of construction in nineteenth and twentieth century architecture. Cambridge, Massachusetts Institute of Tecnology, 1995. 
GIEDION, Sigfried. The eternal Present the beginnings of Architecture. A contribution on Constancy and Change. New York, Bollingen Foundation, 1963 (edición consultada: El presente eterno: los comienzos de la arquitectura. Madrid: Alianza Forma, 1981.

GROPIUS, Walter. Internationale Architecture. Bauhaus Bücher I. (1a edición). München, Albert Langen Verlag, 1927

KRUCKET, Bruno. Complex Ordinariness. The Upper Lawn Pavillion de Alison y Peter Smitshon. Zurich, gta Verlag, 2002.

LAMBERT, Phyllis (ed.). Mies van der Rohe in America, (catálogo de la exposición "Mies in America". Québec, Canadian Centre for Architecture, Withney Museum of American Art y Hatje Cantz, 2001).

LE CORBUSIER. Le Modulor. Buenos Aires, Poseidon, 1953, (edición consultada: El Modulor y Modulor 2, Buenos Aires, Poseidon, 1976).

LE CORBUSIER. Oeuvre complète 1910-1969 (8 volumes). Basilea, Birkhäuser-Publishers for Architecture, 1999.

LE CORBUSIER. Precisiones, respecto a un estado actual de la arquitectura y el urbanismo. Barcelona, Apóstrofe, 1999.

LEWITT, Sol. Cube, Nueva York, John Weber Gallery; Roma, Mario Peroni; Colonia, Verlag der Buchhandlung Walther Köning, 1990.

LIETZMANN, Walther. Anschauliche Topology. München, Verlag Von R. Oldenbourg, 1955.

LIGTELIJN, Vincent (ed.). Aldo van Eyck. Works. Basel, Boston, Berlin, Birkhäuser, 1999. Ed. original: Aldo van Eyck, Werken. Bussum, Thoth publishers, 1999. 
MALDONADO, Tomás. Vanguardia y racionalidad. Artículos, ensayos y otros escritos 1946-1974. (1a edición). Barcelona, Gustavo Gili, 1977.

McCOY, Esther. Five california architects. Nueva York, Praeger Publishers, 1975.

MEYER, Hannes. "Die neue Welt". Das Werk, número especial 7, 1926.

NEUTRA, Richard. Life and Shape. Nueva York, Appelton-century-cross, 1962, (edición consultada: Richard Neutra, Vida y Forma, Buenos Aires, Marymar, 1972).

NISHI, Kazuo y HOZUMI, Kazuo. Nihon kenchiku no katachi: seikatsu to kenchiku-zokei no rekishi. Tokyo, Shokokusha Publishing, 1985, (edición consultada: What is japanese architecture?, Tokyo, Kondansha international, 1996).

OCKMAN, Joan. Architecture Culture 1943-1968: A documentary Anthology. (1a edición). Nueva York, Columbia University Graduate School of Architecture, Planning \& Preservation, \& Rizzoli, 1993

PEREC, Georges. Espèces de espaces. París, ed. Galilée, 1974.

RASMUSSEN, Steen Eiler. Experiencing Architecture. (1a edición) Cambridge, The MIT Press, 1959

RATTEMBURY, Kester, HANDINGHAM, Samantha. Superscrit \#3. Richard Rogers. The Pompidou Centre. Oxon, Routledge, 2012.

ROTH, Alfred. The New Architecture / Die Neue Architektur / La Nouvelle Architecture. Zürich, Dr. H. Girsberger, 1940

ROWE, Colin. «Las matemáticas de la vivienda ideal» en: Manierismo y arquitectura moderna y otros ensayos, Gustavo Gili, Barcelona, 1978, 1999 (ed. original The Mathematics of the Ideal Ville and other Essays, Londres, 1976). 


\section{RYKWER}

T, Joseph. La casa de Adán en el Paraíso. Barcelona, Gustavo Gili, 1974 (Colección Arquitectura y Crítica)

SCHNAIDT, Claude. Hannes Meyer. Zürich, Verlag Arthur Niggli AG, 1965.

SHEINE, Judith (ed.). "Casa Schindler-Chace, West Hollywood, California”, 2G, núm. 7, 1998, (número monográfico 10 casas, R.M. Schindler).

SMITHSON, Alison and Peter. The Chargued Void: Architecture. New York, The Monacelli Press, 2001.

SMITHSON,, Alison and Peter, The Chargued Void: Urbanism. New York, The Monacelli Press, 2001.

SMITHSON, Alison and Peter. Cambiando el arte de habitar. Piezas de Mies. Sueños de los Eames. Los Smithsons. Barcelona, Gustavo Gili, 2001, (título y edición original: Changing the art of inhabitation. Mies' pieces. Eames' dreams. The Smithsons. Londres, Artemis London Ldt, 1994).

SPELLMAN, Catherine (ed.); UNGLAUB, Karl (ed.). Peter Smithson. Conversaciones con estudiantes. Barcelona, Gustavo Gili, 2004. Edición española a cargo de Moisés Puente.

STRAWINSKY, Igor. Poética Musical. Madrid, Taurus, 1977.

TAUT, Bruno. La casa y la vida japonesa. Colección Arquithemas, no 19. Barcelona, Ed. Fundación Caja de Arquitectos, 2007. Título y edición original. Das japanische Haus un sein Leben, Berlín, Gerb Mann Verlag, 1937

TORROJA, Eduardo. Razón y ser de los tipos estructurales. Madrid, Consejo Superior de Investigaciones Científicas, 1991.

UTZON, Jorn. Jorn Utzon 1942-1988. Madrid, Centro de Publicaciones Secretaria General Técnica del Ministerio de Obras Públicas, Transportes y Medio Ambiente, 1995. 
VAN EYCK, Aldo, "El Pabellón Sonsbeek, dedicado a la escultura, Arnheim (Holanda)", Domus, núm 460, 1968.

VENTURI, Robert. Complejidad y contradicción en la arquitectura. Barcelona, Gustavo Gili, 1972.

WESTON, Richard. Jorn Utzon. Inspiration. Vision. Architecture. Hellerup: Blondal, 2001.

WILLIAM M.; Sunlighting as a formgiver for architecture. New York, Van Nostrand Reinhold company, 1986.

WINGLER, H. M. Das Bauhaus Weimar, Dessau, Berlin, 1919-1933. (1a edición). Colonia, Bramche, Gebr. Rasch \& Co, 1962 

anexo/planos

previos
anteproyecto / textos situación

documentos documentos / licencia prensa

croquis croquis/parcelación terreno perfiles / terreno

planos planos / arquitectura planos / sección planos / construcción planos / detalle planos/leherhaus

cálculos cálculo / estructura cálculo / pórticos cálculo / cimentación cálculo / saneamiento

elektro

telefonía clima

mediciones 

imágenes

caw carlos a.wandosell

hfg hfg/archiv

traducción

laura urbistondo

\section{tipografía}

este trabajo se ha impreso utilizado la fuente akzidenz grotesk diseñada en 1896 por Günter Gerhard Lange para la fundición Berthold en Berlín, esta tipografía es la precursora de la Helvética. Fue usada como tipo de texto en Europa, especialmente en Suíza. Funciona especialmente bien en literatura técnica como tablas, hojas de balance o en otros casos donde haya poco espacio. 


\section{agradecimientos}

agradezco a:

jose manuel lópez-peláez, director de esta tesis, por su ayuda infatigable y rigurosos consejos.

a mi familia por su confianza.

a la hfg/archiv ulm por la documentación original que he podido consultar, tocar y ordenar. También por sus fondos, por su agradable espacio de investigación y por la amabilidad de las personas que allí trabajan. a marcela quijano por su simpatía y las anécdotas que me ha contado sobre este proyecto.

a mis compañeros de la escuela de arquitectura de toledo por su apoyo, ánimo y entusiasmo.

a francisco alonso por su sensatez. y a manuel de las casas y juan mera por su cariño. 

a nieves, diego y clara 

anexo cd

previos

anteproyecto / textos

situación

documentos

documentos / licencia

prensa

croquis

croquis/parcelación terreno perfiles / terreno

planos

planos / arquitectura

planos / sección

planos / construcción

planos / detalle

planos/leherhaus

cálculos

cálculo / estructura cálculo / pórticos

cálculo / cimentación

cálculo / saneamiento

elektro

telefonía

clima

mediciones 
